\title{
DEVELOPMENT OF OPTIMAL CONTROL SCHEDULING FOR SHORT-TERM WORK ZONES FOR FREEWAY MAINTENANCE
}

\author{
By \\ Udila Shalitha Pilanavithana \\ B.Sc. (Honours) Civil Engineering, University of Moratuwa, Sri Lanka, 2010 \\ M.Sc. Civil Engineering, University of Moratuwa, Sri Lanka, 2014
}

\author{
A thesis \\ presented to Ryerson University \\ in partial fulfillment of the \\ requirements for the degree of \\ Master of Applied Science \\ in the program of \\ Civil Engineering
}

Toronto, Ontario, Canada, 2018

(C) Udila Shalitha Pilanavithana 2018 


\section{AUTHOR'S DECLARATION}

\section{AUTHOR'S DECLARATION FOR ELECTRONIC SUBMISSION OF A THESIS}

I hereby declare that I am the sole author of this thesis. This is a true copy of the thesis, including any required final revisions, as accepted by my examiners.

I authorize Ryerson University to lend this thesis to other institutions or individuals for the purpose of scholarly research.

I further authorize Ryerson University to reproduce this thesis by photocopying or by other means, in total or in part, at the request of other institutions or individuals for the purpose of scholarly research.

I understand that my thesis may be made electronically available to the public. 


\title{
DEVELOPMENT OF OPTIMAL CONTROL SCHEDULING FOR SHORT-TERM WORK ZONES FOR FREEWAY MAINTENANCE
}

\author{
Udila Shalitha Pilanavithana \\ Master of Applied Science, 2018 \\ Transportation Engineering \\ Ryerson University
}

\begin{abstract}
The sustained deterioration of the freeway infrastructure of a nation has resulted in an increase in the number, duration, and scope of maintenance projects. In order to enhance the mobility and safety of freeway segments plagued by work zone activities, transportation agencies and professionals have been exploring the potential benefits of efficient and economical maintenance scheduling. This thesis proposes systematic methodology for the optimization of work zone scheduling based on analytical and simulation models to estimate total project cost. Multiregression models were developed using microsimulation and embedded them into the costs models and costs were predicted. Solver optimizer was used to find the optimal start and end times, productivity indices, and corresponding sub-sectional lengths of project by minimizing the total project cost. Case studies were conducted to assess the performance of the proposed methodology. Lastly, conclusions were made to support transportation agencies in the development of work zone management plans.
\end{abstract}




\section{ACKNOWLEDGEMENTS}

It is my honour and pleasure to have my advisor, Dr. Said Easa, for his enlightening guidance, extensive advice, and persistent encouragement throughout my Master of Applied Science degree at Ryerson University. I am deeply indebted to him for training me to think in a more creative and precise manner for both theoretical and experimental studies, which is the greatest influence he has had on my life. As an international student, his acceptance, trust and belief in me and trust on each single work I did was tremendous. I am truly privileged to be one of his students. From the bottom of my heart, I would like to express my deepest appreciation for his passionate effort on my research career and lifelong achievements.

I would like to express my gratitude to the graduate program administrator, Rachel Peluso, for her remarkable assistance and guidance for each and every official process necessary to complete my degree requirements. Furthermore, I am grateful to all of the academic and non-academic staff for providing continuous support throughout my academic career at Ryerson University.

I must express my love and gratefulness to my father, Yogananda Pilanavithana, and my mother, Padma Shanthi Kumarasiri, for their selfless sacrifice in my upbringing. You were my first and greatest teachers. I am blessed with their world of love, constant source of support, and encouragement in every moment in my life. They are the happiest persons on this earth with this achievement. I owe my whole life to you, my loving father and mother.

I give my admiration and limitless gratitude to my only brother, Gagana Pilanavithana, his remarkable and countless love, support, patience, and understanding during the entire course of my research were crucial for me to successfully finish my study to an advanced degree. He and his family sacrificed by giving me and my family shelter and protection that he was a father, a brother, and a friend to me is wordless to define. May all of your dreams come true.

Last but not least, I am glad to express my warmth sincere to my loving wife, Nadeeka Pilanavithana and son, Didula Pilanavithana for their unconditional love and for inspiring me to pursue my own dreams. Your patience and understanding are undoubtedly the most irreplaceable elements of this thesis. You make it all worthwhile. 


\section{DEDICATION}

To my loving brother, Gagana Pilanavithana, for being a

father, brother \& friend.

To my loving parents,

you are the true measure of my accomplishment.

To my wife and son,

for the world of love. 


\section{TABLE OF CONTENTS}

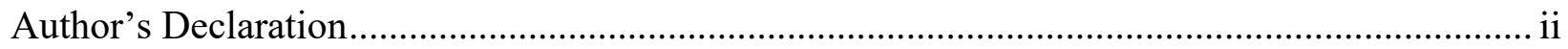

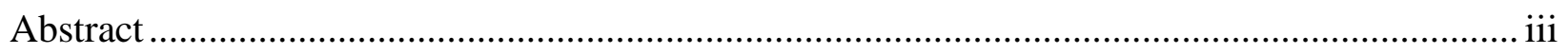

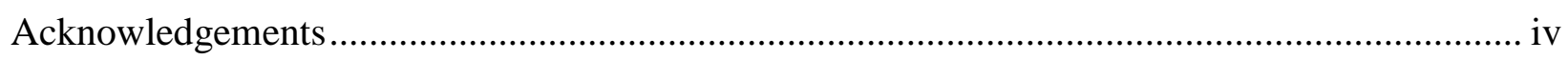

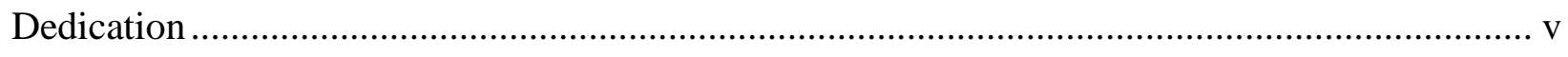

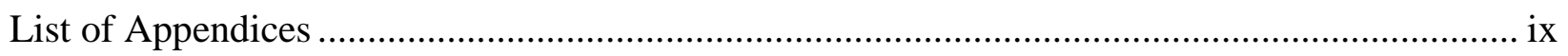

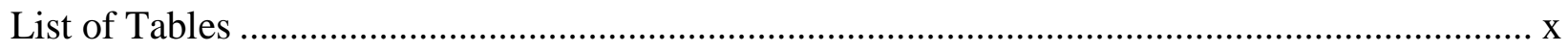

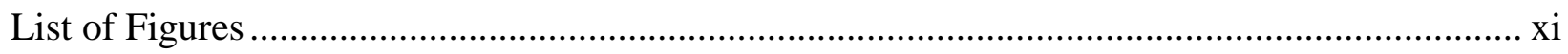

CHAPTER 1: INTRODUCTION ................................................................................................ 1

1.1 Background and Research Motivation ..................................................................... 1

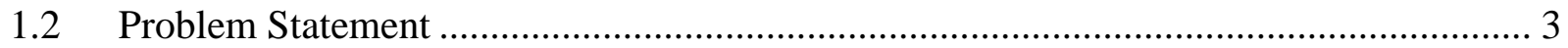

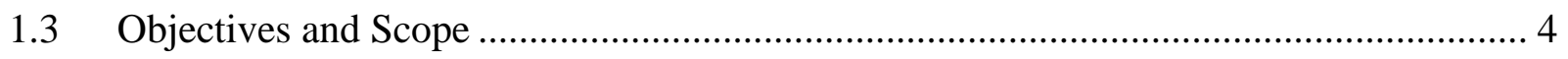

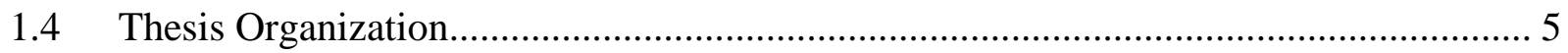

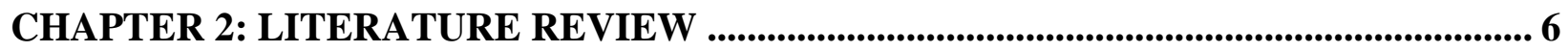

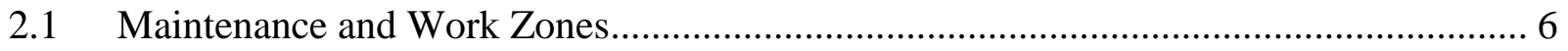

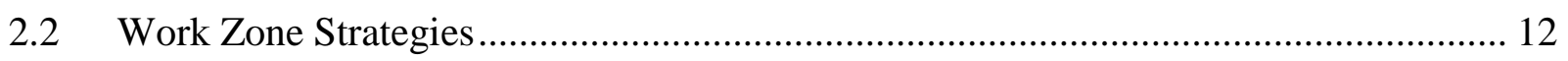

2.2.1 Temporary Traffic Control (TTC) Devices and Applications .............................. 13

2.2.2 Merge Concepts ........................................................................................ 14

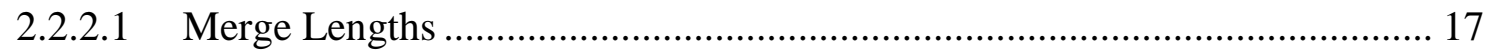

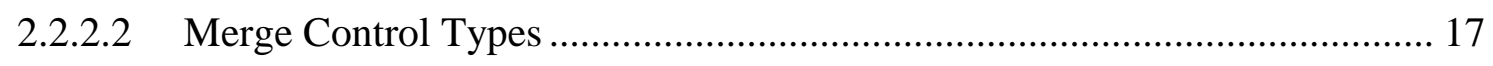

2.3 Free Flow Speed (FFS) and Capacity ................................................................ 18

2.4 Work Zones Applications................................................................................... 20

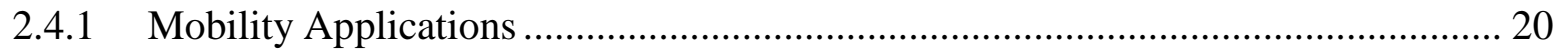

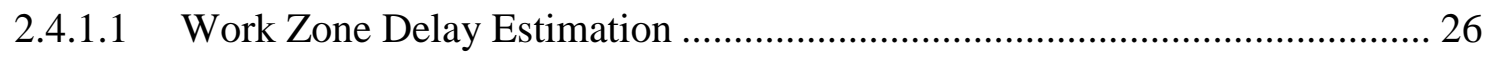

2.4.1.2 Analytical Method: Delay Models ........................................................... 27

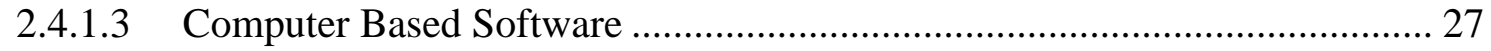

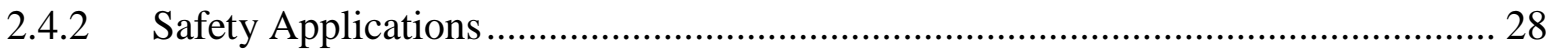




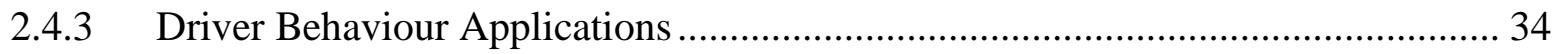

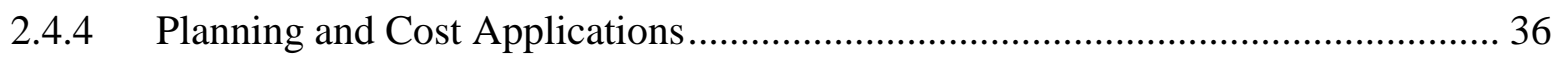

2.4.5 Decision Variables in Work Zone Applications ................................................. 38

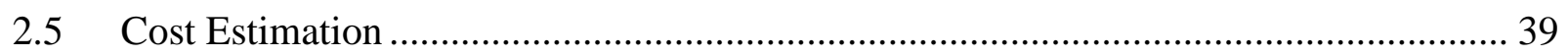

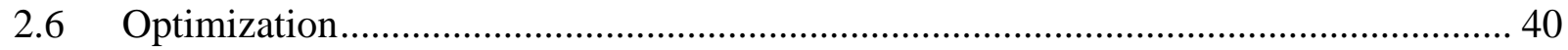

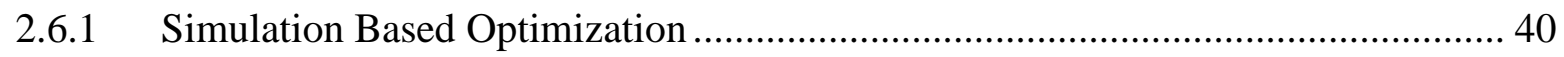

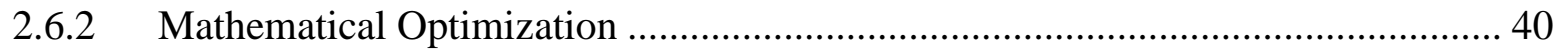

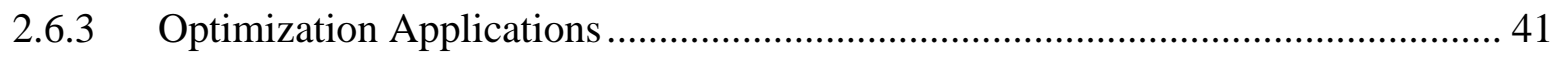

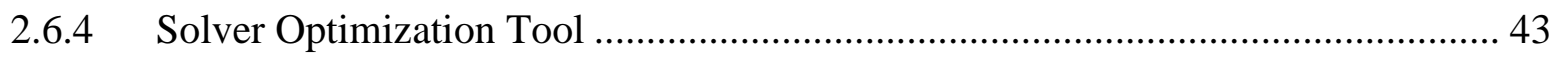

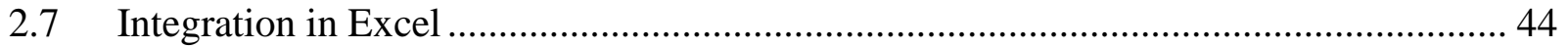

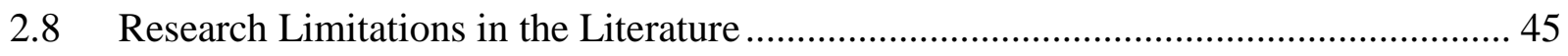

\section{CHAPTER 3: DEVELOPMENT OF REGRESSION MODELS FOR WORK ZONE DELAY USING CORSIM ......................................................................................................................... 46}

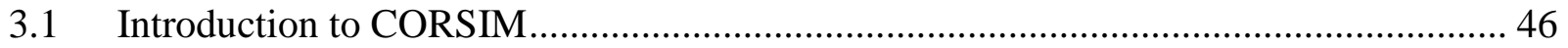

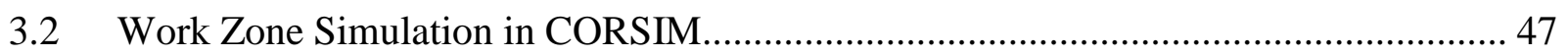

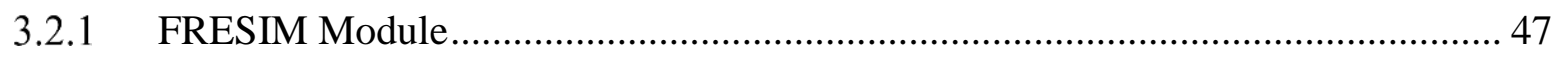

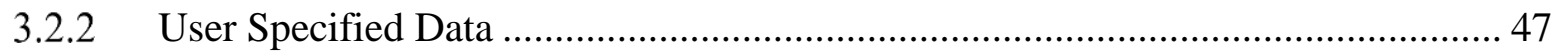

3.2.3 Measure of Effectiveness (MOEs) in CORSIM ………...................................... 49

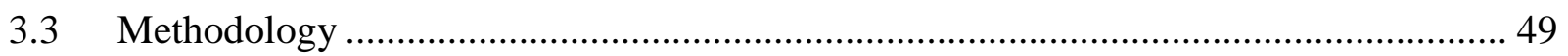

3.3.1 FRESIM Model Development .............................................................................. 51

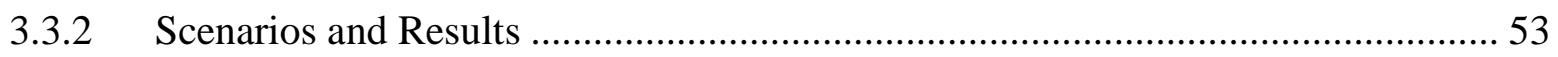

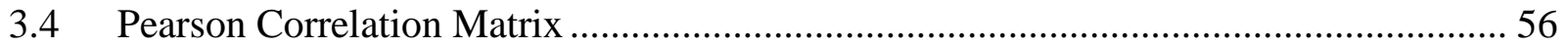

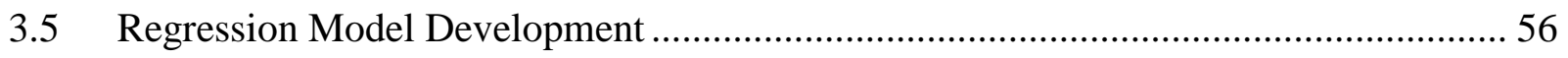

3.5.1 Undersaturated Flow Condition.......................................................................... 57

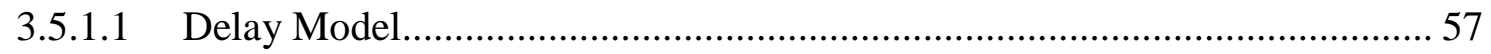

3.5.1.2 Average Speed Model............................................................................... 58

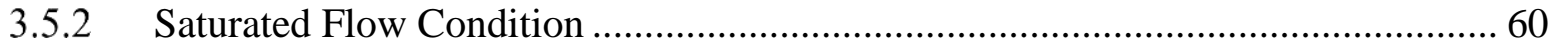

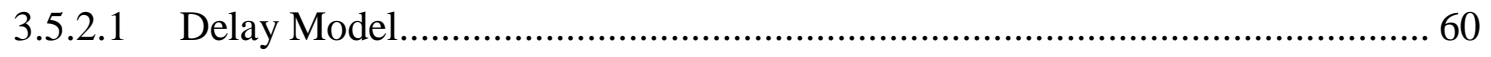

3.5.2.2 Average Speed Model ............................................................................. 60 


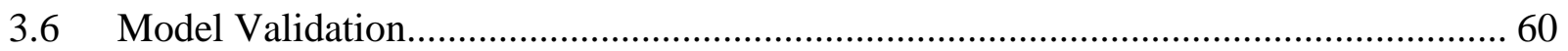

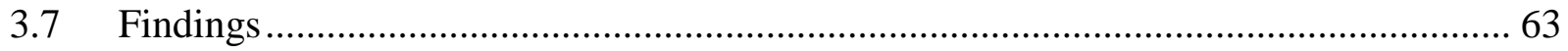

\section{CHAPTER 4: IMPROVED WORK ZONE COST MODEL AND SCHEDULING

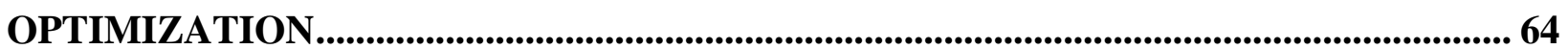

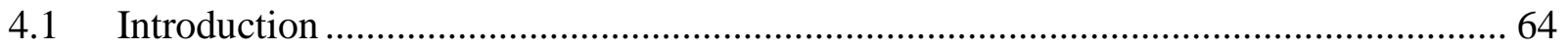

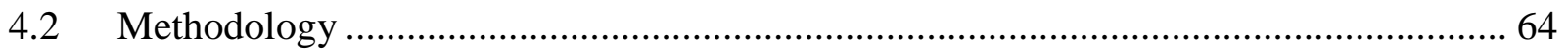

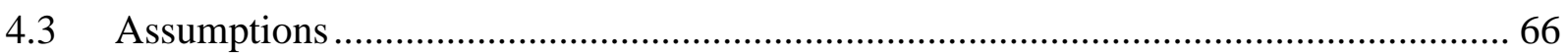

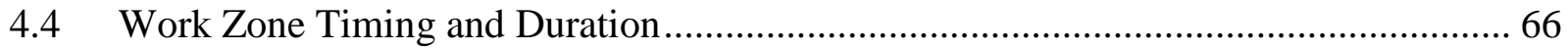

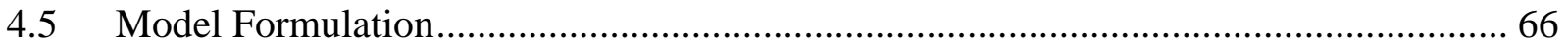

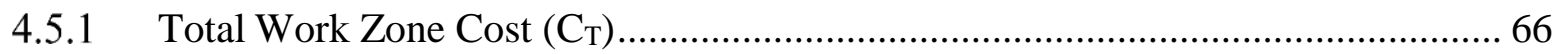

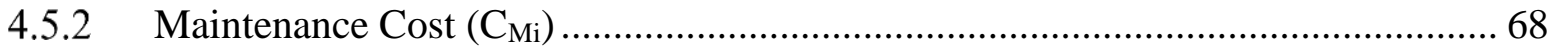

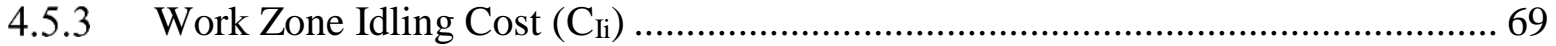

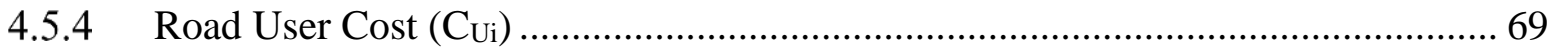

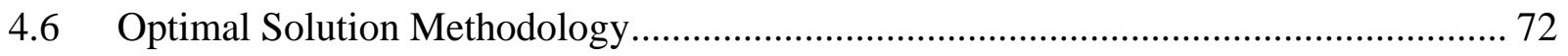

4.6.1 Solver Setup Procedure ....................................................................................... 73

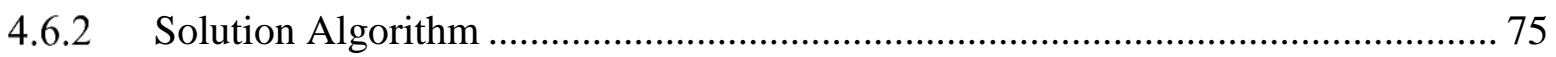

CHAPTER 5: CASE STUDIES................................................................................................... 77

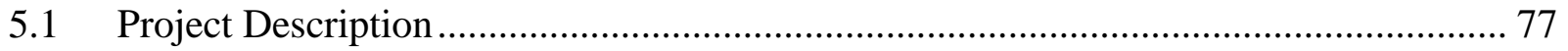

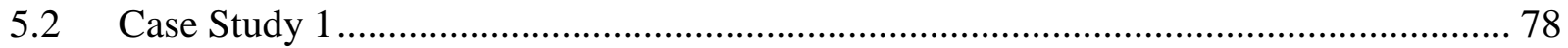

5.2.1 Traffic Flow Data............................................................................................ 78

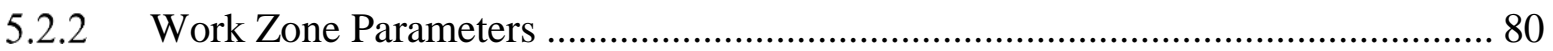

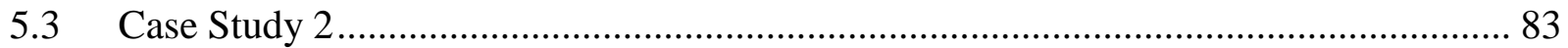

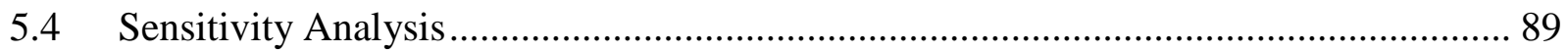

CHAPTER 6: CONCLUSIONS AND FUTURE RESEARCH.........................................92

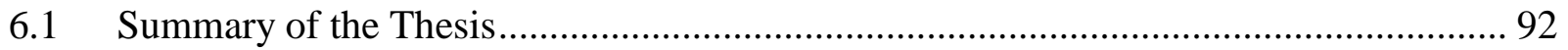

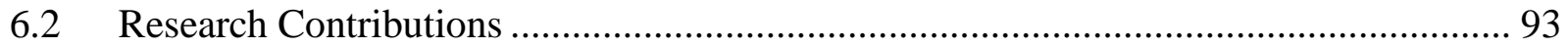

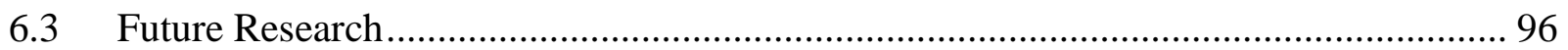




\section{LIST OF APPENDICES}

APPENDIX A: FRESIM Module and Work Zone Models in CORSIM............................... 99

Figure A.1: CORSIM TRAFED Window for Work Zone Network Development..................... 101

Figure A.2: Closer image of 1 lane closure of 3 lane freeway work zone network in FRESIM module. 102

Figure A.3: Closer image of 2 lane closure of 3 lane freeway work zone network in FRESIM module. 103

Figure A.4: Animation Window of Freeway Work Zone Network in FRESIM Module 104

APPENDIX B: Tables of Simulation Scenarios and Results 105

Table B.1: Undersaturated Condition - 50 mph Speed Limit 107

Table B.2: Saturated Condition - 50 mph Speed Limit. 112

Table B.3: Undersaturated Condition - 55 mph Speed Limit 120

Table B.4: Saturated Condition - 55 mph Speed Limit 125

APPENDIX C: Delay and Speed Models for 55 mph Speed Limit 133

Figure C.1: Actual vs. Calibrated Values for Delay Model (55 mph, Undersaturated) 136

Figure C.2: Actual vs. Calibrated Values for Average Speed Model ( $55 \mathrm{mph}$, Undersaturated) 136 Figure C.3: Actual vs. Calibrated Values for Delay Model (55 mph, Saturated). 137

Figure C.4: Actual vs. Calibrated Values for Average Speed Model (55 mph, Saturated) 137 


\section{LIST OF TABLES}

Table 2.1: Recommended Advance Warning Sign Minimum Spacing ........................................ 8

Table 2.2: Taper Length Criteria for TTC Zone ……….......................................................... 11

Table 2.3: Formulas for Determining Taper Length............................................................ 11

Table 2.4: Summary of Work Zone Strategies - Advantages and Disadvantages ....................... 12

Table 2.5: Mobility References on Work Zone Applications ..................................................... 25

Table 2.6: Safety References on Work Zone Applications........................................................... 33

Table 2.7: Driver Behaviour References on Work Zone Applications .......................................... 35

Table 2.8: Planning References on Work Zone Applications.................................................... 38

Table 2.9: Methods of Operational Research .......................................................................... 41

Table 3.1: Undersaturated Condition - 50 mph Speed Limit .................................................... 54

Table 3.2: Saturated Condition - 50 mph Speed Limit ................................................................ 55

Table 3.3: Correlation Coefficients for Decision Variables - Under Saturated (50 mph Limit).. 56

Table 3.4: Correlation Coefficients for Decision Variables - Saturated (50 mph Limit)............. 56

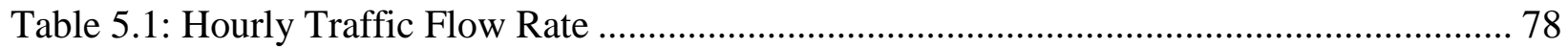

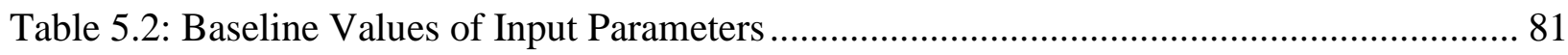

Table 5.3: Unit Maintenance Cost and Production Time ……………………………………........ 81

Table 5.4: Optimized Schedules for $1.8 \mathrm{mi}$ - One Period Scenario .............................................. 82

Table 5.5: Optimized Schedule A for $5 \mathrm{mi}$ - Three Period Scenario …………………………..... 83

Table 5.6: Optimized Schedule B for $5 \mathrm{mi}$ - Three Period Scenario …………………………..... 84

Table 5.7: Optimized Schedule C for $5 \mathrm{mi}$ - Three Period Scenario ……………………............ 85

Table 5.8: Optimized Schedule A for 5 mi - Five Period Scenario …………………………....... 86

Table 5.9: Optimized Schedule B for $5 \mathrm{mi}$ - Five Period Scenario................................................ 87

Table 5.10: Optimized Schedule C for 5 mi - Five Period Scenario............................................... 88

Table 5.11: Hourly Traffic Volume vs. Total Project Cost (Schedule C 5-mi) ............................. 91 


\section{LIST OF FIGURES}

Figure 2.1: Major Components of a Temporary Traffic Control Zone............................................ 7

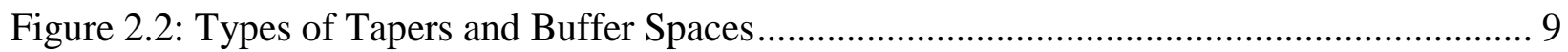

Figure 2.3: Double Lane Closure on a Freeway and Anticipated Tapers and Buffer Spaces....... 10

Figure 2.4: Stationary Lane Closure on a Divided Highway...................................................... 15

Figure 2.5: Lanes Involved in Merging Maneuvers............................................................. 16

Figure 2.6: Sign for Lanes Involved in Merging Maneuvers.......................................................... 16

Figure 2.7: Speed - Flow Curves with Breakpoints and Capacities ............................................. 20

Figure 2.8: Solver Parameters Dialog Box …………............................................................ 43

Figure 3.1: FRESIM Link Properties Window ………............................................................ 48

Figure 3.2: Activity Diagram for the Proposed Methodology ……………………….............. 50

Figure 3.3: Schematic Diagram of the Developed Model in CORSIM for a $60 \mathrm{mph}$ Design Speed

Figure 3.4: R-Squared and p-Values for the Delay Model by Minitab ...................................... 57

Figure 3.5: Residuals vs. Fitted Values for Delay Model by Minitab ........................................... 58

Figure 3.6: R-Squared and p-Value for the Speed Model by Minitab ........................................... 59

Figure 3.7: Residuals vs. Fitted Values for Speed Model by Minitab .......................................... 59

Figure 3.8: Actual vs. Calibrated Data for Delay Model (50 mph, Undersaturated)...................... 61

Figure 3.9: Actual vs. Calibrated Data for Speed Model (50 mph, Undersaturated) ..................... 61

Figure 3.10: Actual vs. Calibrated Data for Delay Model (50 mph, Saturated) ............................ 62

Figure 3.11: Actual vs. Calibrated Data for Speed Model (50 mph, Saturated) ............................ 62

Figure 4.1: Activity Diagram of Total Work Zone Scheduling Methodology ............................... 65

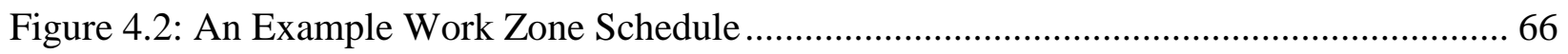

Figure 4.3: Activity Diagram for Solver Optimal Solution Methodology ..................................... 73

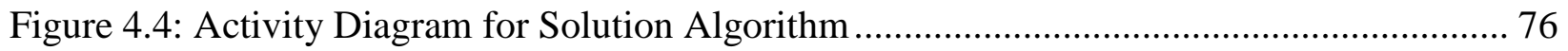

Figure 5.1: Location of Work Zone on I-287 …………............................................................. 77

Figure 5.2: I-287 Hourly Traffic Flow Rate Prediction Curve and Extracted Flow Rate Curve.. 79

Figure 5.3: Maintenance and Total Cost vs. Crew Index (k)..................................................... 89

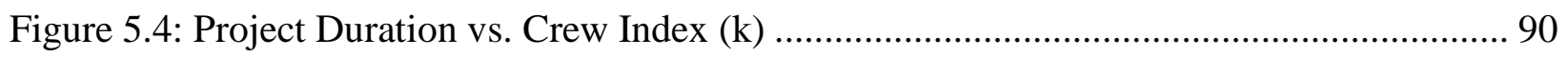

Figure 5.5: Maintenance and Total Cost vs. Project Duration.................................................... 90

Figure 5.6: Total Project Cost vs. Hourly Traffic Volume change \% (Schedule C 5-mi)............ 91 


\section{CHAPTER 1}

\section{INTRODUCTION}

\subsection{Background and Research Motivation}

The prosperity and economic growth of a nation is heavily influenced by well-organized and trustworthy transportation systems that support the increase in demand for many modes of surface travel. That being said, the total highway miles traveled by vehicles worldwide has increased at a much higher rate than the rise in available highway capacity. The weakening of national highway systems has a large impact on vehicle wear-and-tear, fuel consumption, travel time, congestion, comfort and public safety. In order to keep up with the increase in demand and deliver a good level of service to road users, the work zone has become a mandatory element of highway systems. Work zones are recognized as a significant source of freeway incidents as they involve frequent lane closures and lane merges that last for different periods of time. Work zones generate road user delays, traffic incidents, safety hazards, and vehicle emissions.

Chien and Kyriacos (2015) point out that the cost of traffic congestion to road users in the United States (US) was $\$ 121$ billion in 2011. This final total included the costs associated with 5.5 billion hours of delay and 2.9 billion gallons of wasted fuel. It is noteworthy that the delays produced by work zones on freeways represented approximately $24 \%$ of total non-recurring delays and $10 \%$ of overall delays (Federal Highway Administration (FHWA), 2004). The 2008 Highway Statistic report (FHWA, 2008) revealed that more than $4 \%$ of the 8 million miles of public roads have lane closures related to work zones each year due to the growing demand of vehicle miles traveled, aging infrastructure, and highway improvement projects. In 2013, the Environmental Protection Agency reported that $27 \%$ of US greenhouse gas (GHG) emissions were from the transportation sector (Chien and Kyriacos, 2015).

Maintenance activities usually reduce the number of available lanes for live traffic, leading to a reduction in roadway capacity and the formation of traffic bottlenecks. Hence, state and federal transportation agencies are encountering great challenges in conducting maintenance projects resourcefully, efficiently, and economically while ensuring work zone safety and mobility and diminishing traffic interruptions. In order to strategically address the aforementioned drawbacks 
and needs, transportation agencies are encouraging construction engineers, traffic engineers, safety experts and other technical specialists to incorporate the development of comprehensive work zone management plans in the early planning stage (FHWA, 2005). The start and end time, duration of activities, lane closure configuration, traffic management strategies, and type of construction operation are major concerns in the development of successful work zone management plans. Most of these strategies only affect agency and road user costs over the duration of the construction. These decisions are considered short-term work zone decisions.

Although various candidate transportation management approaches exist and traffic volume varies by day of the week and time of the day, it is an exciting task to design the most suitable work zone management plan and poor choices can be quite costly. Road user delay generated by the friction of work zones is influenced by many factors. Work zone layout parameters, speed restrictions, heavy vehicle percentages, and available live lanes during construction can be highlighted as key factors affecting road user delay. Environmental conditions and driver behaviour are also contributors to this delay. On the other hand, project cost is one of the main decision parameters at the management level. Therefore, Departments of Transportation (DOTs) need to estimate traffic flow characteristics related to work zones in order to accurately predict the relevant costs and make wise road network maintenance decisions in order to provide a high level of service for road users.

Total project cost is comprised of a few associated costs including maintenance cost, idling cost, user delay cost, vehicle operating cost, accident cost, and emission cost. User delay cost is a product of delay and the monetary value of time. The final report on work zone optimization provided by Chien and Kyriacos (2015) revealed that the existing analytical models used by DOTs were developed using traditional formulas and deterministic theories, resulting in possible inaccurate estimations of delay and associated costs. In order to overcome those shortcomings and provide more reliable predictions of the cost of maintenance activities, this study used microsimulation-based regression models for delay and incorporated them to optimize the subsectional lengths of total projects and associated schedule subjects to user defined constraints, which minimizes the sum of the above mentioned maintenance, idling, delay, operational, accident, and emission costs. 


\subsection{Problem Statement}

Despite the aforementioned drawbacks, it is necessary to develop a sophisticated analytical approach to generate more accurate cost measure predictions for work zone decision making. The general work zone scheduling optimization problem examined in this thesis can be defined as follows:

A road segment with length $\mathrm{L}$ and number of lanes $\mathrm{N}$ is required to be maintained within the time period $S_{i}$ to $E_{i}$ where $i=1,2, \ldots, n$ and designated for sub-activity sections within the entire work zone segment. Given the necessary user specified project data, road geometric data, traffic flow data, and relevant cost factors, decision makers seek to establish the most cost effective work zone schedule plan to meet the following demands:

1) Which maintenance intensity level (appropriate crew with personnel and equipment) is needed in order to minimize the duration and cost?

2) What is the optimal maintenance frequency and time intervals?

3) How should the road maintenance work zone segment be divided into sub-maintenance divisions? How long should each sub-work zone division be? What is the necessary crew intensity for each sub-work zone division?

4) At what times should the lanes in each work zone be closed and reopened to live traffic under time-varying traffic inflows?

5) What is the total delay and cost pertaining to each work zone period under the given sectional length, dynamic flow, heavy vehicle percentage, and available number of open lanes?

When all of the strategies that are only temporary influences during the maintenance time period are taken into consideration, the optimal work zone schedule plan is defined as the one that minimizes the project total cost $(\mathrm{C})$ which is comprised of three components:

\section{Maintenance Cost (Agency Cost) Module $\left(\mathrm{C}_{\mathrm{M}}\right)$ \\ II. Idling Cost Module $\left(\mathrm{C}_{\mathrm{I}}\right)$ \\ III. User Cost Module $\left(\mathrm{C}_{\mathrm{U}}\right)$}

The development of a model that minimizes total cost while generating an optimal work zone schedule for freeway maintenance projects an important requirement of transportation planning. 


\subsection{Objectives and Scope}

In order to reduce the workload on highway agencies and their commitment to a reliable decision making process in the early planning stages of maintenance projects, this research study aims to develop a systematic decision aid tool which integrates delay and cost decisions into one comprehensive optimization framework. The proposed methodology focuses on maintenance activity projects for multiple-lane freeways under time-dependent inflows in a network. This study provides a comprehensive decision support tool capable of generating and evaluating different work zone schedules as well as automatically searching for high quality solutions by fulfilling the research objectives outlined below.

1. To conduct a comprehensive literature review of work zone applications.

2. To implement real world work zone scenarios in a micro-simulation platform using highly sophisticated CORSIM software.

3. To develop innovative multi-regression models to predict traffic delay by performing microsimulations according to different work zone layout data, road geometry, speed transitions, and traffic flow data.

4. To develop a model to estimate the dynamic traffic flow using analytical software.

5. To improve the developed cost model by integrating the innovative delay and flow models.

6. To develop a novel model to search for optimal start and end times (schedules) for the subsections of the entire project that minimize the total agency cost using Non-Linear and Evolutionary optimization techniques.

7. To establish an innovative, comprehensive decision support tool capable of generating and evaluating different work zone schedules as well as automatically searching for high quality solutions.

By meeting these objectives, this research study will help relevant agencies and Departments of Transportation create trustworthy work zone schedules with minimized cost and enhanced road user satisfaction, increasing the nation's economic prosperity. 


\subsection{Thesis Organization}

In order to meet these research objectives, this thesis is divided into six chapters.

Chapter 1, "Introduction", presents the background and research motivation, problem statement, and research objectives and scope of the research.

Chapter 2, "Literature Review", focuses on reviewing work zone concepts, strategies, work zone applications, microsimulation, optimization and research limitations. This section reviews the relevant research conducted in the last twenty years. Based on the findings of the literature review, the potential contributions of this study are addressed.

Chapter 3, "Microsimulation and Model Development", describes the microscopic simulation tool used in this research study and the simulation approach used to develop analytical models for work zone delay and average speed. The strengths and weaknesses of the CORSIM simulation tool, different work zone scenarios, decision variables, and model validation are also discussed in this chapter.

Chapter 4, "Improved Work Zone Cost Model and Scheduling Optimization", transforms the cost model improved in this study into the objective function of the optimization problem. The total project cost is evaluated as the minimization objective using the regression models developed in Chapter 3. The primary components of the cost model and their parameters are thoroughly discussed in this chapter. Moreover, the incorporation of the Solver optimizer into the scheduling optimization is defined and a solution algorithm is presented.

Chapter 5, "Case Studies", uses two case studies to evaluate the validity of the developed scheduling optimization model using real work site data. The results revealed that the optimization model delivered successful time periods, productivity indices and optimal sub-sectional work zone lengths while minimizing the total cost.

The conclusions, research contributions and direction for potential future studies are discussed in Chapter 6. 


\section{CHAPTER 2}

\section{LITERATURE REVIEW}

\subsection{Maintenance and Work Zones}

There is a wide discrepancy between professionals and the general public on the exact scope and definition of "maintenance", especially the difference between maintenance and rehabilitation projects. Some professionals believe that maintenance only involves relatively low-cost treatments serving to slow the rate of deterioration by identifying and addressing particular pavement deficiencies (such as seal coats, cracking sealing, pothole patching, joint sealing, grinding, milling, and grooving) and that rehabilitation involves the more forceful treatments involving the repair of the segments of existing pavement to reinstate the deterioration course (such as overlay, removing and replacing the wearing course) (Yang, 2010). Maintenance duration can be classified as short term, intermediate, and long term. Short term usually includes activities like pothole patching, lane marking, and crack sealing that require a number of hours. Hence, road users have to expect delays and shortcomings for a shorter time period. Long term projects such as bridge constructions and road rehabilitations need long time periods that may spread over days, months or even years. These situations give options to road users to divert to other roads by nearest interchanges or use advance information systems to decide alternate route to minimize delays and costs in long run.

The Highway Capacity Manual (HCM, 2010) defines a work zone as "a segment of highway in which maintenance and construction operations reduce the number of lanes available to traffic or affect the operational characteristics of the traffic flowing through the segment". Bryden and Mace (2002) state that the layout of a work zone ensures a distinct separation between the live lanes and the activity spaces while providing buffer spaces to safeguard road users and workers who may unintentionally stray outside of their designated areas. As figure 2.1 illustrates, there are four major components in the Temporary Traffic Control (TTC) Zone of a construction area, according to the Manual on Uniform Traffic Control Devices (MUTCD) (2009):

1. Advance Warning Area

2. Transition Area

3. Activity Area

4. Termination Area 


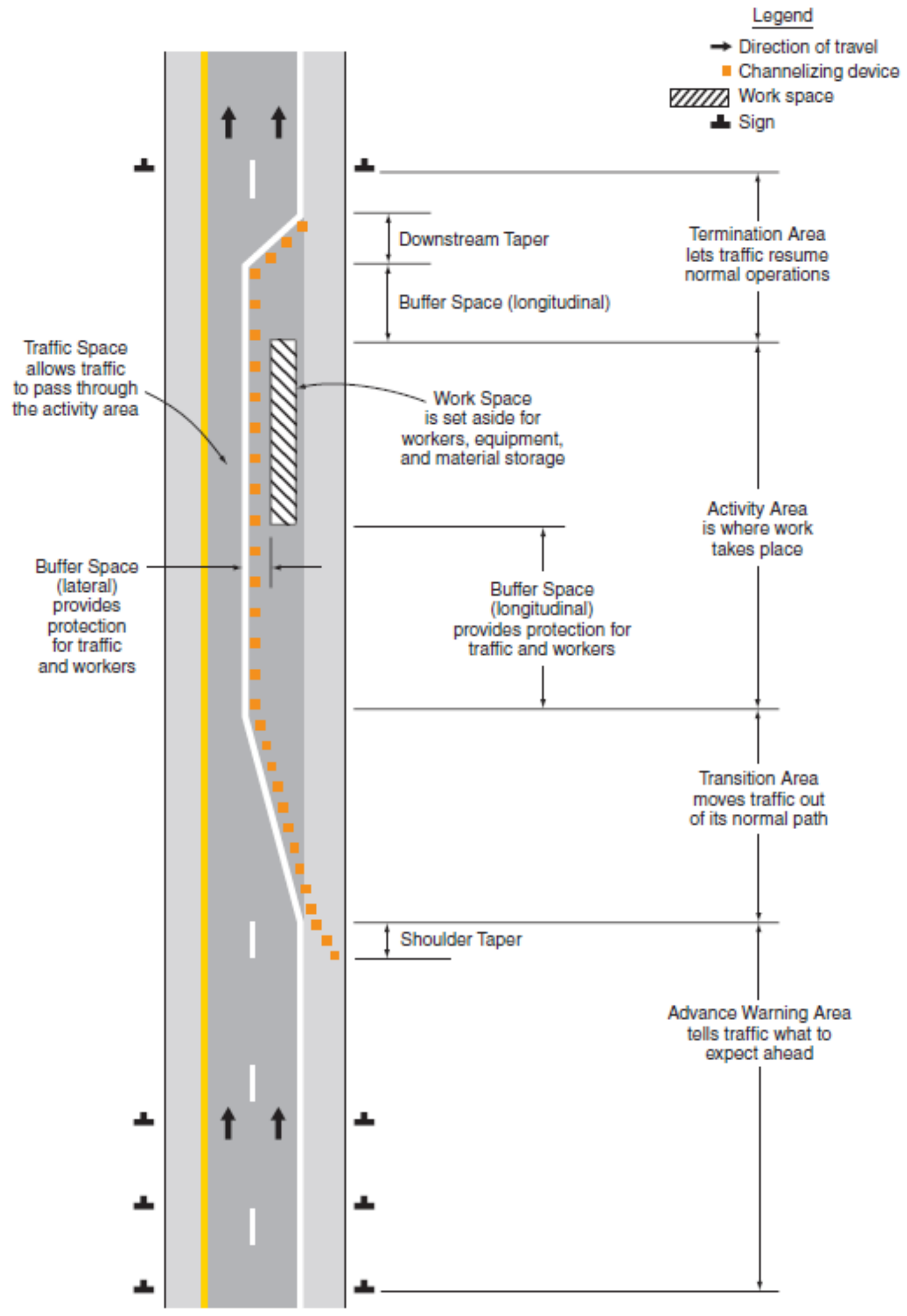

Figure 2.1: Major Components of a Temporary Traffic Control Zone (MUTCD, 2009) 


\section{Temporary Traffic Control (TTC) Zone}

A TTC zone is a segment where road user conditions are changed because of construction activities and involves the use of TTC devices, uniformed law enforcement officers, or authorized personnel. A work zone is usually indicated by signs, channelizing devices, barriers, pavement markings, and/or work vehicles. The TTC zone extends from the first warning sign or high-intensity rotating, flashing, oscillating, or strobe lights on a vehicle to the END ROAD WORK sign or the last TTC device (MUTCD, 2009).

\section{Advance Warning Area}

According to the MUTCD (2009), the advance warning area is the segment of the roadway where road users are informed about the upcoming work zone. Since two or more advance warning signs are regularly used, the advance warning area should extend 1,500 ft (450 m) or more for open highway conditions and $0.5 \mathrm{mi}(800 \mathrm{~m})$ or more on freeways and expressways. The effective location of the first warning sign in advance of the transition area (taper) in feet should be extensively long from lane width (8-12) times the speed limits in mph (MUTCD, 2009). Table 2.1 shows the recommended advance warning sign minimum spacing.

Table 2.1: Recommended Advance Warning Sign Minimum Spacing (MUTCD, 2009)

\begin{tabular}{|c|c|c|c|}
\hline \multirow{2}{*}{ Road Type } & \multicolumn{3}{|c|}{ Distance Between Signs } \\
\cline { 2 - 4 } & A & B & C \\
\hline Urban (Low Speed) & 100 feet & 100 feet & 350 feet \\
\hline Urban (High Speed) & 350 feet & 350 feet & 500 feet \\
\hline Rural & 500 feet & 500 feet & 2,640 feet \\
\hline Expressway/Freeway & 1,000 feet & 1,500 feet & \multicolumn{2}{|c|}{} \\
\hline
\end{tabular}

\section{Transition Area and Tapers}

The transition area is the segment of the roadway where road users are redirected out of their expected path. Transition areas typically involve the strategic use of tapers to merge live traffic from the existing lane into another guided lane. Tapers are formed using a series of channelizing devices and, in some cases, pavement markings to direct traffic outside of the normal path. Figures 
2.2 and 2.3 illustrate different types of tapers and buffer spaces according to the number of lane closures. The corresponding taper length (L) is determined using Tables 2.2 and 2.3. The maximum distance between devices (in feet or meters) in a taper should not exceed 1.0 times the speed limit in mph (MUTCD, 2009).

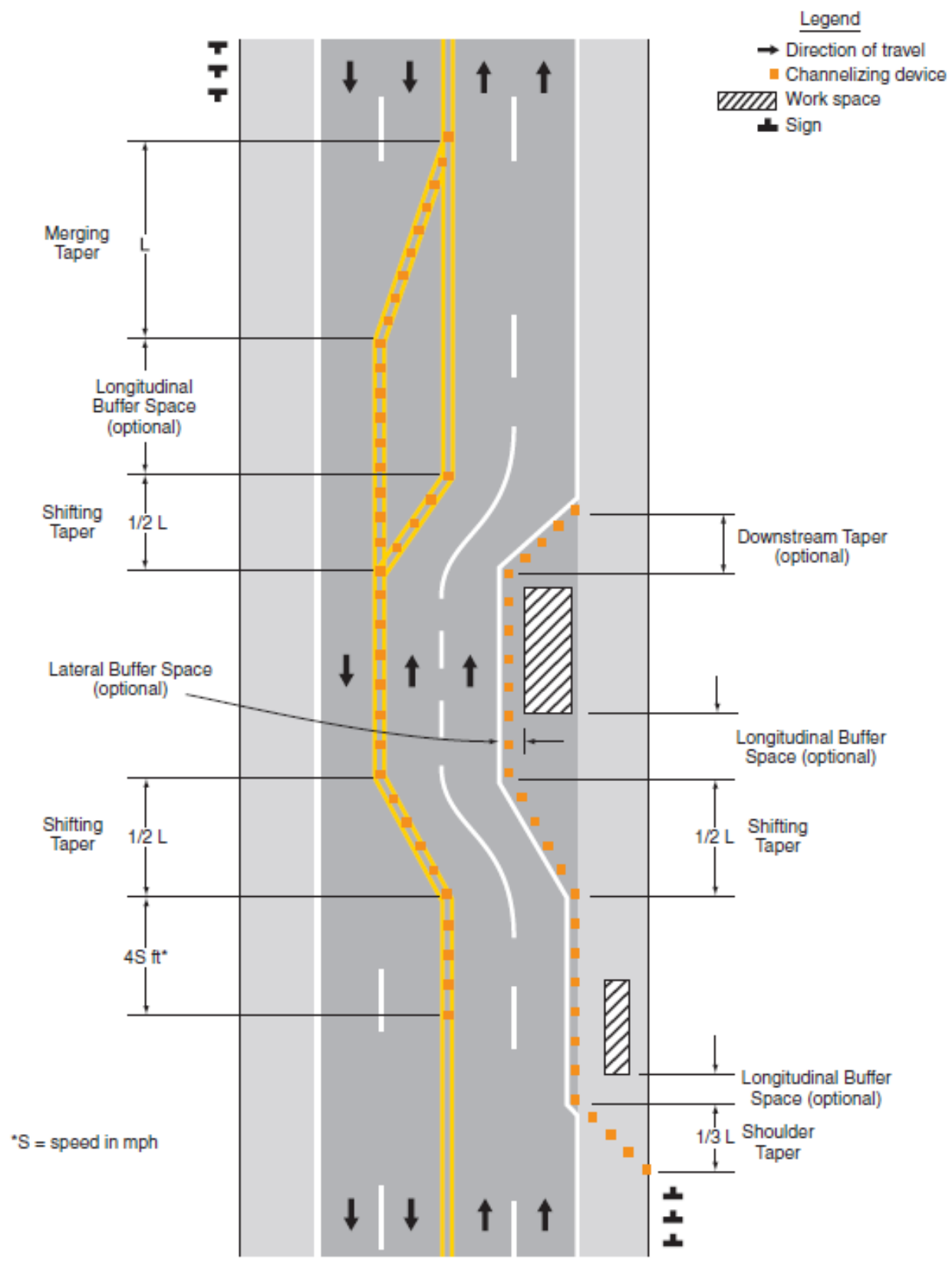

Figure 2.2: Types of Tapers and Buffer Spaces (MUTCD, 2009) 


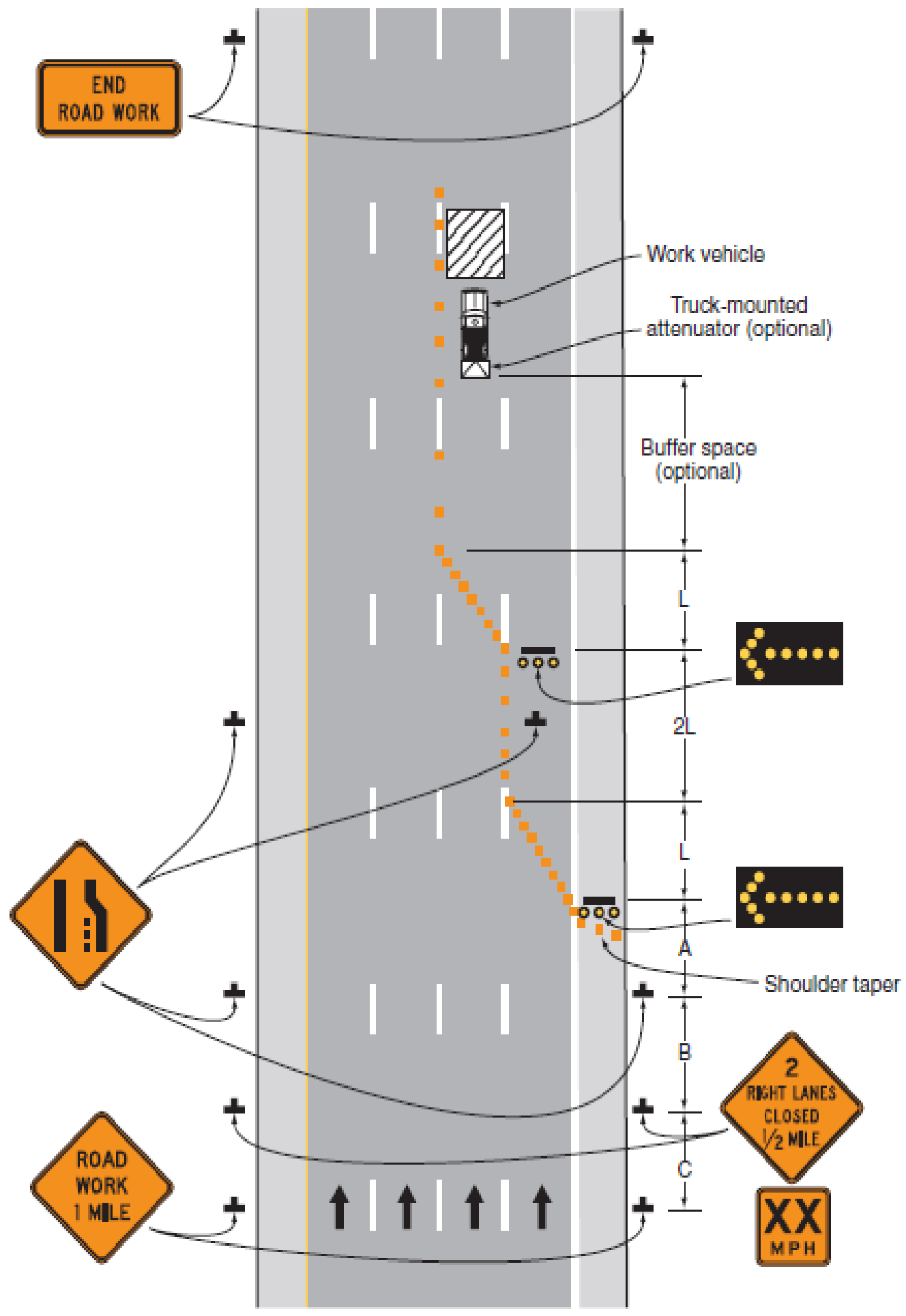

Figure 2.3: Double Lane Closure on a Freeway and Anticipated Tapers and Buffer Spaces (MUTCD, 2009) 
Table 2.2: Taper Length Criteria for TTC Zone (MUTCD, 2009)

\begin{tabular}{|c|c|}
\hline Type of Taper & Taper Length (L) \\
\hline Merging Taper & At least L \\
\hline Shifting Taper & At least $0.5 \mathrm{~L}$ \\
\hline Shoulder Taper & At least $0.33 \mathrm{~L}$ \\
\hline One-Lane, Two-Way Traffic Taper & 50 feet minimum, 100 feet maximum \\
\hline Downstream Taper & 50 feet minimum, 100 feet maximum \\
\hline
\end{tabular}

Table 2.3: Formulas for Determining Taper Length (MUTCD, 2009)

\begin{tabular}{|c|c|}
\hline Speed (S) & Taper Length (L) in Feet \\
\hline 40 mph or less & $\mathrm{L}=\frac{\mathrm{WS}^{2}}{60}$ \\
\hline $45 \mathrm{mph}$ or more & $\mathrm{L}=\mathrm{WS}$ \\
\hline
\end{tabular}

Where $\mathrm{W}=$ lane width in feet and $\mathrm{S}=$ posted speed limit in $\mathrm{mph}$.

\section{Activity Area}

The activity area is the segment of the roadway where the construction or maintenance activity takes place. It is comprised of 3 components: the workspace, the traffic space, and the buffer space. The work space can be stationary or mobile, depending on the type of work. Buffer spaces, as shown in Figure 2.1, are located longitudinally and laterally with respect to the direction of the traffic flow. The allowable values of the longitudinal buffer length are determined based on the allowable stopping sight distance which varies according to the design speed (MUTCD, 2009).

\section{Termination Area}

The termination area is the segment of the roadway that redirects road users back into their normal path and to the design speed of normal road conditions. It extends from the downstream end of the activity area to the last temporary traffic control (TTC) device. A research study conducted by Bai and $\mathrm{Li}$ (2006) revealed that the termination area has the lowest number of crashes in the work zone. 


\subsection{Work Zone Strategies}

Work zone strategies are implemented in order to allow traffic to pass through or around the facility under construction or maintenance by means of an infrastructure and applicable temporary traffic controls. According to Elghamrawy (2011), nine strategies are widely implemented in highway work zones, and these strategies are mentioned in the Transportation Management Plans (TMP) of special projects (IDOT, 2002).

These strategies are: (1) alternating one-way operation; (2) detour; (3) diversion; (4) full road closure; (5) intermittent closure; (6) lane closure; (7) lane constriction; (8) median crossover; and (9) use of the shoulder. Each of these nine strategies has its own fundamental characteristics and offers a distinctive set of advantages and disadvantages, as summarized in Table 2.4. The selection method of a work zone strategy is influenced by many factors including the number of lanes, geometric and structural design, highway and worker safety, accessibility, capacity and queues, constructability, and cost consequences (Elghamrawy, 2011).

Table 2.4: Summary of Work Zone Strategies - Advantages and Disadvantages (Elghamrawy, 2011)

\begin{tabular}{|l|l|l|l|}
\hline No. & Strategy & Advantages & Disadvantages \\
\hline 1 & $\begin{array}{l}\text { Alternating One-Way } \\
\text { Operation }\end{array}$ & Low agency cost; Flexible & $\begin{array}{l}\text { Stopping of traffic; Capacity } \\
\text { reduction }\end{array}$ \\
\hline 2 & Detour & $\begin{array}{l}\text { Flexible; Cost depends on } \\
\text { detour plan }\end{array}$ & $\begin{array}{l}\text { Capacity reduction; } \\
\text { Degrading of existing roads }\end{array}$ \\
\hline 3 & Diversion & $\begin{array}{l}\text { Traffic-work separation; Low } \\
\text { impact on traffic }\end{array}$ & $\begin{array}{l}\text { Higher cost; Right-of-way is } \\
\text { required }\end{array}$ \\
\hline 4 & Full Road Closure & $\begin{array}{l}\text { Expedited construction; } \\
\text { Traffic-work separation }\end{array}$ & $\begin{array}{l}\text { Another strategy is required; } \\
\text { High traffic impact }\end{array}$ \\
\hline 5 & Intermittent Closure & Flexible; Low agency cost & $\begin{array}{l}\text { Short-term work zones; High } \\
\text { traffic impact }\end{array}$ \\
\hline
\end{tabular}




\begin{tabular}{|l|l|l|l|}
\hline 6 & Lane Closure & $\begin{array}{l}\text { Service maintained; Low } \\
\text { agency cost }\end{array}$ & $\begin{array}{l}\text { Capacity reduced; High } \\
\text { traffic impact }\end{array}$ \\
\hline 7 & Lane Constriction & Low impact on traffic & Undesirable lane width \\
\hline 8 & Median Crossover & $\begin{array}{l}\text { Traffic separation; Low } \\
\text { impact on traffic }\end{array}$ & Capacity reduced; High cost \\
\hline 9 & Use of Shoulder & Low cost & $\begin{array}{l}\text { Displace disabled vehicles } \\
\text { refuge }\end{array}$ \\
\hline
\end{tabular}

\subsubsection{Temporary Traffic Control (TTC) Devices and Applications}

Traffic control devices are defined as any signs, signals, markings, and other devices used to guide, warn, or regulate traffic, placed on, over, or adjacent to a roadway (MUTCD, 2009). Six of the ten parts of the MUTCD manual focus on Temporary Traffic Control devices. When the normal function of the roadway is interrupted, TTC planning provides movement continuity of motor vehicles, transit operations, and accessibility to property and utilities (MUTCD, 2009). The manual outlines a number of factors that govern TTC planning, including:

1. Type of Highway

2. Road User Conditions

3. Duration of Operations

4. Physical Constraints

5. The proximity of the workspace or incident management activity to road users.

The MUTCD manual (2009) offers guidance for the application and implementation of various types of devices. Some of these devices are:

1. Temporary control signs

2. Arrow panels

3. Channelizing devices 
4. Temporary raised pavement markers

5. High-level working devices

6. Portable changeable message signs

7. Temporary traffic barriers

8. Delineators

9. Lighting devices

10. Crash cushions

11. Vehicle-arresting systems

12. Rumble strips

13. Screens

The use of TTC devices must follow the agency's objective guidelines for roadway safety, considering different factors such as traffic conditions, site conditions, traffic volume, and the cost effectiveness of candidate safety alternative devices (Wolff and Terry, 2006).

The selection of TTC devices depends on the nature of the activity (MUTCD, 2009). The closer the work zone activities are to live traffic, the higher the number of necessary TTC devices. Fortysix typical work zone applications are included in the MUTCD manual with illustrations of the signs required, and comprehensive information for the order, location, and spacing of these signs. An example of a proposed long-term, intermediate and short-term (typical application 33) work zone application is the stationary lane closure on a divided highway, as shown in Figure 2.4 (MUTCD, 2009). The distances A, B, and C for the typical applications are calculated using Table 2.1 (MUTCD, 2009).

\subsubsection{Merge Concepts}

Lane regulator techniques assist the merging process to reduce freeway user stress levels and enhance safety. By guiding the driver at or to a specific point, occurrences of queue jumping and weaving are decreased and capacity is increased. These approaches are executed using variations of the early merge, late merge, or signal merge control concepts. Both control arrangements can be static or dynamic. 

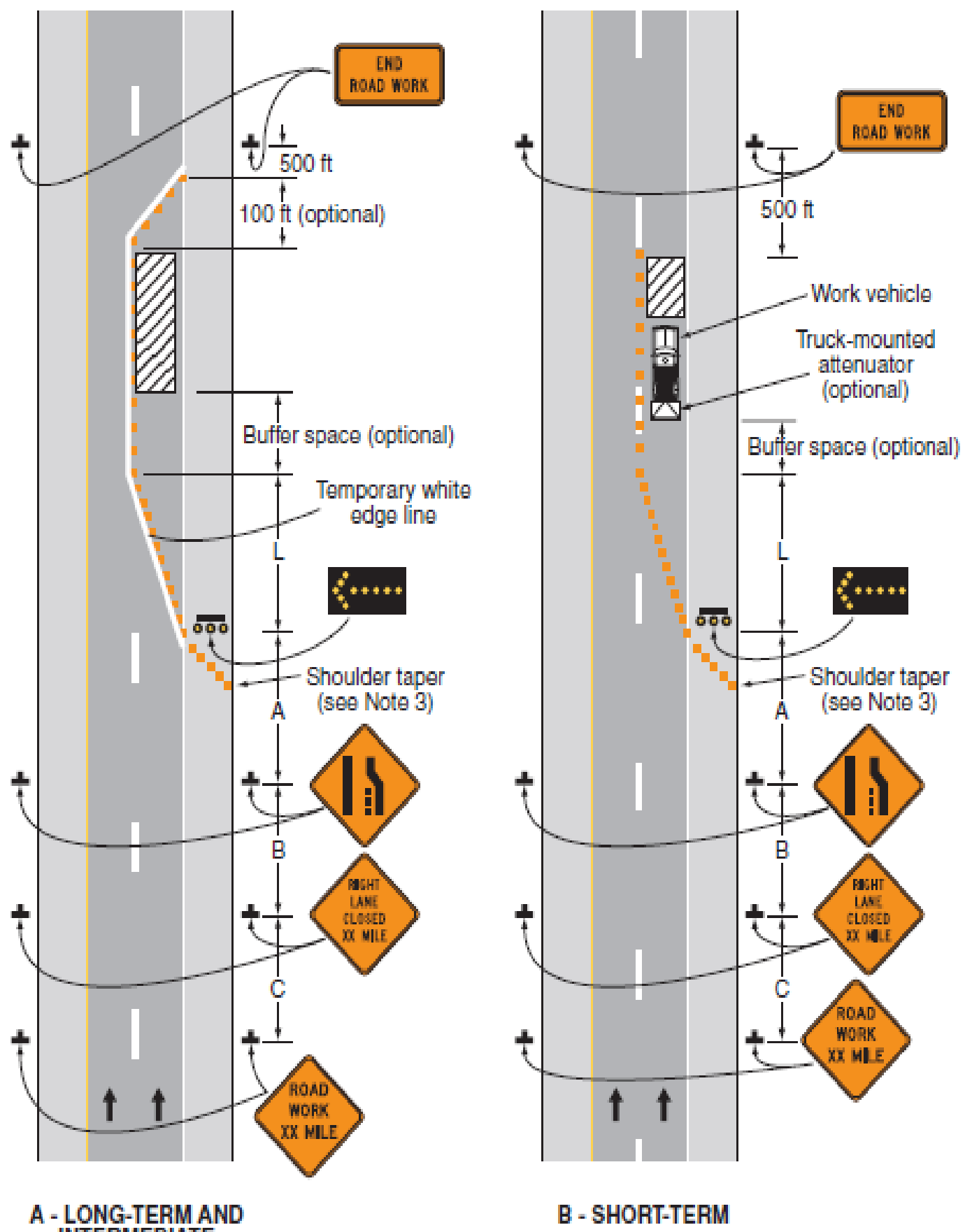

\section{A - LONG-TERM AND INTERMEDIATE}

Figure 2.4: Stationary Lane Closure on a Divided Highway

(Typical Application 33 - MUTCD, 2009) 
Static merge control typically makes use of signs that display a single message at all times and in the same location, regardless of traffic time. Dynamic merge control involves real-time control measures used to decide whether or not to activate additional signage upstream to furthermore inform approaching drivers (Kurker, 2013). A basic lane closure and lane changing maneuver is illustrated in Figure 2.5.

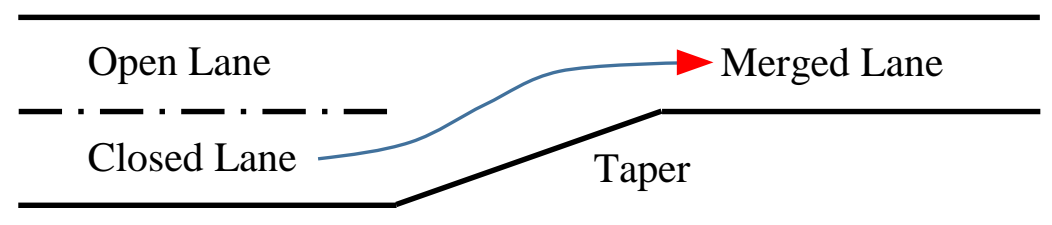

Figure 2.5: Lanes Involved in Merging Maneuvers

A traffic control device such as the W4- 2 sign shown in Figure 2.6 is placed to warn approaching vehicles that a certain merging maneuver is required ahead.

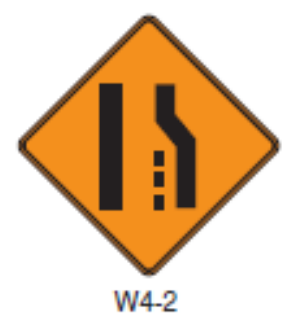

Figure 2.6: Sign for Lanes Involved in Merging Maneuvers (MUTCD, 2009)

Proper guidance for lane changing maneuvers is an important operational issue for the enhancement of traffic safety and efficiency. In general, existing merge controls can be divided into five categories (Kang, 2006):

1. Nebraska Department of Roads (NDOR) Merge

2. Static Early Merge (SEM)

3. Dynamic Early Merge (DEM)

4. Static Late Merge (SLM)

5. Dynamic Late Merge (DLM)

6. Joint Merge Control (JMC)

7. Signalized Merge Control (SMC)

The theoretical development and field applications of these existing merge control categories are discussed in the following subsections. 


\subsubsection{Merge Lengths}

According to the MUTCD guidelines (2009), merge length (L) should be determined according to the speed limits and offsets in order to allow an adequate distance to safely complete the lane changing maneuver (see Table 2.2). In cases involving the closure of multiple lanes, there should be a $2 \mathrm{~L}$ straight distance between the preceding downstream merge point and the next upstream merge point. This gives drivers enough time to perceive and react to the merge process in a safe and efficient manner, as illustrated in Figure 2.3.

\subsubsection{Merge Control Types}

\section{Nebraska Department of Roads (NDOR) Merge Control}

NDOR is a conventional lane-merge control method (also called No-Merge Control) in which drivers are informed of the upcoming lane closure using signs placed on both sides of the roadway about 1.0 and 0.5 miles prior to the work-zone taper. Additionally, lane-reduction signs are placed on both sides of the roadway 1,500 ft ahead of the upstream end of the taper. A flashing-arrow panel is usually placed at the beginning of the upstream end of the taper (Kang, 2006).

\section{Early Merge Control (EMC)}

EMC is a lane-merge control method that alerts drivers of upcoming lane closures before the work zone. This gives road users enough time to find a gap in the traffic and complete the lane changing maneuver (merging) prior to the closure. This process is more effective when the corresponding traffic demand is low compared to the available capacity; The system breaks down with high demand and fewer gaps (Yang et al., 2009).

\section{Late Merge Control (LMC)}

LMC us a lane-merge control method that allows for the use of the full capacity of the freeway approaching a work zone in order to minimize the length of queue propagation in conditions where demand approaches capacity. This is succeeded by informing drivers to use total lanes followed by a "take turns" method once drivers arrive at the proposed merge point. Delft University in the Netherlands calls this type the "Zipper" method, in which drivers do not change lanes until a given distance from the lane drop (Walters et al., 2000). This distance is more less than the distance 
applies in the early merge process. Walters et al (2000) also state that the proper application and efficient use of this method can significantly improve throughputs while reducing queue propagation up to 50 percent.

\section{Joint Merge Control (JMC)}

JMC is a lane-merge control method used in temporary and long-term work zones. This method makes use of signs in the advance warning area and channeling devices in the transition zone in order to generate an evenly balanced flow of vehicles in each lane. By applying a sequence of warning signs and a "funnel-shaped" arrangement with traffic control devices at the entrance of the transition zone, the JMC method simultaneously merges two lanes into one lane (Wolshon et al., 2012).

\section{Signalized Merge Control (SMC)}

SMC is a lane-merge control method in which traffic signals that are usually located at intersections, are placed in work zones in order to regulate the movement of traffic. This method was created in order to control merging in sites with heavy congestion (where demand exceeds capacity under saturated flow conditions). Conventional merge concepts such as the early merge and late merge are favourable as long as traffic demands remain lower than the work zone capacity. Yang et al. (2009) state that the early and late merge control approaches are highly efficient between 700 and 800 passenger cars per hour per lane (pcphpl), when the experimental technique of lane-based signal merge (LBSM) could handle well above that flow rates and were efficient with high percentages of heavy vehicles.

\subsection{Free Flow Speed (FFS) and Capacity}

According to the Highway Capacity Manual (2010), Free flow speed is defined as the theoretical speed when the density and flow rate of the segment are both zero. Chapter 11 of the manual also states that the free flow speed on freeways is expected to prevail at flow rates between 0 and 1,000 passenger cars per hour per lane (pc/h/ln). Speed is insensitive to flow rates.

The free flow speed of a basic freeway section is affected by three variables:

1. Lane Width 


\section{Lateral Clearance}

\section{Total Ramp Density}

The Highway Capacity Manual (2010) presents a set of speed-flow curves for basic freeway segments operating under base conditions (see Figure 2.7). It highlights five curves, one for each of the five free flow speed levels: $75 \mathrm{mi} / \mathrm{h}, 70 \mathrm{mi} / \mathrm{h}, 65 \mathrm{mi} / \mathrm{h}, 60 \mathrm{mi} / \mathrm{h}$, and $55 \mathrm{mi} / \mathrm{h}$.

Each curve is comprised of a range of flows from $0 \mathrm{pc} / \mathrm{h} / \mathrm{ln}$ to a break point in which the speed remains constant at the FFS. A more detailed outline is provided below.

$\mathrm{FFS}=75 \mathrm{mi} / \mathrm{h}: 0-1,000 \mathrm{pc} / \mathrm{h} / \mathrm{ln}$

$\mathrm{FFS}=70 \mathrm{mi} / \mathrm{h}: 0-1,200 \mathrm{pc} / \mathrm{h} / \mathrm{ln}$

$\mathrm{FFS}=65 \mathrm{mi} / \mathrm{h}: 0-1,400 \mathrm{pc} / \mathrm{h} / \mathrm{ln}$

$\mathrm{FFS}=60 \mathrm{mi} / \mathrm{h}: 0-1,600 \mathrm{pc} / \mathrm{h} / \mathrm{ln}$

$\mathrm{FFS}=55 \mathrm{mi} / \mathrm{h}: 0-1,800 \mathrm{pc} / \mathrm{h} / \mathrm{ln}$

At the break point of each curve mentioned above, the speed declines at an increasing rate until capacity is reached.

The capacity of a freeway varies along with the free flow speed. According to the HCM (2010), under base conditions, the following capacities are included under each FFS category.

$70-75 \mathrm{mi} / \mathrm{h}$ FFS: $\quad$ Capacity $-2,400 \mathrm{pc} / \mathrm{h} / \mathrm{ln}$

$65 \mathrm{mi} / \mathrm{h}$ FFS: $\quad$ Capacity $-2,350 \mathrm{pc} / \mathrm{h} / \mathrm{ln}$

$60 \mathrm{mi} / \mathrm{h} \mathrm{FFS:} \quad$ Capacity $-2,300 \mathrm{pc} / \mathrm{h} / \mathrm{ln}$

$55 \mathrm{mi} / \mathrm{h}$ FFS: $\quad$ Capacity $-2,250 \mathrm{pc} / \mathrm{h} / \mathrm{ln}$ 


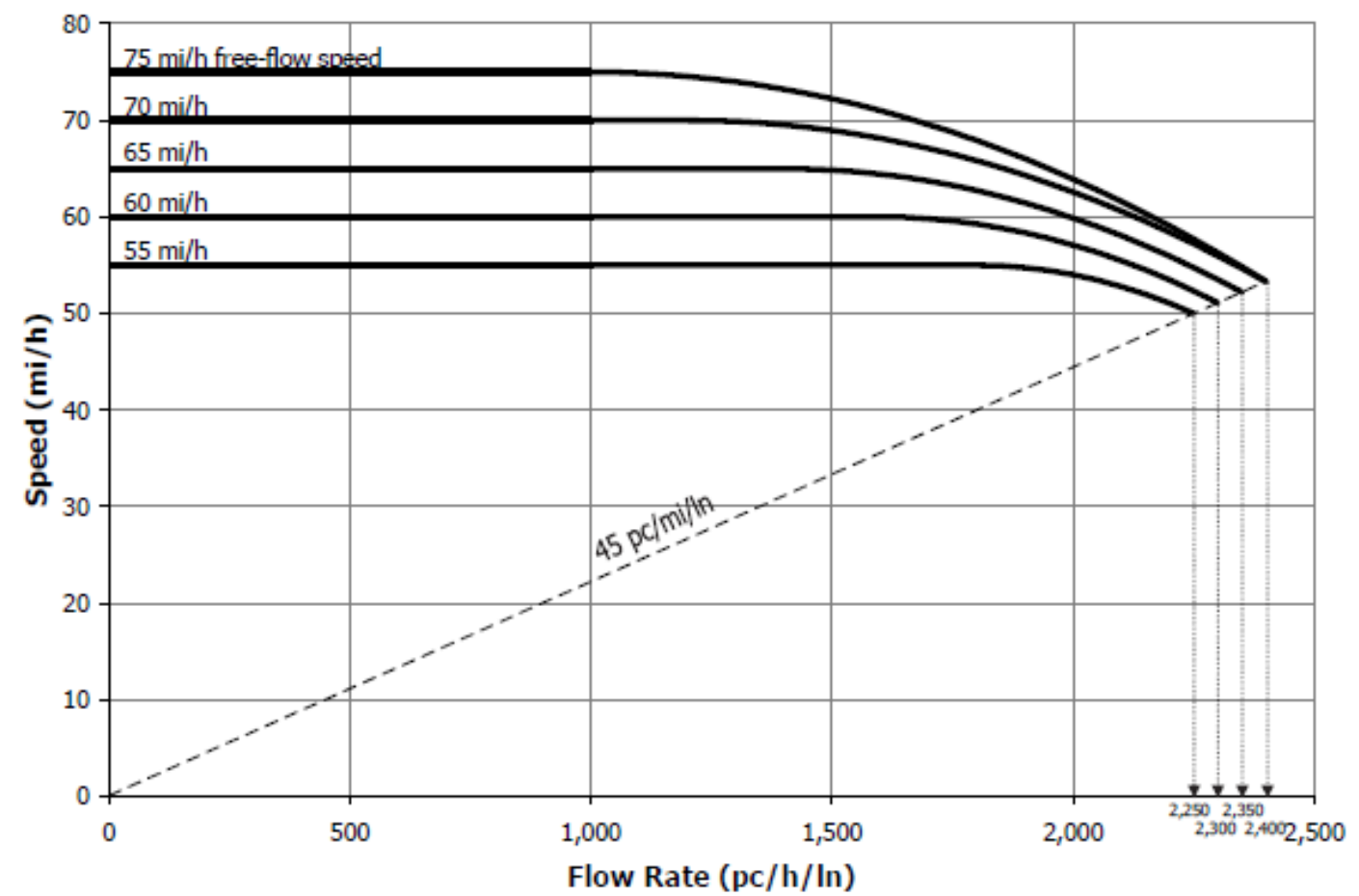

Figure 2.7: Speed - Flow Curves with Breakpoints and Capacities (HCM, 2010)

\subsection{Work Zones Applications}

\subsubsection{Mobility Applications}

Mobility is the most important element considered in transportation engineering. When work zones with construction, patching, paving, lane marking, debris removal and weeding take place on freeways and highways, the full capacity of the segment is temporarily reduced. Friction on throughputs is generated by lane closures, speed limits, channelizing devices and longitudinal barriers. This always increases the density, which leads to a reduced Level of Service (LOS).

Son (1999) incorporated fluid approximations to establish the queueing model for average delay of two-lane highway lane closures. Fluid approximations and stochastic models were originally developed by Newell in 1969. Chandury and Wolshon (2000) proved that the car-following model used in the Corridor Simulation (CORSIM - microsimulation) tool are in line with field data using Global Positioning System (GPS) technology. Turley (2002) presented a Generalized Linear Model (GLM) for speed by evaluating Arrow-Panel Caution Displays. The author conducted 
experiments to evaluate the effectiveness of "Dancing Diamonds" and "Flashing Box" displays on speed reduction and lane migration.

Curtis and Funderburg (2003) used the QuickZone software tool developed by the Federal Highway Administration (FHWA) to estimate work zone delays and maximum queue lengths. It helps to plan work phasing and detour routes to minimize delays and driver frustration. Chin (2004) developed a moving slot model and framework for operational strategies on slot/lane assignment rules. This model can be used to manage the highway space for interactions between the entrance and exit process to maximize capacity accounting for vehicle maneuvers. The intention was to apply Automated Highway Systems without changing system configurations while optimizing performance in terms of capacity and travel time.

An online algorithm for variable speed limit control at work zones was introduced by Kang (2004). The proposed model and algorithm optimize the speed-limit based on the evolution of dynamic traffic conditions and macroscopic traffic characteristics. Scriba and Seplow (2005) reviewed the mobility regulations updated by the FHWA in order to address the issues associated with traffic congestion. These regulations were intended to facilitate the consideration of mobility impacts across the project development stages and implementation strategies. According to the field experiments carried out by Zech et al. (2005), the 3M rumble strips and police presence are most effective for the control of speed in work zones.

Kang (2006) developed an advanced Dynamic Lane Merge (DLM) control model and operational algorithm. The optimization took into account the interactions between speed, flow and work zone capacity. The author also developed a Dynamic Variable Speed Limit (VSL) model and operational algorithm. The primary focus was the maximization of work zone throughput while optimizing the sequence of transition speeds. Variable message sign boards were incorporated to display variable speeds. Kang and Chang (2006) proposed a speed control strategy called the Timeof-Day Speed Limit (TOD SL). This strategy allows planners to establish optimal real-time speed limits by maximizing the use of available historical data. The logic behind the strategy uses different time periods throughout the day and varying traffic conditions.

Wolshon and Lambert (2006) proposed a reversible lane concept that achieves optimum traffic flow by minimizing work zone delays. Scriba and Seplow (2006) pointed out the need for new 
policies and practices to improve mobility in work zones following a comprehensive review of the rules and policies adopted by different states in the USA. Kim (2008) investigated the traffic characteristics upstream of a work zone and developed a mechanistic model of capacity based on merging behaviour in work zones. The author introduced a model capable of estimating work zone capacity according to the lane closure configuration and traffic conditions such as heavy vehicle percentage, merging patterns, merging time and queue discharge flow rate. Chen (2008) established a work zone simulation model to represent the work zone traffic flow patterns and vehicular behaviour using the VISSIM microscopic simulation tool.

Li (2008) strongly recommended a Speed Monitoring Display (SMD) for significant speed reductions after conducting extensive experiments of six different scenarios using display size, flashing rate and a warning message. The author also developed a sequential algorithm to distinguish vehicle platooning or bunching to allow vehicles to respond to the SMD technology. $\mathrm{Li}$ also proposed a disaggregate regression model to predict the probability of speeding for any given vehicle. Scriba and Feast (2009) reviewed the applicability, capability and practicality of the QuickZone, Construction Analysis for Pavement Rehabilitation Strategies (CA4PRS), QUEWZ98, Critical Lane Volume Analysis (CLV), Highway Capacity Software (HCS), Synchro, VISSIM and CORSIM simulation tools in different states in the USA.

Kang and Chang (2009) proposed a Lane Based Dynamic Merge (LBDM) Model and operational algorithm. Their study focused on the selection of control variables (Early Merge and Late Merge) and their thresholds in traffic flow dynamics. Chen et al. (2010) introduced a logistic regression model to mimic dynamic diversion behaviour (queue propagation) in upstream traffic. More importantly, the researchers incorporated a number of entry and exit ramps and well-calibrated VISSIM model to the study conducted by Jackson (2010) which made use of a Side-Fire Radar and sensors to detect real time traffic data to be used in Variable Message Signs (VMS) and showed that smart work zones increase mobility. Wang (2010) developed an optimized queue prediction spreadsheet tool for the Alabama DOT.

Collura et al. (2010) assessed the data requirements, ability to simulate work zone strategies, relative reliability and accuracy of the QuickZone, QUEWZ, CA4PRS and CORSIM simulation tools. They concluded that QuickZone and QUEWZ were able to predict reasonable queue lengths 
according to their field observations. Chung (2011) presented a method to quantify non-recurrent traffic congestion using the Total Delay (TD) function based on traffic flow data and spatiotemporal work zone information. The author emphasized the practicality of the findings for the performance evaluation of congestion management programs for work zones. Radwan et al. (2011) evaluated the operational effectiveness of the Simplified Dynamic Lane Merge Systems (SDLMS) i.e. Early Merge and Late Merge in the presence of VSL. The simulated results revealed that a late merge, with or without VSL, produced higher mean throughputs for all adherence levels (compliance rates) of motorists.

Zheng et al. (2011) conducted a comparison study of the three existing capacity prediction models. The model presented in the Highway Capacity Manual (2000), the multi-linear regression model and the fuzzy logic based artificial neural network model were tested for accuracy using Dutch case studies. The prediction error was also evaluated. The fuzzy logic based artificial neural network model showed the highest accuracy with a $20 \%$ reduction in prediction error. Wasson et al. (2011) conducted a large study of concurrent enforcement in work zones and extensive space mean speed measurement using probe vehicle data with Bluetooth detectors and different enforcement strategies. The results revealed a statistically significant reduction in space mean speeds caused by the highly concentrated enforcement presence in work zone areas and improved compliance with work zone speed limits.

$\mathrm{Ng}$ (2012) addressed two major limitations of work zone optimization models for two-lane highways. First, he used the stochastic nature of the vehicle arrivals by promising the uncertainty of traffic flow. Second, a traffic flow theory-based cell transmission model was employed to yield a more accurate and realistic modeling of traffic flow dynamics. The Cell Transmission Model (CTM) was introduced by Daganzo in 1994-1995. CTM uses the discrete approximation of the hydrodynamics traffic flow model and is capable of accurately modelling real-world queuing and shockwaves. Zhizhou et al. (2013) investigated the influence of large vehicles on traffic flow speed and speed variance. The authors created a VSL strategy based on the gap acceptance theory considering the large vehicle mix rate and a polynomial fitting model was developed for traffic flow variance vs large vehicle rate affiliation. 
Kurker (2013) assessed Dynamic Traffic Assignment (DTA) equipped with Early Merge, Late Merge and Fixed Cycle Work Zone Signal Merge Control (FCWZSMC) using VISSIM simulations. The author developed guidelines for the selection of merge concepts according to the traffic flow. FCWZSMC was recommended for multiple lane closures and high traffic flows. Ding et al. (2013) assessed mobility in regards to transition area length and speed limit values. Travel time was established as the key parameter for the evaluation and development of the influence model for mobility. Isaiah (2014) reviewed some of the commercially available Automated Speed Identification (ASI) technologies by testing three Photo Speed Enforcement (PSE) packages. The results revealed the strengths and weaknesses of each technology and their applicable environments.

Qu (2014) proposed delay estimation based on Travel Time Reliability (TTR). More information regarding his findings can be found in the planning and cost aspects section. Du and Chien (2014) developed guidelines for the use of the road shoulder by live traffic in order to increase the capacity of work zones. Turley et al. (2014) presented a Generalized Linear Model (GLM) for speed by evaluating the Arrow-Panel Caution Displays. They conducted experiments to evaluate the effectiveness of "Dancing Diamonds" and "Flashing Box" displays on speed reduction, lane migration and conflicts. The authors recommended the use of the Dancing Diamonds caution displays in the MUTCD. Zhu (2015) proposed a model for the calculation of two-lane highway capacity and delay. The author also introduced a pre-timed signal control strategy while using the VISSIM model to validate the mathematical model.

Patil (2015) evaluated the use of Portable Traffic Signal (PTS) systems for long rural two-lane work zones. The study compared three different conditions for controlling one-lane traffic by deploying flagger and PTS system combinations in conjunction with pilot car operations. A PTS unit without flagger operation was recommended for long rural two-lane highways. Yeom (2015) developed capacity and Free Flow Speed (FFS) models calibrated using three sources: field data, sensor data and literature achieves. The author also presented methodology for the calibration of work zone capacity in the microsimulation (VISSIM) tool. This capacity model is expected to be amalgamated into the next issue of the Highway Capacity Manual. 
Bie et al. (2016) contributed research findings on driver compliance variation on VSL, contributing factors for driver compliance using linear regression, model for dynamic driver compliance and guidelines for VSL algorithm design. Abdelmohsen (2016) carried out studies considering a large number of parameters to obtain better real-world environments and scenarios. The author focused on a model to minimize traffic delay and made contributions to cast and safety too. Zhang (2016) claimed that the use of hard shoulders and reversible High Occupancy Vehicles (HOV) lanes increase the capacity in work zones. The author also highlighted that dynamic tolls and VSL have less of an effect on mobility in work zones. Ahmed et al. (2016) found that Portable Variable Message Signs (PVMS) did not significantly affect mobility in work zones, although surveys have indicated that PVMS is an effective tool.

Gambatese and Zhang (2016) recommended $35 \mathrm{mph}$ advisory signs in work zones based on a field study conducted in Oregon. Furthermore, they revealed passenger cars accounted more speed reduction than trucks and no statistical difference between adjacent vehicles with or without speed limit according to the field experiment. Liu et al. (2017) incorporated the one-sample percentile value test and two-sample Kolmogorov-Smirnov (K-S) test estimation tools in order to compare the speed and flow characteristics between work zone and non-work zone environments. More than $50 \%$ of evaluated work zones experienced speed reductions with in and the upstream of the work zones while increasing in speed observed in half of the work zones for 10\%-50\% of the time. Pilanavithana et al. (2018) conducted a comprehensive literature review of freeway work zone applications and a summary of the sample references on mobility applications including the analytical tools used in each research study are provided in Table 2.5 for easy reference.

Table 2.5: Mobility References on Work Zone Applications (Pilanavithana et al., 2018)

\begin{tabular}{|l|l|l|l|ll|}
\hline No & Sample References & Type & Country $^{\mathbf{a}}$ & Analytical Tools Used & \\
\hline 1 & Turley (2002) & Journal & USA & $\begin{array}{l}\text { Regression Analysis, Statistical } \\
\text { Analysis }\end{array}$ & \\
\hline 2 & Liu et al. (2017) & Journal & China, USA & Statistical Analysis & \\
\hline 3 & Bie et al. (2016) & Journal & Canada & $\begin{array}{l}\text { Regression Analysis, Statistical } \\
\text { Analysis }\end{array}$ & \\
\hline 4 & Chung (2011) & Journal & Korea & Statistical Analysis & \\
\hline 5 & $\begin{array}{l}\text { Radwan et al. } \\
(2011)\end{array}$ & Journal & USA & \multicolumn{2}{|l|}{ Statistical Analysis } \\
\hline 6 & Zheng et al. (2011) & Journal & SWZ, NLD & $\begin{array}{l}\text { Fuzzy Logic Artificial } \\
\text { Networks Neural }\end{array}$ \\
\hline
\end{tabular}




\begin{tabular}{|c|c|c|c|c|}
\hline 7 & Zhu (2015) & MASc & USA & $\begin{array}{lll}\begin{array}{l}\text { Regression } \\
\text { Analysis }\end{array} & \text { Analysis, } & \text { Sensitivity } \\
\end{array}$ \\
\hline 8 & $\begin{array}{l}\text { Abdelmohsen } \\
\text { (2016) }\end{array}$ & $\mathrm{PhD}$ & USA & $\begin{array}{l}\text { Non-Dominated } \\
\text { Algorithm }\end{array}$ \\
\hline 9 & Patil (2015) & MASc & USA & Statistical Analysis \\
\hline 10 & Yeom (2015) & $\mathrm{PhD}$ & USA & $\begin{array}{l}\text { Regression Analysis, } \\
\text { Analysis }\end{array}$ \\
\hline 11 & Kim (2008) & $\mathrm{PhD}$ & USA & Probability Analysis \\
\hline 12 & Kang (2006) & $\mathrm{PhD}$ & USA & $\begin{array}{llll}\text { Extended Kalman Filtering (EKF) } \\
\text { Algorithm }\end{array}$ \\
\hline 13 & $\mathrm{Qu}(2014)$ & $\mathrm{PhD}$ & USA & Genetic Algorithm, Statistical Analysis \\
\hline 14 & Li (2008) & MASc & USA & $\begin{array}{l}\text { Statistical Analysis, Cost-Benefit } \\
\text { Analysis }\end{array}$ \\
\hline 15 & Chin (2004) & $\mathrm{PhD}$ & USA & Probability Analysis \\
\hline 16 & Zhang (2016) & MASc & USA & $\begin{array}{llr}\begin{array}{l}\text { Agent-Based } \\
\text { Assignment }\end{array} & \text { Dynamic } & \text { Traffic } \\
\end{array}$ \\
\hline 17 & $\begin{array}{l}\text { Du and Chien } \\
(2014)\end{array}$ & Journal & USA, & $\begin{array}{lll}\begin{array}{l}\text { Statistical } \\
\text { Analysis }\end{array} & \text { Analysis, } & \text { Sensitivity } \\
\end{array}$ \\
\hline 18 & $\begin{array}{l}\begin{array}{l}\text { Kang and Chang } \\
(2006)\end{array} \\
\end{array}$ & Journal & USA & Min-Max Optimization Criterion \\
\hline 19 & Ahmed et al. (2016) & Journal & AE, USA & Statistical Analysis \\
\hline 20 & $\mathrm{Ng}(2012)$ & Journal & SA & Integer Linear Programs \\
\hline 21 & Kang et al. (2004) & Journal & USA & $\begin{array}{l}\text { Lindo-API Linear } \text { Optimization } \\
\text { Program }\end{array}$ \\
\hline 22 & Isaiah (2014) & MASc & USA & $\begin{array}{l}\text { Qualitative Analysis, Citable Test } \\
\text { Analysis }\end{array}$ \\
\hline 23 & Son (1999) & Journal & Korea & Statistical Analysis \\
\hline 24 & Kurker et al (2014) & Report & USA & $\begin{array}{l}\text { Statistical Analysis, } \\
\text { Analysis }\end{array}$ \\
\hline 25 & Kurker (2013) & $\mathrm{N}$ & & Statistical Analysis \\
\hline 26 & Ding et al. (2013) & al & SA & ion Analysis \\
\hline 27 & $\begin{array}{l}\text { Weng and Meng } \\
\text { (2011a) }\end{array}$ & Journal & Singapore & Decision Tree-Based Approach \\
\hline
\end{tabular}

${ }^{a}$ USA - United State of America UAE - United Arab Emirates SWZ- Switzerland NLD Netherland

\subsubsection{Work Zone Delay Estimation}

Work zone delays can be divided into five categories (Nang, 2010):

1. Deceleration delay by vehicles when approaching a work zone.

2. Moving delay by vehicles travelling through work zones at lower speeds.

3. Acceleration delay by vehicles during acceleration when leaving a work zone. 
4. Queuing delay due to the ratio of vehicle arrivals and discharge rates.

5. Detour delay due to the additional time necessary to travel the extra distance imposed by the detour.

In the last decade, a number of manual and computer based approaches have been developed to estimate work zone delays.

\subsubsection{Analytical Method: Delay Models}

The Deterministic Queuing Model and the Shock Wave Model are two well-known methods that are broadly used to analyze queuing delays caused by bottleneck (Nang, 2010). According to the Transportation Research Board (2010), the deterministic queuing analysis method is the standard delay estimation technique for freeways in the Highway Capacity Manual. This is essentially a graphical procedure involving a deterministic queuing diagram in which the $\mathrm{x}$-coordinate represents the time and the y-coordinate represents the cumulative number of vehicles. According to the shock wave method, the traffic flow is supposed to behave like a fluid and a backward shock wave propagates when the demand exceeds the available capacity. This method is also used to estimate incident congestion. Nevertheless, the shockwave speed is assessed based on traffic density, which is difficult to measure or estimate (Nang, 2010).

\subsubsection{Computer Based Software}

QUEWZ and QUICKZONE are two well-known software that are used to estimate queue lengths and delays in work zones. Both software programs simulate the traffic flow at a macroscopic level. QUEWZ is capable of evaluating the queue and user costs. The most recent upgraded package is QUEWZ-98. This version is capable of analyzing traffic conditions on a freeway segment for normal and lane closure conditions and providing estimates of the additional road user costs while calculating queue resulting from a work zone lane closure. The calculated user costs include travel time, vehicle operating cost, and excess emissions.

QUICKZONE is a software developed by Microsoft Excel that is used to estimate work zone delay. This software is smart enough to identify the delay impacts of alternative project phasing plans, trade-off analyses between construction costs and delay costs, examine the impacts of 
construction staging according to the location of the mainline, time of day and assessment of delay mitigation strategies. Still, this program has a greater user input demand for a particular project. It is important to note that neither of these programs has the ability to optimize work zone planning aspects.

\subsubsection{Safety Applications}

Since it is not possible to fully close a freeway or highway segment, works zones must coexist with live traffic. Narrowed lanes, vehicle merges, delineation and channelization devices, barriers and construction equipment collectively create a hazardous environment for all road users and workers. Consequently, the above environment creates unusual travel behaviour that violates driver expectancy on the road ahead. As a result, this environment has the potential to adversely impact the safety of workers and roadway users. As a result, researchers have made work zone safety a priority in their research efforts.

Chambless et al. (2002) determined the severity, driver, location, and misjudgement characteristics that were over-represented in work zone crashes. The intention is to provide direction in the enhancement of safety in work zones and the development of strategies to mitigate these factors. This study involved a large crash data set for the Alabama, Michigan and Tennessee states. Turley (2002) developed a Generalized Linear Model (GLM) for speed by evaluating the Arrow-Panel Caution Displays. The author conducted experiments to evaluate the effectiveness of "Dancing Diamonds" and "Flashing Box" displays on speed reduction and conflicts. The results revealed that the dancing diamonds displays decreased driver speed, increasing safety. According to questionnaire surveys, drivers considered dancing diamonds displays to be better method of promoting safe driving near work zones. Law enforcement has been recognized as one of the most effective speed reduction methods available to enhance work zone safety, however, there is no guidance on the intervals at which such enforcement should be incorporated.

Schrock and Ullman (2003) conducted research on the spacing of law enforcement pullout areas in highway work zones. The study focused on law enforcement and contractor opinions on the spacing criteria for pullout areas. The results indicated that the spacing for pullout areas should be

2 to 3 miles and no longer than 3 miles for alternative work zones with closed emergency shoulders. Speed is one of the biggest factors in the severity of crashes and errant vehicle 
behaviour. Wang et al. (2003) presented speed reduction strategies for highway work zones. The authors identified the potential of fluorescent orange sheeting, innovative message signs and changeable message signs with radar for speed reductions. More interestingly, the speed reduction influence of fluorescent sheeting and innovative message strategies diminished over time. The results also revealed that both strategies influenced speed more during the daytime than at night, truck drivers showed less of a reaction than passenger cars, and changeable message signs significantly reduced speed in the immediate vicinity without demonstrating a novelty effect.

Scriba and Seplow (2005) reviewed the safety regulations updated by the FHWA in order to address the issues associated with work zone safety. Landa (2005) found that between 1996 and 2000 , non-motorist fatalities in work zones increased by almost $70 \%$ and accounted for $15 \%$ of all fatalities resulting from crashes in work zones. This study focused on the identification of factors influencing pedestrian and cyclist safety in work zones. The author also introduced new work zone configurations, safety measures and implementation processes. Lastly, the author proposed that Part VI of the MUTCD be updated to accommodate non-motorists in work zones, that the Florida Maintenance of Traffic (MOT) standards index sheets be updated to include multilane highway situations, and that the Florida crash report format be modified to include more details regarding the work zone designs and crashes. Scriba and Seplow (2006) pointed out the need for new policies and practices to improve safety in work zones after a comprehensive review of the rules and policies adopted by different states in the USA. Many of the models and safety predictions were developed based on crash data comprised of fatal and injury crashes. Some studies only included property damage crashes. Temporary Traffic Control (TTC) Devices made significant influence on research studies.

Li (2007) proposed four Crash Severity Index (CSI) models, two of which were DriverIndependent (DI-CSI) models and 2 of which were Driver-Dependent (DD-CSI) models. DI-CSI models allow for the evaluation of driving risk levels in work zones without human factors. DDCSI models allow for the evaluation of driving risk levels involving driver demographic characteristics and driver errors. The study was extended to evaluate crash characteristics, risk factors, environmental factors and the effectiveness of TTC. Arditi et al. (2007) investigated the influence of lighting and weather on fatal accidents. The results revealed that nighttime work zones were more hazardous than daytime work zones and that the weather parameter had a limited 
influence. Li and Bai (2008) conducted a study to identify the deficiencies in the TTC measures in practice. The results revealed that flagger, flasher and pavement centre/edge lines were effective in reducing fatalities and that TTC devices helped prevent some common human errors. The authors also compared the characteristics of fatal and injury accidents in work zones. The researchers predicted that head-on collisions would be the dominant type for fatal accidents while rear-end collisions would be the dominant type for injury accidents. Furthermore, they emphasized that a large percentage of fatal accidents involved trucks, a large percentage of injury accidents involved light-duty vehicles, that alcohol impairment and speeding accounted for a much larger portion of fatal crashes, smaller headways caused a higher percentage of injury crashes, and that unfavourable lighting and complicated road geometry contributed to a higher number of fatal accidents than injury accidents.

Chen (2008) developed a crash prediction model using regression analysis. The results revealed that construction type is a significant factor in work zone crashes. The study also involved the development of a VISSIM model and a conflict analysis based on the simulation results in order to assist in the safety impact analysis. Zech et al. (2008) conducted a field study to measure the effectiveness of three commonly used Changeable Message Signs (CMS) messages. The Measure of Effectiveness (MOE) was defined as a reduction in vehicular speeds and variances in highway work zones. The results revealed that the "WORK ZONE | MAX SPEED | $45 \mathrm{MPH}$ BE | PREPARED | TO STOP" message was the most effective in reducing speeds and increasing work zone safety. Wong (2009) introduced a Risk Index (RI) to measure the level of injury risk in work zones.

The safety benefits of ArmorGuard ${ }^{\mathrm{TM}}$ barriers were extensively studied by Wong, who concluded that these barriers could be used to assure the safety of workers. Li and Bai (2009) examined work zone risk factors and their impact on crash severity by developing a logistic regression model which can be used to help users choose effective safety counter measures in work zones. Table 2 shows the references that discuss the application of safety measures in work zones. In 2010, many research studies were published on work zone safety. Li (2010) published some guidelines for safety audits after conducting questionnaire surveys. Tay and Barros (2010) investigated the effect of VMS on human attitudes and speed changes. The authors found that many of the advanced technologies focus on improving mobility rather than safety. Their study examined some anti- 
speeding messages using VMS in the field and questionnaire surveys. The results indicated that the messages had a relatively small impact on driver attitudes and speed.

Hallowell et al. (2010) analyzed the attributes and potential impacts of a mobile barrier trailer while giving special attention to nighttime work zones. The authors discussed the pros and cons of existing barrier systems and lighting schemes and made recommendations on mobile barrier and illuminance categories required for work zones. Lindheimer (2010) conducted a safety evaluation of work zone practices in Utah. He reviewed part 6 of MUTCD and compared the differences between the 2003 and 2009 editions. Using the results, the author developed standards concerning the conditions of signs and delineation devices, determined the related risk factors, and created an analysis tool using a spread sheet to quantify the risk. Bai et al. (2010) investigated motorist reactions to Portable Changeable Message Signs (PCMSs) with words and a temporary traffic sign (W20-1, "Road Work Ahead"). The mean change in speed was evaluated according to above sign setups. PCMSs were most effective for trucks while the W20-1 sign was most effective for passenger cars and semitrailers. Li (2010) reviewed the current worldwide road safety audit practices using the literature and questionnaire surveys. The author's findings shed light on the leading causes of work zone safety problems, effective countermeasures, safety audit team compositions and their tasks and tools.

Reiprich et al. (2010) examined the demographic influences and characteristics of accidents. According to their findings, males under the age 25 were overrepresented in accidents, particularly at night, and the majority of accidents took place during daylight or twilight. Early warning systems in highway work zones are associated with in-vehicle technologies (radio frequencies, navigation systems, smart phones...etc.) and on ground systems (PCMSs, auditory warnings such as sirens). Phanomchoeng et al. (2010) presented a directional sound for long distance auditory warnings that can be generated from work zones. They used an annular pattern of flat-panel speakers to send a directional sound along the travel lane while making a sound level difference of $6 \mathrm{~dB}$ or higher between adjacent lanes up to 40m from the system. Schneider (2010) focused on worker safety enhancement by introducing escape paths for flaggers, the application of Automated Flagger Assist Devices (AFADs) and one-way paths for internal circulation to minimize vehicle backing. Elghamrawy (2011) conducted field experiments to evaluate the effectiveness of temporary rumble strips prior to and at the edge of work zones by analyzing the sound levels 
generated by tires. This was proposed to alert inattentive drivers prior to and within the work zone. The author also developed crash severity indices based on crash contribution factors and a novel metric for the estimation of the monetary value of crash costs.

Nannapaneni (2011) used questionnaire surveys and field tests to estimate the effect of Steady Burn Lights (SBLs) on channelizing drums vs crash occurrence at night. The author concluded that the SBLs on drums increased the occurrence of risky driver behaviour. Drivers travelled too close to the drums and at higher speeds. The author proposed that the use of SBLs be discontinued. Bai and Li (2011) carried out field experiments and surveys to examine driver acceptance of and speed reduction due to Emergency Flasher Traffic Control Devices (EFTCD). The EFTCD was assembled using vehicle emergency warning flashers. The researchers concluded that the device effectively reduced speed and proposed the implementation of EFTD by requiring drivers to turn on their flashers when stopped at the entrance of work zones on one-lane two-way highways. Hajbabaie et al. (2011) used field tests to evaluate the use of Speed Photo-Radar Enforcement (SPE) and concluded that it had a positive impact on speed reduction. Wong et al. (2011) identified four factors that contribute to the severity of intrusion accidents. They concluded that short-term work zones and workers on foot resulted in increased accidents. Mathes (2012) proposed a line of communication model to assure the safety of workers and stressed the importance of incident inventories at job sites.

Ding et al. (2013) assessed safety using the Transition Area Length and speed limit values. The Minimum Safety Distance Equation (MSDE) was used as the key parameter for the evaluation and development of an influence model for safety. Huang and Bai (2014) found that graphic aided PCMSs reduced the mean speed of vehicles. Chen and Trako (2014) established a negative binomial model for crash frequencies supported by questionnaire surveys. Kurker et al. (2014) used a work zone VISSIM model vehicle trajectories in FHWA's Surrogate Safety Assessment Model (SSAM) to conduct the traffic conflict assessment to quantify the safety. Abdelmohsen (2016) presented a model to minimize crash occurrence using multi-objective optimization techniques. Miatudila (2016) introduced multinomial logit models to analyze the severity of crashes and countermeasures to mitigate crash occurrence. Qi and Zhao (2017) presented an interesting signalized lane control strategy and cycle lengths to minimize conflicts related to lane merges and rear-end collisions on freeways. Qiao et al. (2017) conducted research on a smart 
phone based warning system with male and female voices. The results revealed that voice aided warnings significantly reduced acceleration rates and speed when the headway time and distance were significantly longer. Zhang and Gambatese (2017) found that PCMSs and radar speed displays were the most effective speed reduction tools. Pilanavithana et al. (2018) summarized sample safety references and analytical tools. The results are presented in Table A.1.

Table 2.6: Safety References for Work Zone Applications (Pilanavithana et al., 2018)

\begin{tabular}{|c|c|c|c|c|}
\hline No & Sample References & Type & Country & Analytical Tools Used \\
\hline 1 & Qi and Zhao (2017) & Journal & USA & Statistical Analysis \\
\hline 2 & $\mathrm{Li}$ and Bai 2008(a) & Journal & USA & $\begin{array}{l}\text { Regression Analysis, Statistical } \\
\text { Analysis }\end{array}$ \\
\hline 3 & Mathes (2012) & MASc & USA & $\begin{array}{l}\text { Regression Analysis, } \\
\text { Analysis }\end{array}$ \\
\hline 4 & Abdelmohsen (2016) & $\mathrm{PhD}$ & USA & $\begin{array}{l}\text { Optimization - NSGA2, Statistical } \\
\text { Analysis }\end{array}$ \\
\hline 5 & Chen (2008) & $\mathrm{PhD}$ & USA & $\begin{array}{l}\text { Regression Analysis, } \\
\text { Analysis }\end{array}$ \\
\hline 6 & $\begin{array}{l}\text { Chambless et al. } \\
(2002)\end{array}$ & Journal & USA & Graphical and Statistical Analysis \\
\hline 7 & Elghamrawy (2011) & $\mathrm{PhD}$ & USA & $\begin{array}{l}\text { Optimization, Statistical and } \\
\text { Sensitivity Analysis }\end{array}$ \\
\hline 8 & $\begin{array}{l}\text { Nannapaneni (2011), } \\
\text { Miatudila (2016) }\end{array}$ & $\mathrm{PhD}$ & USA & Statistical Analysis \\
\hline 9 & $\mathrm{Li}(2007)$ & $\mathrm{PhD}$ & USA & $\begin{array}{l}\text { Statistical Analysis, } \\
\text { Analysis }\end{array}$ \\
\hline 10 & Wong (2009) & MASc & USA & $\begin{array}{l}\text { Cost-Benefit and Regression } \\
\text { Analysis }\end{array}$ \\
\hline 11 & Bai et al. (2010) & Journal & USA & Statistical Analysis \\
\hline 12 & Li and Bai (2009) & Journal & USA & $\begin{array}{l}\text { Statistical Analysis, Regression } \\
\text { Analysis }\end{array}$ \\
\hline 13 & $\begin{array}{l}\text { Phanomchoeng et al. } \\
(2010)\end{array}$ & Journal & USA & $\begin{array}{l}\text { Sound Wave Mechanics, Graphical } \\
\text { Analysis }\end{array}$ \\
\hline 14 & $\begin{array}{l}\text { Schrock and Ullman } \\
(2003)\end{array}$ & Journal & USA & Delphi Method, Graphical Analysis \\
\hline 15 & Kurker et al. (2014) & Report & USA & $\begin{array}{l}\text { Statistical Analysis, Sensitivity } \\
\text { Analysis }\end{array}$ \\
\hline 16 & Ding et al. (2013) & Journal & China & Regression Analysis \\
\hline 17 & Meng et al. (2010) & Journal & Singapore & Quantitative Risk Assessment Model \\
\hline
\end{tabular}




\subsubsection{Driver Behaviour Applications}

Driving is a learned skill which requires multitasking and multiprocessing events that take place every fraction of a second. When humans drive through a work zone they have to acknowledge the changes in their expectance of road ahead due to disturbance generated by lane changes, lane width reductions, TTC devices... etc. so on and so forth. Hence many of the research were done to measure driver behavior with utmost difficult task of predicting the stochastic nature of their movements. Most of the researchers incorporated driving simulators at this work to judge the human behaviors at environment made close to real world.

Whitmire (2007) investigated the effectiveness of in-vehicle information technologies. He used NASA TLX and the simulation sickness examination survey in order to evaluate mental attributes such as work load. The results indicated that auditory information required less reaction time than visual information. The participant group without any audio-visual aids showed speed violations throughout the work zone. Heaslip et al. (2011) evaluated the effectiveness of selected work zone guidelines published by the FHWA for older drivers and pedestrians. According to their study VMSs, static signage and flashing arrow boards were effective in changing driver expectancy of the road features ahead andled to positive decision making to achieve uniform driver behaviour. Taylor et al. (2013) conducted an interesting field study and online survey to examine driver behaviour in work zones. The authors used an instrumented vehicle with different sensors to correct real field data and drive recorder software to analyze driver behaviour. The results revealed that drivers were not comfortable driving through the work zones and were willing to follow the front vehicle.

Adeli (2014) performed a series of studies to evaluate driver speed variations according to speed limits and road work signs. The results revealed that drivers were mostly compliant with the speed limit. Moreover, age, road familiarity and experience had a noteworthy impact on speed limit compliance. Moradpour et al. (2015) compared the Conventional Lane Merge (CLM) in MUTCD and the Missouri Department of Transportation (MoDOT) configuration using TTC and demographical influences for a Ford pickup simulator. The authors found no statistical difference in travel time between the configurations presented in the MUTCD and MoDOT guidelines. Furthermore, the results indicated a trivial influence of age and gender on travel time. Zehtabi 
(2014) examined driver perception of surroundings at work zones. The prospect-theory and Genetic Algorithm (GA) were used to develop a longitudinal acceleration model. The variables taken into account included work zone length, TTC barrier types, intensity and speed.

Shakouri et al. (2016) investigated driver merging behaviour data in work zone configurations using a driving simulator and questionnaire surveys. Motion sickness assessment was also performed for the participants in his study to make sure the confident on taking the test. The findings were supported to the research on effects of work zone configuration and traffic density on performance variables and subjective work load of drivers. Nadathur and Narayanan (2016) performed driving simulator experiments to categorized high risk driver patterns according to demographical influences. According to the analysis, the 25-44 and 65+ age groups were categorized as high risk drivers and the MoDOT left merge alternate sign configuration for MUTCD showed better and safer merging behaviour with low risk. Pilanavithana et al. (2018) summarized sample driver behaviour references and analytical tools. The results are displayed in Table A.2.

Table 2.7: Driver Behaviour References on Work Zone Applications (Pilanavithana et al., 2018)

\begin{tabular}{|l|l|l|l|l|}
\hline No & Sample References & Type & Country & Analytical Tools Used \\
\hline 1 & Hamdar et al. (2016) & Journal & $\begin{array}{l}\text { USA, } \\
\text { Lebanon }\end{array}$ & $\begin{array}{l}\text { Optimization - Genetic Algorithm, } \\
\text { Statistical Analysis }\end{array}$ \\
\hline 2 & Heaslip et al. (2011) & Journal & USA & Statistical Analysis \\
\hline 3 & Shakouri et al. (2016) & Journal & USA & $\begin{array}{l}\text { NASA-TLX and Motion Sickness } \\
\text { Assessment }\end{array}$ \\
\hline 4 & Adeli (2014) & MASc & USA & Statistical Analysis \\
\hline 5 & $\begin{array}{l}\text { Nadathur and Narayanan } \\
(2016)\end{array}$ & MASc & USA & Optimization - Solver \\
\hline 6 & Zehtabi (2014) & MASc & USA & $\begin{array}{l}\text { Optimization - Genetic Algorithm, } \\
\text { Statistical Analysis }\end{array}$ \\
\hline 7 & Moradpour et al. (2015) & Journal & USA & Statistical Analysis \\
\hline 8 & Whitmire (2007) & PhD & USA & $\begin{array}{l}\text { NASA-TLX and Motion Sickness, } \\
\text { Statistical Analysis }\end{array}$ \\
\hline 9 & Weng and Meng (2011b) & Journal & Singapore & Traffic Flow Fundamental Diagram \\
\hline
\end{tabular}




\subsubsection{Planning and Cost Applications}

Freeway maintenance, rehabilitation and construction involve high agency costs and disruptive delays for road users. Many research studies are being conducted worldwide in order to minimize the total cost of construction by optimizing work zone planning, scheduling and traffic control. Work zone planning and cost applications are discussed in this section.

Schonfeld et al. (2002) used multi-objective optimization in order to develop a model to minimize total cost by optimizing the work zone length and cycle times. They considered the costs related to maintenance, labour and equipment idle and user delay. The time varying traffic flow, travel speeds, maintenance breaks, and work zone setup costs were used as decision factors which could then be analysed using the proposed method. Mohan and Gautam (2002) conducted a comprehensive literature review and accident cost comparisons to summarize collision type percentages and their associated costs. Sukumaran et al. (2006) presented a model for the stochastic analysis of factors affecting work zone schedules using a Monte-Carlo simulation and the Analytic Hierarchy Process (AHP). Their model was capable of predicting schedule changes and regulating counter measures for necessary changes.

Tang and Chien (2008) developed a work zone scheduling model considering the discrete timecost relationship. In order to minimize the total cost, the researchers incorporated the maintenance time and associated costs in the genetic algorithm optimization process. Kaewmoracharoen (2009) developed a work zone visualization model using 3-D models linked with scheduling data. The author also used surveys in order to get information regarding the industrial influence on work zone visualization. Project visualization was identified as a low cost communication technique that can also be used for work zone mobility. Yang (2010) presented the framework and systematic methodology for the optimization of critical work zone decisions considering cost-effectiveness. The author also developed analytical and simulation models that are capable of estimating shortterm impacts during the maintenance process as well as long-term impacts over the pavement life cycle. Two-Stage Modified Population-Based Simulated Annealing (2PBSA) was used to search for a near-optimal solution. 
Chou (2010) introduced Simulation Based Secondary Incident Filtering (SBSIF) methodology to evaluate proposed Traffic Incident Management (TIM) programs as well as a three-stage timesaving process for the evaluation of the benefits of TIM programs. The author also analyzed occupancy and access violations of concurrent flow lanes and proposed modeling techniques to simulate violations. Antoniou et al. (2011) stated that Greece has less guidelines and practical experience on work zones than North America and other countries around the world. The authors developed a number of guidelines for time-space scheduling on Greek motorways. Elghamrawy (2011) worked on developing an optimization model to minimize work zone costs, including construction costs, user delay costs and accident costs. The proposed model was capable of optimizing work zone length, speed limit, starting time, TTC policy and barrier type.

Qu (2014) developed a work zone schedule model that considers work zone cost variables by incorporating Travel Time Reliability (TTR) measures. Du and Chien (2014) suggested a model to optimize work zone length by considering the dynamic traffic volume and road capacity. Light condition, heavy vehicle percentage and lane width were all considered as variables in the proposed model and the results were used to evaluate the delay and cost parameters. The authors also established guidelines for the use of the road shoulder under various work zone scenarios. In their final report on the optimization of work zones, Chien and Kyriacos (2015) presented a methodology that minimizes the total work zone impact costs (including maintenance costs, idling costs, vehicle emissions, and user costs) yielded by the optimized sub-segment lengths of an entire work zone and the associated schedules for corresponding sub-segments. Abdelmohsen (2016) developed a novel multi-objective optimization model for work zone layouts to minimize construction costs. In his study, the author evaluated TTC measures and other work zone layout parameters including flaggers, spotters and TTC devices that were then incorporated into the model.

Pilanavithana et al. (2018) summarized work zone cost application references and analytical tools for easy reference. The results are displayed in Table 2.6. 
Table 2.8: Planning References on Work Zone Applications (Pilanavithana et al., 2018)

\begin{tabular}{|c|c|c|c|c|}
\hline No & Sample References & Type & Country & Analytical Tools Used \\
\hline 1 & Abdelmohsen (2016) & $\mathrm{PhD}$ & USA & $\begin{array}{l}\text { Optimization-NSGA2, Statistical } \\
\text { Analysis }\end{array}$ \\
\hline 2 & Schonfeld et al. (2002) & Journal & USA & Optimization, Sensitivity Analysis \\
\hline 3 & $\begin{array}{l}\text { Elghamrawy (2011), } \\
\text { Qu (2014) }\end{array}$ & $\mathrm{PhD}$ & USA & $\begin{array}{l}\text { Optimization - GA, Statistical and } \\
\text { Sensitivity Analysis }\end{array}$ \\
\hline 4 & Du and Chien (2014) & Journal & USA, China & $\begin{array}{l}\text { Statistical Analysis, } \\
\text { Analysis, }\end{array}$ \\
\hline 5 & Tang and Chien (2008) & Journal & USA & $\begin{array}{l}\text { Optimization - GA, Elitist Selection, } \\
\text { Sensitivity Analysis }\end{array}$ \\
\hline 6 & $\begin{array}{l}\text { Sukumaran et al. } \\
(2006)(a)\end{array}$ & Journal & USA & $\begin{array}{l}\text { Monte Carlo Simulation, Statistical } \\
\text { Analysis }\end{array}$ \\
\hline 7 & $\begin{array}{l}\text { Sukumaran et al. } \\
(2006)(b)\end{array}$ & Journal & USA & $\begin{array}{l}\text { Monte Carlo Simulation, Analytic } \\
\text { Hierarchy Process (AHP) }\end{array}$ \\
\hline 8 & Schonfeld et al. (2002) & Journal & USA & $\begin{array}{l}\text { Optimization - Iteration, Sensitivity } \\
\text { Analysis }\end{array}$ \\
\hline 9 & $\begin{array}{l}\text { Kaewmoracharoen } \\
\text { (2009) }\end{array}$ & $\mathrm{PhD}$ & USA & Statistical Analysis \\
\hline 10 & Yang (2010) & $\mathrm{PhD}$ & USA & $\begin{array}{lll}\text { Simulated Annealing, } & \text { Statistical } \\
\text { Analysis } & & \\
\end{array}$ \\
\hline 11 & Chou (2010) & $\mathrm{PhD}$ & USA & $\begin{array}{l}\text { Simulation, Regression Analysis, } \\
\text { Sensitivity Analysis }\end{array}$ \\
\hline 12 & $\mathrm{Qu}(2014)$ & $\mathrm{PhD}$ & USA & $\begin{array}{l}\text { Optimization - Genetic Algorithm, } \\
\text { Sensitivity Analysis }\end{array}$ \\
\hline 13 & Wiegand (2007) & MASc & USA & Statistical Analysis \\
\hline 14 & $\begin{array}{l}\text { Hajdin and } \\
\text { Lindenmann (2007) }\end{array}$ & Journal & Switzerland & Optimization \\
\hline 15 & $\begin{array}{l}\text { Sukumaran et al. } \\
(2006)\end{array}$ & Journal & USA & $\begin{array}{l}\text { Monte Carlo Simulation, Statistical } \\
\text { Analysis }\end{array}$ \\
\hline
\end{tabular}

\subsubsection{Decision Variables in Work Zone Applications}

The literature review conducted by Pilanavithana et al. (2018) revealed that a higher number of decision (also called design) variables were taken into account when studying all of the aspects with respect to work zones. The following decision variables were widely used in mobility studies: work zone configurations, AADT, speed, design speed, delay, volume, lane capacity, headway distance, headway times, directional split, vehicle length, weather, lighting, vehicle classifications, heavy vehicle percentage, VSL, road class, the position of the closed lane and the length of the ramp. Agency costs (maintenance, traffic mitigation, equipment/labour idling, routine 
maintenance) and user costs (delay, vehicle operating, expected accident cost) were the dominant decision variables in cost and planning studies.

\subsection{Cost Estimation}

Total project cost can be divided into two categories: agency cost and user cost. Agency cost includes all of the costs incurred directly by the agency over the life of the project or a specific planning period. From a long-term viewpoint, the agency incurs initial construction costs, including idling costs, future maintenance costs and associated administrative costs. In terms of work zones, agency costs can be treated as any expenses required to finish the maintenance activities based on the work types. Those usually include labour, equipment, materials, traffic control costs, and administration costs (single cost rate per lane mile).

User costs include delay, vehicle operating, accident, and emission costs incurred by the users of a facility during work zone activities. User delay cost result from increases in travel time due to reduced capacity (reduced speed) throughout the work zone segments. Congestion delays and detour delays also affect user delay, as discussed in subsection 2.4.1.1. Vehicle operating costs include any costs associated with owning, operating, and maintaining a vehicle, including fuel consumption, wear and tare and repairs. Road geometry, speed limits, vehicle dynamics, road condition and type, and environmental factors all affect vehicle operating costs. Operating costs can be calculated empirically or mechanistically, deterministically or probabilistically (Nang, 2010). The majority of studies make use of the regression analysis of historical information or simulation results to estimate operating costs.

Accident costs are related to past crash data, vehicle mileage, work zone configuration and average cost per crash. The crash rate is usually defined as the number of crashes per 100 million vehicle miles of travel (100 M VMT). Chien and Schonfeld (2001) estimated work zone crash costs using the product of the number of crashes per 100 million vehicle hours multiplied by the increasing delay and the cost per crash. The crash rates of various functional roadway classes are fairly well established, however, it is not easy to estimate those rates due to limited data and the large variety of work zone types (Nang, 2010). 


\subsection{Optimization}

\subsubsection{Simulation Based Optimization}

Although the deterministic queuing model is widely used to estimate delay, it often underestimates delay by not considering approaching and shock-wave delays. In general, analytical methodologies may not generate precise delay estimates for a complicated existing road network (Yang, 2010). Microscopic simulation tools are widely used in order to solve various problems in work zone studies, including the evaluation of traffic management plans, the prediction of capacity and queue length, and the optimization of traffic controls. CORSIM (including NETSIM and FRESIM), VISSIM, PARAMICS, and INTEGRATION are the most popular microscopic simulation tools. Each tool has its own different measures of effectiveness (MOE's). With respect to work zone analysis, delay, travel time, and speed are commonly used MOEs.

The mathematical optimization method combined with simulation is an effective tool for the analysis of complex stochastic optimization problems, especially when the decision variables are interdependent and complex in nature. According to the comprehensive literature review conducted by Pilanavithana et al. (2018), it could see that, many of the studies based on simulation based optimization. Simulation results can be used to develop regression models and the modern mathematical optimization techniques described in the following sub-section can be incorporated in order to provide more precise optimization and generate end results closer to real-world applications.

\subsubsection{Mathematical Optimization}

Optimization is the act of generating the finest or most effective result under given circumstances using various resources. In any science and technology discipline, including design, construction, and system maintenance, professionals must make many technological and managerial decisions when unveiling their strategies. The ultimate objective of all of these approaches is to minimize the required effort or to maximize the desired benefit.

Since any practical situation can be expressed as a function of certain decision variables, optimization can be defined as the process of finding the conditions that provide the maximum or minimum values of a function. There is no particular method available to competently solve all 
optimization problems. A number of optimization methods have been developed to solve similar types of optimization problems. The best possible seeking methods are also known as Mathematical Programming Techniques and are generally studied as a part of operations research. Operations research is a branch of mathematics concerned with the application of scientific methods and technology to decision making while achieving optimal solutions.

\subsubsection{Optimization Applications}

In order to understand the current optimization methods, it is critical to discuss the history of optimization. The beginning of optimization models can be traced back to the time of Newton, Lagrange, and Cauchy. The advancements in the differential calculus methods of optimization were made possible by the contributions of Newton and Leibnitz. The basics of the calculus of variations, which deals with the minimization of functions, were introduced by Bernoulli, Euler, Lagrange, and Weirstrass. The process of optimization for constrained problems, which includes the addition of unknown multipliers, became known by the name of its inventor, Lagrange. Cauchy introduced the first application of the steepest descent method to solve unconstrained minimization problems. Following those early contributions, slight progress was made until the middle of the twentieth century, when high-speed computers made the implementation of optimization procedures possible and stimulated further research on new methods. Remarkable improvements followed, producing an enormous volume of literature on optimization techniques. This improvement also resulted in the establishment of several new well-defined areas in optimization theory. Table 2.7 shows a summary of operational research methods.

Table 2.9: Operational Research Methods (Rao, 2009)

\begin{tabular}{|c|c|c|}
\hline $\begin{array}{c}\text { Mathematical Programming or } \\
\text { Optimization Techniques }\end{array}$ & $\begin{array}{c}\text { Stochastic Process } \\
\text { Techniques }\end{array}$ & Statistical Methods \\
\hline Calculus methods & Statistical decision theory & Regression analysis \\
\hline Calculus of variations & Markov processes & Cluster analysis \\
\hline Nonlinear programming & Queueing theory & Pattern recognition \\
\hline Geometric programming & Renewal theory & Design of experiments \\
\hline Quadratic programming & Simulation methods & Discriminate analysis \\
\hline Linear programming & Reliability theory & (factor analysis) \\
\hline
\end{tabular}




\begin{tabular}{|l|l|l|}
\hline Dynamic programming & & \\
Integer programming & & \\
Stochastic programming & & \\
Separable programming & & \\
Multi-objective programming & & \\
Network methods: CPM and PERT & & \\
Game theory & & \\
\hline Modern or Non-Traditional Optimization Techniques & \\
\hline Genetic algorithms & & \\
Simulated annealing & & \\
Ant colony optimization & & \\
Particle swarm optimization & \\
Neural networks & & \\
Fuzzy optimization & & \\
\hline
\end{tabular}

Modern optimization applications, also called non-traditional optimization techniques, have arisen as powerful and widespread methods used to solve complex engineering optimization problems. These methods include genetic algorithms, simulated annealing, particle swarm optimization, ant colony optimization, neural network-based optimization, and fuzzy optimization. Genetic algorithms are computerized search and optimization algorithms based on the mechanics of natural genetics and natural selection proposed by John Holland in 1975. The simulated annealing method is based on the mechanics of the cooling process of molten metals through annealing. This method was developed by Kirkpatrick, Gelatt, and Vecchi.

The particle swarm optimization algorithm represents the behaviour of social organisms such as a colony or swarm of insects (for example, ants, termites, bees, and wasps), a flock of birds, or a school of fish. The algorithm was proposed by Kennedy and Eberhart in 1995. The ant colony optimization method is grounded on the cooperative behaviour of ant colonies, which are able to find the shortest path from their nest to a food source. The method was originally introduced by Marco Dorigo in 1992. The neural network methods are based on the enormous computational supremacy of the nervous system to solve perceptional problems in the presence of a massive 
amount of sensory data using parallel processing. This method was initially used for optimization by Hopfield and Tank in 1985. The fuzzy optimization method was established to solve optimization problems involving design data, objective function, and constraints presented in an imprecise format involving vague linguistic explanations. The fuzzy methodologies for single and multi-objective optimization in engineering design were originally presented by Rao in 1986.

\subsubsection{Solver Optimization Tool}

The main computer-based spreadsheets include Lotus, Excel and Quatro. All of these spreadsheets have built-in optimizers which allow for the solving of linear, non-linear and integer programs. The Solver is one of the predominant optimization tools built into the Microsoft Excel Spreadsheet. The Solver tool has the following capabilities when solving programming problems:

1. Solve linear and nonlinear optimization problems.

2. Allows integer and binary conditions to be applied to decision variables.

3. Works for up to 200 decision variables and many constrained inputs.

The Solver tool has different input parameters, as illustrated in Figure 2.8.

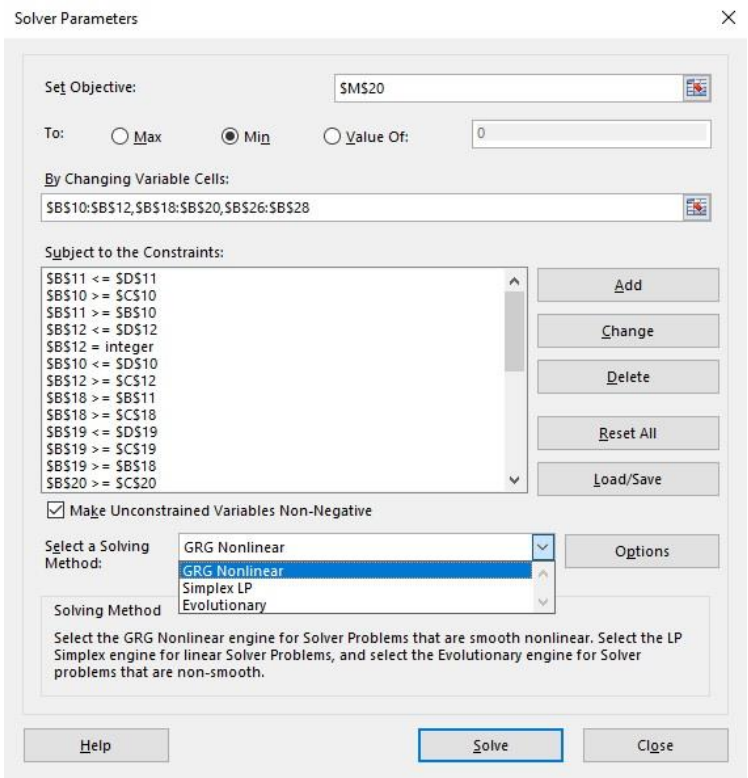

Figure 2.8: Solver Parameters Dialogue Box 
The parameters can be named as follows:

1. Objective Cell

2. Changing Variable Cell

3. Constraints

4. Solving Methods

By feeding all of the required data and solving method, the Solver generates the optimized solution in the objective cell for pre-defined objective as Maximum, Minimum or a certain value. More excitingly, the Solver is capable of applying modern optimization methods such as the Genetic and Evolutionary algorithm techniques to search for precise answers for the requirements.

\subsection{Integration in Excel}

Excel works developed the Excelab add-in to the Microsoft excel spreadsheet, which is highly capable of computing integrations. The "QUADF" function can be used to compute a proper or

improper integral $\int_{a}^{b} f(x) . d x$ using highly precise adaptive algorithms. With optional arguments, the user can override the default integration algorithm as well as supply singular points for the integrand $f(\mathrm{x})$, if applicable. QUADF can also be nested in order to compute multiple integrals in any order (ExcelWorks, 2018).

Syntax $\quad=$ QUADF (f, $\mathrm{x}, \mathrm{a}, \mathrm{b}$, [options])

Where,

$\mathrm{f}=$ Integrand formula

$\mathrm{x}=\mathrm{A}$ reference to the variable of integration

$\mathrm{a}=$ The integral lower limit

$\mathrm{b}=$ The integral upper limit

Options = A set of key/value pairs for algorithmic controls. 


\subsection{Research Limitations in the Literature}

The results of the comprehensive literature review reveal that many methods, both analytical and simulation based, have been introduced and applied in many practical situations in road maintenance studies. Those studies include but are not limited to the assessment of work zone impacts and the optimization of work zone decisions. Due to the complex nature of optimization problems, the heuristic algorithm was adopted as the dominant problem solving approach.

While the long term maintenance decision optimization studies were separated from the short term maintenance decision optimization studies, some short term optimization strategies may affect long term maintenance activities. With respect to short-term work zone decision optimization, the state-of-practice reveals that administrative agencies choose the best strategy from several alternatives (e.g. decisions regarding lane-closure periods from weekday night closure, weekday off-peak daytime closure, weekend closure) instead of applying optimization technology. This up-

to-date research study focuses on developing advanced optimization methods based on some simplified assumptions that may close some of the gaps between research and real world applications.

The majority of studies are based on analytic methods, which may not be accurate due to oversimplified assumptions for the dynamic nature of compound traffic networks. A smaller number of studies are based on simulation with optimization. A noteworthy drawback is that simulation is a very time-consuming way to evaluate the objective function in an optimization process. Recent studied have revealed that the existing analytical models used by DOTs were developed based on traditional formulas and deterministic theories. The delay and cost estimations may therefore be inaccurate. All of these limitations show the need for upgraded algorithms and theories using more powerful and sophisticated simulation and optimization applications which will generate more precise and accurate end results that meet real world demands. 


\section{CHAPTER 3}

\section{DEVELOPMENT OF REGRESSION MODELS FOR WORK ZONE DELAY USING CORSIM}

\subsection{Introduction to CORSIM}

Traffic simulation models can be divided into three main categories: Macroscopic, Mesoscopic, and Microscopic. Macroscopic simulation models represent the traffic flow as fluid with particular characteristics through the aggregate traffic variables such as traffic density, flow, and mean speed. Mesoscopic simulation models track individual vehicles while grouping them into platoons with identical behaviours. Thus the accuracy level of predictions lies in the middle of the microscopic and macroscopic simulation models. Microscopic simulation models look at the behaviour of each individual vehicle in the traffic flow, regardless of the movements of adjacent vehicles. The corresponding behaviours include both longitudinal (car-following behaviour) and lateral (lanechanging behaviour) movements. The precision of microscopic simulation models is much higher than the other two categories.

CORSIM is a sophisticated and powerful tool used to simulate pre-specified work zone scenarios based on the detailed representation of work zone layout parameters, traffic characteristics, geometric characteristics, and traffic control measures. CORSIM can be classified as a microscopic simulation tool operated in a stochastic environment. This tool randomly feeds vehicles into the specified road network second-by-second with respect to the local interaction rules. Those rules represent built-in phenomena such as the Pitt car following model used for the simulation of driver behaviour, lane changing situations, and emergency braking situations. CORSIM consists of two simulation modules called NETSIM and FRESIM. NETSIM was originally introduced in early 1970 under the direction of the Federal Highway Administration (FHWA). NETSIM is used to simulate surface streets while FRESIM is used for highway and freeway simulations.

This software has the ability to simulate complex road scenarios while handling networks of up to 500 nodes and 1,000 links containing up to 20,000 vehicles at one time. The features available for work zone simulations and the associated MOEs are discussed in the next subsection. Model 
development, simulation scenarios, and developed delay models are described in the latter part of this chapter.

\subsection{Work Zone Simulation in CORSIM}

Input data specified by the user comprised of series "record types" in CORSIM model. These record types, called "entries", contain a specific set of data items and a designated identification number. In the current study, FRESIM was used as the work zone simulation module in CORSIM and contained different record types with entries (described below).

\subsubsection{FRESIM Module}

FRESIM is the module that specializes in highway and freeway simulations and it provides comprehensive procedures to model freeway incidents, road geometry, traffic characteristics, driver behaviour, and vehicle dynamics. This module is recommended by the FRESIM user manual for the modeling of work zones.

The primary impact of freeway work zones on the network is a reduction in capacity due to lane closures. Three types of incidents can be applied to specified road network models in order to generate the impact of lane closures: blockages, rubbernecking, and lane drop facilities. Rubbernecking has been used in recent studies to represent the reduction in capacity for vehicles in the remaining open lanes in the work zone area. In this study, the lane drop feature was extensively used to reduce the number of open lanes and increase the number of open lanes following the work zone. This feature enables users to create the merge (taper) section in the work zone while reducing live lanes. The user can specify the exact location to start merge and complete lane drop and vice versa to increase the lanes.

\subsubsection{User Specified Data}

The FRESIM module allows users to develop the road network using nodes and links. Freeway nodes are used to connect links, and therefore have no editable properties, unlike the surface nodes in NETSIM. The maximum number of lanes in one direction is limited to 5 and the maximum number of lane drops is limited to 3 . The number of lane additions is also limited to 3. Each link 
has editable properties called General, Lanes, Lane Add/Drop, Graphics, Trucks, HOV, Incidents, and Detectors, as illustrated in Figures 3.1 (a) and (b).

General properties include the link length, Free Flow Speed, Superelevation, Pavement Type, Radius for Horizontal Alignment, Grade for Vertical Alignment, Startup Delay, and CarFollowing Sensitivity Multiplier. Users can simultaneously instruct the program to collect speed and headway statistics as required by the specified length from the upstream node. This tool uses metric units such as feet and miles per hour.

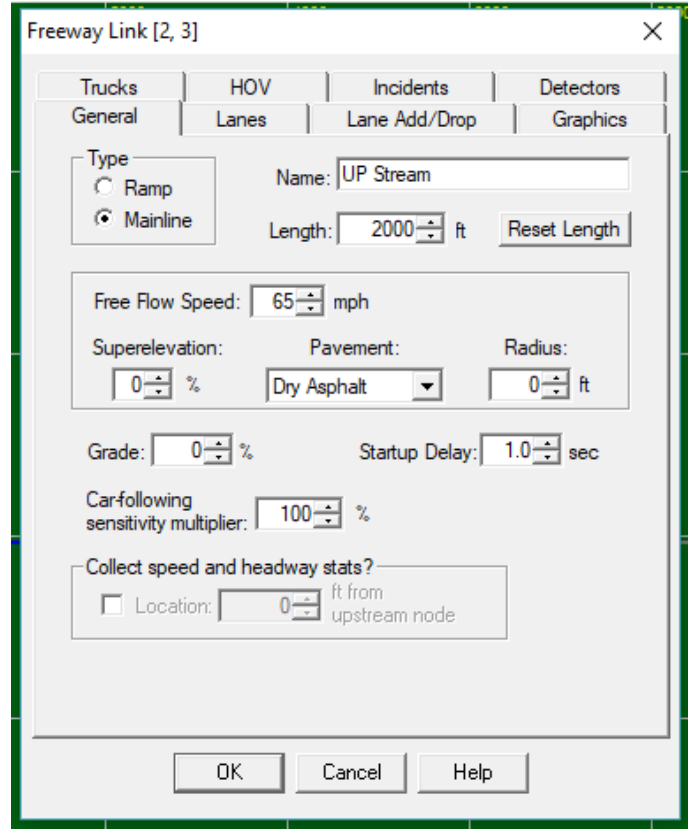

(a): General Properties

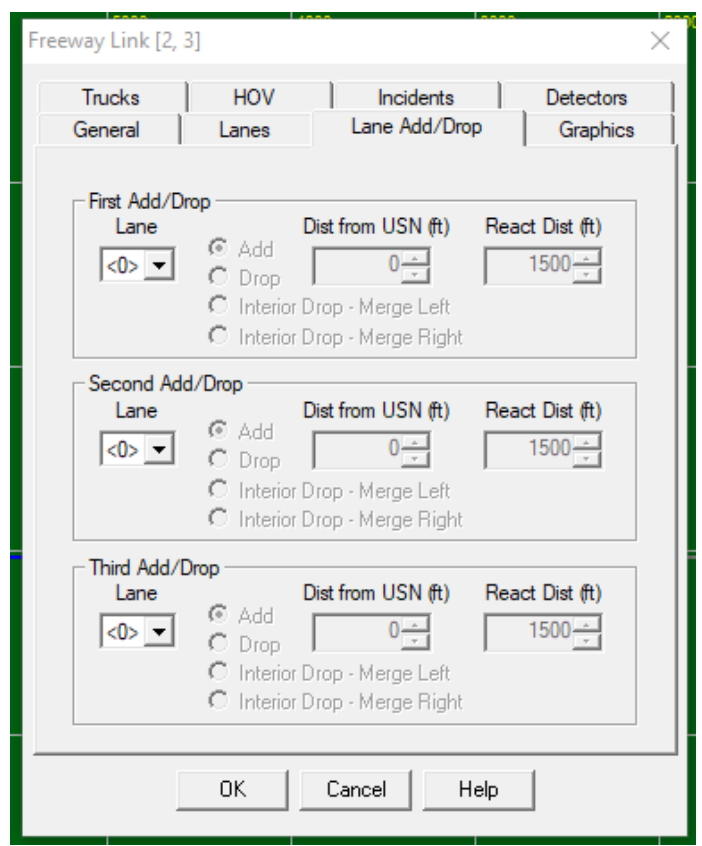

(b): Lane Drop Properties

Figure 3.1: FRESIM Link Properties Window (CORSIM TSIS ver.6.2)

Lane drop properties include the number of lane drops and the designated number lanes to be dropped at a specified distance from the upstream node (that is the start point of the activity area in the work zone). It is important to mention that FRESIM allows users to specify the driver reaction distance in the upstream for the beginning of the lane drop location. This virtually generates an advanced warning area for the upstream vehicles.

Entry properties are another important inputs specified by the user that feed the network as source node. In that entry, the start time and corresponding flow (as a volume or count), truck percentage, carpool percentage, percentage of non-HOV vehicles that violate HOV lanes, and the lane 
distribution of entering vehicles (leftmost lane to rightmost lane) can be specified according to the road network data.

\subsubsection{Measure of Effectiveness (MOEs) in CORSIM}

The CORSIM output file consists of the NETSIM and FRESIM link statistic data and networkwide average statistics for each time period. Since this study focused on evaluating the impact of work zones from the system point of view, the "Total Delay" and "Average Speed" were the major MOEs considered. The FRESIM output file consists of the time statistics described below.

Move Time $=$ Total theoretical time for discharged vehicles to travel the length of the link if movement is unimpeded at the free-flow speed. This is the Travel Distance Total divided by the free-flow speed on the link.

Total Time $=$ Total travel time on the link for all discharged vehicles under any given incidents on the link.

Delay Time $=$ The difference between the total travel time and the moving time. This represents the time that vehicles are delayed if they cannot travel at the free flow speed. The delay per vehicle in seconds is obtained by dividing the total discharged vehicles and converting the results into seconds.

In order to reduce the statistical variance in the simulation output results, multiple simulation replications must be run with different numbers of random seeds. The run time of each simulation can be specified by the user and depends on the scope of the size of the network, the number of time periods, and the traffic congestion level. In this study, each simulation scenario was run for $3600 \mathrm{~s}$ for more precise output results.

\subsection{Methodology}

A step by step process was used to develop the regression equations for delay and average speed in order to ensure high accuracy. First, the decision variables were selected and their relevant values were specified. Second, all of the applicable scenarios were developed with respect to these values. Third, each scenario was developed in the FRESIM simulation module and all of the relevant MOEs were recorded. A Pearson Correlation Matrix was then created to investigate the 
correlation for each independent variable. According to the results of the matrix, the significant variables were selected and 4 regression models were developed for delay (2) and average speed (2). Finally, the model validation process was carried out for all 4 models. Figure 3.2 shows the activity diagram for the proposed methodology.

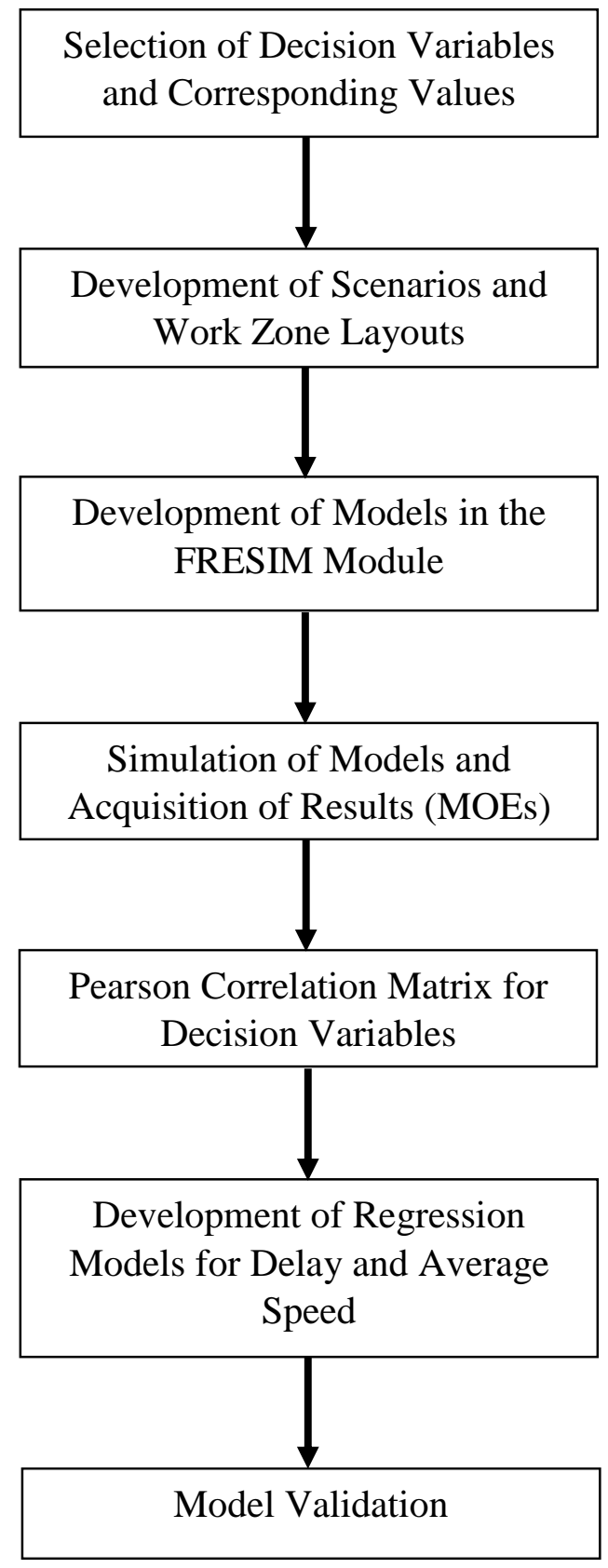

Figure 3.2: Activity Diagram for the Proposed Methodology 


\subsubsection{FRESIM Model Development}

Before developing the model, it is important to ensure that the significant decision variables are applicable in the simulation process. According to a review conducted by Pilanavithana et al. (2018), the length of the activity area, traffic flow, number of open lanes and heavy vehicle percentage all significantly affect the estimation of delay and average speed in work zones. With this guidance, the model was created by changing the above decision variables corresponding to each scenario, as illustrated in Figure 3.2. The related CORSIM network diagrams and simulation figures are presented in Appendix B.

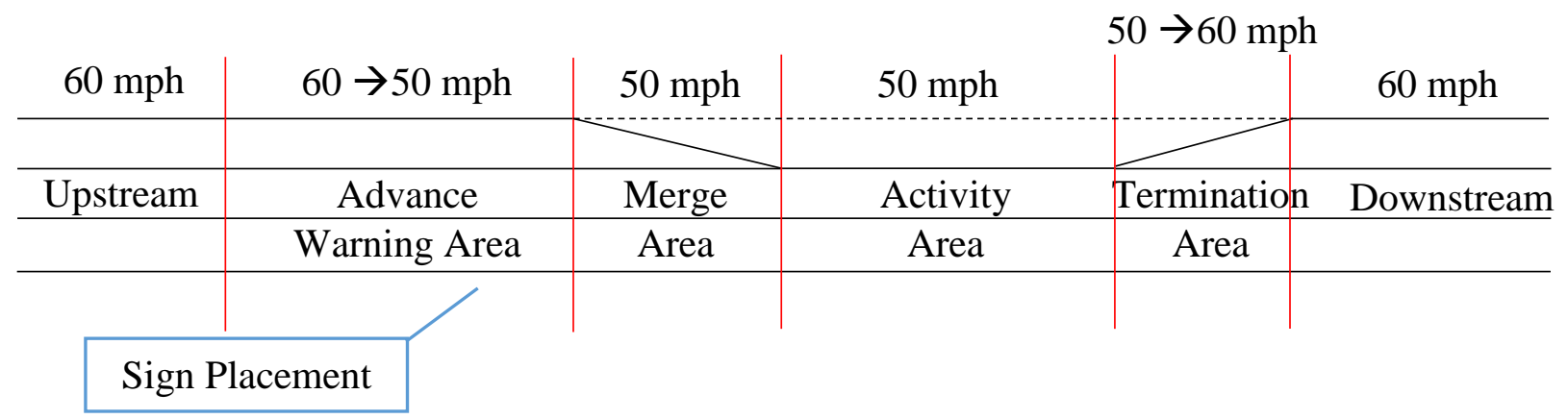

Figure 3.3: Schematic Diagram of Developed Model in CORSIM for a $60 \mathrm{mph}$ Design Speed

\section{Number of Lanes}

A freeway segment with three lanes in one direction was used in the simulation model. Lane drops are conducted as one and two lanes for all considered scenarios separately.

\section{Source Node}

This source node feeds the vehicles into the network in a stochastic nature. The flow rate was changed to generate different scenarios and vehicle per lane per hour was multiplied by the total number of lanes to obtain the total number of vehicles per hour to feed into the source node properties. Flow rate is varied as 500, 1000, 1500, 2000, and $2400 \mathrm{veh} / \mathrm{h} / \mathrm{ln}$ basis.

\section{Upstream}

A fixed upstream length of $2000 \mathrm{ft}$ from the upstream node of the advance warning area to the source node was used in all of the work zone scenarios. 


\section{Advance Warning Area}

According to MUTCD 2009, the total length of the advance warning area is the sum of the distances of three warning signs along that segment, as discussed in Table 2.1. Therefore, the total length can be calculated as follows:

Distance A + Distance B + Distance C $=1000 \mathrm{ft}+1500 \mathrm{ft}+2640 \mathrm{ft}=5140 \mathrm{ft}$

\section{Merge Area}

The taper length was calculated based on the values in Tables 2.2 and 2.3 provided by MUTCD (2009). According to the comprehensive literature review and relevant data, this study focused on two speed scenarios $(60 \mathrm{mph}$ and $65 \mathrm{mph}$ ) in which the corresponding work zone speed limits were $50 \mathrm{mph}$ and $55 \mathrm{mph}$, respectively. The merge lengths are calculated as follows:

- One lane closure:

Merge length $(50 \mathrm{mph})=\mathrm{L}=$ Lane Width $\times$ Speed Limit $=12 \times 50=600 \mathrm{ft}$ Merge length $(55 \mathrm{mph})=\mathrm{L}=$ Lane Width $\times$ Speed Limit $=12 \times 55=660 \mathrm{ft}$

- Two Lane Closure (refer figure 2.3):

Merge Length $(50 \mathrm{mph})=\mathrm{L}+2 \mathrm{~L}+\mathrm{L}=600 \mathrm{ft}+1200 \mathrm{ft}+600 \mathrm{ft}=2400 \mathrm{ft}$

Merge Length $(55 \mathrm{mph})=\mathrm{L}+2 \mathrm{~L}+\mathrm{L}=660 \mathrm{ft}+1320 \mathrm{ft}+660 \mathrm{ft}=2640 \mathrm{ft}$

\section{Length of Activity Area}

The length of the activity area has a significant impact on mobility and delay, therefore, the scenarios were simulated using different lengths $(1000 \mathrm{ft}, 1500 \mathrm{ft}, 2000 \mathrm{ft}, 2500 \mathrm{ft}, 3000 \mathrm{ft}, 3500$ $\mathrm{ft}, 4000 \mathrm{ft}$ ).

\section{Termination Area}

The termination area length was set to $100 \mathrm{ft}$ for one lane closure and $200 \mathrm{ft}$ for two lane closures, as per the guidelines in Table 2.2. 


\section{Early Merge Concept in the Model}

Kurker et al. (2014) modeled the early merge technique for different lengths and concluded that one-quarter mile is ample distance for an early merge because the warning sign distance should be long enough to prevent visual distractions from upstream. Hence, upstream drivers can react to the lane changing requirements more efficiently by finding a safe gap and completing the maneuver prior to the lane closure. In this study, the reaction distance was set to $1500 \mathrm{ft}$ prior to the merge area start point.

\section{Heavy Vehicle Percentage}

The heavy vehicle percentage also affects mobility and delay. The percentage of heavy vehicles was therefore varied within the scenarios $(0,2,4,5,6,8,10)$.

\subsubsection{Scenarios and Results}

Because of the four decision variables and the large set of corresponding values, many scenarios were modeled in the FRESIM module. The main criteria used to separate scenarios was the speed limit. 490 scenarios were developed and modeled for each speed limit and a total of 980 scenarios were modeled. The output results (MOEs) for delay and average speed were tabulated against the corresponding scenario.

When the flow rate is increased while varying other variables, the mobility of the network is transformed from undersaturated flow conditions (uncongested traffic flow) to saturated flow (congested traffic flow) conditions. In the saturated condition, the model generates excessive delays and diminished average speeds. The output results and corresponding scenarios are therefore divided into two categories: undersaturated and saturated conditions. The primary determinants for the above categories are the Volume/Capacity (V/C) ratio and the average speed. Tables 3.1 and 3.2 provide a sample of the simulated scenarios and the corresponding MOEs for the undersaturated and saturated conditions corresponding to a $50 \mathrm{mph}$ speed limit. All of the relevant scenarios and results for the 50 and $55 \mathrm{mph}$ speed limits are presented in Appendix B. 
Table 3.1: Undersaturated Condition - $50 \mathrm{mph}$ Speed Limit

\begin{tabular}{|c|c|c|c|c|c|c|c|c|c|}
\hline $\begin{array}{c}\text { Scenario } \\
\text { ID }\end{array}$ & $\begin{array}{c}\text { Flow } \\
(\text { veh/h/ln) }\end{array}$ & $\begin{array}{c}\text { Activity } \\
\text { Length } \\
\text { (ft) }\end{array}$ & $\begin{array}{l}\text { Merge } \\
\text { Length }\end{array}$ & $\begin{array}{c}\text { Number } \\
\text { of Open } \\
\text { Lanes }\end{array}$ & $\begin{array}{l}\text { HV } \\
\%\end{array}$ & $\begin{array}{c}\text { Speed } \\
\text { Limit } \\
(\mathbf{m i} / \mathbf{h r})\end{array}$ & $\begin{array}{c}\mathbf{F F S} \\
(\mathbf{m i} / \mathbf{h r})\end{array}$ & $\begin{array}{l}\text { Average } \\
\text { Delay } \\
\text { (sec/veh) }\end{array}$ & $\begin{array}{c}\text { Average } \\
\text { Speed } \\
\text { (mi/hr) }\end{array}$ \\
\hline 1 & 500 & 1000 & 600 & 2 & 0 & 50 & 60 & 1.90 & 55.23 \\
\hline 2 & 500 & 1000 & 2400 & 1 & 0 & 50 & 60 & 4.54 & 53.51 \\
\hline 3 & 1000 & 1000 & 600 & 2 & 0 & 50 & 60 & 4.75 & 54.09 \\
\hline 4 & 1500 & 1000 & 600 & 2 & 0 & 50 & 60 & 8.99 & 52.48 \\
\hline 5 & 500 & 1500 & 600 & 2 & 0 & 50 & 60 & 1.99 & 55.08 \\
\hline 6 & 500 & 1500 & 2400 & 1 & 0 & 50 & 60 & 5.23 & 53.17 \\
\hline 7 & 1000 & 1500 & 600 & 2 & 0 & 50 & 60 & 5.11 & 53.88 \\
\hline 8 & 1500 & 1500 & 600 & 2 & 0 & 50 & 60 & 9.30 & 52.1 \\
\hline 9 & 500 & 2000 & 600 & 2 & 0 & 50 & 60 & 2.33 & 54.7 \\
\hline 10 & 500 & 2000 & 2400 & 1 & 0 & 50 & 60 & 6.10 & $\begin{array}{l}52.8 \\
\end{array}$ \\
\hline 11 & 1000 & 2000 & 600 & 2 & 0 & 50 & 60 & 5.47 & 53.56 \\
\hline 12 & 1500 & 2000 & 600 & 2 & 0 & 50 & 60 & 10.11 & 51.78 \\
\hline 13 & 500 & 2500 & 600 & 2 & 0 & 50 & 60 & 2.45 & 54.32 \\
\hline 14 & 500 & 2500 & 2400 & 1 & 0 & 50 & 60 & 6.65 & 52.62 \\
\hline 15 & 1000 & 2500 & 600 & 2 & 0 & 50 & 60 & 5.83 & 53.13 \\
\hline 16 & 1500 & 2500 & 600 & 2 & 0 & 50 & 60 & 10.67 & 51.51 \\
\hline 17 & 500 & 3000 & 600 & 2 & 0 & 50 & 60 & 2.47 & 54.21 \\
\hline 18 & 500 & 3000 & 2400 & 1 & 0 & 50 & 60 & 7.46 & 52.14 \\
\hline 19 & 1000 & 3000 & 600 & 2 & 0 & 50 & 60 & 6.77 & 52.67 \\
\hline 20 & 1500 & 3000 & 600 & 2 & 0 & 50 & 60 & 11.48 & 51.12 \\
\hline 21 & 500 & 3500 & 600 & 2 & 0 & 50 & 60 & 2.86 & 53.76 \\
\hline 22 & 500 & 3500 & 2400 & 1 & 0 & 50 & 60 & 8.11 & 51.7 \\
\hline 23 & 1000 & 3500 & 600 & 2 & 0 & 50 & 60 & 6.78 & 52.58 \\
\hline 24 & 500 & 4000 & 600 & 2 & 0 & 50 & 60 & 2.90 & 53.65 \\
\hline 25 & 500 & 4000 & 2400 & 1 & 0 & 50 & 60 & 8.93 & 51.54 \\
\hline 26 & 1000 & 4000 & 600 & 2 & 0 & 50 & 60 & 7.49 & 52.23 \\
\hline 27 & 1500 & 4000 & 600 & 2 & 0 & 50 & 60 & 12.84 & 50.61 \\
\hline 28 & 1500 & 3500 & 600 & 2 & 0 & 50 & 60 & 12.25 & 50.86 \\
\hline 29 & 500 & 1000 & 600 & 2 & 2 & 50 & 60 & 1.94 & 55.49 \\
\hline 30 & 500 & 1000 & 2400 & 1 & 2 & 50 & 60 & 4.99 & 53.34 \\
\hline 31 & 1000 & 1000 & 600 & 2 & 2 & 50 & 60 & 4.73 & 54.1 \\
\hline 32 & 500 & 1500 & 600 & 2 & 2 & 50 & 60 & 2.09 & 55.15 \\
\hline 33 & 500 & 1500 & 2400 & 1 & 2 & 50 & 60 & 5.42 & 53.18 \\
\hline 34 & 1000 & 1500 & 600 & 2 & 2 & 50 & 60 & 5.17 & 53.86 \\
\hline 35 & 500 & 2000 & 600 & 2 & 2 & 50 & 60 & 2.35 & 54.68 \\
\hline 36 & 500 & 2000 & 2400 & 1 & 2 & 50 & 60 & 6.05 & 52.77 \\
\hline 37 & 1000 & 2000 & 600 & 2 & 2 & 50 & 60 & 5.63 & 53.5 \\
\hline
\end{tabular}


Table 3.2: Saturated Condition - $50 \mathrm{mph}$ Speed Limit

\begin{tabular}{|c|c|c|c|c|c|c|c|c|c|}
\hline $\begin{array}{c}\text { Scenario } \\
\text { ID }\end{array}$ & $\begin{array}{c}\text { Flow } \\
(\mathrm{veh} / \mathbf{h} / \mathbf{l n})\end{array}$ & $\begin{array}{c}\text { Activity } \\
\text { Length } \\
\text { (ft) }\end{array}$ & $\begin{array}{l}\text { Merge } \\
\text { Length }\end{array}$ & $\begin{array}{c}\text { Number } \\
\text { of Open } \\
\text { Lanes }\end{array}$ & $\begin{array}{c}\mathbf{H V} \\
\%\end{array}$ & $\begin{array}{l}\text { Speed } \\
\text { Limit } \\
(\mathbf{m i} / \mathbf{h r})\end{array}$ & $\begin{array}{c}\text { FFS } \\
(\mathbf{m i} / \mathbf{h r})\end{array}$ & $\begin{array}{l}\text { Average } \\
\text { Delay } \\
\text { (sec/veh) }\end{array}$ & $\begin{array}{c}\text { Average } \\
\text { Speed } \\
\text { (mi/hr) }\end{array}$ \\
\hline 1 & 1000 & 1000 & 2400 & 1 & 0 & 50 & 60 & 178.98 & 24.48 \\
\hline 2 & 1500 & 1000 & 2400 & 1 & 0 & 50 & 60 & 646.18 & 9.34 \\
\hline 3 & 2000 & 1000 & 600 & 2 & 0 & 50 & 60 & 204.13 & 20.75 \\
\hline 4 & 2000 & 1000 & 2400 & 1 & 0 & 50 & 60 & 770.13 & 8.4 \\
\hline 5 & 2400 & 1000 & 600 & 2 & 0 & 50 & 60 & 259.96 & 17.83 \\
\hline 6 & 2400 & 1000 & 2400 & 1 & 0 & 50 & 60 & 815.05 & 8.38 \\
\hline 7 & 1000 & 1500 & 2400 & 1 & 0 & 50 & 60 & 190.92 & 23.97 \\
\hline 8 & 1500 & 1500 & 2400 & 1 & 0 & 50 & 60 & 635.82 & 9.69 \\
\hline 9 & 2000 & 1500 & 600 & 2 & 0 & 50 & 60 & 199.21 & 21.58 \\
\hline 10 & 2000 & 1500 & 2400 & 1 & 0 & 50 & 60 & 735.74 & 8.81 \\
\hline 11 & 2400 & 1500 & 600 & 2 & 0 & 50 & 60 & 257.93 & 18.42 \\
\hline 12 & 2400 & 1500 & 2400 & 1 & 0 & 50 & 60 & 834.36 & 8.56 \\
\hline 13 & 1000 & 2000 & 2400 & 1 & 0 & 50 & 60 & 197.27 & 29.91 \\
\hline 14 & 1500 & 2000 & 2400 & 1 & 0 & 50 & 60 & 630.94 & 9.99 \\
\hline 15 & 2000 & 2000 & 600 & 2 & 0 & 50 & 60 & 205.16 & 21.84 \\
\hline 16 & 2000 & 2000 & 2400 & 1 & 0 & 50 & 60 & 774.30 & 9.03 \\
\hline 17 & 2400 & 2000 & 600 & 2 & 0 & 50 & 60 & 254.26 & $\begin{array}{l}19.1 \\
\end{array}$ \\
\hline 18 & 2400 & 2000 & 2400 & 1 & 0 & 50 & 60 & 830.77 & 8.89 \\
\hline 19 & 1000 & 2500 & 2400 & 1 & 0 & 50 & 60 & 191.81 & 24.83 \\
\hline 20 & 1500 & 2500 & 2400 & 1 & 0 & 50 & 60 & 607.07 & 10.45 \\
\hline 21 & 2000 & 2500 & 600 & 2 & 0 & 50 & 60 & 204.12 & 22.3 \\
\hline 22 & 2000 & 2500 & 2400 & 1 & 0 & 50 & 60 & 733.84 & 9.38 \\
\hline 23 & 2400 & 2500 & 600 & 2 & 0 & 50 & 60 & 252.52 & 19.6 \\
\hline 24 & 2400 & 2500 & 2400 & 1 & 0 & 50 & 60 & 805.32 & 9.12 \\
\hline 25 & 1000 & 3000 & 2400 & 1 & 0 & 50 & 60 & 193.24 & 25.15 \\
\hline 26 & 1500 & 3000 & 2400 & 1 & 0 & 50 & 60 & 626.02 & 10.73 \\
\hline 27 & 2000 & 3000 & 600 & 2 & 0 & 50 & 60 & 204.68 & 22.85 \\
\hline 28 & 2000 & 3000 & 2400 & 1 & 0 & 50 & 60 & 776.76 & 9.44 \\
\hline 29 & 2400 & 3000 & 600 & 2 & 0 & 50 & 60 & 255.30 & 20.13 \\
\hline 30 & 2400 & 3000 & 2400 & 1 & 0 & 50 & 60 & 824.75 & 9.48 \\
\hline 31 & 1000 & 3500 & 2400 & 1 & 0 & 50 & 60 & 186.42 & 26.05 \\
\hline 32 & 1500 & 3500 & 2400 & 1 & 0 & 50 & 60 & 625.30 & 10.99 \\
\hline 33 & 2000 & 3500 & 600 & 2 & 0 & 50 & 60 & 205.86 & 23.27 \\
\hline 34 & 2000 & 3500 & 2400 & 1 & 0 & 50 & 60 & 771.50 & 9.75 \\
\hline 35 & 2400 & 3500 & 600 & 2 & 0 & 50 & 60 & 257.33 & 20.45 \\
\hline 36 & 2400 & 3500 & 2400 & 1 & 0 & 50 & 60 & 815.90 & 9.7 \\
\hline 37 & 1000 & 4000 & 2400 & 1 & 0 & 50 & 60 & 188.36 & 26.3 \\
\hline
\end{tabular}




\subsection{Pearson Correlation Matrix}

Before developing the regression models, a Pearson Correlation Matrix was created to examine the collinearity between different independent variables (Yeom, 2015). The results are presented in Tables 3.3 and 3.4 for the undersaturated and saturated conditions of a $50 \mathrm{mph}$ speed limit. Four independent variables are included in the table.

Table 3.3: Correlation Coefficients for Decision Variables - Undersaturated (50 mph Limit)

\begin{tabular}{|c|c|c|c|c|}
\hline Variables & Flow & $\begin{array}{c}\text { Activity } \\
\text { Length }\end{array}$ & $\begin{array}{c}\text { Open } \\
\text { Lanes }\end{array}$ & $\begin{array}{c}\text { Heavy } \\
\text { Vehicle \% }\end{array}$ \\
\hline Flow & 1 & & & \\
\hline Activity Length & 0 & 1 & & \\
\hline Open Lanes & 0.52 & 0 & 1 & \\
\hline Heavy Vehicle \% & 0 & 0 & 0 & 1 \\
\hline
\end{tabular}

Table 3.4: Correlation Coefficients for Decision Variables - Saturated (50 mph Limit)

\begin{tabular}{|c|c|c|c|c|}
\hline Variables & Flow & $\begin{array}{c}\text { Activity } \\
\text { Length }\end{array}$ & $\begin{array}{c}\text { Open } \\
\text { Lanes }\end{array}$ & $\begin{array}{c}\text { Heavy } \\
\text { Vehicle \% }\end{array}$ \\
\hline Flow & 1 & & & \\
\hline Activity Length & $1.59 \mathrm{E}-18$ & 1 & & \\
\hline Open Lanes & 0.45 & 0 & 1 & \\
\hline Heavy Vehicle \% & 0 & 0 & 0 & 1 \\
\hline
\end{tabular}

\subsection{Regression Model Development}

Since there are four decision variables, multiple regression was used to develop the delay and speed models. Of the 490 scenarios corresponding to a $50 \mathrm{mph}$ speed limit, 196 scenarios were categorized as undersaturated and 294 scenarios were categorized as saturated. Of the 490 scenarios corresponding to a $55 \mathrm{mph}$ speed limit, 197 scenarios were categorized as undersaturated and 293 scenarios were categorized as saturated. Minitab 17 was used as the statistical software to analyze and develop the regression models. $75 \%$ of the scenarios in each category were used to calibrate the models, while the remaining $25 \%$ of the scenarios were used to validate the models (Yeom, 2015). The sample sizes were large enough to obtain a precise estimate of the strength of the relationship between the dependent and independent variables. Data with large residuals were 
automatically screened out by Minitab and models were presented for each category. Normality is satisfied since there are more than 15 data points for each category. The following subsections describe the models and their properties using the notations below.

Flow Rate $=\mathrm{F}$

Activity Area Length $=\mathrm{L}$

Number of Open Lanes $=\mathrm{N}$

Heavy Vehicle Percentage $=\mathrm{H}$

\subsubsection{Undersaturated Flow Condition - $50 \mathrm{mph}$}

\subsubsection{Delay Model}

$$
\begin{aligned}
\text { Delay }= & 10.78-(0.02122 * \mathrm{~F})+\left(0.00306^{*} \mathrm{~L}\right)-(0.38 * \mathrm{~N})-(1.151 * \mathrm{H})+\left(0.000012^{*} \mathrm{~F}^{\wedge} 2\right)+ \\
& \left(0.101 * \mathrm{H}^{\wedge} 2\right)+\left(0.002022^{*} \mathrm{~F}^{*} \mathrm{~N}\right)-\left(0.00092 * \mathrm{~L}^{*} \mathrm{~N}\right)-(0.000163 * \mathrm{~L} * \mathrm{H})-\left(0.378^{*} \mathrm{~F}^{*} \mathrm{H}\right)
\end{aligned}
$$

\section{Goodness of Fit: $\quad$ R-Squared $=\mathbf{7 7 . 0 7 \%} \quad$ p-Values $<0.001$}

Hence, all of the variables satisfactorily explained the delay variation and this model is recommended for delay for undersaturated flow conditions with a $50 \mathrm{mph}$ speed limit.

The R-Squared and p-value for the model provided by Minitab are illustrated in Figure 3.4.

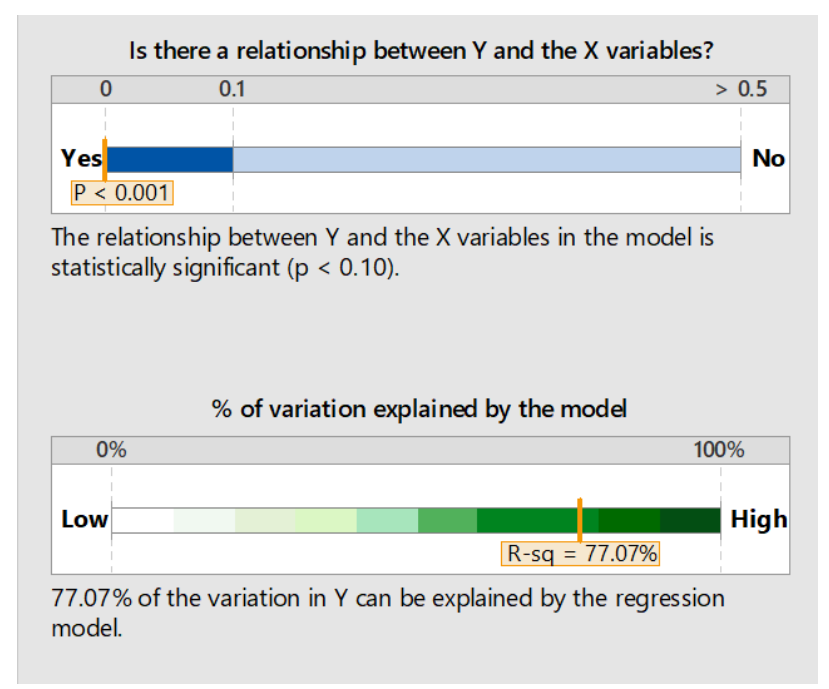

Figure 3.4: R-Squared and p-Values for the Delay Model by Minitab 
Figure 3.5 shows the residuals vs fitted values. As we can see, the majority of the points fall randomly on both sides of zero with a few large residuals marked in red.

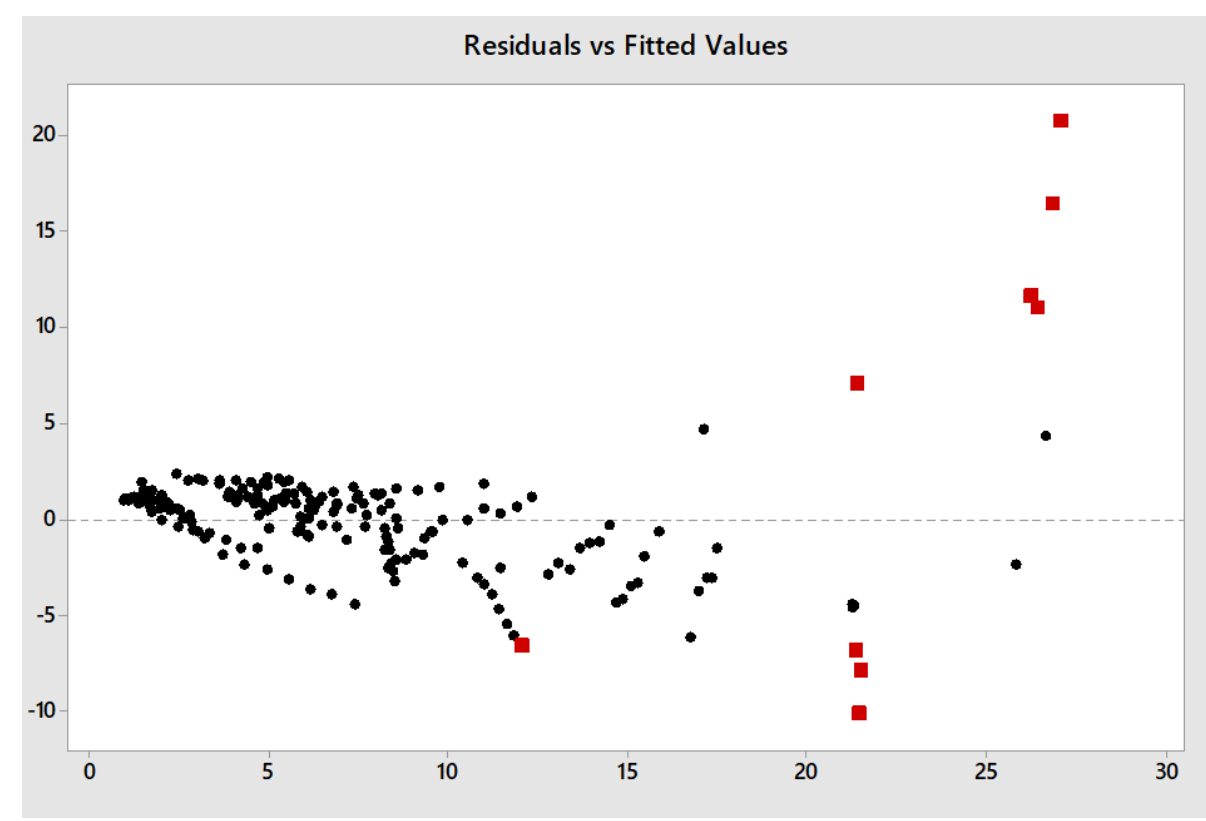

Figure 3.5: Residuals vs. Fitted Values for Delay Model by Minitab

\subsubsection{Average Speed Model}

Average Speed $=51.293+(0.0048 * \mathrm{~F})-(0.0011 * \mathrm{~L})+(1.496 * \mathrm{~N})+(0.374 * \mathrm{H})-\left(0.000004 * \mathrm{~F}^{\wedge} 2\right)-$ $\left(0.02916 * \mathrm{H}^{\wedge} 2\right)-\left(0.000609 * \mathrm{~F}^{*} \mathrm{H}\right)+(0.000056 * \mathrm{~L} * \mathrm{H})+\left(0.1032 * \mathrm{~N}^{*} \mathrm{H}\right)$

\section{Goodness of Fit: $\quad$ R-Squared $=\mathbf{8 0 . 4 1 \%} \quad$ p-Values $<0.001$}

Hence, all of the variables satisfactorily explained the delay variation and this model is recommended for average speed for undersaturated flow conditions with a $50 \mathrm{mph}$ speed limit.

The R-Squared and p-value for the model provided by Minitab are illustrated in Figure 3.6. 


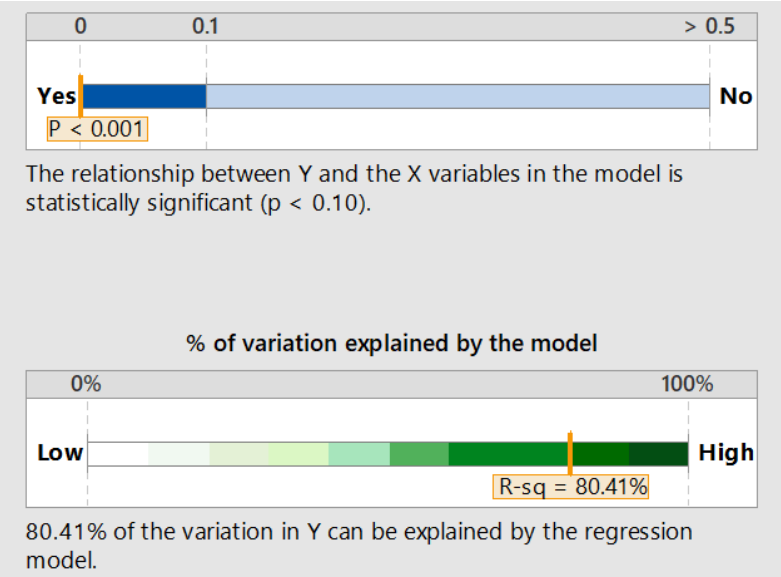

Figure 3.6: R-Squared and p-Value for the Speed Model by Minitab

Figure 3.7 shows the residuals vs fitted values. As we can see, the majority of the points fall randomly on both sides of zero with a few large residuals marked in red.

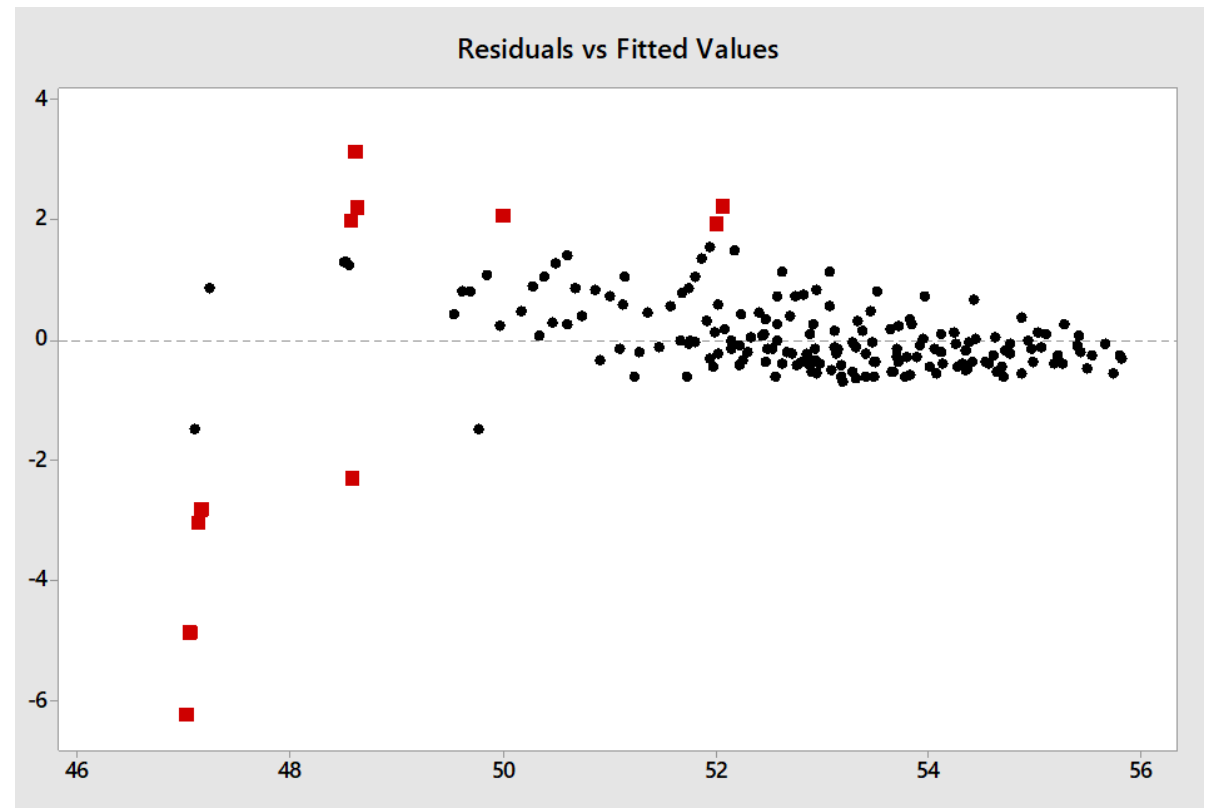

Figure 3.7: Residuals vs. Fitted Values for Speed Model by Minitab 


\subsubsection{Saturated Flow Condition - $50 \mathrm{mph}$}

\subsubsection{Delay Model}

$$
\begin{aligned}
\text { Delay }= & -389+1.6008 * \mathrm{~F}+0.00677 * \mathrm{~L}-722.4 * \mathrm{~N}+53.26 * \mathrm{H}-0.000348^{*} \mathrm{~F}^{\wedge} 2-0.333^{*} \mathrm{H}^{\wedge} 2- \\
& 0.00001 * \mathrm{~F} * \mathrm{~L}+0.0531 * \mathrm{~F} * \mathrm{~N}-0.01222 * \mathrm{~F} * \mathrm{H}+0.00845^{*} \mathrm{~L} * \mathrm{~N}-7.72 * \mathrm{~N}^{*} \mathrm{H}
\end{aligned}
$$

Goodness of Fit: $\quad$ R-Squared $=\mathbf{9 9 . 0 3 \%} \quad$ p-Values $<0.001$

Hence, all of the variables satisfactorily explained the delay variation and this model recommended is for delay for saturated flow conditions with a $50 \mathrm{mph}$ speed limit.

\subsubsection{Average Speed Model}

Average Speed $=11.17-0.007337 * \mathrm{~F}+0.000576 * \mathrm{~L}+13.16 * \mathrm{~N}-0.4642 * \mathrm{H}$

Goodness of Fit: $\quad$ R-Squared $=\mathbf{6 6 . 4 5 \%} \quad$ p-Values $<0.001$

Hence, all of the variables satisfactorily explained the delay variation and this model is recommended for delay for saturated flow conditions with a $50 \mathrm{mph}$ speed limit.

All of the developed models and graphs for the $55 \mathrm{mph}$ speed limit are provided in Appendix D.

\subsection{Model Validation}

The proposed models were validated using $25 \%$ of the simulation scenarios of each category, as described in subsection 3.7. The validation data set of each category was substituted in the proposed models and generated the calibrated values for delay and speed (Y-Calibrated). The original delay and speed values in the validation data sets were named $\mathrm{Y}-$ Actual.

The $\mathrm{Y}$ - Actual values were then plotted against the $\mathrm{Y}$ - Calibrated values and the distribution of points around the 45-degree line of fit was examined. All of the graphs showed a satisfactory distribution of points, confirming that the models provided accurate predictions. Figures 3.8, 3.9, 3.10 and 3.11 illustrate the models related to the $50 \mathrm{mph}$ speed limit category. 


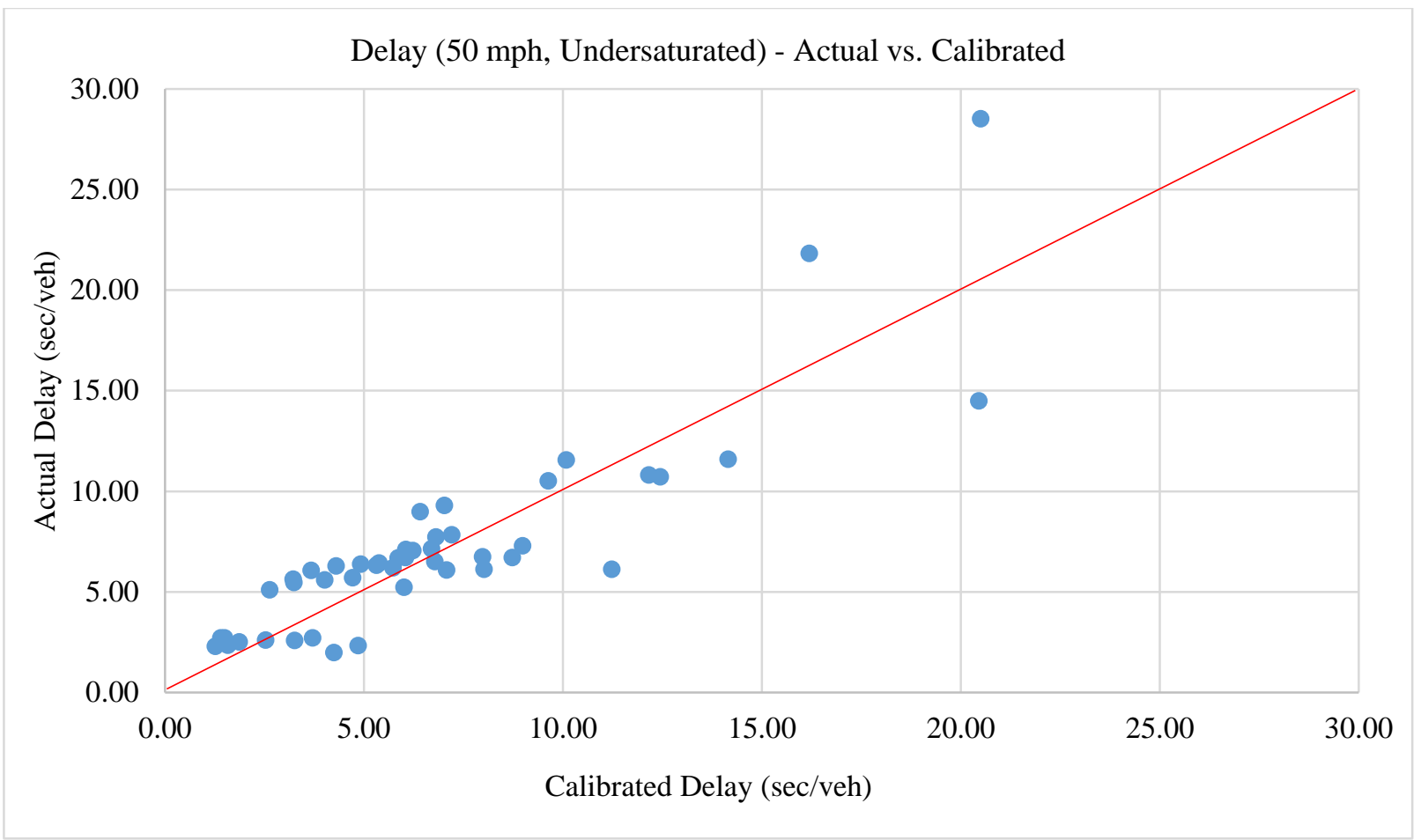

Figure 3.8: Actual vs. Calibrated Data for Delay Model (50 mph, Undersaturated)

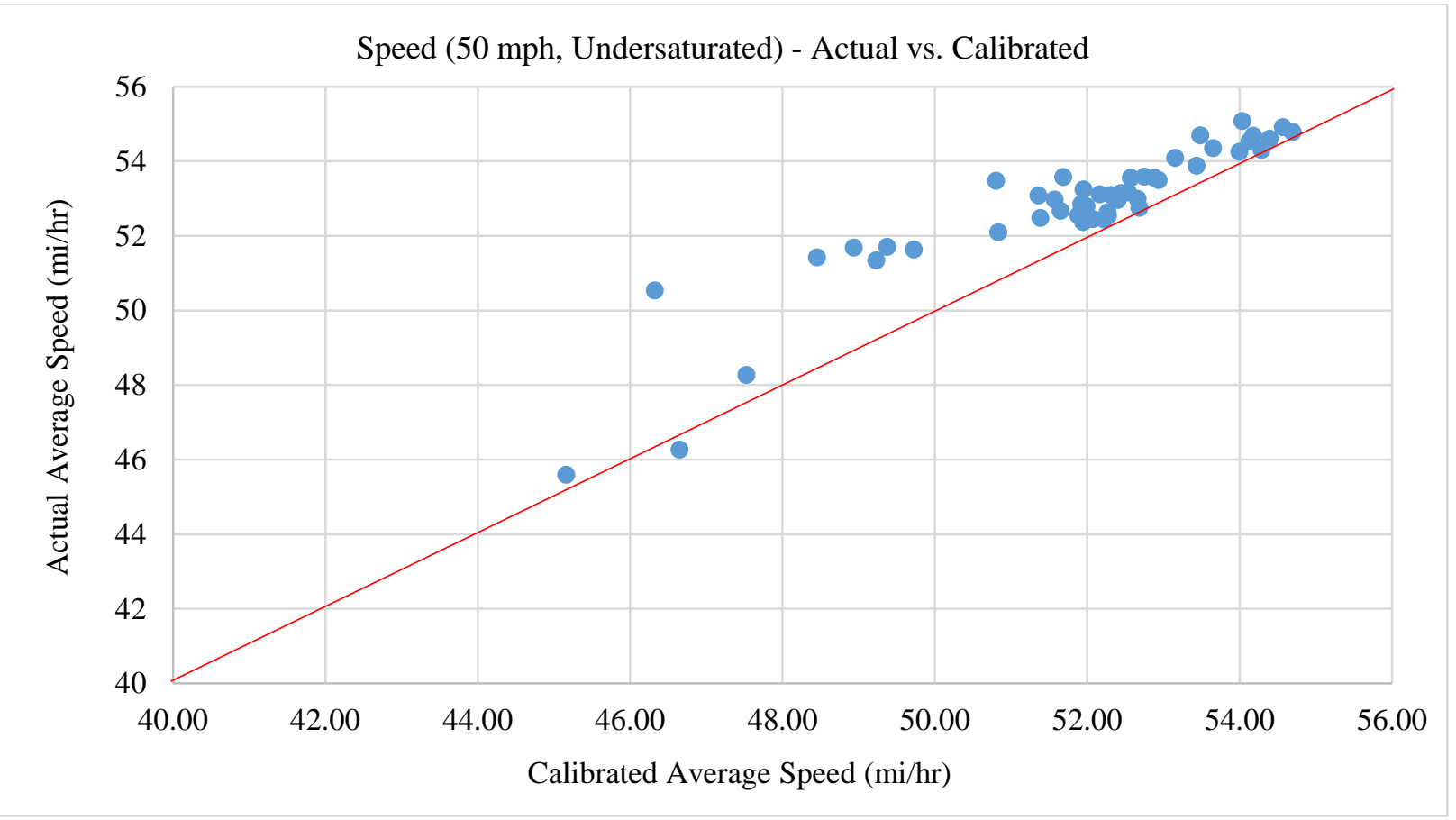

Figure 3.9: Actual vs. Calibrated Data for Speed Model (50 mph, Undersaturated) 


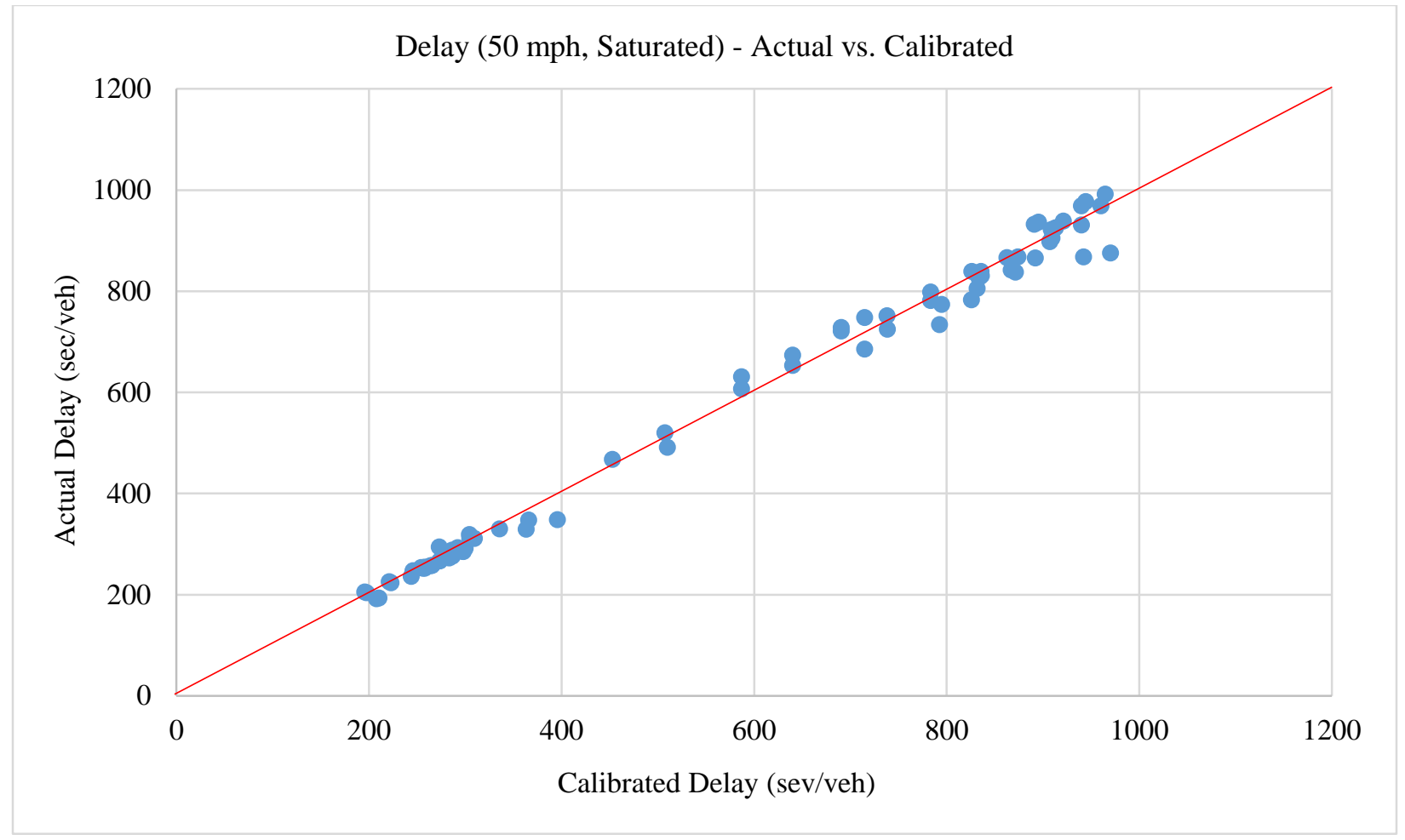

Figure 3.10: Actual vs. Calibrated Data for Delay Model (50 mph, Saturated)

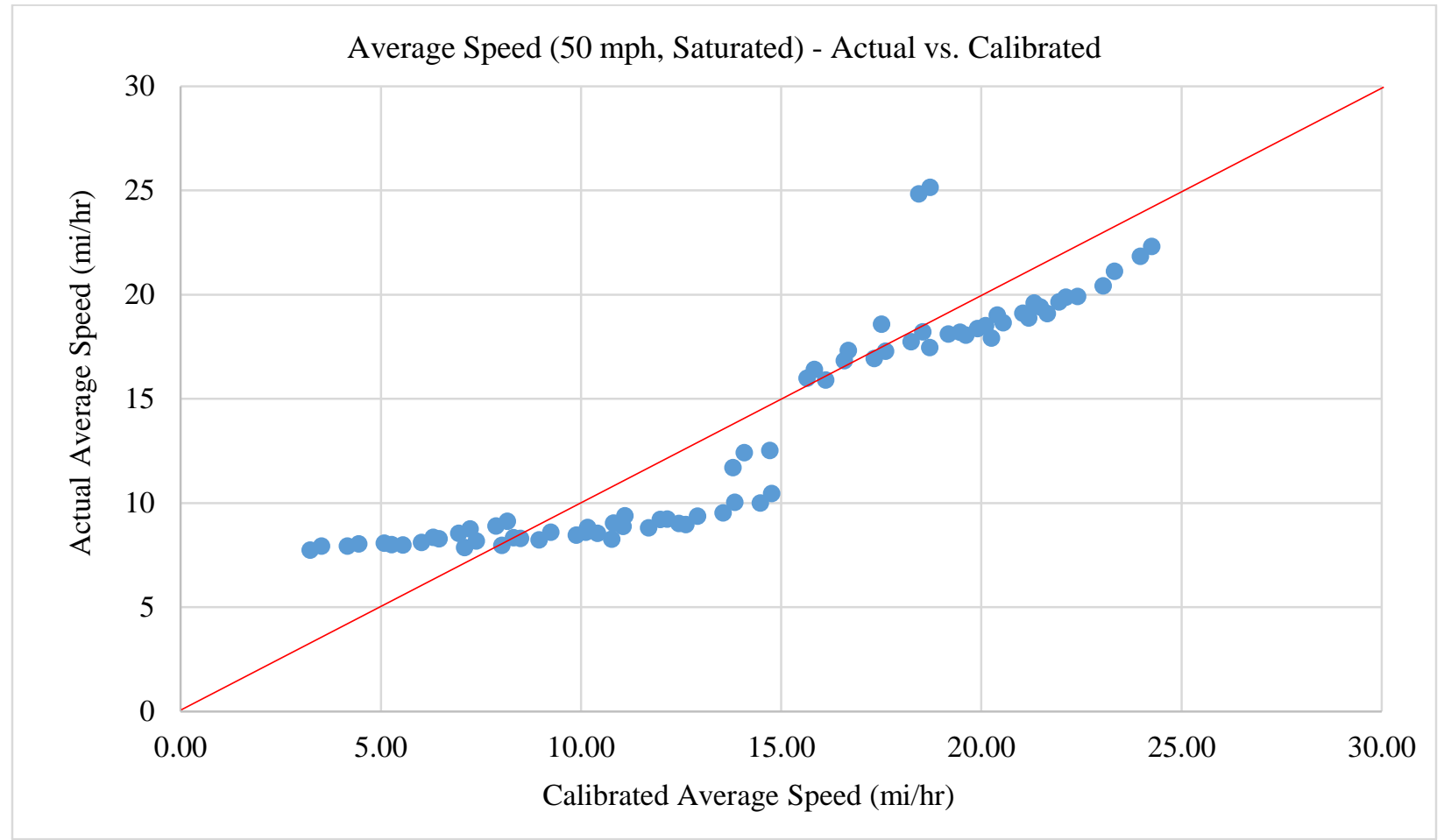

Figure 3.11: Actual vs. Calibrated Data for Speed Model (50 mph, Saturated) 


\subsection{Findings}

This chapter presented a synthesis of freeway work zone traffic prediction models that include delay and average speed. In the progression of freeway work zone traffic analysis, the authors developed delay and average speed models using simulated work zone scenarios in the FRESIM module of the CORSIM traffic simulation software. The following findings were obtained:

- Freeway work zone delay and average speed models for 3 lane freeways were developed using the following independent variables: hourly flow rate, activity area length, number of open lanes, and heavy vehicle percentage.

- The flow rate and number of open lanes are key variables that affect the prediction of delay and average speed.

- The presence of work zones during congested flow conditions generates significant delays and reduced average speeds compared to undersaturated flow conditions.

- The use of a sophisticated microsimulation tool is a very efficient and practical means of estimating freeway delays and average speed for both non-work zone and work zone conditions during congested and uncongested flow conditions with the presence of speed limits.

- The proposed models were validated using simulation data that were not used in the model calibration process. The models successfully predicted delay and average speed.

The proposed delay models are used to calculate delay related costs under the user cost domain in the following chapter. Recent studies have used complex delay models with the requirement of large number of input data including average speed. The proposed delay models are straightforward and efficient in predicting delays and the application of the cost estimation process for work zone scheduling.

In closing, the authors are hopeful that operating agencies and potential users will find these models valuable and simple to use, and that the models will enhance the predictability of traffic behaviours in freeway work zone areas. 


\section{CHAPTER 4}

\section{IMPROVED WORK ZONE COST MODEL AND SCHEDULING OPTIMIZATION}

\subsection{Introduction}

This chapter considers work zone activities in which a freeway project is separated into several work zones sequentially along the same direction of the mainline freeway. The fundamental methodology used in this study involved the development of a total cost objective function and which was then used to optimize work zone lengths and schedules. The traffic volume at any given time was estimated using a novel model developed in this study. Delays due to work zone activities were predicted using innovative multi-regression models developed in Chapter 3 using microsimulation. As discussed in the literature review, the total cost function includes all of the cost components that significantly influence the optimized work zone schedules with optimal lengths. This study focused on the cost model developed in the final report on optimizing work zones by Chien and Kyriacos (2015) and the user delay cost defined by Yang (2010). Cost minimization and optimal work zone scheduling are done with the methodology described below and a Solver optimizer tool.

\subsection{Methodology}

First, the cost model presented by Chien and Kyriacos (2015) was refined using the user delay cost function proposed by Yang (2010). Second, the user delay in the cost function was predicted using the delay models developed in Chapter 3. Third, a traffic flow prediction model was developed to feed the total delay and total flow estimation functions. In order to calculate the total traffic flow and total delay for a given start and end time period, the Excel-based add-in was used as integrator. The final step involves the estimation of the total cost.

In the second phase, the improved cost model was fed into the Solver optimization tool in the Microsoft Excel spreadsheet. Multiple arguments and logics were incorporated into both the spreadsheet and Solver tool in order to generate optimized work zone schedules and the corresponding sub work zone lengths. An activity diagram for the minimum cost solution analysis is presented in Figure 4.1. The optimization process is described in more detail in an upcoming subsection. 


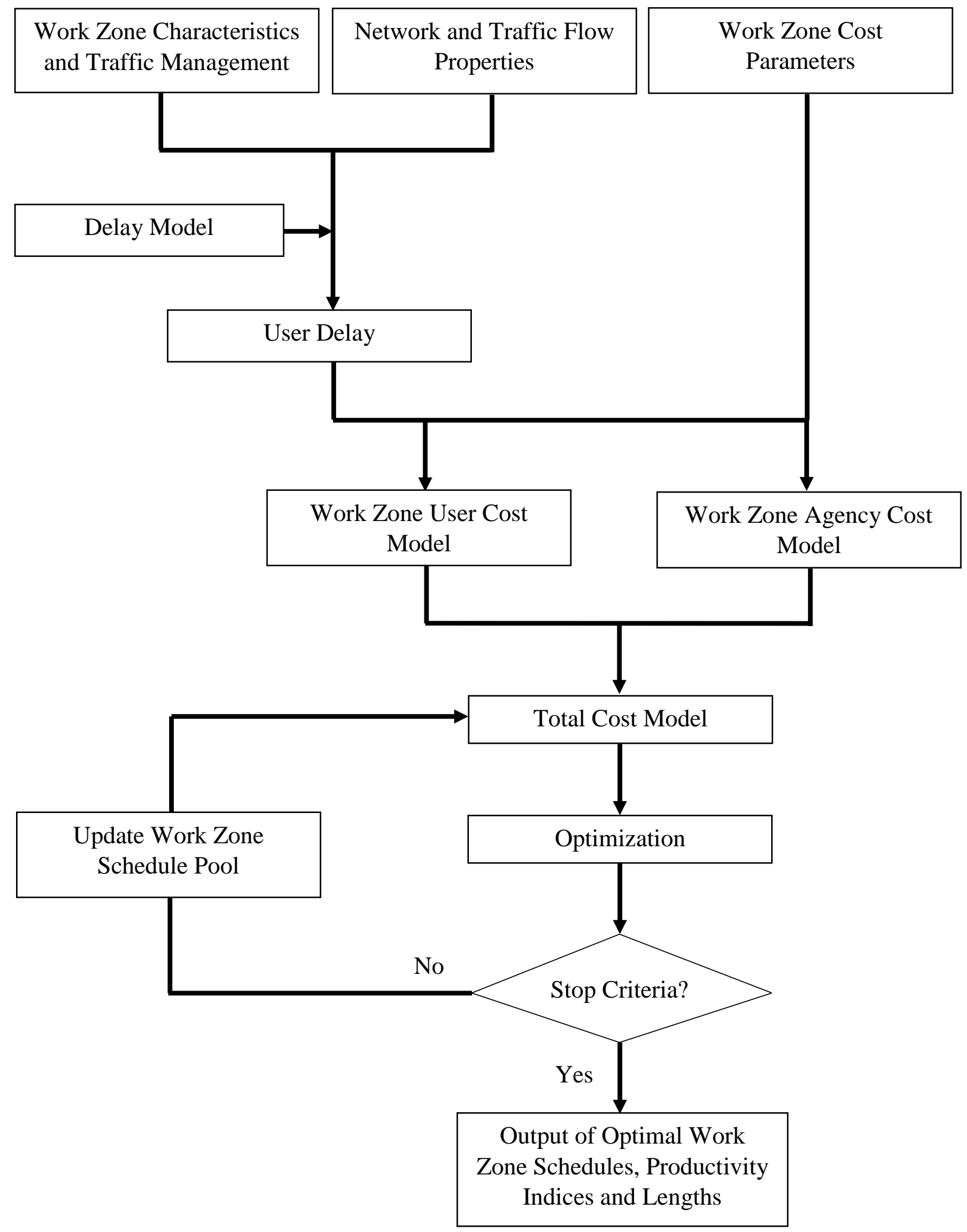

Figure 4.1: Activity Diagram for Total Work Zone Scheduling Methodology 


\subsection{Assumptions}

The total cost function was developed based on the assumptions outlined below:

1. The total number of vehicles within the study is taken into consideration by the model. The heavy vehicle percentage is separately fed into the delay model.

2. The project duration is linearly correlated with the work zone length.

3. The total number of lanes, design speed and work zone speed limit are predefined by the user and a corresponding delay model is chosen.

\subsection{Work Zone Timing and Duration}

Traffic demand varies over time. It is necessary to know the schedule and duration of a work zone. The time span of a work zone is determined by two parameters: activity starting time (S) and activity ending time (E). This time span can take place at any time of the day and any day of the week. Sometimes, the work zone duration involves multiple days with work breaks. An example of a work zone schedule is illustrated in Figure 4.2.

$\mathrm{D}=\mathrm{E}-\mathrm{S}$

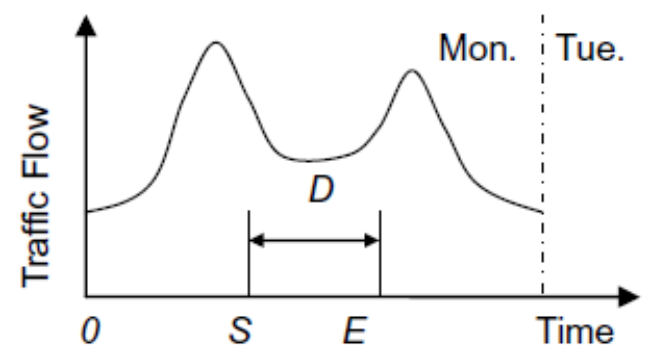

Figure 4.2: An Example Work Zone Schedule

\subsection{Model Formulation}

\subsubsection{Total Work Zone Cost (CT)}

Total cost is the objective function of optimization. Total cost is composed of three cost components: The Maintenance Cost $\left(\mathrm{C}_{\mathrm{M}}\right)$ module and the Idling Cost $\left(\mathrm{C}_{\mathrm{I}}\right)$ module (Agency cost module), and the Road User Cost $\left(\mathrm{C}_{\mathrm{U}}\right)$ module. Idling cost involves the idling time between each working period. This formation can be expressed as follows (Chien and Kyriacos, 2015):

$$
\mathrm{C}_{\mathrm{T}}=\mathrm{C}_{\mathrm{M}}+\mathrm{C}_{\mathrm{I}}+\mathrm{C}_{\mathrm{U}}
$$


When there are multiple work zones (I) involved in one maintenance project, Eq. 5 can be written as Eq. 6:

$$
\mathrm{C}_{\mathrm{T}}=\sum_{\mathrm{i}=1}^{\mathrm{I}} \mathrm{C}_{\mathrm{m}, \mathrm{i}}+\mathrm{C}_{\mathrm{I}, \mathrm{i}}+\mathrm{C}_{\mathrm{U}, \mathrm{i}}
$$

Where "i" is an index of work zones and "I" denotes the total number of work zones (including work breaks). The objective function $\mathbf{C}_{\mathbf{T}}$ should be minimized according to some practical constraint such as project length, minimum and maximum duration of project activities,

productivity factors, and congested flow periods. A detailed description of those constraints is provided below.

\section{Project Length $\left(\mathrm{L}_{M}\right)$}

When there are several work zones arranged sequentially along the mainline, the sum of work zone lengths must be equal to the total project length $\left(\mathrm{L}_{\mathrm{M}}\right)$ :

$$
\sum_{\mathrm{i}=1}^{\mathrm{I}} l_{i}^{k}=\mathrm{L}_{\mathrm{M}}, \forall i, k
$$

Where, $\boldsymbol{l}_{\boldsymbol{i}}^{\boldsymbol{k}}$ is the length of the work zone $i$. The superscript $k$ represents the index of available production options with respect to the number of crew personnel and their time durations for maintenance (in hour per lane mile).

\section{Minimum Duration of Maintenance Activities ( $\left.\mathbf{D}_{\min }\right)$}

There is a minimum time period required to install and remove maintenance equipment or provide break periods for personnel. This time duration is defined as $\mathrm{D}_{\min }$ and provides the lower limit for the duration of maintenance activities. Thus, each work zone duration should be greater than or equal to the minimum duration, as shown below.

$$
\mathrm{D}_{i} \geq \mathrm{D}_{\min }, \forall i
$$

\section{Maximum Duration of Maintenance Activities ( $\left.D_{\max }\right)$}

The maximum duration of maintenance activities is a primary constraint of projects that is specified according to budget limitations and management decisions. The total duration of sequential work zones should be less than or equal to the specified maximum project duration, as shown below. 


$$
\sum_{\mathrm{i}=1}^{\mathrm{I}} \mathrm{D}_{\mathrm{i}} \leq \mathrm{D}_{\max }, \forall i
$$

The formulation of these three cost components is discussed in the following subsections.

\subsubsection{Maintenance $\operatorname{Cost}\left(\mathrm{C}_{\mathrm{Mi}}\right)$}

Maintenance cost is a function of the fixed cost, variable cost, and work zone length. This combination can be represented as follows:

$$
\mathrm{C}_{\mathrm{mi}}=\mathrm{z}_{1}+\mathrm{z}_{2}^{\mathrm{k}} \cdot \mathrm{l}_{\mathrm{i}}^{\mathrm{k}} \cdot \mathrm{N}
$$

Where:

$\mathbf{z}_{\mathbf{1}}=$ Fixed cost for setting up and removing a work zone

$\mathbf{z}_{2}^{\mathbf{k}}=$ Unit maintenance cost in \$ / lane-mile with respect to the " $k$ " index of feasible production options to perform a given type of maintenance work according to the productive efficiency by number of crew members

$\mathbf{N}=$ Number of maintained lanes in $\mathbf{i}^{\text {th }}$ work zone

According to Eq. 10, there is an assumption that the maintenance cost is linearly related to the length of the work zone.

The duration of the maintenance activity in work zone $\mathbf{i}$ is denoted as $\mathbf{D}_{\mathbf{i}}$. It is the duration between the starting time $\left(\mathbf{S}_{\mathbf{i}}\right)$ and ending time $\left(\mathbf{E}_{\mathbf{i}}\right)$ of work zone $\mathbf{i}$. $\mathbf{D}_{\mathbf{i}}$ is also defined as a function of $\mathbf{z}_{\mathbf{3}}, \mathbf{l}_{\mathbf{i}}^{\mathbf{k}}$ and $\mathbf{z}_{4} \mathbf{k}$. $\mathbf{z}_{3}$ denotes the time required to set up and tear down a work zone. The unit production time $\mathbf{z}_{4}^{\mathbf{k}}$ represents the hours needed to complete one-lane mile of maintenance corresponding to production option $\mathbf{k}$. Therefore,

$$
D_{i}=E_{i}-S_{i}=z_{3}+z_{4}^{k} \cdot l_{i}^{k} \cdot N
$$

From Eq. 11, $\mathbf{l}_{\mathbf{i}}^{\mathbf{k}}$ can be derived as:

$$
\mathrm{l}_{\mathrm{i}}^{\mathrm{k}}=\frac{\mathrm{Ei}-\mathrm{Si}-\mathrm{z}_{3}}{\mathrm{z}_{4}^{\mathrm{k}} \cdot \mathrm{N}}
$$


From Eq. 10, $\mathbf{C}_{\mathbf{m i}}$ can be rewritten as:

$$
\mathrm{C}_{\mathrm{mi}}=\mathrm{z}_{1}+\mathrm{z}_{2}^{\mathrm{k}} \cdot \frac{\mathrm{Ei}-\mathrm{Si}-\mathrm{z}_{3}}{\mathrm{z}_{4}^{\mathrm{k}}}, \forall i, k
$$

\subsubsection{Work Zone Idling Cost $\left(\mathrm{Cl}_{\mathrm{Ii}}\right)$}

Work zone idling, or no-work perform, is considered a dummy work zone with a variable time duration and no productivity (zero-mile length). The idling cost component is a product of its duration $\mathbf{D}_{\mathbf{i}}$ and the average idling cost $\mathbf{V}_{\mathbf{I}}$, as shown below.

$$
\mathrm{C}_{\mathrm{Ii}}=\mathrm{V}_{\mathrm{I}} \cdot \mathrm{D}_{\mathrm{i}}=\mathrm{V}_{\mathrm{I}} \cdot\left(\mathrm{S}_{\mathrm{i}+1}-\mathrm{E}_{\mathrm{i}}\right), \forall i
$$

\subsubsection{Road User Cost (CUi)}

Road users incur costs as a result of reduced travel speed, restricted capacity in work zones, and additional travel distance due to detours. Road user cost is comprised of four sub-cost components: delay cost, vehicle operating cost, accident cost, and emission cost. These costs are incurred in each work zone $\mathbf{i}$, and denoted as $\mathbf{C}_{\mathbf{D i}}, \mathbf{C}_{\mathbf{V i}}, \mathbf{C}_{\mathbf{A i}}$, and $\mathbf{C}_{\mathbf{E i}}$, respectively. Therefore,

$$
\mathrm{C}_{\mathrm{u}}=\sum_{\mathrm{i}=1}^{\mathrm{I}} \mathrm{C}_{\mathrm{U}, \mathrm{i}}=\sum_{\mathrm{i}=1}^{\mathrm{I}}\left(\mathrm{C}_{\mathrm{D}, \mathrm{i}}+\mathrm{C}_{\mathrm{V}, \mathrm{i}}+\mathrm{C}_{\mathrm{A}, \mathrm{i}}+\mathrm{C}_{\mathrm{E}, \mathrm{i}}\right)
$$

The following subsections describe the formulation of these four costs with their corresponding formula.

\section{User Delay $\operatorname{Cost}\left(C_{D, i}\right)$}

Yang (2010) stated that delay cost should be determined using the amount and value of lost time resulting from delays caused by work zones. In this study, only mainline delay is taken into consideration under user delay. Thus,

$$
\mathrm{C}_{\mathrm{D}, \mathrm{i}}=\mathrm{V}_{\mathrm{D}} \cdot \mathrm{D}_{\mathrm{D}, \mathrm{i}}, \forall i
$$

Where,

$\mathbf{V}_{\mathbf{D}}=$ Monetary value of time 
$\mathbf{D}_{\mathbf{D}, \mathbf{i}}=$ The total delay caused by the $\mathbf{i}^{\text {th }}$ work zone (the calculation is mentioned in the next subsection)

\section{Total Delay $\left(\mathrm{D}_{\mathbf{D}, \mathrm{i}}\right)$}

Total delay can be calculated using the delay models developed in Chapter 3 and the anytime traffic flow model. The traffic flow model was developed using the actual hourly traffic flow data from the case study in the Matlab software. The total delay for each work zone during the starting time $\left(\mathbf{S}_{\mathbf{i}}\right)$ and ending time ( $\left.\mathbf{E}_{\mathbf{i}}\right)$ was calculated using integration and should be substituted in Eq. 16 to calculate user delay cost $\left(\mathbf{C D}_{\mathbf{D}}\right)$. Integration can be written as:

$$
D_{D, i}=\int_{S_{i}}^{E_{i}}(\text { Delay Model x Flow Model }) d t
$$

\section{Vehicle Operating Cost $\left(\mathrm{C}_{\mathrm{V}, \mathrm{i}}\right)$}

Speed variations due to work zone speed limits and decreased capacity due to lane closures have a considerable effect on vehicle operating costs. This results an excess fuel and oil consumption, maintenance and wear and tear on tires. The vehicle operating cost of each work zone can be calculated analytically by multiplying the total delay (as calculated eq. 17) with the unit vehicle idling cost denoted as Vo. Thus,

$$
C_{V, i}=V_{O} \cdot D_{D, i}
$$

\section{Expected Accident $\operatorname{Cost}\left(\mathrm{C}_{\mathrm{A}, \mathrm{i}}\right)$}

Research has shown that crash rates are significantly higher in work zones than in normal road conditions. This hazard is aggravated by high congestion levels. It is important to note that simulation models such as CORSIM are not effective at predicting changes in the expected accident rate. The accident costs incurred by road users at each work zone are analytically calculated from the number of crashes per 100 million vehicle hours of travel $\mathbf{R}_{\mathbf{A}}$ multiplied by the product of the total delay $\left(\mathbf{D}_{\mathbf{D}, \mathbf{i}}\right)$ and the average cost per crash denoted by $\mathbf{V}_{\mathbf{A}}$ (Yang, 2010). Hence,

$$
\mathrm{C}_{\mathrm{A}, \mathrm{i}}=\mathrm{V}_{\mathrm{A}} \cdot \mathrm{D}_{\mathrm{D}, \mathrm{i}} \cdot \mathrm{R}_{\mathrm{A}}
$$




\section{Total Flow $\left(\mathbf{F}_{\mathrm{T}, \mathbf{i}}\right)$}

Total flow can be calculated as follows:

$$
\mathrm{F}_{\mathrm{T}, \mathrm{i}}=\int_{\mathrm{S}_{\mathrm{i}}}^{\mathrm{E}_{\mathrm{i}}}(\text { Flow Model }) \mathrm{dt}
$$

\section{Emission $\operatorname{Cost}\left(\mathrm{C}_{\mathrm{E}, \mathrm{i}}\right)$}

According to the literature review, this component is not usually considered during cost analysis. Vehicle emissions are generally divided into two categories (FHWA, 2011).

- Air Pollutant Emissions:

This includes pollutants emitted directly into the atmosphere such as carbon monoxide (CO), volatile organic compounds, particulate matter, oxides of nitrogen and sulfur (NOX and SOX) and pollutants such as ozone and acidic deposits.

- Greenhouse Gases:

This includes direct emissions that trap heat within the atmosphere and contributing to unfavourable climatic changes. These emissions are not yet recognized as air pollutants, according to the 2011 report by the FHWA.

Because of the impact of air pollutants and greenhouse gases, it is important to analyze the emission costs of work zones. Emission cost can be calculated as follows:

$$
\mathrm{C}_{\mathrm{E}, \mathrm{i}}=\sum_{\mathrm{t}=\mathrm{Si}}^{\mathrm{Ei}}\left(\mathrm{C}_{\mathrm{e}, \mathrm{it}}^{\mathrm{n}}-\mathrm{C}_{\mathrm{e}, \mathrm{it}}^{\mathrm{w}}\right) \cdot \mathrm{F}_{\mathrm{T}, \mathrm{i}}
$$

Where,

$\boldsymbol{C}_{\boldsymbol{e}, \boldsymbol{i t}}^{\boldsymbol{n}}=$ Emission damage cost under normal conditions in $\mathbf{i}^{\text {th }}$ segment

$\boldsymbol{C}_{\boldsymbol{e}, \boldsymbol{i t}}^{\boldsymbol{w}}=$ Emission damage cost under work zone conditions in $\mathbf{i}^{\text {th }}$ segment

After obtaining all of the cost components, the objective total cost function in Equation 5 can be derived as: 
Minimum $\mathrm{C}_{\mathrm{T}}=\sum_{\mathrm{i}=1}^{\mathrm{I}}\left|\begin{array}{c}\mathrm{z}_{1}+\mathrm{z}_{2}^{\mathrm{k}} \cdot \frac{\mathrm{Ei}-\mathrm{Si}-\mathrm{z}_{3}}{\mathrm{z}_{4}^{\mathrm{k}}}+\mathrm{V}_{\mathrm{I}} \cdot\left(\mathrm{S}_{\mathrm{i}+1}-\mathrm{E}_{\mathrm{i}}\right)+\mathrm{V}_{\mathrm{D}} \cdot \mathrm{D}_{\mathrm{D}, \mathrm{i}}+ \\ \mathrm{V}_{\mathrm{O}} \cdot \mathrm{D}_{\mathrm{D}, \mathrm{i}}+\mathrm{V}_{\mathrm{A}} \cdot \mathrm{D}_{\mathrm{D}, \mathrm{i}} \cdot \mathrm{R}_{\mathrm{A}}+\sum_{\mathrm{t}=\mathrm{Si}}^{\mathrm{Ei}}\left(\mathrm{C}_{\mathrm{e}, \mathrm{it}}^{\mathrm{n}}-\mathrm{C}_{\mathrm{e}, \mathrm{it}}^{\mathrm{w}}\right) \cdot \mathrm{F}_{\mathrm{T}, \mathrm{i}}\end{array}\right|$

Constraint to:

Project Length:

$$
\sum_{\mathrm{i}=1}^{\mathrm{I}} \mathrm{l}_{\mathrm{i}}^{\mathrm{k}}=\mathrm{L}_{\mathrm{M}}, \quad \forall i, k
$$

Minimum Project Duration:

$$
\mathrm{D}_{\mathrm{i}} \geq \mathrm{D}_{\min }, \forall i
$$

Minimum Project Duration:

$$
\sum_{\mathrm{i}=1}^{\mathrm{I}} \mathrm{D}_{\mathrm{i}} \leq \mathrm{D}_{\max }, \forall i
$$

\subsection{Optimal Solution Methodology}

This study involved the use of a novel algorithm for the optimization of work zone schedules using the Solver tool in Microsoft Excel Spreadsheets. A detailed description of the Solver tool is provided in the literature review. The total cost function, which is the objective function in this study, is continuous and its decision variables are the work activity starting time $\left(\mathrm{S}_{\mathrm{i}}\right)$, work activity ending time $\left(\mathrm{E}_{\mathrm{i}}\right)$, and productivity index (k - crew category) of work zone $\mathrm{i}$.

According to the literature, it is very rare to find work zone related optimizations using a Solver optimizer. More complex optimization algorithms such as Genetic Algorithms require more expertise, effort and inputs in order to generate solutions. A Solver was used as an optimizing tool during this study in order to increase practicality and applicability. Figure 4.3 illustrates the basic methodology used in the solution process. The rules listed below were applied during the optimization process:

1. Work zones are sequentially scheduled in off-peak time windows within the analysis period and hourly traffic flow analysis is used.

2. Work zones are scheduled only in time windows with the lowest average traffic volumes.

3. Work zones are scheduled in randomly proposed time windows. 


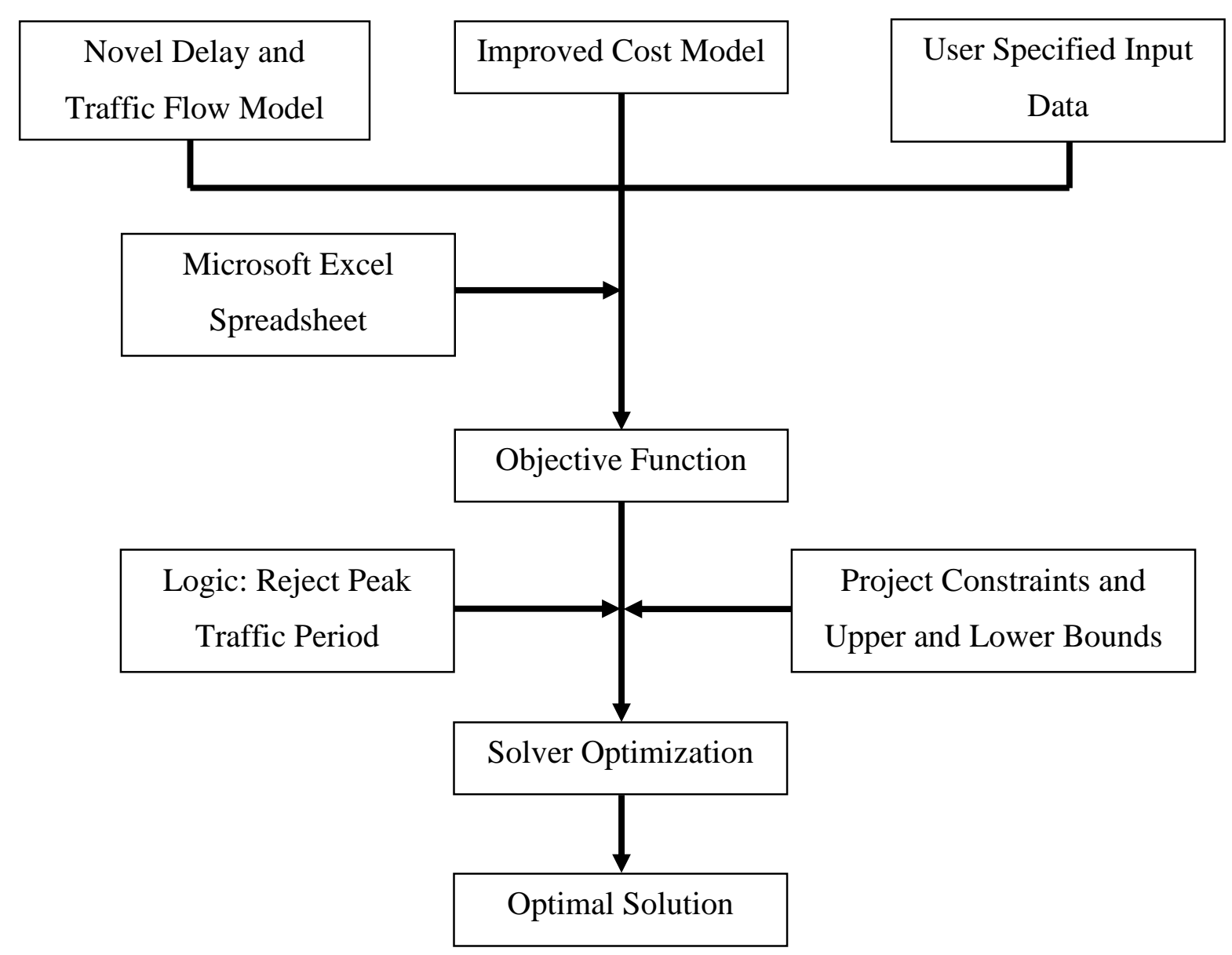

Figure 4.3: Activity Diagram for the Solver Optimal Solution Methodology

\subsubsection{Solver Setup Procedure}

\section{Step 1}

- Setup the user specified inputs in the Excel spreadsheet: Activity Length, Number of Lanes, and Heavy Vehicle Percentage.

- Use the novel delay model and traffic flow model according to the work zone characteristics.

- Apply user specified constraint values to the objective function.

\section{Step 2}

Develop all of the cost calculation steps in Microsoft Excel while incorporating the equations developed in subsection 4.5 and generate the total cost. 


\section{Step 3}

Specify the number of active time periods and idle time periods for a pre-defined total project duration (i.e. $S_{1}$ and $E_{1}, S_{2}$ and $E_{2}, S_{3}$ and $E_{3}, \ldots S_{n}$ and $E_{n}$ ). Every other time period starting from $\mathrm{S}_{1}$ are defined as "Active" periods. The remaining time periods are defined as "Idling" periods.

\section{Step 4}

Develop arguments in the sub-total cost cells of active time periods to reject peak traffic hours and select the schedules related to off-peak time periods only.

Arguments to reject peak traffic period:

$\mathrm{S}_{\mathrm{i}} \geq$ Lower bound of peak traffic period

$\mathrm{S}_{\mathrm{i}} \leq$ Upper bound of peak traffic period

$\mathrm{E}_{\mathrm{i}} \geq$ Lower bound of peak traffic period

$E_{i} \leq$ Upper bound of peak traffic period

$\mathrm{S}_{\mathrm{i}} \leq$ Lower bound of peak traffic period

$E_{i} \geq$ Upper bound of peak traffic period

If any of the randomly generated $S_{i}$ and/or $E_{i}$ value falls under the conditions above, the IF function will reject the sub-total cost value in each active period and will not include it in the solution pool. A sub-total cost cell argument developed for a 5-time period schedule is presented below for illustration purposes.

$=\mathrm{IF}(\mathrm{B} 10<24,(\mathrm{IF}(\mathrm{AND}(\mathrm{B} 10<=\mathrm{H} 22, \mathrm{~B} 10>=\mathrm{G} 22), 1000000, \mathrm{IF}(\mathrm{AND}(\mathrm{B} 11<=\mathrm{H} 22, \mathrm{~B} 11>=\mathrm{G} 22), 1000000, \mathrm{IF}(\mathrm{AND}(\mathrm{B} 10<=$ G22,B11>=H22),1000000,IF(B11>=G23,1000000,SUM(I58,I66,I75,I81,I87,I93))))),(IF(B10<48,(IF(AND(B10<= $\mathrm{H} 23, \mathrm{~B} 10>=\mathrm{G} 23), 1000000, \mathrm{IF}(\mathrm{AND}(\mathrm{B} 11<=\mathrm{H} 23, \mathrm{~B} 11>=\mathrm{G} 23), 1000000, \mathrm{IF}(\mathrm{AND}(\mathrm{B} 10<=\mathrm{G} 23, \mathrm{~B} 11>=\mathrm{H} 23), 1000000, \mathrm{SU}$ $\mathrm{M}(\mathrm{I} 58, \mathrm{I} 66, \mathrm{I75}, \mathrm{I} 81, \mathrm{I} 87, \mathrm{I} 93))))), \mathrm{IF}(\mathrm{B} 10<72, \mathrm{IF}(\mathrm{AND}(\mathrm{B} 10<=\mathrm{H} 24, \mathrm{~B} 10>=\mathrm{G} 24), 1000000, \operatorname{IF}(\mathrm{AND}(\mathrm{B} 11<=\mathrm{H} 24, \mathrm{~B} 11>=\mathrm{G}$ 24),1000000,IF(AND(B10<=G24,B11>=H24),1000000,SUM(I58,I66,I75,I81,I87,I93))))))))

The above "if" statement checks whether the start and end times generated by solver lie within 72 hrs and how they are distributed among days 1,2, and 3. A larger value (1000000) is included for the total cost in the peak-traffic period to reject the time period under consideration if it overlaps with the peak period. 


\section{Step 5}

Set all objective cells, changing variable cells and constraints in the Solver tool.

Objective cell $=$ Total Cost $\quad$ Objective $=$ Minimum

Changing variables $=$ Start and end times of all active periods; Productivity index of each active period

Constraints:

1. All productivity indices $(\mathrm{k})$ are integers.

2. Numerical relations between all of the start and end time periods.

3. Maximum and minimum time of each start and end time.

4. Minimum durations for each time period.

5. Maximum total time duration for the sum of the time durations in all periods.

6. Maximum length for the sum of the completion lengths in each time period.

\subsubsection{Solution Algorithm}

Once all of the required data and information are fed into the system, the Solver begins to generate random start and end times in the changing variable cells. The maintenance costs of each time period are calculated according to those values. The Excel integration function begins to integrate the delay and traffic flow models with respect to time under the initialized starting and ending time by the Solver as the upper and lower integration limits. This generates the total delay and total vehicles for each active time period in the schedule. According to these values, the system calculates the user costs for each active period as well as the idling costs in between. In order to reject the peak hour period under the randomly generated time periods, the sub-total cost cell of each active period checks the argument under step 4. Only the times in the off-peak traffic periods will be included in the solution pool. After the optimization process, the Solver indicates the minimum total cost and corresponding schedule times and productivity indices. Figure 4.4 illustrates the activity diagram for a solution algorithm. 


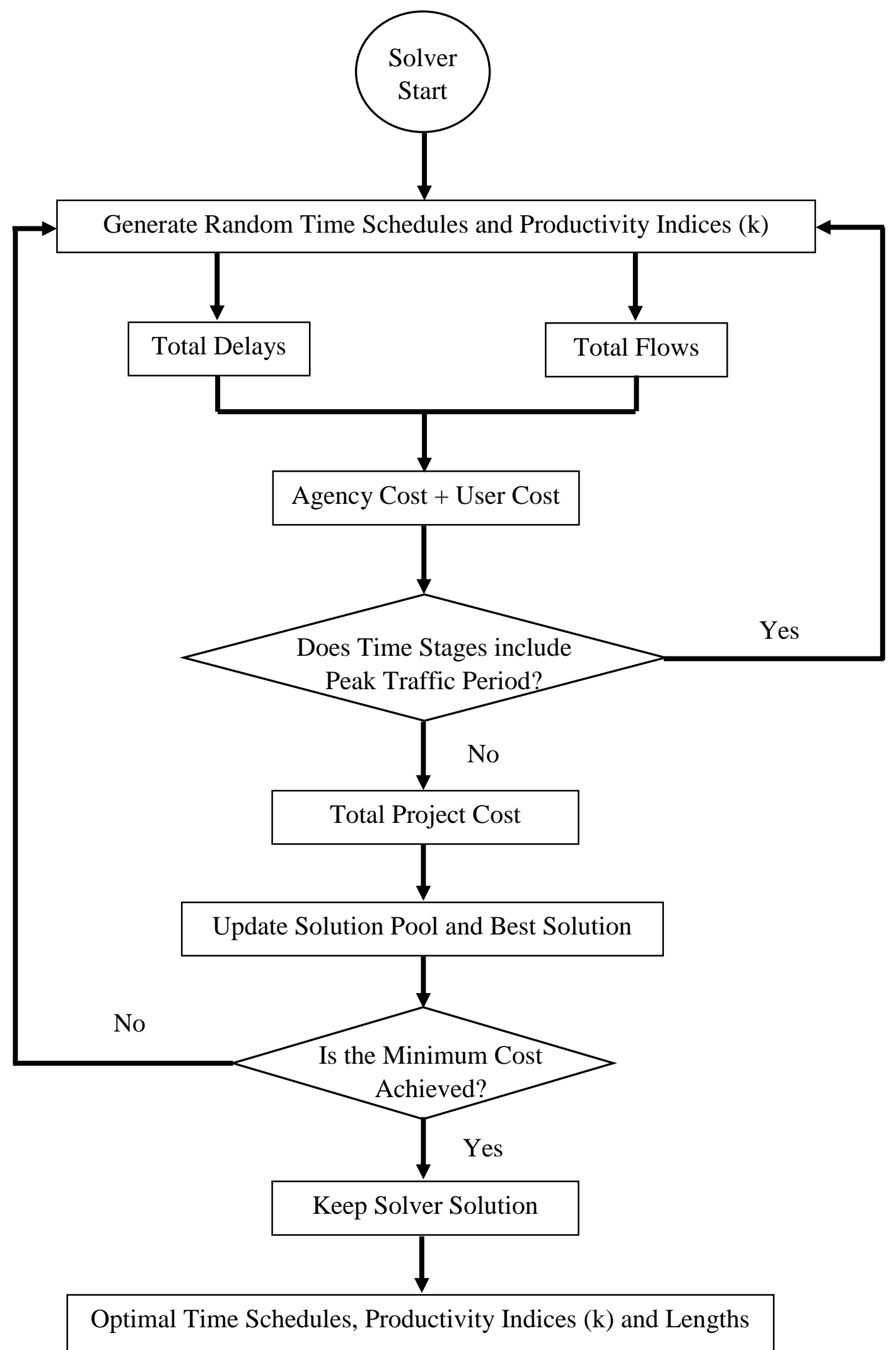

Figure 4.4: Activity Diagram for Solution Algorithm 


\section{CHAPTER 5}

\section{CASE STUDIES}

\subsection{Project Description}

The details of a real work zone case study were extracted from the final report submitted by the New Jersey Institute of Technology (2015). The project data of a segment of Interstate I-287 in New Jersey (4-Lanes in each direction) were used to test the methodology developed in this research study. Chien and Kyriacos (2015) selected this work zone due to the availability of detailed work zone data for this highway segment. Two case studies were conducted using the work zones mentioned above. The case studies are described in the following subsections. Figure 5.1 shows the Google image of the work zone segment.

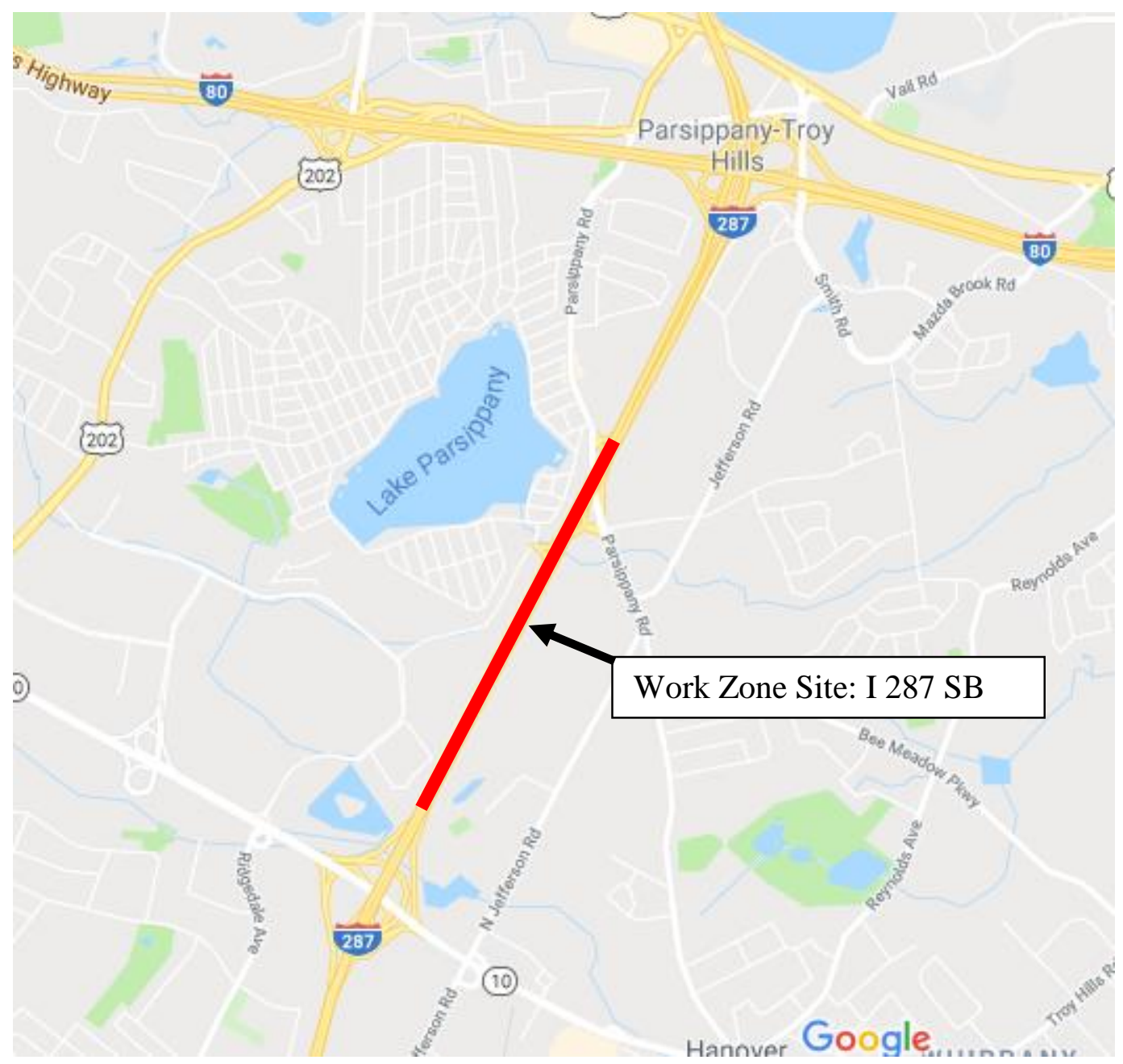

Figure 5.1: Location of Work Zone on I-287 


\subsection{Case Study 1}

The proposed resurfacing involved the short term closure of one of four lanes. The maintenance activity involved a 1.80-mile long highway segment starting from the I-287 southbound milepost 41.24 to milepost 39.29, as illustrated in Figure 5.1. The traffic volume data and work zone characteristics were obtained from the New Jersey Department of Transportation (NJDOT) traffic count data base.

\subsubsection{Traffic Flow Data}

Table 5.1 shows the extracted values for the hourly traffic flow as mentioned in the final report by the New Jersey Institute of Technology (2015) which were retrieved from the traffic count data base (NJDOT, 2013).

Table 5.1: Hourly Traffic Flow Rate (Final report - new jersey institute of technology, 2015)

\begin{tabular}{|c|c|c|c|}
\hline Hour of Day & Flow Rate (veh/hr) & Hour of Day & Flow Rate (veh/hr) \\
\hline 0 & 1048 & 12 & 3200 \\
\hline 1 & 850 & 13 & 3100 \\
\hline 2 & 700 & 14 & 3050 \\
\hline 3 & 650 & 15 & 3100 \\
\hline 4 & 800 & 16 & 3400 \\
\hline 5 & 1100 & 17 & 3750 \\
\hline 6 & 2650 & 18 & 4000 \\
\hline 7 & 5200 & 19 & 3300 \\
\hline 8 & 6100 & 20 & 2500 \\
\hline 9 & 5950 & 21 & 1850 \\
\hline 10 & 4450 & 22 & 1650 \\
\hline 11 & 3400 & 23 & 1450 \\
\hline
\end{tabular}

The above traffic flow data were used to develop a traffic flow model using the Matlab software. The Matlab curve fitting tool was used to find the best function that fit the best curve according to the extracted hourly traffic flow data plot. The results are illustrated in Figure 5.2. 


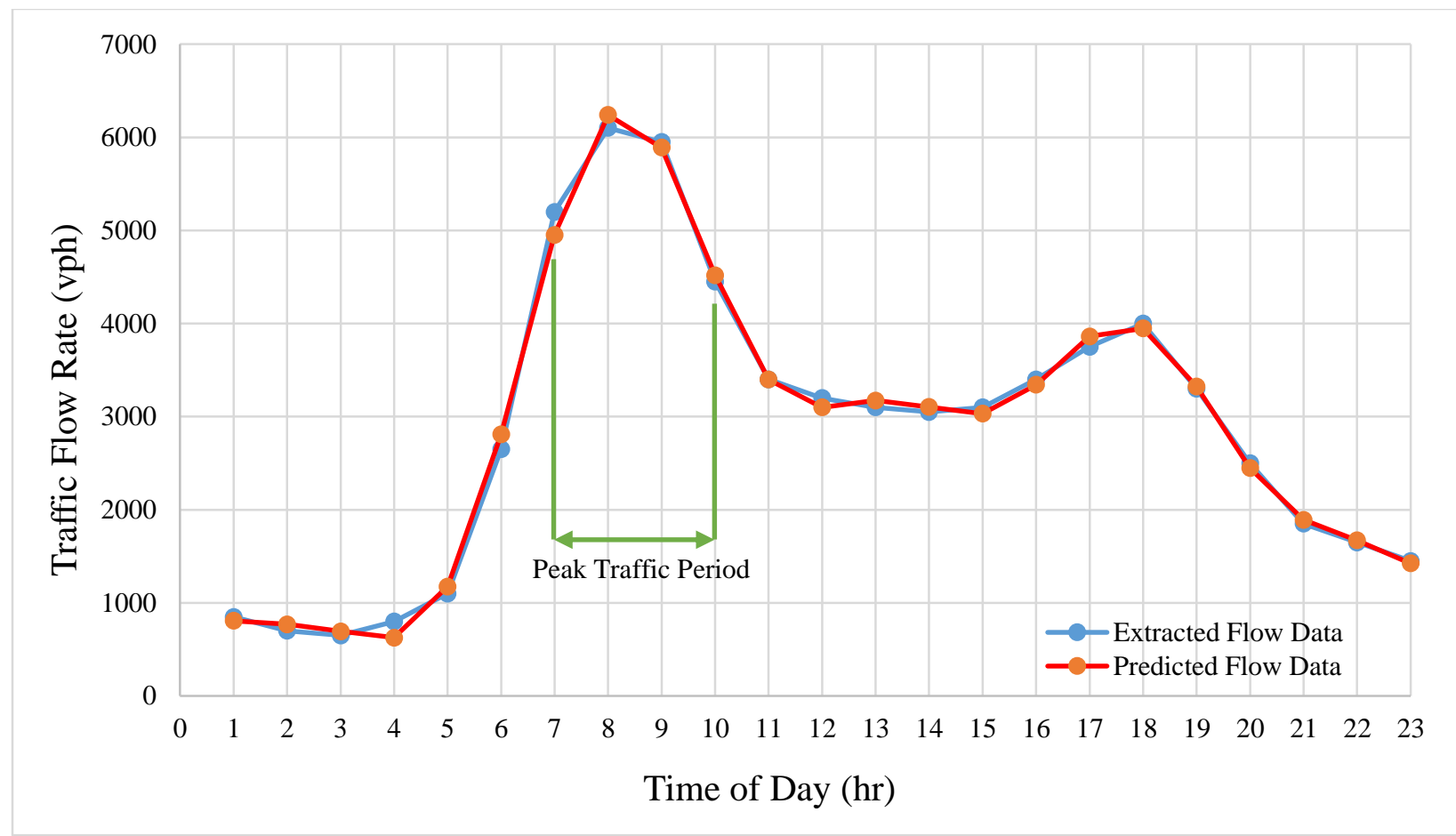

Figure 5.2: I-287 Hourly Traffic Flow Rate Prediction Curve and Extracted Flow Rate Curve

According to the Matlab Curve Fitting tool, the hourly traffic flow represented a Fourier Series with 5 terms, as shown below. " $t$ " denotes the hour of the day.

$$
\begin{aligned}
\mathrm{f}(\mathrm{t})= & \mathrm{a}_{0}+\mathrm{a}_{1} * \cos (\mathrm{t} * \mathrm{w})+\mathrm{b}_{1} * \sin (\mathrm{t} * \mathrm{w})+\mathrm{a}_{2} * \cos \left(2 * \mathrm{t}^{*} \mathrm{w}\right)+\mathrm{b}_{2} * \sin (2 * \mathrm{t} * \mathrm{w})+\mathrm{a}_{3} * \cos \left(3 * \mathrm{t}^{*} \mathrm{w}\right)+ \\
& \mathrm{b}_{3} * \sin \left(3 * \mathrm{t}^{*} \mathrm{w}\right)+\mathrm{a}_{4} * \cos (4 * \mathrm{t} * \mathrm{w})+\mathrm{b}_{4} * \sin (4 * \mathrm{t} * \mathrm{w})+\mathrm{a}_{5} * \cos \left(5 * \mathrm{t}^{*} \mathrm{w}\right)+\mathrm{b}_{5} * \sin \left(5 * \mathrm{t}^{*} \mathrm{w}\right)
\end{aligned}
$$

Coefficients (with 95\% confidence bounds):

$$
\begin{array}{ll}
a_{0}= & 2799(2664,2934) \\
a_{1}= & -1634(-1766,-1501) \\
b_{1}= & 15.9(-259.3,291.1) \\
a_{2}= & -657.3(-905.9,-408.6) \\
b_{2}= & -1005(-1365,-644.6) \\
a_{3}= & 750.5(510.7,990.3) \\
b_{3}= & 266.3(-21.9,554.5) \\
a_{4}= & 70.86(-234.5,92.79)
\end{array}
$$


$b_{4}=345.9(257,434.9)$

$a_{5}=-145.2(-493.8,203.4)$

$b_{5}=\quad-301.5(-420.9,-182.2)$

$w=0.2613(0.2444,0.2783)$

Goodness of fit results:

Summed Square of Residual SSE: 2.072e+05

R-square: 0.9963

Adjusted R-square: 0.9927

RMSE: 137.2

Hence, the proposed traffic flow model successfully predicted the results and used in delay and total flow calculations using integration. It is important to mention that the peak traffic time period was 7:00 AM to 10:00 AM. It is also noteworthy that this model is capable of predicting traffic flow for more than a 24-hour time period, meaning that it can estimate traffic for any time of day from the beginning of the project.

\subsubsection{Work Zone Parameters}

The baseline values of the cost model parameters are presented in Table 5.2. Those values are for the construction of 2-inch asphalt pavement and were extracted from the 2006 Means Heavy Construction Cost Data referred to in Plotner (2005) by Chien and Kyriacos (2015). The available production options $(\mathrm{k})$ are presented in Table 5.3. Those production options were developed by adjusting the baseline labour/equipment cost and daily production data.

In this study, the authors used a delay model applicable for 3 lane freeways. Hence, all of the parameters in Tables 5.2 and 5.3 were applied in this case study. The traffic flow for a four lane highway segment was extracted from the final report from the New Jersey Institute of Technology (2015) and used for the traffic flow of a 3 lane segment. Hence, two lanes were open for traffic during this case study. The heavy vehicle percentage used was $5 \%$. 
Table 5.2: Baseline Values of Input Parameters (Final report - new jersey institute of technology, 2015)

\begin{tabular}{|c|c|c|c|}
\hline Parameters & Definitions & Value & Unit \\
\hline $\mathrm{D}_{\max }$ & Maximum Project Duration & 32 & hour \\
\hline $\mathrm{D}_{\min }$ & Minimum Duration of Maintenance Activities & 3 & hour \\
\hline Peak Hours & Peak Traffic Hour Period & 7:00-10:00 & $\mathrm{AM}$ \\
\hline $\mathrm{L}_{\mathrm{M}}$ & Project Length & 1.8 & mile \\
\hline $\mathrm{R}_{\mathrm{A}}$ & Number of Accidents per 100 Million veh-hour & & \\
\hline $\mathrm{V}_{\mathrm{D}}$ & Monetary Value of Time & 15 & \$/veh-hour \\
\hline $\mathrm{V}_{\mathrm{I}}$ & The Average Idling Cost & 800 & $\$ / \mathrm{hr}$ \\
\hline $\mathrm{V}_{\mathrm{O}}$ & Vehicle Operating Cost & 0.91 & \$/veh-hour \\
\hline $\mathrm{V}_{\mathrm{A}}$ & The Average Cost per Accident & 78000 & $\$$ \\
\hline $\mathrm{Z}_{1}$ & Fixed Setup Cost & 1000 & \$/zone \\
\hline $\mathrm{Z}_{3}$ & Fixed Total Time of Setting and Removing a Zone & 2 & Hours/zone \\
\hline
\end{tabular}

Table 5.3: Unit Maintenance Cost and Production Time (Final report - new jersey institute of technology, 2015)

\begin{tabular}{|c|c|c|}
\hline Crew & $\begin{array}{c}\text { Unit Maintenance Cost } \mathbf{z}_{\mathbf{2}}^{\mathbf{k}} \\
(\$ / \text { /ane-mile) }\end{array}$ & $\begin{array}{c}\text { Unit Production Time } \mathbf{z}_{\mathbf{4}}^{\mathbf{k}} \\
\text { (hour/lane-mile) }\end{array}$ \\
\hline 1 & 24,860 & 6.75 \\
\hline 2 & 24,983 & 5.5 \\
\hline 3 & 25,243 & 4.75 \\
\hline 4 & 26,211 & 3.89 \\
\hline
\end{tabular}

Using the values tabulated above, the solver optimization process was conducted several times for a $1.8 \mathrm{mi}$ work zone case study and one-time period scenario. Each time it generated the minimized cost value and corresponding optimized schedule. The corresponding results for the one-time period are presented in Table 5.4. 
Table 5.4: Optimized Schedules for $1.8 \mathrm{mi}$ - One Period Scenario

\begin{tabular}{|c|c|c|c|}
\hline \multirow{2}{*}{ Optimized Parameter } & \multicolumn{3}{|c|}{ Schedules } \\
\hline & $\mathbf{A}$ & B & $\mathbf{C}$ \\
\hline Starting Time & 12:06:00 PM & 1:30:00 PM & 1:30:00 PM \\
\hline Ending Time & 12:00:00 AM & 12:00:00 AM & 10:30:00 PM \\
\hline Duration (hours) & 11.9 & 10.55 & 9 \\
\hline Maintenance Crew & 2 & 3 & 4 \\
\hline Work Zone Length (mile) & 1.8 & 1.8 & 1.8 \\
\hline Maintenance Cost (\$) & 45,970 & 46,437 & 48,180 \\
\hline Idling Cost (\$) & 0 & 0 & 0 \\
\hline User Delay Cost (\$) & 597 & 523 & 492 \\
\hline Vehicle Operating Cost $(\$)$ & 36 & 32 & 30 \\
\hline Accident Cost (\$) & 124 & 109 & 102 \\
\hline Total User Cost (\$) & 756 & 664 & 624 \\
\hline Emission Cost (\$) & 22 & 20 & 18 \\
\hline Total Cost (\$/Project) & 46,749 & 47,121 & 48,822 \\
\hline Total Cost (\$/Project) - Say & 46,800 & 47,200 & 48,900 \\
\hline
\end{tabular}

Schedule A, which begins at $12.10 \mathrm{pm}$ leads to a minimum cost of $\$ 46,800$ and a project duration of 11.9 hours. There is no idling cost associated with any of the three schedules as maintenance work is scheduled for one-time period only. This is preferable since several time periods would increase the corresponding costs and impact the morning peak traffic duration. Increases in the crew led to reductions in the total duration of the three schedules and increases in the maintenance and total costs. This is discussed in the sensitivity analysis section.

According to the summary of Table 5.4, schedule A is optimal in terms of lowest total project cost. According to the priority of the maintenance activity, agency may prefer schedule $\mathrm{C}$ with the lowest project duration or management decision may be made on schedule B either. 


\subsection{Case Study 2}

The second case study in this report was also conducted using the data obtained from the final report by the New Jersey Institute of Technology (2015). This case study was based on a 5-mile maintenance project on the same facility as case study 1 . All of the baseline input parameters remained the same as the ones in case study 1 except for project duration which was 64 hours instead of 32 hours and project runs which were for 3 and 5 time periods instead of one. The optimization process was conducted several times and generated 3 schedules for each of the 3 and 5time period scenarios. The results are presented in Tables 5.5 to 5.10 (respectively).

Table 5.5: Optimized Schedule A for $5 \mathrm{mi}$ - Three Period Scenario

\begin{tabular}{|l|c|c|c|c|}
\hline \multirow{2}{*}{ Optimized Parameter } & \multicolumn{4}{|c|}{ Schedule A } \\
\cline { 2 - 5 } & $\mathbf{1}$ & $\mathbf{2}$ & $\mathbf{3}$ & Total \\
\hline Starting Time & $5: 05: 00 \mathrm{PM}$ & $6: 55: 00 \mathrm{AM}$ & $10: 05: 00 \mathrm{AM}$ & N/A \\
\hline Ending Time & $6: 55: 00 \mathrm{AM}$ & $10: 05: 00 \mathrm{AM}$ & $12: 00: 00 \mathrm{AM}$ & N/A \\
\hline Duration (hours) & 13.80 & 3.20 & 13.90 & 30.90 \\
\hline Maintenance Crew & 3 & 0 & 3 & N/A \\
\hline Work Zone Length (miles) & 2.48 & 0 & 2.52 & 5.00 \\
\hline Maintenance Cost (\$) & 63,610 & 0 & 64,604 & 128,214 \\
\hline Idling Cost (\$) & 0 & 2,526 & 0 & 2,526 \\
\hline User Delay Cost (\$) & 1,015 & 0 & 1,616 & 2,631 \\
\hline Vehicle Operating Cost (\$) & 62 & 0 & 98 & 160 \\
\hline Accident Cost (\$) & 211 & 0 & 337 & 548 \\
\hline Total User Cost (\$) & 1,288 & 0 & 2,051 & 3,339 \\
\hline Emission Cost (\$) & 18 & 0 & 28 & 46 \\
\hline Total Cost (\$/Project) & 64,916 & 2,526 & 66,683 & 134,125 \\
\hline Total Cost (\$/Project) - Say & $\mathbf{6 5 , 0 0 0}$ & $\mathbf{2 , 6 0 0}$ & $\mathbf{6 6 , 7 0 0}$ & $\mathbf{1 3 4 , 2 0 0}$ \\
\hline
\end{tabular}

According to Table 5.5, the active working hours ranged from 5:05 PM to 6:55 AM and 10:05 AM to 12:00 AM and the duration ranged between $13.8 \mathrm{hrs}$ and $13.9 \mathrm{hrs}$, respectively. Only idling costs were incurred between 6:55 $\mathrm{AM}$ and 10:05 $\mathrm{AM}$ when there was no work to be conducted. The 
total predicted project cost was $\$ 134,200$, and a substantial portion of the total cost involved maintenance costs. The maintenance crew index was 3 for both active working time periods. If the agencies require that the work be completed in less than $30.9 \mathrm{hrs}$, the crew index must be increased and the maintenance work must be sped up. Schedule A can be considered one of the best schedules with 3 periods in order to minimize the total project cost.

Table 5.6: Optimized Schedule B for $5 \mathrm{mi}$ - Three Period Scenario

\begin{tabular}{|l|c|c|c|c|}
\hline \multirow{2}{*}{ Optimized Parameter } & \multicolumn{4}{c|}{ Schedule B } \\
\cline { 2 - 5 } & $\mathbf{1}$ & $\mathbf{2}$ & $\mathbf{3}$ & Total \\
\hline Starting Time & $8: 55: 00 \mathrm{PM}$ & $6: 30: 00 \mathrm{AM}$ & $10: 05: 00 \mathrm{AM}$ & N/A \\
\hline Ending Time & $6: 30: 00 \mathrm{AM}$ & $10: 05: 00 \mathrm{AM}$ & $12: 00: 00 \mathrm{AM}$ & N/A \\
\hline Duration (hours) & 9.5 & 3.6 & 13.9 & 27.00 \\
\hline Maintenance Crew & 4 & 0 & 4 & N/A \\
\hline Work Zone Length (miles) & 1.93 & 0 & 3.07 & 5.00 \\
\hline Maintenance Cost (\$) & 51,604 & 0 & 81,451 & 133,055 \\
\hline Idling Cost (\$) & 0 & 2,880 & 0 & 2,880 \\
\hline User Delay Cost (\$) & 432 & 0 & 1,609 & 2,041 \\
\hline Vehicle Operating Cost (\$) & 27 & 0 & 98 & 125 \\
\hline Accident Cost (\$) & 90 & 0 & 335 & 425 \\
\hline Total User Cost (\$) & 549 & 0 & 2,042 & 2,591 \\
\hline Emission Cost (\$) & 8 & 0 & 27 & 35 \\
\hline Total Cost (\$/Project) & 52,161 & 2,880 & 83,520 & 138,561 \\
\hline Total Cost (\$/Project) - Say & $\mathbf{5 2 , 2 0 0}$ & $\mathbf{2 , 9 0 0}$ & $\mathbf{8 3 , 6 0 0}$ & $\mathbf{1 3 8 , 6 0 0}$ \\
\hline
\end{tabular}

According to Table 5.6, the active working hours ranged from 8:55 PM to 6:30 AM and 10:05 AM to 12:00 AM and the duration ranged between $9.5 \mathrm{hrs}$ and $13.9 \mathrm{hrs}$, respectively. The second time period was identical to schedule A in Table 5.5. Only idling costs were incurred between 6:30 AM and 10:05 AM when there was no work to be conducted. This is only slightly more than schedule A. The total predicted project cost was $\$ 138,600$, and a substantial portion of the total cost involved maintenance costs. The maintenance crew index was 4 (full capacity) for both active 
working time periods, producing a project duration of $27 \mathrm{hrs}$. Schedule B can be considered one of the best schedules with 3 time periods in order to minimize the total project duration.

Table 5.7: Optimized Schedule C for $5 \mathrm{mi}$ - Three Period Scenario

\begin{tabular}{|c|c|c|c|c|}
\hline \multirow{2}{*}{ Optimized Parameter } & \multicolumn{4}{|c|}{ Schedule C } \\
\hline & 1 & 2 & 3 & Total \\
\hline Starting Time & 8:05:00 PM & 6:45:00 AM & 10:10:00 AM & N/A \\
\hline Ending Time & 6:45:00 AM & 10:10:00 AM & 11:00:00 PM & N/A \\
\hline Duration (hours) & 10.7 & 3.4 & 12.8 & 26.9 \\
\hline Maintenance Crew & 4 & 0 & 4 & N/A \\
\hline Work Zone Length (miles) & 2.22 & 0 & 2.78 & 5.00 \\
\hline Maintenance Cost (\$) & 59,242 & 0 & 73,813 & 133,055 \\
\hline Idling Cost (\$) & 0 & 2,740 & 0 & 2,740 \\
\hline User Delay Cost (\$) & 547 & 0 & 1,541 & 2,088 \\
\hline Vehicle Operating Cost (\$) & 33 & 0 & 94 & 127 \\
\hline Accident Cost (\$) & 114 & 0 & 320 & 434 \\
\hline Total User Cost (\$) & 694 & 0 & 1,955 & 2,649 \\
\hline Emission Cost (\$) & 10 & 0 & 26 & 36 \\
\hline Total Cost (\$/Project) & 59,946 & 2,740 & 75,794 & 138,480 \\
\hline Total Cost (\$/Project) - Say & 60,000 & 2,800 & 75,800 & 138,500 \\
\hline
\end{tabular}

According to Table 5.7, the active working hours ranged between 8:05 PM to 6:45 AM and 10:10 AM to 11:00 PM and the duration was $10.7 \mathrm{hrs}$ and $12.8 \mathrm{hrs}$, respectively. The duration of the second period was smaller than schedules A and B in Tables 5.5 and 5.6, respectively. Only idling costs were incurred between 6:45 $\mathrm{AM}$ and 10:10 $\mathrm{AM}$ when there was no work to be conducted. This number is higher than schedule A and lower than schedule B. The total predicted project cost was $\$ 138,500$, and a substantial portion of the total cost involved maintenance costs. The maintenance crew index was 4 (full capacity) for both active working time periods, producing a project duration of $26.9 \mathrm{hrs}$. Schedule $\mathrm{C}$ can be considered the best of the three schedules with 3 time periods in order to minimize the total project duration. 
Table 5.8: Optimized Schedule A for $5 \mathrm{mi}$ - Five Period Scenario

\begin{tabular}{|c|c|c|c|c|c|c|}
\hline \multirow{2}{*}{$\begin{array}{l}\text { Optimized } \\
\text { Parameter }\end{array}$} & \multicolumn{6}{|c|}{ Schedule A } \\
\hline & 1 & 2 & 3 & 4 & 5 & Total \\
\hline Starting Time & 3:20 PM & $8: 40 \mathrm{PM}$ & 9:35 PM & 4:45 AM & 10:15 AM & N/A \\
\hline Ending Time & 8:40 PM & 9:35 PM & 4:45 AM & 10:15 AM & 5:50 AM & N/A \\
\hline Duration (hours) & 5.3 & 0.9 & 7.2 & 5.5 & 19.6 & 38.5 \\
\hline Maintenance Crew & 3 & 0 & 3 & 0 & 2 & N/A \\
\hline $\begin{array}{l}\text { Work Zone Length } \\
\text { (miles) }\end{array}$ & 0.70 & 0 & 1.09 & 0 & 3.21 & 5.00 \\
\hline $\begin{array}{l}\text { Maintenance Cost } \\
\text { (\$) }\end{array}$ & 18,724 & 0 & 28,518 & 0 & 81,139 & 128,381 \\
\hline Idling Cost (\$) & 0 & 691 & 0 & 4,382 & 0 & 5,073 \\
\hline User Delay Cost (\$) & 733 & 0 & 262 & 0 & 1,773 & 2,768 \\
\hline $\begin{array}{l}\text { Vehicle Operating } \\
\text { Cost }(\$)\end{array}$ & 44 & 0 & 16 & 0 & 108 & 168 \\
\hline Accident Cost (\$) & 153 & 0 & 54 & 0 & 369 & 576 \\
\hline Total User Cost (\$) & 930 & 0 & 332 & 0 & 2,250 & 3,512 \\
\hline Emission Cost (\$) & 12 & 0 & 5 & 0 & 31 & 48 \\
\hline $\begin{array}{l}\text { Total Cost } \\
\text { (\$/Project) }\end{array}$ & 19,666 & 691 & 28,855 & 4,382 & 83,420 & 137,014 \\
\hline $\begin{array}{l}\text { Total Cost } \\
\text { (\$/Project) - Say }\end{array}$ & 19,700 & 700 & 28,900 & 4,400 & 83,500 & 137,100 \\
\hline
\end{tabular}

According to Table 5.8, the active working hours ranged between 3:20 PM to 8:40pm, 9:35 PM to 4:45 $\mathrm{AM}$, and 10:15 $\mathrm{AM}$ to 5:50 $\mathrm{AM}$ and the duration was $5.3 \mathrm{hrs}, 7.2 \mathrm{hrs}$ and $19.6 \mathrm{hrs}$, respectively. The duration of the second period was smaller than schedules A and B in Tables 5.5 and 5.6, respectively. Only idling costs were incurred between 8:40 PM to 9:35 PM and 4:45 AM to $10: 15 \mathrm{AM}$ when there was no work to be conducted. The total predicted project cost was $\$$ 137,100 , and a substantial portion of the total cost involved maintenance costs. The maintenance crew index was 3, 3 and 2 for the active working time periods. If the agencies require that the work be completed in less than $38.5 \mathrm{hrs}$, the crew index must be increased and the maintenance work 
must be sped up. Schedule A can be considered one of the best schedules with 5 periods to minimize the total project cost.

Table 5.9: Optimized Schedule B for $5 \mathrm{mi}$ - Five Period Scenario

\begin{tabular}{|c|c|c|c|c|c|c|}
\hline \multirow{2}{*}{$\begin{array}{l}\text { Optimized } \\
\text { Parameter }\end{array}$} & \multicolumn{6}{|c|}{ Schedule B } \\
\hline & $\mathbf{1}$ & 2 & 3 & 4 & 5 & Total \\
\hline Starting Time & $5: 25 \mathrm{PM}$ & $10: 15 \mathrm{PM}$ & $10: 15$ PM & $5: 00 \mathrm{AM}$ & $10: 30 \mathrm{AM}$ & N/A \\
\hline Ending Time & $10: 15$ PM & 10:15 PM & 5:00 AM & $10: 30 \mathrm{AM}$ & $4: 45$ AM & N/A \\
\hline Duration (hours) & 4.8 & 0 & 6.75 & 5.5 & 18.25 & 35.3 \\
\hline Maintenance Crew & 4 & 0 & 2 & 0 & 3 & N/A \\
\hline $\begin{array}{l}\text { Work Zone Length } \\
\text { (miles) }\end{array}$ & 0.72 & 0 & 0.87 & 0 & 3.41 & 5.00 \\
\hline $\begin{array}{l}\text { Maintenance Cost } \\
(\$)\end{array}$ & 19,939 & 0 & 22,573 & 0 & 87,092 & 129,604 \\
\hline Idling Cost (\$) & 0 & 0 & 0 & 4,400 & 0 & 4,400 \\
\hline User Delay Cost (\$) & 518 & 0 & 230 & 0 & 1,656 & 2,404 \\
\hline $\begin{array}{l}\text { Vehicle Operating } \\
\text { Cost }(\$)\end{array}$ & 31 & 0 & 14 & 0 & 101 & 146 \\
\hline Accident Cost (\$) & 108 & 0 & 48 & 0 & 344 & 500 \\
\hline Total User Cost (\$) & 657 & 0 & 292 & 0 & 2,101 & 3,050 \\
\hline Emission Cost (\$) & 9 & 0 & 5 & 0 & 29 & 43 \\
\hline $\begin{array}{l}\text { Total Cost } \\
\text { (\$/Project) }\end{array}$ & 20,605 & 0 & 22,870 & 4,400 & 89,222 & 137,097 \\
\hline $\begin{array}{l}\text { Total Cost } \\
\text { (\$/Project) - Say }\end{array}$ & 20,700 & $\mathbf{0}$ & 22,900 & 4,400 & 89,300 & 137,100 \\
\hline
\end{tabular}

According to Table 5.9, the active working hours ranged between 5:25 PM to 5:00 AM and 10:30 AM to 4:45 AM and the duration was $11.55 \mathrm{hrs}$ and $18.25 \mathrm{hrs}$, respectively. There was no idling time in time period 2 and maintenance activities are to be conducted until the end of time period 3. No idling costs occurred during this period and can therefore be neglected. Only idling costs were incurred between 5:00 AM and 10:30 AM when there was no work to be conducted. This is identical to the $4^{\text {th }}$ period of schedule A in Table 5.8. The total predicted project cost was $\$ 137,100$, 
and a substantial portion of the total cost involved maintenance costs. The maintenance crew index was 4, 2 and 3 for the active working time periods. Schedule B can be considered one of the best schedules with 5 periods in order to minimize the total project duration and cost.

Table 5.10: Optimized Schedule C for $5 \mathrm{mi}$ - Five Period Scenario

\begin{tabular}{|l|c|c|c|c|c|c|}
\hline \multirow{2}{*}{\begin{tabular}{c}
\multicolumn{1}{c}{ Optimized } \\
Parameter
\end{tabular}} & $\mathbf{1}$ & $\mathbf{2}$ & $\mathbf{3}$ & $\mathbf{4}$ & $\mathbf{5}$ & Total \\
\cline { 2 - 7 } & $5: 00 \mathrm{PM}$ & $10: 40 \mathrm{PM}$ & $11: 20 \mathrm{PM}$ & $6: 45 \mathrm{AM}$ & $10: 20 \mathrm{AM}$ & N/A \\
\hline Starting Time & $10: 40 \mathrm{PM}$ & $11: 20 \mathrm{PM}$ & $6: 45 \mathrm{AM}$ & $10: 20 \mathrm{AM}$ & $6: 10 \mathrm{AM}$ & N/A \\
\hline Ending Time & 5.6 & 0.7 & 7.4 & 3.6 & 19.9 & 37.2 \\
\hline Duration (hours) & 3 & 0 & 2 & 0 & 2 & N/A \\
\hline Maintenance Crew & 0.76 & 0 & 0.99 & 0 & 3.25 & 5.00 \\
\hline $\begin{array}{l}\text { Work Zone Length } \\
\text { (miles) }\end{array}$ & 20,208 & 0 & 25,605 & 0 & 82,301 & 128,114 \\
\hline $\begin{array}{l}\text { Maintenance Cost } \\
\text { \$) }\end{array}$ & 0 & 523 & 0 & 2,863 & 0 & 3,386 \\
\hline Idling Cost (\$) & 613 & 0 & 440 & 0 & 1,788 & 2,841 \\
\hline User Delay Cost (\$) & 38 & 0 & 27 & 0 & 109 & 174 \\
\hline $\begin{array}{l}\text { Vehicle Operating } \\
\text { Cost (\$) }\end{array}$ & 128 & 0 & 92 & 0 & 372 & 592 \\
\hline Accident Cost (\$) & 779 & 0 & 559 & 0 & 2,269 & 3,607 \\
\hline Total User Cost (\$) & 10 & 0 & 6 & 0 & 31 & 47 \\
\hline Emission Cost (\$) & 20,997 & 523 & 26,170 & 2,863 & 84,601 & 135,154 \\
\hline $\begin{array}{l}\text { Total Cost } \\
\text { (\$/Project) }\end{array}$ & $\mathbf{6 0 0}$ & $\mathbf{2 6 , 2 0 0}$ & $\mathbf{2 , 9 0 0}$ & $\mathbf{8 4 , 7 0 0}$ & $\mathbf{1 3 5 , 2 0 0}$ \\
\hline Total Cost & & & & & & \\
\hline
\end{tabular}

According to Table 5.10, the active working hours ranged between 5:00 PM to 10:40 PM, 11:20 PM to 6:45 AM and 10:20 AM to 6:10 AM and the duration was 5.6 hrs, $7.4 \mathrm{hrs}$ and $19.9 \mathrm{hrs,}$ respectively. Only idling costs were incurred between 10:40 PM and 11:20 PM and 6:45 AM and 10:20 AM when there was no work to be conducted. The total predicted project cost was $\$ 135,200$, and a substantial portion of the total cost involved maintenance costs. The maintenance crew index was 3, 2 and 2 for the active working time periods. Schedule $C$ can be considered one of the best 
schedules with 5 time periods between the three schedules discussed above in order to minimize the total project cost.

As we can see from Tables 5.5 to 5.10, different optimized schedules are available for 3 and 5 time periods. In the 3 period scenario, $2^{\text {nd }}$ period is idling duration while $2^{\text {nd }}$ and $4^{\text {th }}$ are idling durations in 5 periods scenario. 3 time periods would be best if the priority is the earliest completion of 5mile maintenance project. Generally, lower time durations tend to generate higher costs as agencies have to employ more crew.

\subsection{Sensitivity Analysis}

A sensitivity analysis was conducted for case study 1 by considering the total costs, crew index and project duration. The maintenance costs and total costs were compared to the crew index. The crew index varied from 2 to 4 and the corresponding cost types were evaluated and presented in Figure 5.3. The results reveal that increases in the crew index generate higher total and maintenance costs.

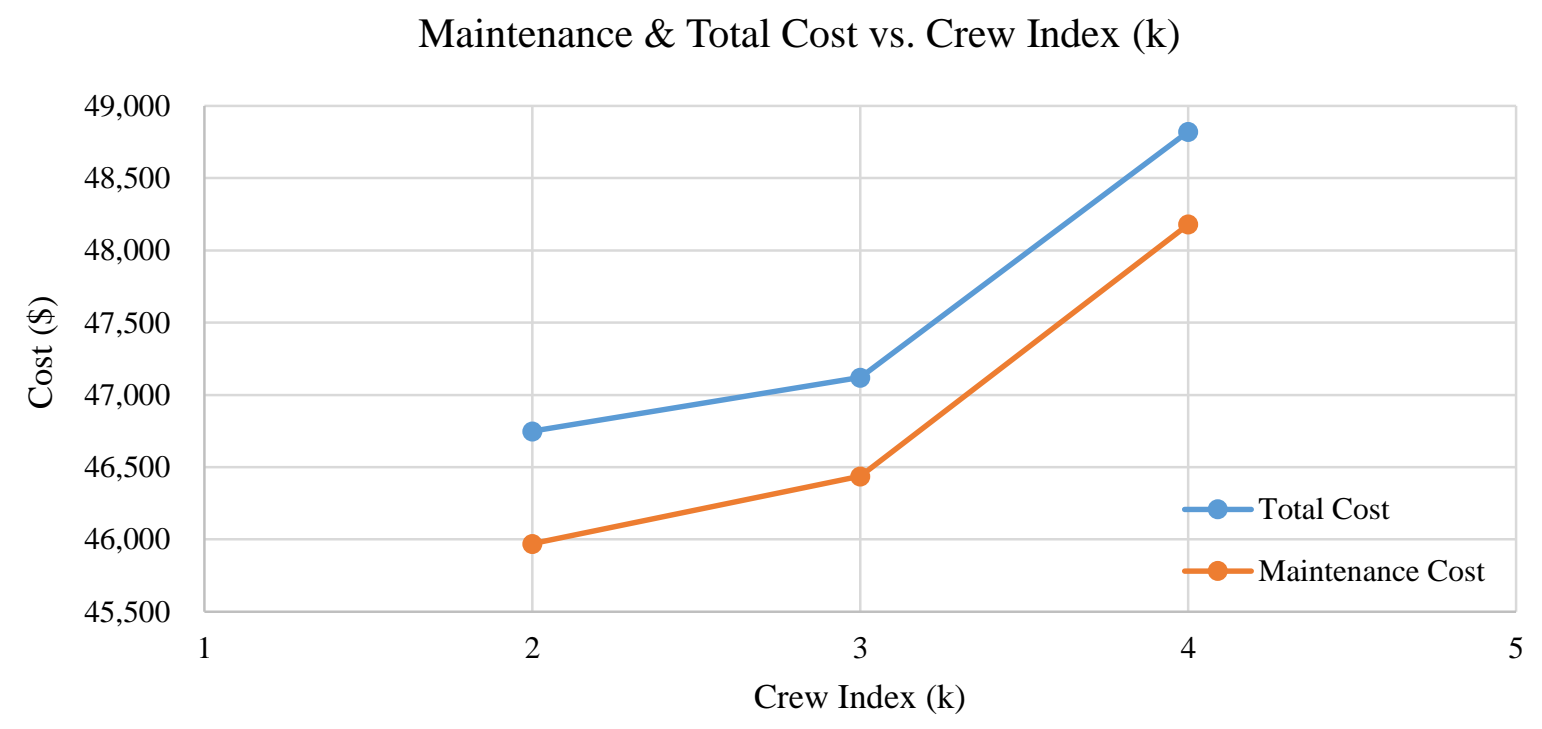

Figure 5.3: Maintenance and Total Cost vs. Crew Index (k)

The total project duration was compared to the crew index. The crew index varied from 2 to 4 and the corresponding project durations were evaluated and presented in Figure 5.4. The results indicate that increases in the crew index generate lower project durations. The maintenance and 
total project cost were compared to the project durations. The results in Figure 5.5 indicate that lower project durations generate higher costs while longer durations account for reduced costs.

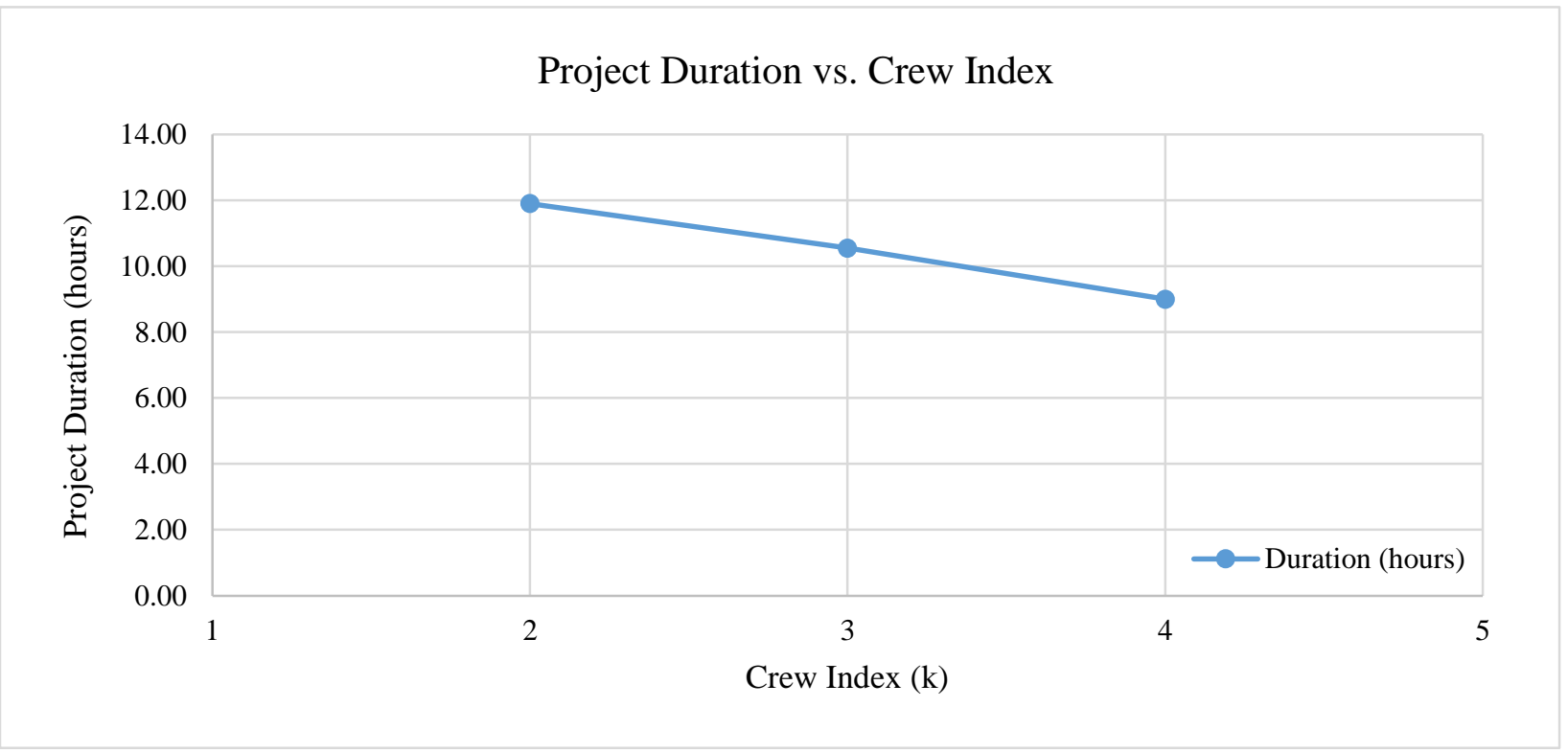

Figure 5.4: Project Duration vs. Crew Index (k)

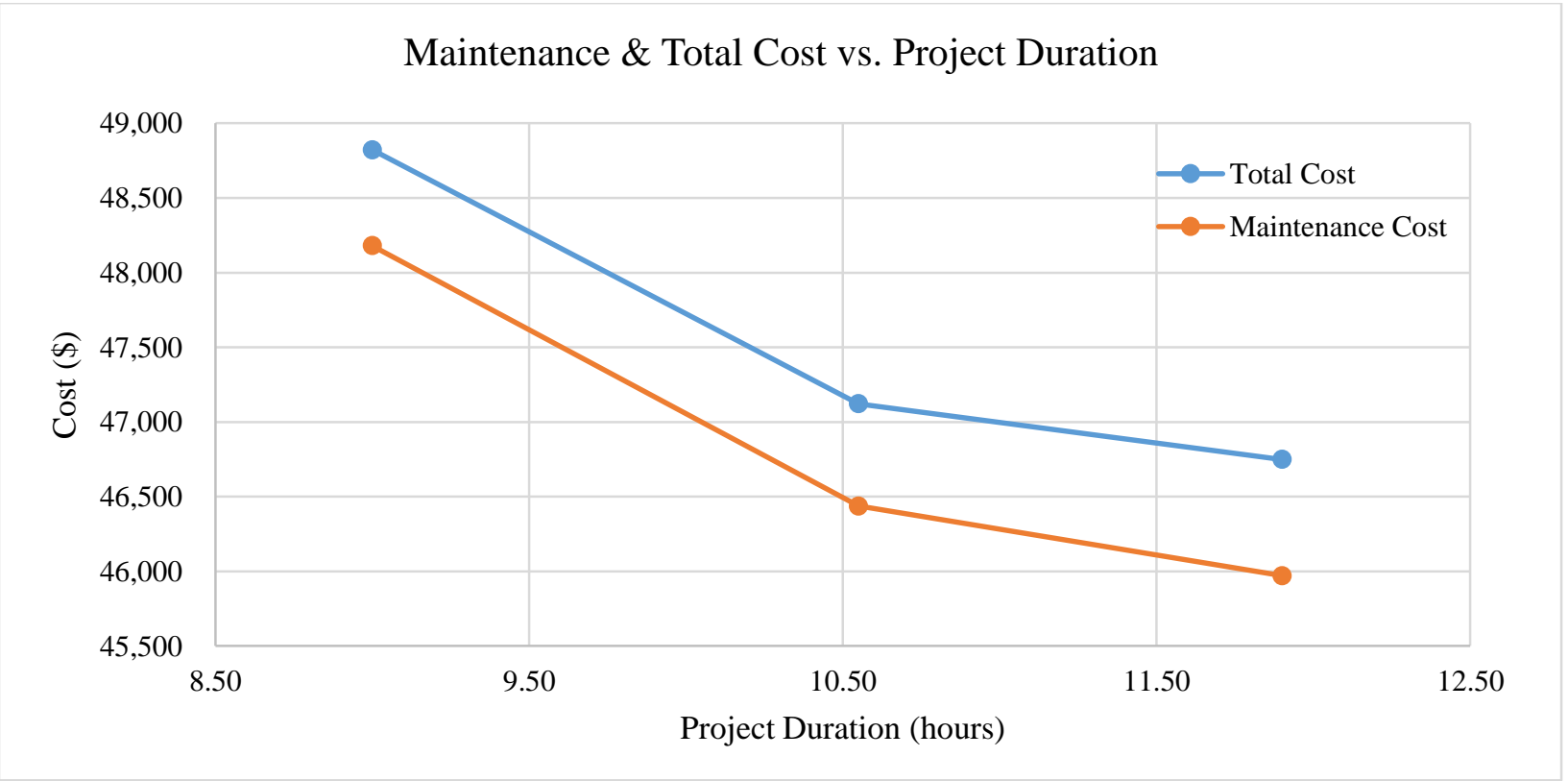

Figure 5.5: Maintenance and Total Cost vs. Project Duration 
A sensitivity analysis was conducted for Schedule C - 5 periods of case study 2. Here, the hourly traffic volume level on the I-287 facility varied between $-40 \%$ to $40 \%$ of the traffic volume. The total cost with respect to the hourly traffic volumes were calculated and evaluated. Table 5.11 shows the corresponding results.

Table 5.11: Hourly Traffic Volume vs. Total Project Cost (Schedule C-5 Periods 5-mi)

\begin{tabular}{|c|c|}
\hline Traffic Volume Ranged \% & Total Cost \\
\hline-40 & 133,600 \\
\hline-30 & 133,900 \\
\hline-20 & 134,300 \\
\hline-10 & 134,700 \\
\hline 0 & 135,200 \\
\hline 10 & 135,800 \\
\hline 20 & 136,400 \\
\hline 30 & 137,100 \\
\hline 40 & 137,900 \\
\hline
\end{tabular}

Figure 5.6 illustrates values of the table above. The results indicate that the total project cost increases as the hourly traffic volume increases.

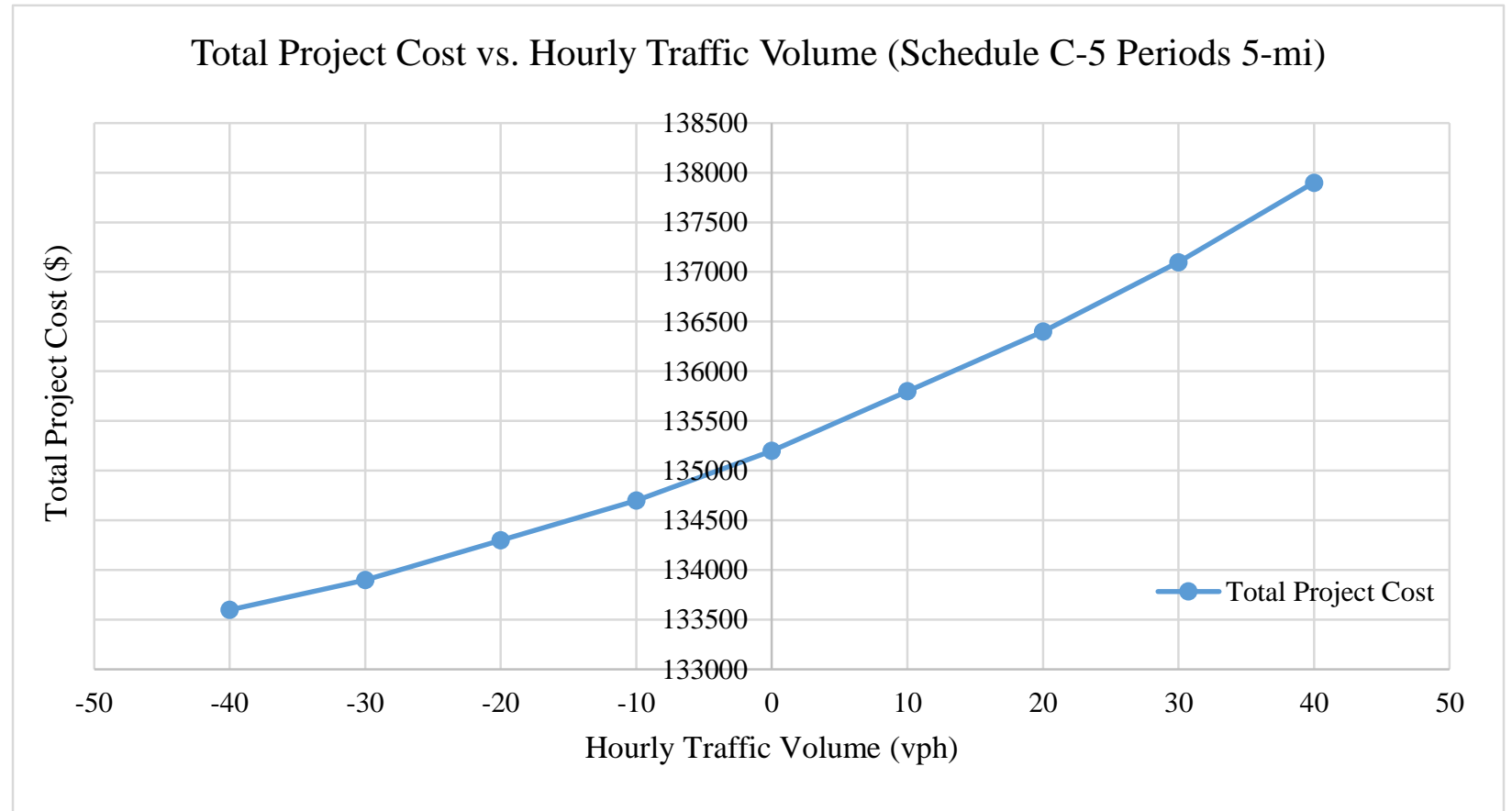

Figure 5.6: Total Project Cost vs. Hourly Traffic Volume Change \% (Schedule C 5-mi) 


\section{CHAPTER 6}

\section{CONCLUSIONS AND FUTURE RESEARCH}

\subsection{Summary of the Thesis}

A substantial portion of each country's present freeways is in poor, moderate, or fair condition. In order to keep the current freeways usable and safe, state and federal transportation agencies have been focusing on maintenance activities in recent years. According to economic analysis, billions of dollars are lost due to non-recurring delays generated by work zones around the nation. One of the principle contributors to delay is capacity reduction due to lane closures and bottlenecks. The resulting interruption to live traffic may significantly affect travel times while creating a hazardous environment for road users and workers. Moreover, these disruptions generate a high volume of emissions and pollutants.

In order to strategically address the aforementioned drawbacks, the Federal Highway Administration has employed the concept of comprehensive Transportation Management Plans (TMPs). TMPs are an innovative combination of valuable strategies comprised of optimized schedules, temporary traffic control measures, encompassing management plans, traffic operation management, safety management, and economic factors. The majority of federal, state, and local highway agencies are now developing and implementing TMPs for planned work zones. As far as mobility and safety should be maximized according to the increasing need of road users, optimized schedules in TMPs remain a challenging task for officials. This challenge may enhance due to the scale and complexity of the project increase.

To support relevant agencies and contractors in the implementation of effective transportation management plans, a comprehensive methodology has been developed in this study to evaluate optimized work zone schedules with minimized total cost. Following a comprehensive review of current trends and future needs of work zone optimization (Chapter 2), the primary objectives were established and priorities were identified. In Chapter 3, a microscopic work zone simulation model was developed using the CORSIM tool with a large number of possible scenarios to evaluate work zone delay and average speed. The decision variables were identified as hourly traffic volume, activity area length, number of open lanes, and heavy vehicle percentage. Innovative multi- 
regression models were developed for delay and average speed using the simulated results in CORSIM.

An improved analytical work zone cost model was developed in Chapter 4 to calculate the total project cost (agency and road users). User delay cost was calculated by incorporating the delay models developed in Chapter 3. Moreover, a novel hourly traffic flow model was developed to support the calculating and integration processes of total delay and flow in the total project cost. A solver optimization based algorithm was developed to search for optimal solutions to proposed work zone schedule optimization problems. Excel Solver optimization was used to find optimal work zone schedules. Chapter 5 evaluated the capability and feasibility of the proposed optimization model using real world case studies. The proposed model quite successfully generated optimal work zone schedules and minimized project costs.

\subsection{Research Contributions}

The main contributions of this study are as follows:

(1) A comprehensive review of freeway work zones and their applications

Work zones, main components, temporary traffic controls, and relevant measures are thoroughly discussed. A review of freeway applications was conducted as a part of this research study and published in Pilanavithana et al. (2018). The important elements of the reviewed publications were tabulated in order to provide readers with quick access to relevant references. In this literature assessment, applications are made on all major aspects named; Mobility, Safety, Driver Behaviour, and Cost and Planning of work zones.

(2) The development of a work zone simulation model to address and represent real world scenarios

Microsimulation is widely used to simulate real world applications. The CORSIM software was extensively used in this study to develop a work zone model. The freeway network was established using the FRESIM module and the relevant decision variables were changed in order to simulate the pre-defined scenarios. Measure of Effectiveness (MOEs) were used to evaluate delay and average speed. The CORSIM software performed quite well and lane add and closure options give 
users more road network customization options according to their needs. CORSIM is highly recommended for work zone simulations.

(3) The development of innovative multi-regression models for work zone delay and average speed

In order to evaluate work zone delay and average speed, it is necessary to have precise prediction models. Although there are many existing prediction models, these models are complex and require more user input data. There is therefore a need for more practical and user friendly models for delay and average speed. In this study, the authors developed multi-regression models using microsimulation results. The main decision variables were hourly traffic flow, activity area length, number of open lanes, and heavy vehicle percentage. The developed regression models successfully predicted delay and average speed.

(4) The development of a novel model to estimate traffic flow

In order to predict traffic flow at any given time, it is necessary to establish accurate estimation models. In this study, the authors developed a new estimation model using field data from a final report by the New Jersey Institute of Technology (2015). The developed model is continuous and comprised of the Fourier Series. The model is capable of estimating traffic at any given time of day and upcoming days for any given road.

(5) The improvement of analytical cost models to evaluate total project cost

The cost model developed by Chien and Kyriacos (2015) was improved using the innovative delay model and traffic flow model developed in this study. The analytic model developed in this study takes into account the agency costs (including maintenance and idling costs) and road user costs (including delay cost, vehicle operating cost, accident cost and emission cost). The traffic flow and delay estimations of previous approaches were complicated and less accurate. With this improved analytical cost model, agencies and contractors can easily evaluate the total project costs according to background information and user inputs. 
(6) The incorporation of Solver software for optimization

Many studies have made use of complex optimization methodologies using Genetic Algorithms and Neural Networks. While highly precise, these tools require more user inputs and contain a complicated framework, making them more complex and time consuming to apply at the industry level. It is therefore essential to explore a more convenient and practical optimization tool. In this study, the solver software built into Microsoft Excel was used in the optimization process. It is more user oriented and less complex. The applicability of this software was examined using case studies.

(7) The development of an efficient algorithm to solve the optimization problem

A heuristic algorithm was developed to solve the work zone scheduling optimization problem in the Excel-based solver. In this algorithm, random start and end time values and production indices are predicted for given periods in the schedule and the corresponding total cost is calculated. If the proposed time periods lie within the pre-defined congested flow period, those time intervals are rejected by the logic developed and the process is started again. Successful candidate time periods are saved in the solution pool and the program searches for the minimum cost over the solutions. The minimized cost and corresponding time values are presented at the end. Processing times are increased along with increases in the active and idling time periods.

(8) Simulation based - optimized scheduling for the transportation management planning of work zones

Incorporating all of the above contributions, this study involved the development of simulationbased optimized multi-dimensional schedules to minimize work zone costs using a Solver. By considering a realistic, continuous time-cost relationship and dynamic traffic demands, this study delivers a real-world approach to scheduling minimum cost operations for freeway maintenance. The predicted start and end time values consisted of both active and idling working periods. The simulation-based user delay cost is more realistic than traditional moving and queuing delay models. By embedding more accurate parameter values and input data, the precision of the predictions is increased. 
(9) Estimating work intensity in terms of the crew index and optimal sub-sectional length

During the optimization, the program justifies the required man/equipment power in terms of the crew index that should be used by the agency or contractor. The work zone scheduling also delivers the optimal sub-sectional lengths to be completed in order to minimize the total cost. This valuable information can be incorporated into transportation management plans.

\subsection{Future Research}

This research study addressed several research gaps in the development of work zone scheduling optimization models. Despite the successful application of the proposed work zone optimization model, the authors recognize that there is room for improvement. The following are suggestions for future work zone research:

(1) The extension of the microsimulation model to incorporate the proximity of interchanges is valuable as diverted traffic and associated delays can be incorporated into the delay models. Furthermore, future research should explore other work zone lane drop configurations that are followed by a lane shift or crossover within the work zone to explore relative capacities and potential queue interaction effects.

(2) Work zone simulation calibration for the merge, diverge and weaving segments of the facility is recommended for future research. More research attention is needed for those complicated scenarios as they are practical and take place in real-world situations.

(3) It may be necessary to re-examine several variables that were not selected in the final microsimulation models in order to enhance the accuracy of the models. These variables include the merge concept, work intensity, driver behaviour, signage and police enforcement, and intelligent transport systems.

(4) In this study and previous studies, the impact of work zones on safety was evaluated using the accident cost which involves a simple model relating accident rates to total user delays. In reality, accident rates during road construction may be attributed to environmental factors, lighting conditions, work zone length, work intensity, heavy vehicle percentage, driver 
characteristics...etc. The incorporation of these factors would enhance the accident cost prediction accuracy.

(5) The current study used a simplified cost model to evaluate operating and emission costs, but the Measure of effectiveness (MOEs) of the CORSIM software generates output results for fuel consumption and emissions. Future research can include these data to modify operating and emission models to improve practicality.

(6) According to the 2011 FHWA report on work zone road user costs, cost aspects such as timerelated vehicle depreciation costs due to delays and vehicle operating costs by vehicle types should be considered in future research. Potential researchers can refer to the above report for the refinement of the cost model.

(7) With the current advances in science and technology, autonomous vehicles will be penetrating the market very soon. The functionality of work zone aspects in the presence of autonomous vehicles will change current applications and future research must focus on smart work zones with driverless vehicle technologies.

(8) Field validation is recommended for the developed models and optimization processes. While the current simulations and optimization processes yield sensible results, it would be appropriate for the results to be compared with and validated using field applications.

(9) Multi-objective optimization is paramount for transportation agencies and contractors to optimize work zones by minimizing or maximizing two or more objective functions such as delay and cost, delay and accidents... etc. This would be vital for future research as two or more aspects are taken in to consideration at the same time. 
APPENDICES 
APPENDIX A 
1. The CORSIM TRAFED window for work zone network development is shown in Figure A.1.

2. A developed work zone network diagram in the FRESIM module of the CORSIM microsimulation tool for one lane closure on a 3 lane freeway is shown in Figure A.2.

3. A developed work zone network diagram in the FRESIM module of the CORSIM microsimulation tool for two lane closures on a 3 lane freeway is shown in Figure A.3.

4. An animation window of one lane closure on a 3 lane freeway work zone in the FRESIM module is shown in Figure A.4. 
$=\mathrm{A}$

Corsin City
EV Demo

Incident Demo
Interchange Demo

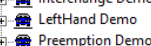

Th

- Two-Lane Highway Demo

7 - Vdila Practice

- Work Zone

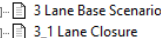

3-1 Lane Closure
(-⿴囗十) Network (".tno)

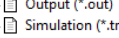

(4)- 3.2 Lane Closure

T-D Joint Merge

由-口 TEST

- T TEST2
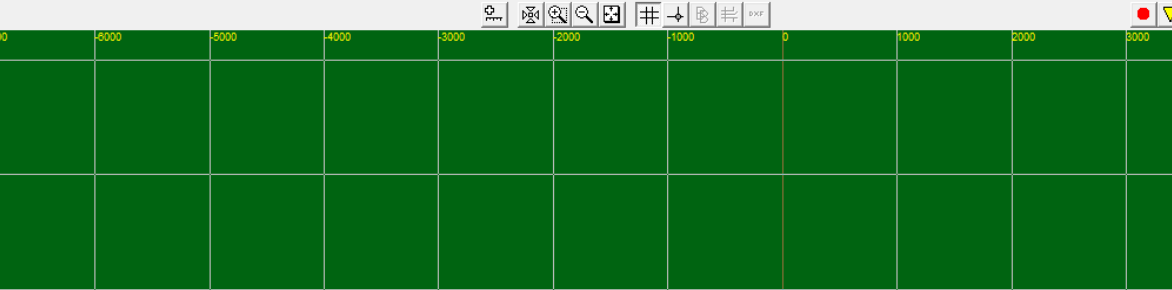

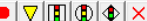

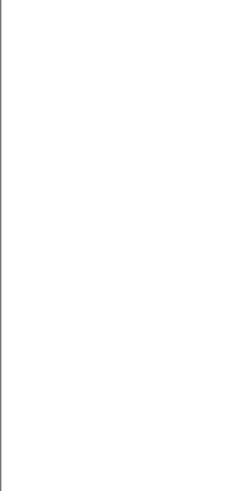

Welcomel TRAFED

1811.0, 4165:

由

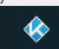

日 $\mathrm{B} 9$ -

w目

9 晜

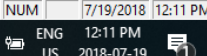

Figure A.1: CORSIM TRAFED Window for Work Zone Network Development 


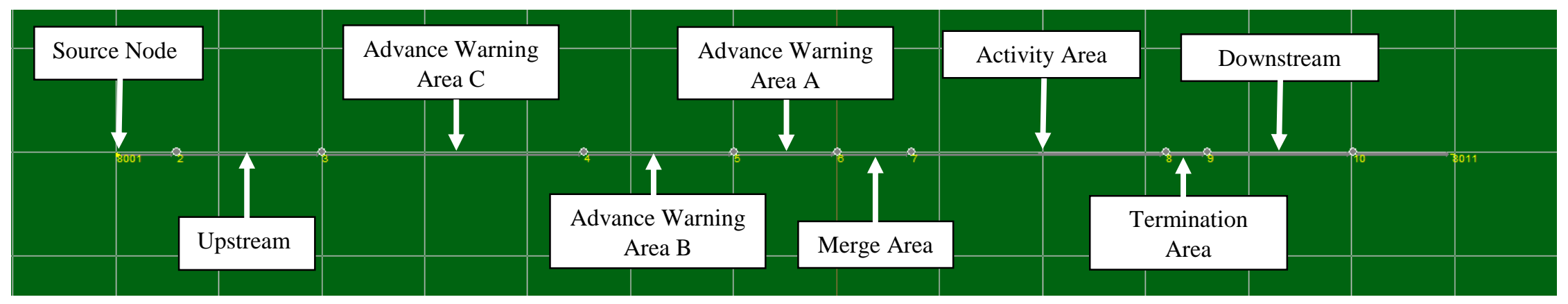

Figure A.2: Closer Image of 1 Lane Closure of 3 Lane Freeway Work Zone Network in the FRESIM Module 


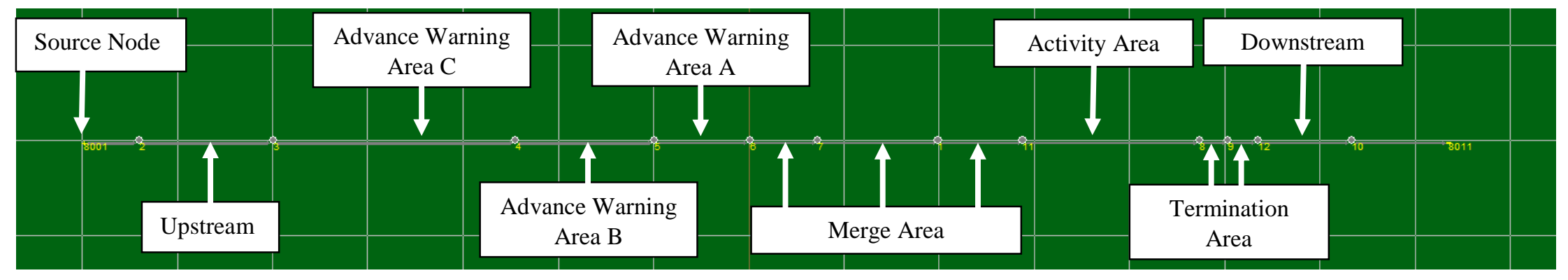

Figure A.3: Closer Image of 2 Lane Closure of 3 Lane Freeway Work Zone Network in the FRESIM Module 


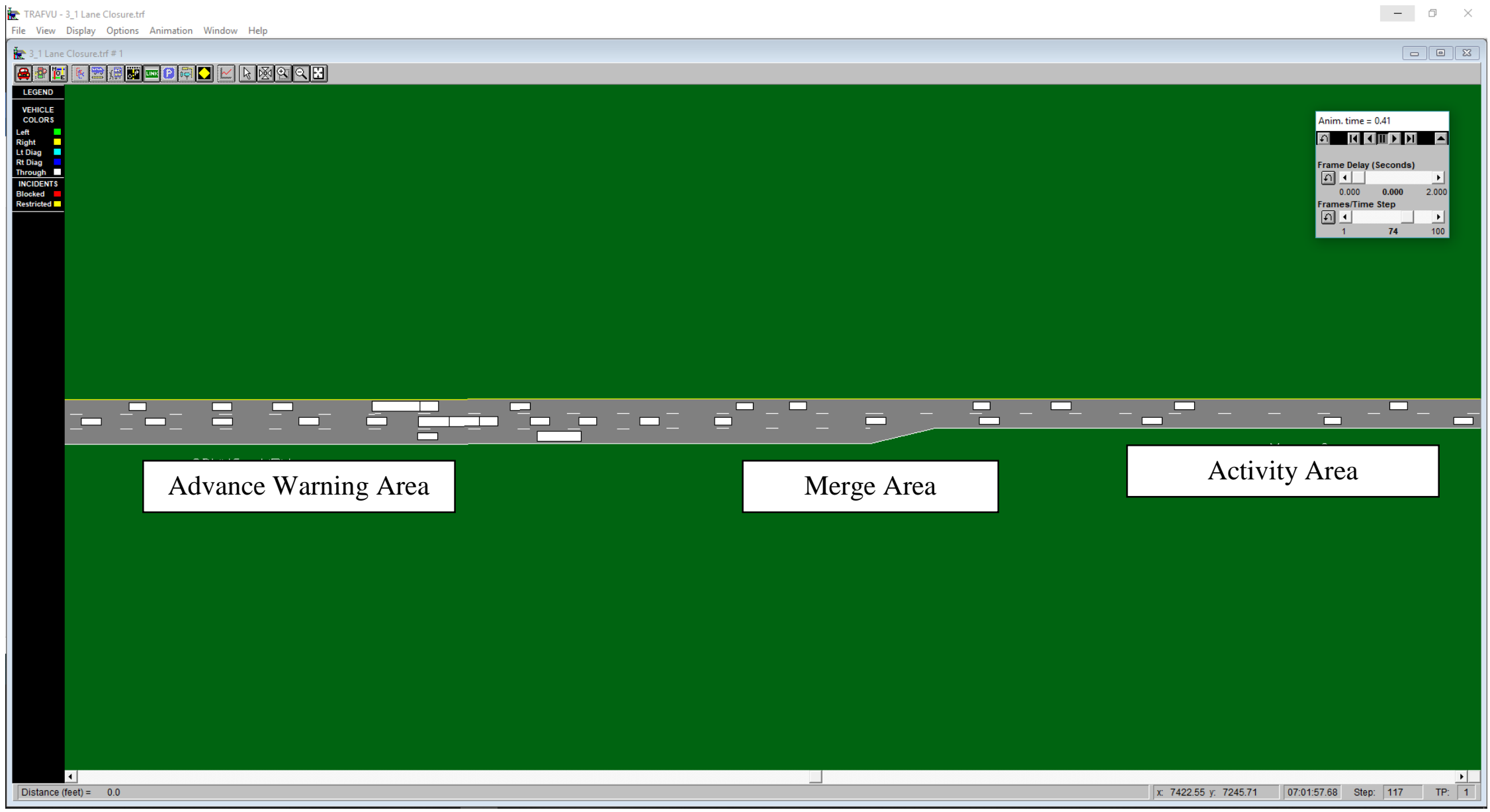

Figure A.4: Animation Window of a Freeway Work Zone Network in the FRESIM Module 
APPENDIX B 
1. Table B.1. shows all of the simulation scenarios corresponding to the undersaturated condition for a $50 \mathrm{mph}$ speed limit. The average delay and speed results are mentioned in separate columns.

2. Table B.2. shows all of the simulation scenarios corresponding to the saturated condition for a $50 \mathrm{mph}$ speed limit. The average delay and speed results are mentioned in separate columns.

3. Table B.3. shows all of the simulation scenarios corresponding to the undersaturated condition for a $55 \mathrm{mph}$ speed limit. The average delay and speed results are mentioned in separate columns.

4. Table B.4. shows all of the simulation scenarios corresponding to the saturated condition for a $55 \mathrm{mph}$ speed limit. The average delay and speed results are mentioned in separate columns. 
Table B.1: Undersaturated Condition - $50 \mathrm{mph}$ Speed Limit

\begin{tabular}{|c|c|c|c|c|c|c|c|c|c|}
\hline $\begin{array}{c}\text { Scenario } \\
\text { ID }\end{array}$ & $\begin{array}{c}\text { Flow } \\
\text { (veh/h/ln) }\end{array}$ & $\begin{array}{c}\text { Activity } \\
\text { Length } \\
\text { (ft) }\end{array}$ & $\begin{array}{l}\text { Merge } \\
\text { Length }\end{array}$ & $\begin{array}{c}\text { Number } \\
\text { of Open } \\
\text { Lanes }\end{array}$ & $\underset{\%}{\mathbf{H V}}$ & $\begin{array}{c}\text { Speed } \\
\text { Limit } \\
(\mathrm{mi} / \mathrm{hr})\end{array}$ & $\begin{array}{c}\text { FFS } \\
(\mathbf{m i} / \mathbf{h r})\end{array}$ & $\begin{array}{c}\text { Average } \\
\text { Delay } \\
\text { (sec/veh) }\end{array}$ & $\begin{array}{c}\text { Average } \\
\text { Speed } \\
(\mathbf{m i} / \mathbf{h r})\end{array}$ \\
\hline 1 & 500 & 1000 & 600 & 2 & 0 & 50 & 60 & 1.90 & 55.23 \\
\hline 2 & 500 & 1000 & 2400 & 1 & 0 & 50 & 60 & 4.54 & 53.51 \\
\hline 3 & 1000 & 1000 & 600 & 2 & 0 & 50 & 60 & 4.75 & 54.09 \\
\hline 4 & 1500 & 1000 & 600 & 2 & 0 & 50 & 60 & 8.99 & 52.48 \\
\hline 5 & 500 & 1500 & 600 & 2 & 0 & 50 & 60 & 1.99 & 55.08 \\
\hline 6 & 500 & 1500 & 2400 & 1 & 0 & 50 & 60 & 5.23 & 53.17 \\
\hline 7 & 1000 & 1500 & 600 & 2 & 0 & 50 & 60 & 5.11 & 53.88 \\
\hline 8 & 1500 & 1500 & 600 & 2 & 0 & 50 & 60 & 9.30 & 52.1 \\
\hline 9 & 500 & 2000 & 600 & 2 & 0 & 50 & 60 & 2.33 & 54.7 \\
\hline 10 & 500 & 2000 & 2400 & 1 & 0 & 50 & 60 & 6.10 & 52.8 \\
\hline 11 & 1000 & 2000 & 600 & 2 & 0 & 50 & 60 & 5.47 & 53.56 \\
\hline 12 & 1500 & 2000 & 600 & 2 & 0 & 50 & 60 & 10.11 & 51.78 \\
\hline 13 & 500 & 2500 & 600 & 2 & 0 & 50 & 60 & 2.45 & 54.32 \\
\hline 14 & 500 & 2500 & 2400 & 1 & 0 & 50 & 60 & 6.65 & 52.62 \\
\hline 15 & 1000 & 2500 & 600 & 2 & 0 & 50 & 60 & 5.83 & 53.13 \\
\hline 16 & 1500 & 2500 & 600 & 2 & 0 & 50 & 60 & 10.67 & 51.51 \\
\hline 17 & 500 & 3000 & 600 & 2 & 0 & 50 & 60 & 2.47 & 54.21 \\
\hline 18 & 500 & 3000 & 2400 & 1 & 0 & 50 & 60 & 7.46 & 52.14 \\
\hline 19 & 1000 & 3000 & 600 & 2 & 0 & 50 & 60 & 6.77 & 52.67 \\
\hline 20 & 1500 & 3000 & 600 & 2 & 0 & 50 & 60 & 11.48 & 51.12 \\
\hline 21 & 500 & 3500 & 600 & 2 & 0 & 50 & 60 & 2.86 & 53.76 \\
\hline 22 & 500 & 3500 & 2400 & 1 & 0 & 50 & 60 & 8.11 & 51.7 \\
\hline 23 & 1000 & 3500 & 600 & 2 & 0 & 50 & 60 & 6.78 & 52.58 \\
\hline 24 & 500 & 4000 & 600 & 2 & 0 & 50 & 60 & 2.90 & 53.65 \\
\hline 25 & 500 & 4000 & 2400 & 1 & 0 & 50 & 60 & 8.93 & 51.54 \\
\hline 26 & 1000 & 4000 & 600 & 2 & 0 & 50 & 60 & 7.49 & 52.23 \\
\hline 27 & 1500 & 4000 & 600 & 2 & 0 & 50 & 60 & 12.84 & 50.61 \\
\hline 28 & 1500 & 3500 & 600 & 2 & 0 & 50 & 60 & 12.25 & 50.86 \\
\hline 29 & 500 & 1000 & 600 & 2 & 2 & 50 & 60 & 1.94 & 55.49 \\
\hline 30 & 500 & 1000 & 2400 & 1 & 2 & 50 & 60 & 4.99 & 53.34 \\
\hline 31 & 1000 & 1000 & 600 & 2 & 2 & 50 & 60 & 4.73 & 54.1 \\
\hline 32 & 500 & 1500 & 600 & 2 & 2 & 50 & 60 & 2.09 & 55.15 \\
\hline 33 & 500 & 1500 & 2400 & 1 & 2 & 50 & 60 & 5.42 & 53.18 \\
\hline 34 & 1000 & 1500 & 600 & 2 & 2 & 50 & 60 & 5.17 & 53.86 \\
\hline 35 & 500 & 2000 & 600 & 2 & 2 & 50 & 60 & 2.35 & 54.68 \\
\hline 36 & 500 & 2000 & 2400 & 1 & 2 & 50 & 60 & 6.05 & 52.77 \\
\hline 37 & 1000 & 2000 & 600 & 2 & 2 & 50 & 60 & 5.63 & 53.5 \\
\hline
\end{tabular}




\begin{tabular}{|c|c|c|c|c|c|c|c|c|c|}
\hline 38 & 1500 & 2000 & 600 & 2 & 2 & 50 & 60 & 10.53 & 51.64 \\
\hline 39 & 500 & 2500 & 600 & 2 & 2 & 50 & 60 & 2.59 & 54.36 \\
\hline 40 & 500 & 2500 & 2400 & 1 & 2 & 50 & 60 & 7.15 & 52.37 \\
\hline 41 & 1000 & 2500 & 600 & 2 & 2 & 50 & 60 & 6.07 & 53.15 \\
\hline 42 & 1500 & 2500 & 600 & 2 & 2 & 50 & 60 & 11.56 & 51.35 \\
\hline 43 & 500 & 3000 & 600 & 2 & 2 & 50 & 60 & 2.71 & 54.09 \\
\hline 44 & 500 & 3000 & 2400 & 1 & 2 & 50 & 60 & 7.34 & 52.13 \\
\hline 45 & 1000 & 3000 & 600 & 2 & 2 & 50 & 60 & 6.46 & 52.86 \\
\hline 46 & 1500 & 3000 & 600 & 2 & 2 & 50 & 60 & 11.74 & 51.06 \\
\hline 47 & 500 & 3500 & 600 & 2 & 2 & 50 & 60 & 2.74 & 53.93 \\
\hline 48 & 500 & 3500 & 2400 & 1 & 2 & 50 & 60 & 8.11 & 51.74 \\
\hline 49 & 1000 & 3500 & 600 & 2 & 2 & 50 & 60 & 7.14 & 52.49 \\
\hline 50 & 1500 & 3500 & 600 & 2 & 2 & 50 & 60 & 12.56 & 50.95 \\
\hline 51 & 500 & 4000 & 600 & 2 & 2 & 50 & 60 & 3.14 & 53.61 \\
\hline 52 & 500 & 4000 & 2400 & 1 & 2 & 50 & 60 & 8.86 & 51.81 \\
\hline 53 & 1000 & 4000 & 600 & 2 & 2 & 50 & 60 & 7.33 & 52.38 \\
\hline 54 & 1500 & 4000 & 600 & 2 & 2 & 50 & 60 & 13.50 & 50.56 \\
\hline 55 & 1500 & 1000 & 600 & 2 & 2 & 50 & 60 & 9.02 & 52.46 \\
\hline 56 & 1500 & 1500 & 600 & 2 & 2 & 50 & 60 & 10.21 & 51.93 \\
\hline 57 & 500 & 1000 & 600 & 2 & 4 & 50 & 60 & 2.11 & 55.17 \\
\hline 58 & 500 & 1000 & 2400 & 1 & 4 & 50 & 60 & 5.38 & 53.22 \\
\hline 59 & 1000 & 1000 & 600 & 2 & 4 & 50 & 60 & 5.02 & 54.16 \\
\hline 60 & 1500 & 1000 & 600 & 2 & 4 & 50 & 60 & 9.94 & 52.19 \\
\hline 61 & 500 & 1500 & 600 & 2 & 4 & 50 & 60 & 2.18 & 55.3 \\
\hline 62 & 500 & 1500 & 2400 & 1 & 4 & 50 & 60 & 5.93 & 53.11 \\
\hline 63 & 1000 & 1500 & 600 & 2 & 4 & 50 & 60 & 5.38 & 53.9 \\
\hline 64 & 1500 & 1500 & 600 & 2 & 4 & 50 & 60 & 10.82 & 51.71 \\
\hline 65 & 500 & 2000 & 600 & 2 & 4 & 50 & 60 & 2.35 & 54.92 \\
\hline 66 & 500 & 2000 & 2400 & 1 & 4 & 50 & 60 & 6.34 & 53 \\
\hline 67 & 1000 & 2000 & 600 & 2 & 4 & 50 & 60 & 5.59 & 53.59 \\
\hline 68 & 1500 & 2000 & 600 & 2 & 4 & 50 & 60 & 10.73 & 51.69 \\
\hline 69 & 500 & 2500 & 600 & 2 & 4 & 50 & 60 & 2.52 & 54.54 \\
\hline 70 & 500 & 2500 & 2400 & 1 & 4 & 50 & 60 & 7.10 & 52.44 \\
\hline 71 & 1000 & 2500 & 600 & 2 & 4 & 50 & 60 & 6.30 & 53.1 \\
\hline 72 & 1500 & 2500 & 600 & 2 & 4 & 50 & 60 & 12.11 & 51.13 \\
\hline 73 & 500 & 3000 & 600 & 2 & 4 & 50 & 60 & 2.66 & 54.33 \\
\hline 74 & 500 & 3000 & 2400 & 1 & 4 & 50 & 60 & 7.63 & 52.33 \\
\hline 75 & 1000 & 3000 & 600 & 2 & 4 & 50 & 60 & 6.72 & 52.79 \\
\hline 76 & 1500 & 3000 & 600 & 2 & 4 & 50 & 60 & 12.67 & 50.85 \\
\hline 77 & 500 & 3500 & 600 & 2 & 4 & 50 & 60 & 3.00 & 53.9 \\
\hline 78 & 500 & 3500 & 2400 & 1 & 4 & 50 & 60 & 8.45 & 52 \\
\hline
\end{tabular}




\begin{tabular}{|c|c|c|c|c|c|c|c|c|c|}
\hline 79 & 1000 & 3500 & 600 & 2 & 4 & 50 & 60 & 7.38 & 52.55 \\
\hline 80 & 1500 & 3500 & 600 & 2 & 4 & 50 & 60 & 13.07 & 50.75 \\
\hline 81 & 500 & 4000 & 600 & 2 & 4 & 50 & 60 & 3.02 & 53.94 \\
\hline 82 & 500 & 4000 & 2400 & 1 & 4 & 50 & 60 & 9.17 & 51.75 \\
\hline 83 & 1000 & 4000 & 600 & 2 & 4 & 50 & 60 & 7.55 & 52.39 \\
\hline 84 & 1500 & 4000 & 600 & 2 & 4 & 50 & 60 & 14.15 & 50.41 \\
\hline 85 & 500 & 1000 & 600 & 2 & 5 & 50 & 60 & 1.92 & 55.53 \\
\hline 86 & 500 & 1000 & 2400 & 1 & 5 & 50 & 60 & 5.18 & 53.51 \\
\hline 87 & 1000 & 1000 & 600 & 2 & 5 & 50 & 60 & 4.91 & 54.22 \\
\hline 88 & 1500 & 1000 & 600 & 2 & 5 & 50 & 60 & 10.31 & 52.01 \\
\hline 89 & 500 & 1500 & 600 & 2 & 5 & 50 & 60 & 2.21 & 55.02 \\
\hline 90 & 500 & 1500 & 2400 & 1 & 5 & 50 & 60 & 5.66 & 53.11 \\
\hline 91 & 1000 & 1500 & 600 & 2 & 5 & 50 & 60 & 5.56 & 53.8 \\
\hline 92 & 1500 & 1500 & 600 & 2 & 5 & 50 & 60 & 10.70 & 51.75 \\
\hline 93 & 500 & 2000 & 600 & 2 & 5 & 50 & 60 & 2.30 & 54.79 \\
\hline 94 & 500 & 2000 & 2400 & 1 & 5 & 50 & 60 & 6.43 & 52.75 \\
\hline 95 & 1000 & 2000 & 600 & 2 & 5 & 50 & 60 & 5.71 & 53.56 \\
\hline 96 & 1500 & 2000 & 600 & 2 & 5 & 50 & 60 & 11.60 & 51.43 \\
\hline 97 & 500 & 2500 & 600 & 2 & 5 & 50 & 60 & 2.66 & 54.3 \\
\hline 98 & 500 & 2500 & 2400 & 1 & 5 & 50 & 60 & 6.72 & 52.54 \\
\hline 99 & 1000 & 2500 & 600 & 2 & 5 & 50 & 60 & 6.38 & 53.12 \\
\hline 100 & 1500 & 2500 & 600 & 2 & 5 & 50 & 60 & 11.98 & 51.17 \\
\hline 101 & 500 & 3000 & 600 & 2 & 5 & 50 & 60 & 2.71 & 54.16 \\
\hline 102 & 500 & 3000 & 2400 & 1 & 5 & 50 & 60 & 8.21 & 51.93 \\
\hline 103 & 1000 & 3000 & 600 & 2 & 5 & 50 & 60 & 6.82 & 52.75 \\
\hline 104 & 1500 & 3000 & 600 & 2 & 5 & 50 & 60 & 13.56 & 50.66 \\
\hline 105 & 500 & 3500 & 600 & 2 & 5 & 50 & 60 & 2.93 & 54.19 \\
\hline 106 & 500 & 3500 & 2400 & 1 & 5 & 50 & 60 & 8.57 & 51.9 \\
\hline 107 & 1000 & 3500 & 600 & 2 & 5 & 50 & 60 & 7.06 & 52.57 \\
\hline 108 & 500 & 4000 & 600 & 2 & 5 & 50 & 60 & 3.10 & 53.95 \\
\hline 109 & 500 & 4000 & 2400 & 1 & 5 & 50 & 60 & 9.46 & 51.62 \\
\hline 110 & 1000 & 4000 & 600 & 2 & 5 & 50 & 60 & 7.56 & 52.45 \\
\hline 111 & 1500 & 4000 & 600 & 2 & 5 & 50 & 60 & 15.22 & 50.19 \\
\hline 112 & 1500 & 3500 & 600 & 2 & 5 & 50 & 60 & 13.99 & 50.52 \\
\hline 113 & 500 & 1000 & 600 & 2 & 6 & 50 & 60 & 2.06 & 55.49 \\
\hline 114 & 500 & 1000 & 2400 & 1 & 6 & 50 & 60 & 5.35 & 53.4 \\
\hline 115 & 1000 & 1000 & 600 & 2 & 6 & 50 & 60 & 5.12 & 54.17 \\
\hline 116 & 1500 & 1000 & 600 & 2 & 6 & 50 & 60 & 10.55 & 52.05 \\
\hline 117 & 500 & 1500 & 600 & 2 & 6 & 50 & 60 & 2.18 & 55.27 \\
\hline 118 & 500 & 1500 & 2400 & 1 & 6 & 50 & 60 & 6.14 & 53.18 \\
\hline 119 & 1000 & 1500 & 600 & 2 & 6 & 50 & 60 & 5.51 & 53.81 \\
\hline
\end{tabular}




\begin{tabular}{|c|c|c|c|c|c|c|c|c|c|}
\hline 120 & 500 & 2000 & 600 & 2 & 6 & 50 & 60 & 2.42 & 54.86 \\
\hline 121 & 500 & 2000 & 2400 & 1 & 6 & 50 & 60 & 6.53 & 52.9 \\
\hline 122 & 1000 & 2000 & 600 & 2 & 6 & 50 & 60 & 6.08 & 53.43 \\
\hline 123 & 1500 & 2000 & 600 & 2 & 6 & 50 & 60 & 13.23 & 50.92 \\
\hline 124 & 500 & 2500 & 600 & 2 & 6 & 50 & 60 & 2.50 & 54.81 \\
\hline 125 & 500 & 2500 & 2400 & 1 & 6 & 50 & 60 & 7.06 & 52.63 \\
\hline 126 & 1000 & 2500 & 600 & 2 & 6 & 50 & 60 & 6.19 & 53.25 \\
\hline 127 & 1500 & 2500 & 600 & 2 & 6 & 50 & 60 & 21.83 & 48.28 \\
\hline 128 & 500 & 3000 & 600 & 2 & 6 & 50 & 60 & 2.71 & 54.25 \\
\hline 129 & 500 & 3000 & 2400 & 1 & 6 & 50 & 60 & 7.73 & 52.55 \\
\hline 130 & 1000 & 3000 & 600 & 2 & 6 & 50 & 60 & 6.70 & 52.98 \\
\hline 131 & 1500 & 3000 & 600 & 2 & 6 & 50 & 60 & 14.18 & 50.48 \\
\hline 132 & 500 & 3500 & 600 & 2 & 6 & 50 & 60 & 2.98 & 54.04 \\
\hline 133 & 500 & 3500 & 2400 & 1 & 6 & 50 & 60 & 8.69 & 52.08 \\
\hline 134 & 1000 & 3500 & 600 & 2 & 6 & 50 & 60 & 7.25 & 52.59 \\
\hline 135 & 1500 & 3500 & 600 & 2 & 6 & 50 & 60 & 14.30 & 50.41 \\
\hline 136 & 500 & 4000 & 600 & 2 & 6 & 50 & 60 & 3.24 & 53.73 \\
\hline 137 & 500 & 4000 & 2400 & 1 & 6 & 50 & 60 & 9.29 & 51.79 \\
\hline 138 & 1000 & 4000 & 600 & 2 & 6 & 50 & 60 & 7.69 & 52.32 \\
\hline 139 & 1500 & 4000 & 600 & 2 & 6 & 50 & 60 & 15.92 & 49.96 \\
\hline 140 & 1500 & 1500 & 600 & 2 & 6 & 50 & 60 & 11.85 & 51.39 \\
\hline 141 & 500 & 1000 & 600 & 2 & 8 & 50 & 60 & 2.06 & 55.58 \\
\hline 142 & 500 & 1000 & 2400 & 1 & 8 & 50 & 60 & 5.26 & 53.66 \\
\hline 143 & 1000 & 1000 & 600 & 2 & 8 & 50 & 60 & 5.28 & 54.2 \\
\hline 144 & 1500 & 1000 & 600 & 2 & 8 & 50 & 60 & 13.63 & 50.81 \\
\hline 145 & 500 & 1500 & 600 & 2 & 8 & 50 & 60 & 2.33 & 55.24 \\
\hline 146 & 500 & 1500 & 2400 & 1 & 8 & 50 & 60 & 6.12 & 53.27 \\
\hline 147 & 1000 & 1500 & 600 & 2 & 8 & 50 & 60 & 5.72 & 53.78 \\
\hline 148 & 1500 & 1500 & 600 & 2 & 8 & 50 & 60 & 11.30 & 51.72 \\
\hline 149 & 500 & 2000 & 600 & 2 & 8 & 50 & 60 & 2.47 & 54.94 \\
\hline 150 & 500 & 2000 & 2400 & 1 & 8 & 50 & 60 & 6.50 & 52.97 \\
\hline 151 & 1000 & 2000 & 600 & 2 & 8 & 50 & 60 & 6.12 & 53.58 \\
\hline 152 & 1500 & 2000 & 600 & 2 & 8 & 50 & 60 & 28.52 & 46.27 \\
\hline 153 & 500 & 2500 & 600 & 2 & 8 & 50 & 60 & 2.71 & 54.61 \\
\hline 154 & 500 & 2500 & 2400 & 1 & 8 & 50 & 60 & 7.85 & 52.45 \\
\hline 155 & 1000 & 2500 & 600 & 2 & 8 & 50 & 60 & 6.74 & 53.09 \\
\hline 156 & 1500 & 2500 & 600 & 2 & 8 & 50 & 60 & 14.50 & 50.54 \\
\hline 157 & 500 & 3000 & 600 & 2 & 8 & 50 & 60 & 2.71 & 54.52 \\
\hline 158 & 500 & 3000 & 2400 & 1 & 8 & 50 & 60 & 7.90 & 52.51 \\
\hline 159 & 1000 & 3000 & 600 & 2 & 8 & 50 & 60 & 7.13 & 52.83 \\
\hline 160 & 1500 & 3000 & 600 & 2 & 8 & 50 & 60 & 16.78 & 49.79 \\
\hline
\end{tabular}




\begin{tabular}{|c|c|c|c|c|c|c|c|c|c|}
\hline 161 & 500 & 3500 & 600 & 2 & 8 & 50 & 60 & 3.00 & 54.18 \\
\hline 162 & 500 & 3500 & 2400 & 1 & 8 & 50 & 60 & 8.59 & 52.12 \\
\hline 163 & 1000 & 3500 & 600 & 2 & 8 & 50 & 60 & 7.34 & 52.55 \\
\hline 164 & 1500 & 3500 & 600 & 2 & 8 & 50 & 60 & 16.70 & 49.81 \\
\hline 165 & 500 & 4000 & 600 & 2 & 8 & 50 & 60 & 3.38 & 53.92 \\
\hline 166 & 500 & 4000 & 2400 & 1 & 8 & 50 & 60 & 8.59 & 52.12 \\
\hline 167 & 1000 & 4000 & 600 & 2 & 8 & 50 & 60 & 7.75 & 52.38 \\
\hline 168 & 1500 & 4000 & 600 & 2 & 8 & 50 & 60 & 16.76 & 49.79 \\
\hline 169 & 500 & 1000 & 600 & 2 & 10 & 50 & 60 & 2.21 & 55.54 \\
\hline 170 & 500 & 1000 & 2400 & 1 & 10 & 50 & 60 & 5.78 & 53.46 \\
\hline 171 & 1000 & 1000 & 600 & 2 & 10 & 50 & 60 & 5.47 & 54.28 \\
\hline 172 & 1500 & 1000 & 600 & 2 & 10 & 50 & 60 & 47.89 & 40.77 \\
\hline 173 & 500 & 1500 & 600 & 2 & 10 & 50 & 60 & 2.40 & 55.2 \\
\hline 174 & 500 & 1500 & 2400 & 1 & 10 & 50 & 60 & 6.48 & 53.29 \\
\hline 175 & 1000 & 1500 & 600 & 2 & 10 & 50 & 60 & 5.77 & 53.92 \\
\hline 176 & 1500 & 1500 & 600 & 2 & 10 & 50 & 60 & 43.31 & 42.17 \\
\hline 177 & 500 & 2000 & 600 & 2 & 10 & 50 & 60 & 2.69 & 54.91 \\
\hline 178 & 500 & 2000 & 2400 & 1 & 10 & 50 & 60 & 6.72 & 52.86 \\
\hline 179 & 1000 & 2000 & 600 & 2 & 10 & 50 & 60 & 6.12 & 53.48 \\
\hline 180 & 1500 & 2000 & 600 & 2 & 10 & 50 & 60 & 31.02 & 45.6 \\
\hline 181 & 500 & 2500 & 600 & 2 & 10 & 50 & 60 & 2.62 & 54.69 \\
\hline 182 & 500 & 2500 & 2400 & 1 & 10 & 50 & 60 & 7.30 & 52.67 \\
\hline 183 & 1000 & 2500 & 600 & 2 & 10 & 50 & 60 & 6.77 & 53.23 \\
\hline 184 & 1500 & 2500 & 600 & 2 & 10 & 50 & 60 & 37.52 & 44.08 \\
\hline 185 & 500 & 3000 & 600 & 2 & 10 & 50 & 60 & 2.93 & 54.34 \\
\hline 186 & 500 & 3000 & 2400 & 1 & 10 & 50 & 60 & 8.38 & 52.25 \\
\hline 187 & 1000 & 3000 & 600 & 2 & 10 & 50 & 60 & 7.27 & 52.85 \\
\hline 188 & 1500 & 3000 & 600 & 2 & 10 & 50 & 60 & 37.89 & 44.34 \\
\hline 189 & 500 & 3500 & 600 & 2 & 10 & 50 & 60 & 3.02 & 54.45 \\
\hline 190 & 500 & 3500 & 2400 & 1 & 10 & 50 & 60 & 8.90 & 52.22 \\
\hline 191 & 1000 & 3500 & 600 & 2 & 10 & 50 & 60 & 7.60 & 52.61 \\
\hline 192 & 500 & 4000 & 600 & 2 & 10 & 50 & 60 & 3.24 & 53.82 \\
\hline 193 & 500 & 4000 & 2400 & 1 & 10 & 50 & 60 & 9.82 & 51.67 \\
\hline 194 & 1000 & 4000 & 600 & 2 & 10 & 50 & 60 & 7.73 & 52.46 \\
\hline 195 & 1500 & 4000 & 600 & 2 & 10 & 50 & 60 & 23.42 & 48.09 \\
\hline 196 & 1500 & 3500 & 600 & 2 & 10 & 50 & 60 & 36.87 & 44.63 \\
\hline
\end{tabular}


Table B.2: Saturated Condition - $50 \mathrm{mph}$ Speed Limit

\begin{tabular}{|c|c|c|c|c|c|c|c|c|c|}
\hline $\begin{array}{c}\text { Scenario } \\
\text { ID }\end{array}$ & $\begin{array}{c}\text { Flow } \\
(\text { veh/h/ln) }\end{array}$ & $\begin{array}{c}\text { Activity } \\
\text { Length } \\
\text { (ft) }\end{array}$ & $\begin{array}{l}\text { Merge } \\
\text { Length }\end{array}$ & $\begin{array}{c}\text { Number } \\
\text { of Open } \\
\text { Lanes }\end{array}$ & $\begin{array}{l}\mathrm{HV} \\
\%\end{array}$ & $\begin{array}{c}\text { Speed } \\
\text { Limit } \\
(\mathbf{m i} / \mathbf{h r})\end{array}$ & $\underset{(\mathbf{m i} / \mathbf{h r})}{\mathbf{F F S}}$ & $\begin{array}{c}\text { Average } \\
\text { Delay } \\
\text { (sec/veh) }\end{array}$ & $\begin{array}{c}\text { Average } \\
\text { Speed } \\
(\mathbf{m i} / \mathbf{h r})\end{array}$ \\
\hline 1 & 1000 & 1000 & 2400 & 1 & 0 & 50 & 60 & 178.98 & 24.48 \\
\hline 2 & 1500 & 1000 & 2400 & 1 & 0 & 50 & 60 & 646.18 & 9.34 \\
\hline 3 & 2000 & 1000 & 600 & 2 & 0 & 50 & 60 & 204.13 & 20.75 \\
\hline 4 & 2000 & 1000 & 2400 & 1 & 0 & 50 & 60 & 770.13 & 8.4 \\
\hline 5 & 2400 & 1000 & 600 & 2 & 0 & 50 & 60 & 259.96 & 17.83 \\
\hline 6 & 2400 & 1000 & 2400 & 1 & 0 & 50 & 60 & 815.05 & 8.38 \\
\hline 7 & 1000 & 1500 & 2400 & 1 & 0 & 50 & 60 & 190.92 & 23.97 \\
\hline 8 & 1500 & 1500 & 2400 & 1 & 0 & 50 & 60 & 635.82 & 9.69 \\
\hline 9 & 2000 & 1500 & 600 & 2 & 0 & 50 & 60 & 199.21 & 21.58 \\
\hline 10 & 2000 & 1500 & 2400 & 1 & 0 & 50 & 60 & 735.74 & 8.81 \\
\hline 11 & 2400 & 1500 & 600 & 2 & 0 & 50 & 60 & 257.93 & 18.42 \\
\hline 12 & 2400 & 1500 & 2400 & 1 & 0 & 50 & 60 & 834.36 & 8.56 \\
\hline 13 & 1000 & 2000 & 2400 & 1 & 0 & 50 & 60 & 197.27 & 29.91 \\
\hline 14 & 1500 & 2000 & 2400 & 1 & 0 & 50 & 60 & 630.94 & 9.99 \\
\hline 15 & 2000 & 2000 & 600 & 2 & 0 & 50 & 60 & 205.16 & 21.84 \\
\hline 16 & 2000 & 2000 & 2400 & 1 & 0 & 50 & 60 & 774.30 & 9.03 \\
\hline 17 & 2400 & 2000 & 600 & 2 & 0 & 50 & 60 & 254.26 & 19.1 \\
\hline 18 & 2400 & 2000 & 2400 & 1 & 0 & 50 & 60 & 830.77 & 8.89 \\
\hline 19 & 1000 & 2500 & 2400 & 1 & 0 & 50 & 60 & 191.81 & 24.83 \\
\hline 20 & 1500 & 2500 & 2400 & 1 & 0 & 50 & 60 & 607.07 & 10.45 \\
\hline 21 & 2000 & 2500 & 600 & 2 & 0 & 50 & 60 & 204.12 & 22.3 \\
\hline 22 & 2000 & 2500 & 2400 & 1 & 0 & 50 & 60 & 733.84 & 9.38 \\
\hline 23 & 2400 & 2500 & 600 & 2 & 0 & 50 & 60 & 252.52 & 19.6 \\
\hline 24 & 2400 & 2500 & 2400 & 1 & 0 & 50 & 60 & 805.32 & 9.12 \\
\hline 25 & 1000 & 3000 & 2400 & 1 & 0 & 50 & 60 & 193.24 & 25.15 \\
\hline 26 & 1500 & 3000 & 2400 & 1 & 0 & 50 & 60 & 626.02 & 10.73 \\
\hline 27 & 2000 & 3000 & 600 & 2 & 0 & 50 & 60 & 204.68 & 22.85 \\
\hline 28 & 2000 & 3000 & 2400 & 1 & 0 & 50 & 60 & 776.76 & 9.44 \\
\hline 29 & 2400 & 3000 & 600 & 2 & 0 & 50 & 60 & 255.30 & 20.13 \\
\hline 30 & 2400 & 3000 & 2400 & 1 & 0 & 50 & 60 & 824.75 & 9.48 \\
\hline 31 & 1000 & 3500 & 2400 & 1 & 0 & 50 & 60 & 186.42 & 26.05 \\
\hline 32 & 1500 & 3500 & 2400 & 1 & 0 & 50 & 60 & 625.30 & 10.99 \\
\hline 33 & 2000 & 3500 & 600 & 2 & 0 & 50 & 60 & 205.86 & 23.27 \\
\hline 34 & 2000 & 3500 & 2400 & 1 & 0 & 50 & 60 & 771.50 & 9.75 \\
\hline 35 & 2400 & 3500 & 600 & 2 & 0 & 50 & 60 & 257.33 & 20.45 \\
\hline 36 & 2400 & 3500 & 2400 & 1 & 0 & 50 & 60 & 815.90 & 9.7 \\
\hline 37 & 1000 & 4000 & 2400 & 1 & 0 & 50 & 60 & 188.36 & 26.3 \\
\hline
\end{tabular}




\begin{tabular}{|c|c|c|c|c|c|c|c|c|c|}
\hline 38 & 1500 & 4000 & 2400 & 1 & 0 & 50 & 60 & 613.92 & 11.17 \\
\hline 39 & 2000 & 4000 & 600 & 2 & 0 & 50 & 60 & 207.23 & 23.55 \\
\hline 40 & 2000 & 4000 & 2400 & 1 & 0 & 50 & 60 & 765.42 & 10.18 \\
\hline 41 & 2400 & 4000 & 600 & 2 & 0 & 50 & 60 & 252.07 & 21.21 \\
\hline 42 & 2400 & 4000 & 2400 & 1 & 0 & 50 & 60 & 824.73 & 9.78 \\
\hline 43 & 1000 & 1000 & 2400 & 1 & 2 & 50 & 60 & 253.43 & 19.27 \\
\hline 44 & 1500 & 1000 & 2400 & 1 & 2 & 50 & 60 & 695.67 & 8.7 \\
\hline 45 & 2000 & 1000 & 600 & 2 & 2 & 50 & 60 & 227.59 & 19.32 \\
\hline 46 & 2000 & 1000 & 2400 & 1 & 2 & 50 & 60 & 842.56 & 7.9 \\
\hline 47 & 2400 & 1000 & 600 & 2 & 2 & 50 & 60 & 268.85 & 17.53 \\
\hline 48 & 2400 & 1000 & 2400 & 1 & 2 & 50 & 60 & 867.49 & 8.05 \\
\hline 49 & 1000 & 1500 & 2400 & 1 & 2 & 50 & 60 & 226.57 & 21.3 \\
\hline 50 & 1500 & 1500 & 2400 & 1 & 2 & 50 & 60 & 678.13 & 9.13 \\
\hline 51 & 2000 & 1500 & 600 & 2 & 2 & 50 & 60 & 228.69 & 19.85 \\
\hline 52 & 2000 & 1500 & 2400 & 1 & 2 & 50 & 60 & 824.45 & 8.31 \\
\hline 53 & 2400 & 1500 & 600 & 2 & 2 & 50 & 60 & 262.97 & 18.26 \\
\hline 54 & 2400 & 1500 & 2400 & 1 & 2 & 50 & 60 & 889.33 & 8.1 \\
\hline 55 & 1000 & 2000 & 2400 & 1 & 2 & 50 & 60 & 274.18 & 19.14 \\
\hline 56 & 1500 & 2000 & 2400 & 1 & 2 & 50 & 60 & 673.61 & 9.52 \\
\hline 57 & 2000 & 2000 & 600 & 2 & 2 & 50 & 60 & 225.92 & 20.42 \\
\hline 58 & 2000 & 2000 & 2400 & 1 & 2 & 50 & 60 & 839.08 & 8.46 \\
\hline 59 & 2400 & 2000 & 600 & 2 & 2 & 50 & 60 & 267.37 & 18.51 \\
\hline 60 & 2400 & 2000 & 2400 & 1 & 2 & 50 & 60 & 841.84 & 8.55 \\
\hline 61 & 1000 & 2500 & 2400 & 1 & 2 & 50 & 60 & 294.14 & 18.58 \\
\hline 62 & 1500 & 2500 & 2400 & 1 & 2 & 50 & 60 & 653.25 & 10.04 \\
\hline 63 & 2000 & 2500 & 600 & 2 & 2 & 50 & 60 & 223.53 & 21.12 \\
\hline 64 & 2000 & 2500 & 2400 & 1 & 2 & 50 & 60 & 826.53 & 8.83 \\
\hline 65 & 2400 & 2500 & 600 & 2 & 2 & 50 & 60 & 267.00 & 19.02 \\
\hline 66 & 2400 & 2500 & 2400 & 1 & 2 & 50 & 60 & 866.63 & 8.76 \\
\hline 67 & 1000 & 3000 & 2400 & 1 & 2 & 50 & 60 & 251.82 & 21.13 \\
\hline 68 & 1500 & 3000 & 2400 & 1 & 2 & 50 & 60 & 694.34 & 9.88 \\
\hline 69 & 2000 & 3000 & 600 & 2 & 2 & 50 & 60 & 223.13 & 21.68 \\
\hline 70 & 2000 & 3000 & 2400 & 1 & 2 & 50 & 60 & 809.80 & 9.23 \\
\hline 71 & 2400 & 3000 & 600 & 2 & 2 & 50 & 60 & 259.63 & 19.59 \\
\hline 72 & 2400 & 3000 & 2400 & 1 & 2 & 50 & 60 & 861.29 & 9.23 \\
\hline 73 & 1000 & 3500 & 2400 & 1 & 2 & 50 & 60 & 242.93 & 21.88 \\
\hline 74 & 1500 & 3500 & 2400 & 1 & 2 & 50 & 60 & 658.58 & 10.51 \\
\hline 75 & 2000 & 3500 & 600 & 2 & 2 & 50 & 60 & 224.28 & 22.14 \\
\hline 76 & 2000 & 3500 & 2400 & 1 & 2 & 50 & 60 & 807.92 & 9.55 \\
\hline 77 & 2400 & 3500 & 600 & 2 & 2 & 50 & 60 & 267.20 & 20.02 \\
\hline 78 & 2400 & 3500 & 2400 & 1 & 2 & 50 & 60 & 869.62 & 9.33 \\
\hline
\end{tabular}




\begin{tabular}{|c|c|c|c|c|c|c|c|c|c|}
\hline 79 & 1000 & 4000 & 2400 & 1 & 2 & 50 & 60 & 265.16 & 21.06 \\
\hline 80 & 1500 & 4000 & 2400 & 1 & 2 & 50 & 60 & 788.00 & 10.5 \\
\hline 81 & 2000 & 4000 & 600 & 2 & 2 & 50 & 60 & 224.12 & 22.55 \\
\hline 82 & 2000 & 4000 & 2400 & 1 & 2 & 50 & 60 & 797.44 & 9.68 \\
\hline 83 & 2400 & 4000 & 600 & 2 & 2 & 50 & 60 & 267.12 & 20.44 \\
\hline 84 & 2400 & 4000 & 2400 & 1 & 2 & 50 & 60 & 847.83 & 9.78 \\
\hline 85 & 1000 & 1000 & 2400 & 1 & 4 & 50 & 60 & 296.04 & 17.02 \\
\hline 86 & 1500 & 1000 & 2400 & 1 & 4 & 50 & 60 & 705.23 & 8.56 \\
\hline 87 & 2000 & 1000 & 600 & 2 & 4 & 50 & 60 & 237.48 & 18.8 \\
\hline 88 & 2000 & 1000 & 2400 & 1 & 4 & 50 & 60 & 845.97 & 7.78 \\
\hline 89 & 2400 & 1000 & 600 & 2 & 4 & 50 & 60 & 286.22 & 16.65 \\
\hline 90 & 2400 & 1000 & 2400 & 1 & 4 & 50 & 60 & 939.27 & 7.51 \\
\hline 91 & 1000 & 1500 & 2400 & 1 & 4 & 50 & 60 & 312.70 & 16.68 \\
\hline 92 & 1500 & 1500 & 2400 & 1 & 4 & 50 & 60 & 740.96 & 8.61 \\
\hline 93 & 2000 & 1500 & 600 & 2 & 4 & 50 & 60 & 237.47 & 19.4 \\
\hline 94 & 2000 & 1500 & 2400 & 1 & 4 & 50 & 60 & 890.70 & 7.75 \\
\hline 95 & 2400 & 1500 & 600 & 2 & 4 & 50 & 60 & 286.71 & 17.26 \\
\hline 96 & 2400 & 1500 & 2400 & 1 & 4 & 50 & 60 & 903.04 & 7.84 \\
\hline 97 & 1000 & 2000 & 2400 & 1 & 4 & 50 & 60 & 325.61 & 16.6 \\
\hline 98 & 1500 & 2000 & 2400 & 1 & 4 & 50 & 60 & 728.07 & 8.96 \\
\hline 99 & 2000 & 2000 & 600 & 2 & 4 & 50 & 60 & 236.05 & 19.88 \\
\hline 100 & 2000 & 2000 & 2400 & 1 & 4 & 50 & 60 & 867.96 & 8.23 \\
\hline 101 & 2400 & 2000 & 600 & 2 & 4 & 50 & 60 & 276.40 & 18.1 \\
\hline 102 & 2400 & 2000 & 2400 & 1 & 4 & 50 & 60 & 936.66 & 8.11 \\
\hline 103 & 1000 & 2500 & 2400 & 1 & 4 & 50 & 60 & 330.01 & 16.82 \\
\hline 104 & 1500 & 2500 & 2400 & 1 & 4 & 50 & 60 & 721.38 & 9.37 \\
\hline 105 & 2000 & 2500 & 600 & 2 & 4 & 50 & 60 & 247.46 & 19.91 \\
\hline 106 & 2000 & 2500 & 2400 & 1 & 4 & 50 & 60 & 837.84 & 8.6 \\
\hline 107 & 2400 & 2500 & 600 & 2 & 4 & 50 & 60 & 288.28 & 18.2 \\
\hline 108 & 2400 & 2500 & 2400 & 1 & 4 & 50 & 60 & 932.30 & 8.36 \\
\hline 109 & 1000 & 3000 & 2400 & 1 & 4 & 50 & 60 & 311.65 & 18 \\
\hline 110 & 1500 & 3000 & 2400 & 1 & 4 & 50 & 60 & 728.07 & 9.55 \\
\hline 111 & 2000 & 3000 & 600 & 2 & 4 & 50 & 60 & 245.52 & 20.49 \\
\hline 112 & 2000 & 3000 & 2400 & 1 & 4 & 50 & 60 & 843.87 & 8.88 \\
\hline 113 & 2400 & 3000 & 600 & 2 & 4 & 50 & 60 & 273.20 & 19.18 \\
\hline 114 & 2400 & 3000 & 2400 & 1 & 4 & 50 & 60 & 913.42 & 8.78 \\
\hline 115 & 1000 & 3500 & 2400 & 1 & 4 & 50 & 60 & 282.54 & 19.68 \\
\hline 116 & 1500 & 3500 & 2400 & 1 & 4 & 50 & 60 & 731.71 & 9.79 \\
\hline 117 & 2000 & 3500 & 600 & 2 & 4 & 50 & 60 & 247.87 & 20.8 \\
\hline 118 & 2000 & 3500 & 2400 & 1 & 4 & 50 & 60 & 847.68 & 9.22 \\
\hline 119 & 2400 & 3500 & 600 & 2 & 4 & 50 & 60 & 291.13 & 19.01 \\
\hline
\end{tabular}




\begin{tabular}{|c|c|c|c|c|c|c|c|c|c|}
\hline 120 & 2400 & 3500 & 2400 & 1 & 4 & 50 & 60 & 900.82 & 9 \\
\hline 121 & 1000 & 4000 & 2400 & 1 & 4 & 50 & 60 & 335.56 & 17.7 \\
\hline 122 & 1500 & 4000 & 2400 & 1 & 4 & 50 & 60 & 690.15 & 10.34 \\
\hline 123 & 2000 & 4000 & 600 & 2 & 4 & 50 & 60 & 255.44 & 20.83 \\
\hline 124 & 2000 & 4000 & 2400 & 1 & 4 & 50 & 60 & 858.18 & 9.35 \\
\hline 125 & 2400 & 4000 & 600 & 2 & 4 & 50 & 60 & 284.75 & 19.6 \\
\hline 126 & 2400 & 4000 & 2400 & 1 & 4 & 50 & 60 & 737.04 & 9.34 \\
\hline 127 & 1000 & 1000 & 2400 & 1 & 5 & 50 & 60 & 313.00 & 16.28 \\
\hline 128 & 1500 & 1000 & 2400 & 1 & 5 & 50 & 60 & 722.44 & 8.46 \\
\hline 129 & 2000 & 1000 & 600 & 2 & 5 & 50 & 60 & 267.36 & 17.42 \\
\hline 130 & 2000 & 1000 & 2400 & 1 & 5 & 50 & 60 & 856.22 & 7.64 \\
\hline 131 & 2400 & 1000 & 600 & 2 & 5 & 50 & 60 & 294.80 & 16.59 \\
\hline 132 & 2400 & 1000 & 2400 & 1 & 5 & 50 & 60 & 925.75 & 7.77 \\
\hline 133 & 1000 & 1500 & 2400 & 1 & 5 & 50 & 60 & 332.56 & 15.76 \\
\hline 134 & 1500 & 1500 & 2400 & 1 & 5 & 50 & 60 & 779.01 & 8.35 \\
\hline 135 & 2000 & 1500 & 600 & 2 & 5 & 50 & 60 & 252.95 & 18.56 \\
\hline 136 & 2000 & 1500 & 2400 & 1 & 5 & 50 & 60 & 874.11 & 7.98 \\
\hline 137 & 2400 & 1500 & 600 & 2 & 5 & 50 & 60 & 290.10 & 17.12 \\
\hline 138 & 2400 & 1500 & 2400 & 1 & 5 & 50 & 60 & 925.51 & 8 \\
\hline 139 & 1000 & 2000 & 2400 & 1 & 5 & 50 & 60 & 329.11 & 16.41 \\
\hline 140 & 1500 & 2000 & 2400 & 1 & 5 & 50 & 60 & 685.84 & 9.22 \\
\hline 141 & 2000 & 2000 & 600 & 2 & 5 & 50 & 60 & 253.97 & 19.09 \\
\hline 142 & 2000 & 2000 & 2400 & 1 & 5 & 50 & 60 & 866.02 & 8.3 \\
\hline 143 & 2400 & 2000 & 600 & 2 & 5 & 50 & 60 & 293.26 & 17.46 \\
\hline 144 & 2400 & 2000 & 2400 & 1 & 5 & 50 & 60 & 921.77 & 7.98 \\
\hline 145 & 1000 & 2500 & 2400 & 1 & 5 & 50 & 60 & 348.00 & 15.9 \\
\hline 146 & 1500 & 2500 & 2400 & 1 & 5 & 50 & 60 & 748.13 & 9.01 \\
\hline 147 & 2000 & 2500 & 600 & 2 & 5 & 50 & 60 & 252.28 & 19.64 \\
\hline 148 & 2000 & 2500 & 2400 & 1 & 5 & 50 & 60 & 879.53 & 8.49 \\
\hline 149 & 2400 & 2500 & 600 & 2 & 5 & 50 & 60 & 284.94 & 18.32 \\
\hline 150 & 2400 & 2500 & 2400 & 1 & 5 & 50 & 60 & 873.48 & 8.51 \\
\hline 151 & 1000 & 3000 & 2400 & 1 & 5 & 50 & 60 & 365.11 & 15.6 \\
\hline 152 & 1500 & 3000 & 2400 & 1 & 5 & 50 & 60 & 719.45 & 9.45 \\
\hline 153 & 2000 & 3000 & 600 & 2 & 5 & 50 & 60 & 252.13 & 20.18 \\
\hline 154 & 2000 & 3000 & 2400 & 1 & 5 & 50 & 60 & 876.67 & 8.69 \\
\hline 155 & 2400 & 3000 & 600 & 2 & 5 & 50 & 60 & 283.00 & 18.75 \\
\hline 156 & 2400 & 3000 & 2400 & 1 & 5 & 50 & 60 & 902.55 & 8.73 \\
\hline 157 & 1000 & 3500 & 2400 & 1 & 5 & 50 & 60 & 380.54 & 15.43 \\
\hline 158 & 1500 & 3500 & 2400 & 1 & 5 & 50 & 60 & 685.78 & 10.03 \\
\hline 159 & 2000 & 3500 & 600 & 2 & 5 & 50 & 60 & 262.84 & 20.11 \\
\hline 160 & 2000 & 3500 & 2400 & 1 & 5 & 50 & 60 & 882.48 & 8.74 \\
\hline
\end{tabular}




\begin{tabular}{|c|c|c|c|c|c|c|c|c|c|}
\hline 161 & 2400 & 3500 & 600 & 2 & 5 & 50 & 60 & 294.35 & 18.89 \\
\hline 162 & 2400 & 3500 & 2400 & 1 & 5 & 50 & 60 & 911.37 & 8.92 \\
\hline 163 & 1000 & 4000 & 2400 & 1 & 5 & 50 & 60 & 328.57 & 17.92 \\
\hline 164 & 1500 & 4000 & 2400 & 1 & 5 & 50 & 60 & 752.07 & 9.62 \\
\hline 165 & 2000 & 4000 & 600 & 2 & 5 & 50 & 60 & 275.89 & 20 \\
\hline 166 & 2000 & 4000 & 2400 & 1 & 5 & 50 & 60 & 834.78 & 9.33 \\
\hline 167 & 2400 & 4000 & 600 & 2 & 5 & 50 & 60 & 287.63 & 19.56 \\
\hline 168 & 2400 & 4000 & 2400 & 1 & 5 & 50 & 60 & 959.12 & 8.97 \\
\hline 169 & 1000 & 1000 & 2400 & 1 & 6 & 50 & 60 & 384.84 & 13.69 \\
\hline 170 & 1500 & 1000 & 2400 & 1 & 6 & 50 & 60 & 738.86 & 8.36 \\
\hline 171 & 2000 & 1000 & 600 & 2 & 6 & 50 & 60 & 255.35 & 17.94 \\
\hline 172 & 2000 & 1000 & 2400 & 1 & 6 & 50 & 60 & 844.81 & 7.68 \\
\hline 173 & 2400 & 1000 & 600 & 2 & 6 & 50 & 60 & 302.72 & 16.28 \\
\hline 174 & 2400 & 1000 & 2400 & 1 & 6 & 50 & 60 & 944.09 & 7.56 \\
\hline 175 & 1000 & 1500 & 2400 & 1 & 6 & 50 & 60 & 344.51 & 15.26 \\
\hline 176 & 1500 & 1500 & 2400 & 1 & 6 & 50 & 60 & 783.50 & 8.25 \\
\hline 177 & 2000 & 1500 & 600 & 2 & 6 & 50 & 60 & 257.23 & 18.37 \\
\hline 178 & 2000 & 1500 & 2400 & 1 & 6 & 50 & 60 & 878.93 & 7.98 \\
\hline 179 & 2400 & 1500 & 600 & 2 & 6 & 50 & 60 & 302.34 & 16.79 \\
\hline 180 & 2400 & 1500 & 2400 & 1 & 6 & 50 & 60 & 970.39 & 7.57 \\
\hline 181 & 1000 & 2000 & 2400 & 1 & 6 & 50 & 60 & 421.74 & 13.31 \\
\hline 182 & 1500 & 2000 & 2400 & 1 & 6 & 50 & 60 & 751.80 & 8.81 \\
\hline 183 & 2000 & 2000 & 600 & 2 & 6 & 50 & 60 & 257.31 & 18.87 \\
\hline 184 & 2000 & 2000 & 2400 & 1 & 6 & 50 & 60 & 905.17 & 7.96 \\
\hline 185 & 2400 & 2000 & 600 & 2 & 6 & 50 & 60 & 286.62 & 17.74 \\
\hline 186 & 2400 & 2000 & 2400 & 1 & 6 & 50 & 60 & 938.94 & 8.07 \\
\hline 187 & 1000 & 2500 & 2400 & 1 & 6 & 50 & 60 & 348.72 & 15.99 \\
\hline 188 & 1500 & 2500 & 2400 & 1 & 6 & 50 & 60 & 724.78 & 9.21 \\
\hline 189 & 2000 & 2500 & 600 & 2 & 6 & 50 & 60 & 257.65 & 19.41 \\
\hline 190 & 2000 & 2500 & 2400 & 1 & 6 & 50 & 60 & 897.85 & 8.33 \\
\hline 191 & 2400 & 2500 & 600 & 2 & 6 & 50 & 60 & 285.70 & 18.21 \\
\hline 192 & 2400 & 2500 & 2400 & 1 & 6 & 50 & 60 & 934.67 & 8.32 \\
\hline 193 & 1000 & 3000 & 2400 & 1 & 6 & 50 & 60 & 365.87 & 15.68 \\
\hline 194 & 1500 & 3000 & 2400 & 1 & 6 & 50 & 60 & 760.88 & 9.05 \\
\hline 195 & 2000 & 3000 & 600 & 2 & 6 & 50 & 60 & 262.59 & 19.64 \\
\hline 196 & 2000 & 3000 & 2400 & 1 & 6 & 50 & 60 & 896.33 & 8.59 \\
\hline 197 & 2400 & 3000 & 600 & 2 & 6 & 50 & 60 & 281.34 & 18.87 \\
\hline 198 & 2400 & 3000 & 2400 & 1 & 6 & 50 & 60 & 941.23 & 8.65 \\
\hline 199 & 1000 & 3500 & 2400 & 1 & 6 & 50 & 60 & 388.43 & 15.23 \\
\hline 200 & 1500 & 3500 & 2400 & 1 & 6 & 50 & 60 & 754.69 & 9.53 \\
\hline 201 & 2000 & 3500 & 600 & 2 & 6 & 50 & 60 & 258.66 & 20.26 \\
\hline
\end{tabular}




\begin{tabular}{|c|c|c|c|c|c|c|c|c|c|}
\hline 202 & 2000 & 3500 & 2400 & 1 & 6 & 50 & 60 & 911.19 & 8.75 \\
\hline 203 & 2400 & 3500 & 600 & 2 & 6 & 50 & 60 & 289.88 & 19.03 \\
\hline 204 & 2400 & 3500 & 2400 & 1 & 6 & 50 & 60 & 908.49 & 8.89 \\
\hline 205 & 1000 & 4000 & 2400 & 1 & 6 & 50 & 60 & 402.28 & 15.19 \\
\hline 206 & 1500 & 4000 & 2400 & 1 & 6 & 50 & 60 & 762.37 & 9.68 \\
\hline 207 & 2000 & 4000 & 600 & 2 & 6 & 50 & 60 & 259.08 & 20.66 \\
\hline 208 & 2000 & 4000 & 2400 & 1 & 6 & 50 & 60 & 870.57 & 9.22 \\
\hline 209 & 2400 & 4000 & 600 & 2 & 6 & 50 & 60 & 295.16 & 19.2 \\
\hline 210 & 2400 & 4000 & 2400 & 1 & 6 & 50 & 60 & 931.88 & 9.11 \\
\hline 211 & 1000 & 1000 & 2400 & 1 & 8 & 50 & 60 & 435.30 & 12.33 \\
\hline 212 & 1500 & 1000 & 2400 & 1 & 8 & 50 & 60 & 782.40 & 7.85 \\
\hline 213 & 2000 & 1000 & 600 & 2 & 8 & 50 & 60 & 283.53 & 16.76 \\
\hline 214 & 2000 & 1000 & 2400 & 1 & 8 & 50 & 60 & 932.49 & 7.43 \\
\hline 215 & 2400 & 1000 & 600 & 2 & 8 & 50 & 60 & 303.56 & 16.22 \\
\hline 216 & 2400 & 1000 & 2400 & 1 & 8 & 50 & 60 & 973.65 & 7.3 \\
\hline 217 & 1000 & 1500 & 2400 & 1 & 8 & 50 & 60 & 438.15 & 12.65 \\
\hline 218 & 1500 & 1500 & 2400 & 1 & 8 & 50 & 60 & 751.14 & 8.37 \\
\hline 219 & 2000 & 1500 & 600 & 2 & 8 & 50 & 60 & 285.02 & 17.25 \\
\hline 220 & 2000 & 1500 & 2400 & 1 & 8 & 50 & 60 & 953.15 & 7.54 \\
\hline 221 & 2400 & 1500 & 600 & 2 & 8 & 50 & 60 & 302.49 & 16.72 \\
\hline 222 & 2400 & 1500 & 2400 & 1 & 8 & 50 & 60 & 974.75 & 7.62 \\
\hline 223 & 1000 & 2000 & 2400 & 1 & 8 & 50 & 60 & 480.54 & 12.01 \\
\hline 224 & 1500 & 2000 & 2400 & 1 & 8 & 50 & 60 & 798.72 & 8.26 \\
\hline 225 & 2000 & 2000 & 600 & 2 & 8 & 50 & 60 & 279.49 & 17.92 \\
\hline 226 & 2000 & 2000 & 2400 & 1 & 8 & 50 & 60 & 867.78 & 7.87 \\
\hline 227 & 2400 & 2000 & 600 & 2 & 8 & 50 & 60 & 311.81 & 16.94 \\
\hline 228 & 2400 & 2000 & 2400 & 1 & 8 & 50 & 60 & 977.33 & 7.94 \\
\hline 229 & 1000 & 2500 & 2400 & 1 & 8 & 50 & 60 & 467.55 & 12.52 \\
\hline 230 & 1500 & 2500 & 2400 & 1 & 8 & 50 & 60 & 781.81 & 8.87 \\
\hline 231 & 2000 & 2500 & 600 & 2 & 8 & 50 & 60 & 272.82 & 18.65 \\
\hline 232 & 2000 & 2500 & 2400 & 1 & 8 & 50 & 60 & 930.68 & 8.17 \\
\hline 233 & 2400 & 2500 & 600 & 2 & 8 & 50 & 60 & 318.79 & 17.28 \\
\hline 234 & 2400 & 2500 & 2400 & 1 & 8 & 50 & 60 & 968.74 & 8.04 \\
\hline 235 & 1000 & 3000 & 2400 & 1 & 8 & 50 & 60 & 424.30 & 13.98 \\
\hline 236 & 1500 & 3000 & 2400 & 1 & 8 & 50 & 60 & 807.12 & 8.8 \\
\hline 237 & 2000 & 3000 & 600 & 2 & 8 & 50 & 60 & 289.68 & 18.49 \\
\hline 238 & 2000 & 3000 & 2400 & 1 & 8 & 50 & 60 & 888.41 & 8.45 \\
\hline 239 & 2400 & 3000 & 600 & 2 & 8 & 50 & 60 & 311.80 & 17.91 \\
\hline 240 & 2400 & 3000 & 2400 & 1 & 8 & 50 & 60 & 949.47 & 8.33 \\
\hline 241 & 1000 & 3500 & 2400 & 1 & 8 & 50 & 60 & 507.75 & 12.44 \\
\hline 242 & 1500 & 3500 & 2400 & 1 & 8 & 50 & 60 & 796.63 & 9.19 \\
\hline
\end{tabular}




\begin{tabular}{|c|c|c|c|c|c|c|c|c|c|}
\hline 243 & 2000 & 3500 & 600 & 2 & 8 & 50 & 60 & 268.85 & 19.76 \\
\hline 244 & 2000 & 3500 & 2400 & 1 & 8 & 50 & 60 & 918.09 & 8.73 \\
\hline 245 & 2400 & 3500 & 600 & 2 & 8 & 50 & 60 & 311.86 & 18.22 \\
\hline 246 & 2400 & 3500 & 2400 & 1 & 8 & 50 & 60 & 913.05 & 8.7 \\
\hline 247 & 1000 & 4000 & 2400 & 1 & 8 & 50 & 60 & 507.75 & 12.44 \\
\hline 248 & 1500 & 4000 & 2400 & 1 & 8 & 50 & 60 & 796.63 & 9.19 \\
\hline 249 & 2000 & 4000 & 600 & 2 & 8 & 50 & 60 & 277.15 & 19.94 \\
\hline 250 & 2000 & 4000 & 2400 & 1 & 8 & 50 & 60 & 918.09 & 8.73 \\
\hline 251 & 2400 & 4000 & 600 & 2 & 8 & 50 & 60 & 326.33 & 18.44 \\
\hline 252 & 2400 & 4000 & 2400 & 1 & 8 & 50 & 60 & 913.05 & 8.7 \\
\hline 253 & 1000 & 1000 & 2400 & 1 & 10 & 50 & 60 & 551.97 & 10.2 \\
\hline 254 & 1500 & 1000 & 2400 & 1 & 10 & 50 & 60 & 833.44 & 7.52 \\
\hline 255 & 2000 & 1000 & 600 & 2 & 10 & 50 & 60 & 287.65 & 16.57 \\
\hline 256 & 2000 & 1000 & 2400 & 1 & 10 & 50 & 60 & 940.13 & 7.38 \\
\hline 257 & 2400 & 1000 & 600 & 2 & 10 & 50 & 60 & 308.67 & 15.84 \\
\hline 258 & 2400 & 1000 & 2400 & 1 & 10 & 50 & 60 & 992.04 & 7.06 \\
\hline 259 & 1000 & 1500 & 2400 & 1 & 10 & 50 & 60 & 578.80 & 10.12 \\
\hline 260 & 1500 & 1500 & 2400 & 1 & 10 & 50 & 60 & 840.24 & 7.77 \\
\hline 261 & 2000 & 1500 & 600 & 2 & 10 & 50 & 60 & 288.99 & 17.07 \\
\hline 262 & 2000 & 1500 & 2400 & 1 & 10 & 50 & 60 & 939.35 & 7.58 \\
\hline 263 & 2400 & 1500 & 600 & 2 & 10 & 50 & 60 & 328.42 & 16.05 \\
\hline 264 & 2400 & 1500 & 2400 & 1 & 10 & 50 & 60 & 959.06 & 7.63 \\
\hline 265 & 1000 & 2000 & 2400 & 1 & 10 & 50 & 60 & 549.89 & 10.79 \\
\hline 266 & 1500 & 2000 & 2400 & 1 & 10 & 50 & 60 & 814.19 & 8.29 \\
\hline 267 & 2000 & 2000 & 600 & 2 & 10 & 50 & 60 & 296.21 & 17.25 \\
\hline 268 & 2000 & 2000 & 2400 & 1 & 10 & 50 & 60 & 984.76 & 7.56 \\
\hline 269 & 2400 & 2000 & 600 & 2 & 10 & 50 & 60 & 312.45 & 16.84 \\
\hline 270 & 2400 & 2000 & 2400 & 1 & 10 & 50 & 60 & 992.29 & 7.74 \\
\hline 271 & 1000 & 2500 & 2400 & 1 & 10 & 50 & 60 & 520.14 & 11.69 \\
\hline 272 & 1500 & 2500 & 2400 & 1 & 10 & 50 & 60 & 783.16 & 8.6 \\
\hline 273 & 2000 & 2500 & 600 & 2 & 10 & 50 & 60 & 285.17 & 18.06 \\
\hline 274 & 2000 & 2500 & 2400 & 1 & 10 & 50 & 60 & 875.75 & 8.29 \\
\hline 275 & 2400 & 2500 & 600 & 2 & 10 & 50 & 60 & 311.38 & 17.32 \\
\hline 276 & 2400 & 2500 & 2400 & 1 & 10 & 50 & 60 & 968.72 & 7.93 \\
\hline 277 & 1000 & 3000 & 2400 & 1 & 10 & 50 & 60 & 491.66 & 12.42 \\
\hline 278 & 1500 & 3000 & 2400 & 1 & 10 & 50 & 60 & 839.01 & 8.54 \\
\hline 279 & 2000 & 3000 & 600 & 2 & 10 & 50 & 60 & 291.33 & 18.36 \\
\hline 280 & 2000 & 3000 & 2400 & 1 & 10 & 50 & 60 & 899.72 & 8.41 \\
\hline 281 & 2400 & 3000 & 600 & 2 & 10 & 50 & 60 & 312.94 & 17.76 \\
\hline 282 & 2400 & 3000 & 2400 & 1 & 10 & 50 & 60 & 976.29 & 8.33 \\
\hline 283 & 1000 & 3500 & 2400 & 1 & 10 & 50 & 60 & 530.42 & 11.99 \\
\hline
\end{tabular}




\begin{tabular}{|c|c|c|c|c|c|c|c|c|c|}
\hline 284 & 1500 & 3500 & 2400 & 1 & 10 & 50 & 60 & 795.08 & 9.04 \\
\hline 285 & 2000 & 3500 & 600 & 2 & 10 & 50 & 60 & 296.50 & 18.56 \\
\hline 286 & 2000 & 3500 & 2400 & 1 & 10 & 50 & 60 & 920.10 & 8.61 \\
\hline 287 & 2400 & 3500 & 600 & 2 & 10 & 50 & 60 & 319.33 & 17.87 \\
\hline 288 & 2400 & 3500 & 2400 & 1 & 10 & 50 & 60 & 943.47 & 8.44 \\
\hline 289 & 1000 & 4000 & 2400 & 1 & 10 & 50 & 60 & 543.14 & 12.12 \\
\hline 290 & 1500 & 4000 & 2400 & 1 & 10 & 50 & 60 & 755.45 & 9.72 \\
\hline 291 & 2000 & 4000 & 600 & 2 & 10 & 50 & 60 & 300.42 & 18.93 \\
\hline 292 & 2000 & 4000 & 2400 & 1 & 10 & 50 & 60 & 959.53 & 8.75 \\
\hline 293 & 2400 & 4000 & 600 & 2 & 10 & 50 & 60 & 319.22 & 18.52 \\
\hline 294 & 2400 & 4000 & 2400 & 1 & 10 & 50 & 60 & 1011.02 & 8.68 \\
\hline
\end{tabular}


Table B.3: Undersaturated Condition $-55 \mathrm{mph}$ Speed Limit

\begin{tabular}{|c|c|c|c|c|c|c|c|c|c|}
\hline $\begin{array}{c}\text { Scenario } \\
\text { ID }\end{array}$ & $\begin{array}{c}\text { Flow } \\
(\mathbf{v e h} / \mathbf{h} / \mathbf{l n})\end{array}$ & $\begin{array}{c}\text { Activity } \\
\text { Length } \\
\text { (ft) }\end{array}$ & $\begin{array}{l}\text { Merge } \\
\text { Length }\end{array}$ & $\begin{array}{c}\text { Number } \\
\text { of Open } \\
\text { Lanes }\end{array}$ & $\begin{array}{c}\text { HV } \\
\%\end{array}$ & $\begin{array}{c}\text { Speed } \\
\text { Limit } \\
(\mathbf{m i} / \mathbf{h r})\end{array}$ & $\underset{(\mathbf{m i} / \mathbf{h r})}{\mathbf{F F S}}$ & $\begin{array}{c}\text { Delay } \\
\text { (sec/veh) }\end{array}$ & $\begin{array}{c}\text { Average } \\
\text { Speed } \\
(\mathbf{m i} / \mathbf{h r})\end{array}$ \\
\hline 1 & 500 & 1000 & 660 & 2 & 0 & 55 & 65 & 1.94 & 60.25 \\
\hline 2 & 500 & 1000 & 2640 & 1 & 0 & 55 & 65 & 4.54 & 58.19 \\
\hline 3 & 1000 & 1000 & 660 & 2 & 0 & 55 & 65 & 4.34 & 58.9 \\
\hline 4 & 1500 & 1000 & 660 & 2 & 0 & 55 & 65 & 8.04 & 57.19 \\
\hline 5 & 500 & 1500 & 660 & 2 & 0 & 55 & 65 & 2.04 & 59.83 \\
\hline 6 & 500 & 1500 & 2640 & 1 & 0 & 55 & 65 & 4.94 & 57.96 \\
\hline 7 & 1000 & 1500 & 660 & 2 & 0 & 55 & 65 & 4.70 & 58.62 \\
\hline 8 & 1500 & 1500 & 660 & 2 & 0 & 55 & 65 & 8.69 & 56.72 \\
\hline 9 & 500 & 2000 & 660 & 2 & 0 & 55 & 65 & 2.04 & 59.89 \\
\hline 10 & 500 & 2000 & 2640 & 1 & 0 & 55 & 65 & \begin{tabular}{|l|l|}
5.71 \\
\end{tabular} & 57.49 \\
\hline 11 & 500 & 3000 & 2640 & 1 & 0 & 55 & 65 & 6.96 & 56.93 \\
\hline 12 & 1000 & 3000 & 660 & 2 & 0 & 55 & 65 & 5.75 & 57.74 \\
\hline 13 & 1500 & 3000 & 660 & 2 & 0 & 55 & 65 & 10.48 & 55.79 \\
\hline 14 & 500 & 3500 & 660 & 2 & 0 & 55 & 65 & 2.62 & 58.69 \\
\hline 15 & 500 & 3500 & 2640 & 1 & 0 & 55 & 65 & 7.37 & 56.8 \\
\hline 16 & 1000 & 3500 & 660 & 2 & 0 & 55 & 65 & 6.58 & 57.19 \\
\hline 17 & 1500 & 3500 & 660 & 2 & 0 & 55 & 65 & 15.87 & 55.61 \\
\hline 18 & 500 & 4000 & 660 & 2 & 0 & 55 & 65 & 2.74 & 58.48 \\
\hline 19 & 500 & 4000 & 2640 & 1 & 0 & 55 & 65 & 7.97 & 56.55 \\
\hline 20 & 1000 & 4000 & 660 & 2 & 0 & 55 & 65 & 6.72 & 57.09 \\
\hline 21 & 1500 & 4000 & 660 & 2 & 0 & 55 & 65 & 11.59 & 55.4 \\
\hline 22 & 1000 & 2000 & 660 & 2 & 0 & 55 & 65 & 5.20 & 58.18 \\
\hline 23 & 1500 & 2000 & 660 & 2 & 0 & 55 & 65 & 9.20 & 56.5 \\
\hline 24 & 500 & 2500 & 660 & 2 & 0 & 55 & 65 & 2.26 & 59.25 \\
\hline 25 & 500 & 2500 & 2640 & 1 & 0 & 55 & 65 & 6.26 & 57.29 \\
\hline 26 & 1000 & 2500 & 660 & 2 & 0 & 55 & 65 & 5.36 & 57.95 \\
\hline 27 & 1500 & 2500 & 660 & 2 & 0 & 55 & 65 & 9.95 & 56.06 \\
\hline 28 & 500 & 3000 & 660 & 2 & 0 & 55 & 65 & 2.38 & 59.18 \\
\hline 29 & 500 & 1000 & 660 & 2 & 2 & 55 & 65 & 1.90 & 60.15 \\
\hline 30 & 500 & 1000 & 2640 & 1 & 2 & 55 & 65 & 4.87 & 58.01 \\
\hline 31 & 1000 & 1000 & 660 & 2 & 2 & 55 & 65 & 4.45 & 58.96 \\
\hline 32 & 1500 & 1000 & 660 & 2 & 2 & 55 & 65 & 9.30 & 56.73 \\
\hline 33 & 500 & 1500 & 660 & 2 & 2 & 55 & 65 & 1.99 & 59.91 \\
\hline 34 & 500 & 1500 & 2640 & 1 & 2 & 55 & 65 & 5.26 & 57.97 \\
\hline 35 & 1000 & 1500 & 660 & 2 & 2 & 55 & 65 & 4.93 & 58.48 \\
\hline 36 & 1500 & 1500 & 660 & 2 & 2 & 55 & 65 & 9.28 & 56.57 \\
\hline 37 & 1500 & 2500 & 660 & 2 & 2 & 55 & 65 & 10.96 & 55.82 \\
\hline
\end{tabular}




\begin{tabular}{|c|c|c|c|c|c|c|c|c|c|}
\hline 38 & 500 & 3000 & 660 & 2 & 2 & 55 & 65 & 2.40 & 59.18 \\
\hline 39 & 500 & 3000 & 2640 & 1 & 2 & 55 & 65 & 6.82 & 57.07 \\
\hline 40 & 1000 & 3000 & 660 & 2 & 2 & 55 & 65 & 6.35 & 57.53 \\
\hline 41 & 1500 & 3000 & 660 & 2 & 2 & 55 & 65 & 10.98 & 55.72 \\
\hline 42 & 500 & 3500 & 660 & 2 & 2 & 55 & 65 & 2.54 & 58.89 \\
\hline 43 & 500 & 3500 & 2640 & 1 & 2 & 55 & 65 & 7.70 & 56.6 \\
\hline 44 & 1000 & 3500 & 660 & 2 & 2 & 55 & 65 & 6.59 & 57.23 \\
\hline 45 & 1500 & 3500 & 660 & 2 & 2 & 55 & 65 & 12.38 & 55.14 \\
\hline 46 & 500 & 4000 & 660 & 2 & 2 & 55 & 65 & 2.81 & 58.55 \\
\hline 47 & 500 & 4000 & 2640 & 1 & 2 & 55 & 65 & 8.59 & 56.48 \\
\hline 48 & 1000 & 4000 & 660 & 2 & 2 & 55 & 65 & 6.68 & 57.1 \\
\hline 49 & 1500 & 4000 & 660 & 2 & 2 & 55 & 65 & 12.35 & 55.2 \\
\hline 50 & 500 & 2000 & 660 & 2 & 2 & 55 & 65 & 2.09 & 59.65 \\
\hline 51 & 500 & 2000 & 2640 & 1 & 2 & 55 & 65 & 6.17 & 57.56 \\
\hline 52 & 1000 & 2000 & 660 & 2 & 2 & 55 & 65 & 5.12 & 58.34 \\
\hline 53 & 1500 & 2000 & 660 & 2 & 2 & 55 & 65 & 10.44 & 55.95 \\
\hline 54 & 500 & 2500 & 660 & 2 & 2 & 55 & 65 & 2.30 & 59.22 \\
\hline 55 & 500 & 2500 & 2640 & 1 & 2 & 55 & 65 & 6.48 & 57.25 \\
\hline 56 & 1000 & 2500 & 660 & 2 & 2 & 55 & 65 & 5.46 & 58.07 \\
\hline 57 & 500 & 1000 & 660 & 2 & 4 & 55 & 65 & 2.09 & 60.1 \\
\hline 58 & 500 & 1000 & 2640 & 1 & 4 & 55 & 65 & 4.92 & 58.42 \\
\hline 59 & 1000 & 1000 & 660 & 2 & 4 & 55 & 65 & 4.66 & 59.02 \\
\hline 60 & 1500 & 1000 & 660 & 2 & 4 & 55 & 65 & 11.75 & 55.64 \\
\hline 61 & 500 & 1500 & 660 & 2 & 4 & 55 & 65 & 2.21 & 59.97 \\
\hline 62 & 500 & 1500 & 2640 & 1 & 4 & 55 & 65 & 5.52 & 57.74 \\
\hline 63 & 1000 & 1500 & 660 & 2 & 4 & 55 & 65 & 5.14 & 58.6 \\
\hline 64 & 1500 & 1500 & 660 & 2 & 4 & 55 & 65 & 11.34 & 55.75 \\
\hline 65 & 500 & 2000 & 660 & 2 & 4 & 55 & 65 & 2.16 & 59.63 \\
\hline 66 & 1500 & 2500 & 2640 & 1 & 4 & 55 & 65 & 727.58 & 9.4 \\
\hline 67 & 500 & 3000 & 660 & 2 & 4 & 55 & 65 & 2.52 & 59.08 \\
\hline 68 & 500 & 3000 & 2640 & 1 & 4 & 55 & 65 & 7.54 & 56.99 \\
\hline 69 & 1000 & 3000 & 660 & 2 & 4 & 55 & 65 & 6.24 & 57.63 \\
\hline 70 & 1500 & 3000 & 660 & 2 & 4 & 55 & 65 & 11.90 & 55.46 \\
\hline 71 & 500 & 3500 & 660 & 2 & 4 & 55 & 65 & 2.78 & 58.67 \\
\hline 72 & 500 & 3500 & 2640 & 1 & 4 & 55 & 65 & 7.80 & 56.73 \\
\hline 73 & 1000 & 3500 & 660 & 2 & 4 & 55 & 65 & 6.65 & 57.42 \\
\hline 74 & 1500 & 3500 & 660 & 2 & 4 & 55 & 65 & 14.39 & 54.65 \\
\hline 75 & 500 & 4000 & 660 & 2 & 4 & 55 & 65 & 3.00 & 58.8 \\
\hline 76 & 500 & 4000 & 2640 & 1 & 4 & 55 & 65 & 8.64 & 56.37 \\
\hline 77 & 1000 & 4000 & 660 & 2 & 4 & 55 & 65 & 7.30 & 57.02 \\
\hline 78 & 1500 & 4000 & 660 & 2 & 4 & 55 & 65 & 13.72 & 54.79 \\
\hline
\end{tabular}




\begin{tabular}{|c|c|c|c|c|c|c|c|c|c|}
\hline 79 & 500 & 2000 & 2640 & 1 & 4 & 55 & 65 & 6.14 & 57.5 \\
\hline 80 & 1000 & 2000 & 660 & 2 & 4 & 55 & 65 & 5.46 & 58.22 \\
\hline 81 & 1500 & 2000 & 660 & 2 & 4 & 55 & 65 & 11.32 & 55.79 \\
\hline 82 & 500 & 2500 & 660 & 2 & 4 & 55 & 65 & 2.52 & 59.21 \\
\hline 83 & 500 & 2500 & 2640 & 1 & 4 & 55 & 65 & 6.58 & 57.18 \\
\hline 84 & 1000 & 2500 & 660 & 2 & 4 & 55 & 65 & 5.88 & 57.87 \\
\hline 85 & 1500 & 2500 & 660 & 2 & 4 & 55 & 65 & 12.30 & 55.36 \\
\hline 86 & 500 & 1000 & 660 & 2 & 5 & 55 & 65 & 2.02 & 60.37 \\
\hline 87 & 500 & 1000 & 2640 & 1 & 5 & 55 & 65 & 5.11 & 58.13 \\
\hline 88 & 1000 & 1000 & 660 & 2 & 5 & 55 & 65 & 4.76 & 58.83 \\
\hline 89 & 1500 & 1000 & 660 & 2 & 5 & 55 & 65 & 11.36 & 55.89 \\
\hline 90 & 500 & 1500 & 660 & 2 & 5 & 55 & 65 & 2.09 & 60.02 \\
\hline 91 & 500 & 1500 & 2640 & 1 & 5 & 55 & 65 & 5.23 & 58.09 \\
\hline 92 & 1000 & 1500 & 660 & 2 & 5 & 55 & 65 & 5.12 & 58.58 \\
\hline 93 & 1500 & 1500 & 660 & 2 & 5 & 55 & 65 & 13.27 & 55.04 \\
\hline 94 & 500 & 2000 & 660 & 2 & 5 & 55 & 65 & 2.28 & 59.55 \\
\hline 95 & 500 & 2000 & 2640 & 1 & 5 & 55 & 65 & 6.17 & 57.43 \\
\hline 96 & 1000 & 2000 & 660 & 2 & 5 & 55 & 65 & 5.64 & 58.18 \\
\hline 97 & 1000 & 3000 & 660 & 2 & 5 & 55 & 65 & 6.37 & 57.57 \\
\hline 98 & 1500 & 3000 & 660 & 2 & 5 & 55 & 65 & 12.59 & 55.21 \\
\hline 99 & 500 & 3500 & 660 & 2 & 5 & 55 & 65 & 2.83 & 58.83 \\
\hline 100 & 500 & 3500 & 2640 & 1 & 5 & 55 & 65 & 8.02 & 56.77 \\
\hline 101 & 1000 & 3500 & 660 & 2 & 5 & 55 & 65 & 6.78 & 57.39 \\
\hline 102 & 1500 & 3500 & 660 & 2 & 5 & 55 & 65 & 13.23 & 55.08 \\
\hline 103 & 500 & 4000 & 660 & 2 & 5 & 55 & 65 & 2.78 & 58.81 \\
\hline 104 & 500 & 4000 & 2640 & 1 & 5 & 55 & 65 & 8.59 & 56.28 \\
\hline 105 & 1000 & 4000 & 660 & 2 & 5 & 55 & 65 & 7.50 & 56.89 \\
\hline 106 & 1500 & 4000 & 660 & 2 & 5 & 55 & 65 & 16.40 & 54.01 \\
\hline 107 & 1500 & 2000 & 660 & 2 & 5 & 55 & 65 & 11.86 & 55.59 \\
\hline 108 & 500 & 2500 & 660 & 2 & 5 & 55 & 65 & 2.50 & 59.25 \\
\hline 109 & 500 & 2500 & 2640 & 1 & 5 & 55 & 65 & 6.82 & 57.16 \\
\hline 110 & 1000 & 2500 & 660 & 2 & 5 & 55 & 65 & 4.90 & 58.12 \\
\hline 111 & 1500 & 2500 & 660 & 2 & 5 & 55 & 65 & 13.65 & 54.84 \\
\hline 112 & 500 & 3000 & 660 & 2 & 5 & 55 & 65 & 2.74 & 59.1 \\
\hline 113 & 500 & 3000 & 2640 & 1 & 5 & 55 & 65 & 7.25 & 57.05 \\
\hline 114 & 500 & 1000 & 660 & 2 & 6 & 55 & 65 & 1.94 & 60.45 \\
\hline 115 & 500 & 1000 & 2640 & 1 & 6 & 55 & 65 & 4.99 & 58.26 \\
\hline 116 & 1000 & 1000 & 660 & 2 & 6 & 55 & 65 & 4.97 & 58.86 \\
\hline 117 & 1500 & 1000 & 660 & 2 & 6 & 55 & 65 & 12.02 & 55.59 \\
\hline 118 & 500 & 1500 & 660 & 2 & 6 & 55 & 65 & 2.26 & 59.78 \\
\hline 119 & 500 & 1500 & 2640 & 1 & 6 & 55 & 65 & 5.45 & 57.83 \\
\hline
\end{tabular}




\begin{tabular}{|c|c|c|c|c|c|c|c|c|c|}
\hline 120 & 1000 & 1500 & 660 & 2 & 6 & 55 & 65 & 5.00 & 58.7 \\
\hline 121 & 1500 & 1500 & 660 & 2 & 6 & 55 & 65 & 14.20 & 54.71 \\
\hline 122 & 500 & 2000 & 660 & 2 & 6 & 55 & 65 & 2.42 & 59.59 \\
\hline 123 & 500 & 2000 & 2640 & 1 & 6 & 55 & 65 & 6.34 & 57.46 \\
\hline 124 & 500 & 3000 & 2640 & 1 & 6 & 55 & 65 & 7.54 & 56.79 \\
\hline 125 & 1000 & 3000 & 660 & 2 & 6 & 55 & 65 & 6.49 & 57.7 \\
\hline 126 & 1500 & 3000 & 660 & 2 & 6 & 55 & 65 & 13.88 & 54.77 \\
\hline 127 & 500 & 3500 & 660 & 2 & 6 & 55 & 65 & 2.81 & 58.99 \\
\hline 128 & 500 & 3500 & 2640 & 1 & 6 & 55 & 65 & 7.82 & 56.76 \\
\hline 129 & 1000 & 3500 & 660 & 2 & 6 & 55 & 65 & 6.79 & 57.47 \\
\hline 130 & 1500 & 3500 & 660 & 2 & 6 & 55 & 65 & 15.14 & 54.38 \\
\hline 131 & 500 & 4000 & 660 & 2 & 6 & 55 & 65 & 3.02 & 58.78 \\
\hline 132 & 500 & 4000 & 2640 & 1 & 6 & 55 & 65 & 8.52 & 56.53 \\
\hline 133 & 1000 & 4000 & 660 & 2 & 6 & 55 & 65 & 6.97 & 57.21 \\
\hline 134 & 1500 & 4000 & 660 & 2 & 6 & 55 & 65 & 15.39 & 54.37 \\
\hline 135 & 1000 & 2000 & 660 & 2 & 6 & 55 & 65 & 5.50 & 58.29 \\
\hline 136 & 1500 & 2000 & 660 & 2 & 6 & 55 & 65 & 19.47 & 52.72 \\
\hline 137 & 500 & 2500 & 660 & 2 & 6 & 55 & 65 & 2.62 & 59.37 \\
\hline 138 & 500 & 2500 & 2640 & 1 & 6 & 55 & 65 & 6.94 & 57.22 \\
\hline 139 & 1000 & 2500 & 660 & 2 & 6 & 55 & 65 & 6.13 & 57.93 \\
\hline 140 & 1500 & 2500 & 660 & 2 & 6 & 55 & 65 & 13.44 & 54.88 \\
\hline 141 & 500 & 3000 & 660 & 2 & 6 & 55 & 65 & 2.71 & 59.19 \\
\hline 142 & 500 & 1000 & 660 & 2 & 8 & 55 & 65 & 2.30 & 60.27 \\
\hline 143 & 500 & 1000 & 2640 & 1 & 8 & 55 & 65 & 5.74 & 57.96 \\
\hline 144 & 1000 & 1000 & 660 & 2 & 8 & 55 & 65 & 4.94 & 58.78 \\
\hline 145 & 1500 & 1000 & 660 & 2 & 8 & 55 & 65 & 27.27 & 49.72 \\
\hline 146 & 500 & 1500 & 660 & 2 & 8 & 55 & 65 & 2.40 & 60.22 \\
\hline 147 & 500 & 1500 & 2640 & 1 & 8 & 55 & 65 & 5.62 & 57.92 \\
\hline 148 & 1000 & 1500 & 660 & 2 & 8 & 55 & 65 & 5.66 & 58.28 \\
\hline 149 & 1500 & 1500 & 660 & 2 & 8 & 55 & 65 & 16.51 & 53.66 \\
\hline 150 & 500 & 2000 & 660 & 2 & 8 & 55 & 65 & 2.35 & 59.74 \\
\hline 151 & 500 & 2000 & 2640 & 1 & 8 & 55 & 65 & 6.50 & 57.55 \\
\hline 152 & 500 & 3000 & 2640 & 1 & 8 & 55 & 65 & 7.68 & 57.19 \\
\hline 153 & 1000 & 3000 & 660 & 2 & 8 & 55 & 65 & 6.98 & 57.35 \\
\hline 154 & 1500 & 3000 & 660 & 2 & 8 & 55 & 65 & 28.10 & 50.24 \\
\hline 155 & 500 & 3500 & 660 & 2 & 8 & 55 & 65 & 2.78 & 59.12 \\
\hline 156 & 500 & 3500 & 2640 & 1 & 8 & 55 & 65 & 8.11 & 56.82 \\
\hline 157 & 1000 & 3500 & 660 & 2 & 8 & 55 & 65 & 7.01 & 57.32 \\
\hline 158 & 1500 & 3500 & 660 & 2 & 8 & 55 & 65 & 30.72 & 49.57 \\
\hline 159 & 500 & 4000 & 660 & 2 & 8 & 55 & 65 & 3.00 & 58.61 \\
\hline 160 & 500 & 4000 & 2640 & 1 & 8 & 55 & 65 & 9.10 & 56.42 \\
\hline
\end{tabular}




\begin{tabular}{|c|c|c|c|c|c|c|c|c|c|}
\hline 161 & 1000 & 4000 & 660 & 2 & 8 & 55 & 65 & 7.15 & 57.11 \\
\hline 162 & 1500 & 4000 & 660 & 2 & 8 & 55 & 65 & 27.57 & 50.8 \\
\hline 163 & 1000 & 2000 & 660 & 2 & 8 & 55 & 65 & 5.68 & 58.18 \\
\hline 164 & 1500 & 2000 & 660 & 2 & 8 & 55 & 65 & 20.90 & 52.26 \\
\hline 165 & 500 & 2500 & 660 & 2 & 8 & 55 & 65 & 2.66 & 59.27 \\
\hline 166 & 500 & 2500 & 2640 & 1 & 8 & 55 & 65 & 7.27 & 57.07 \\
\hline 167 & 1000 & 2500 & 660 & 2 & 8 & 55 & 65 & 6.01 & 57.92 \\
\hline 168 & 1500 & 2500 & 660 & 2 & 8 & 55 & 65 & 29.16 & 49.79 \\
\hline 169 & 500 & 3000 & 660 & 2 & 8 & 55 & 65 & 2.69 & 58.95 \\
\hline 170 & 500 & 1000 & 660 & 2 & 10 & 55 & 65 & 2.18 & 60.37 \\
\hline 171 & 500 & 1000 & 2640 & 1 & 10 & 55 & 65 & 5.45 & 58.16 \\
\hline 172 & 1000 & 1000 & 660 & 2 & 10 & 55 & 65 & 5.36 & 58.74 \\
\hline 173 & 1500 & 1000 & 660 & 2 & 10 & 55 & 65 & 64.11 & 39.43 \\
\hline 174 & 500 & 1500 & 660 & 2 & 10 & 55 & 65 & 2.33 & 60.25 \\
\hline 175 & 500 & 1500 & 2640 & 1 & 10 & 55 & 65 & 5.71 & 57.99 \\
\hline 176 & 1000 & 1500 & 660 & 2 & 10 & 55 & 65 & 5.40 & 58.58 \\
\hline 177 & 1500 & 1500 & 660 & 2 & 10 & 55 & 65 & 56.05 & 41.82 \\
\hline 178 & 500 & 2000 & 660 & 2 & 10 & 55 & 65 & 2.38 & 59.96 \\
\hline 179 & 500 & 2000 & 2640 & 1 & 10 & 55 & 65 & 6.53 & 57.41 \\
\hline 180 & 500 & 3000 & 2640 & 1 & 10 & 55 & 65 & 7.75 & 56.99 \\
\hline 181 & 1000 & 3000 & 660 & 2 & 10 & 55 & 65 & 6.58 & 57.57 \\
\hline 182 & 1500 & 3000 & 660 & 2 & 10 & 55 & 65 & 45.33 & 45.55 \\
\hline 183 & 500 & 3500 & 660 & 2 & 10 & 55 & 65 & 3.05 & 58.89 \\
\hline 184 & 500 & 3500 & 2640 & 1 & 10 & 55 & 65 & 8.74 & 56.5 \\
\hline 185 & 1000 & 3500 & 660 & 2 & 10 & 55 & 65 & 6.90 & 57.47 \\
\hline 186 & 1500 & 3500 & 660 & 2 & 10 & 55 & 65 & 54.03 & 43.83 \\
\hline 187 & 500 & 4000 & 660 & 2 & 10 & 55 & 65 & 3.14 & 58.77 \\
\hline 188 & 500 & 4000 & 2640 & 1 & 10 & 55 & 65 & 9.07 & 56.37 \\
\hline 189 & 1000 & 4000 & 660 & 2 & 10 & 55 & 65 & 7.70 & 57.07 \\
\hline 190 & 1500 & 4000 & 660 & 2 & 10 & 55 & 65 & 40.48 & 47.33 \\
\hline 191 & 1000 & 2000 & 660 & 2 & 10 & 55 & 65 & 5.87 & 58.31 \\
\hline 192 & 1500 & 2000 & 660 & 2 & 10 & 55 & 65 & 28.25 & 49.82 \\
\hline 193 & 500 & 2500 & 660 & 2 & 10 & 55 & 65 & 2.74 & 59.55 \\
\hline 194 & 500 & 2500 & 2640 & 1 & 10 & 55 & 65 & 7.51 & 57.37 \\
\hline 195 & 1000 & 2500 & 660 & 2 & 10 & 55 & 65 & 6.32 & 58.02 \\
\hline 196 & 1500 & 2500 & 660 & 2 & 10 & 55 & 65 & 50.38 & 44.01 \\
\hline 197 & 500 & 3000 & 660 & 2 & 10 & 55 & 65 & 2.83 & 59.3 \\
\hline
\end{tabular}


Table B.4: Saturated Condition - $55 \mathrm{mph}$ Speed Limit

\begin{tabular}{|c|c|c|c|c|c|c|c|c|c|}
\hline $\begin{array}{c}\text { Scenario } \\
\text { ID }\end{array}$ & $\begin{array}{c}\text { Flow } \\
\text { (veh/h/ln) }\end{array}$ & $\begin{array}{c}\text { Activity } \\
\text { Length } \\
\text { (ft) }\end{array}$ & $\begin{array}{l}\text { Merge } \\
\text { Length }\end{array}$ & $\begin{array}{c}\text { Number } \\
\text { of Open } \\
\text { Lanes }\end{array}$ & $\underset{\%}{\mathbf{H V}}$ & $\begin{array}{l}\text { Speed } \\
\text { Limit } \\
(\mathrm{mi} / \mathrm{hr})\end{array}$ & $\underset{(\mathrm{mi} / \mathrm{hr})}{\text { FFS }}$ & $\begin{array}{c}\text { Average } \\
\text { Delay } \\
\text { (sec/veh) }\end{array}$ & $\begin{array}{c}\text { Average } \\
\text { Speed } \\
(\mathrm{mi} / \mathrm{hr})\end{array}$ \\
\hline 1 & 1000 & 1000 & 2640 & 1 & 0 & 55 & 65 & 177.67 & 25.77 \\
\hline 2 & 1500 & 1000 & 2640 & 1 & 0 & 55 & 65 & 657.05 & 9.45 \\
\hline 3 & 2000 & 1000 & 660 & 2 & 0 & 55 & 65 & 203.68 & 21.41 \\
\hline 4 & 2000 & 1000 & 2640 & 1 & 0 & 55 & 65 & 780.19 & 8.56 \\
\hline 5 & 2400 & 1000 & 660 & 2 & 0 & 55 & 65 & 268.18 & 18.01 \\
\hline 6 & 2400 & 1000 & 2640 & 1 & 0 & 55 & 65 & 834.69 & 8.49 \\
\hline 7 & 1000 & 1500 & 2640 & 1 & 0 & 55 & 65 & 184.22 & 25.65 \\
\hline 8 & 1500 & 1500 & 2640 & 1 & 0 & 55 & 65 & 632.28 & 9.91 \\
\hline 9 & 2000 & 1500 & 660 & 2 & 0 & 55 & 65 & 205.14 & 22.01 \\
\hline 10 & 2000 & 1500 & 2640 & 1 & 0 & 55 & 65 & 756.67 & 8.87 \\
\hline 11 & 2400 & 1500 & 660 & 2 & 0 & 55 & 65 & 264.97 & 18.5 \\
\hline 12 & 2400 & 1500 & 2640 & 1 & 0 & 55 & 65 & 854.39 & 8.52 \\
\hline 13 & 1000 & 2000 & 2640 & 1 & 0 & 55 & 65 & 171.32 & 27.34 \\
\hline 14 & 1500 & 2000 & 2640 & 1 & 0 & 55 & 65 & 647.94 & 10.14 \\
\hline 15 & 1000 & 3000 & 2640 & 1 & 0 & 55 & 65 & 190.10 & 26.68 \\
\hline 16 & 1500 & 3000 & 2640 & 1 & 0 & 55 & 65 & 629.07 & 10.93 \\
\hline 17 & 2000 & 3000 & 660 & 2 & 0 & 55 & 65 & 209.99 & 23.31 \\
\hline 18 & 2000 & 3000 & 2640 & 1 & 0 & 55 & 65 & 772.99 & 9.68 \\
\hline 19 & 2400 & 3000 & 660 & 2 & 0 & 55 & 65 & 261.84 & 20.42 \\
\hline 20 & 2400 & 3000 & 2640 & 1 & 0 & 55 & 65 & 833.96 & 9.19 \\
\hline 21 & 1000 & 3500 & 2640 & 1 & 0 & 55 & 65 & 187.19 & 27.29 \\
\hline 22 & 1500 & 3500 & 2640 & 1 & 0 & 55 & 65 & 644.41 & 11 \\
\hline 23 & 2000 & 3500 & 660 & 2 & 0 & 55 & 65 & 209.71 & 23.83 \\
\hline 24 & 2000 & 3500 & 2640 & 1 & 0 & 55 & 65 & 788.03 & 9.77 \\
\hline 25 & 2400 & 3500 & 660 & 2 & 0 & 55 & 65 & 265.00 & 20.71 \\
\hline 26 & 2400 & 3500 & 2640 & 1 & 0 & 55 & 65 & 872.40 & 9.57 \\
\hline 27 & 1000 & 4000 & 2640 & 1 & 0 & 55 & 65 & 185.12 & 27.93 \\
\hline 28 & 1500 & 4000 & 2640 & 1 & 0 & 55 & 65 & 630.75 & 11.43 \\
\hline 29 & 2000 & 4000 & 660 & 2 & 0 & 55 & 65 & 206.70 & 24.66 \\
\hline 30 & 2000 & 4000 & 2640 & 1 & 0 & 55 & 65 & 796.79 & 10.09 \\
\hline 31 & 2400 & 4000 & 660 & 2 & 0 & 55 & 65 & 265.13 & 21.22 \\
\hline 32 & 2400 & 4000 & 2640 & 1 & 0 & 55 & 65 & 867.99 & 9.81 \\
\hline 33 & 1000 & 1000 & 2640 & 1 & 2 & 55 & 65 & 241.07 & 20.97 \\
\hline 34 & 1500 & 1000 & 2640 & 1 & 2 & 55 & 65 & 706.05 & 8.73 \\
\hline 35 & 2000 & 1000 & 660 & 2 & 2 & 55 & 65 & 238.31 & 19.3 \\
\hline 36 & 2000 & 1000 & 2640 & 1 & 2 & 55 & 65 & 830.06 & 8.21 \\
\hline
\end{tabular}




\begin{tabular}{|c|c|c|c|c|c|c|c|c|c|}
\hline 37 & 2400 & 1000 & 660 & 2 & 2 & 55 & 65 & 278.16 & 17.55 \\
\hline 38 & 2400 & 1000 & 2640 & 1 & 2 & 55 & 65 & 886.29 & 8.08 \\
\hline 39 & 1000 & 1500 & 2640 & 1 & 2 & 55 & 65 & 224.02 & 22.59 \\
\hline 40 & 1500 & 1500 & 2640 & 1 & 2 & 55 & 65 & 692.99 & 9.33 \\
\hline 41 & 2000 & 1500 & 660 & 2 & 2 & 55 & 65 & 230.88 & 20.32 \\
\hline 42 & 2000 & 1500 & 2640 & 1 & 2 & 55 & 65 & 839.44 & 8.42 \\
\hline 43 & 2400 & 1500 & 660 & 2 & 2 & 55 & 65 & 276.20 & 18.15 \\
\hline 44 & 2400 & 1500 & 2640 & 1 & 2 & 55 & 65 & 882.30 & 8.34 \\
\hline 45 & 1000 & 2000 & 2640 & 1 & 2 & 55 & 65 & 248.89 & 21.38 \\
\hline 46 & 1500 & 2000 & 2640 & 1 & 2 & 55 & 65 & 686.51 & 9.66 \\
\hline 47 & 2000 & 2000 & 660 & 2 & 2 & 55 & 65 & 231.41 & 20.93 \\
\hline 48 & 2000 & 2000 & 2640 & 1 & 2 & 55 & 65 & 835.78 & 8.58 \\
\hline 49 & 2400 & 2000 & 660 & 2 & 2 & 55 & 65 & 278.21 & 18.65 \\
\hline 50 & 2400 & 2000 & 2640 & 1 & 2 & 55 & 65 & 904.94 & 8.38 \\
\hline 51 & 2400 & 3000 & 660 & 2 & 2 & 55 & 65 & 274.49 & 19.77 \\
\hline 52 & 2400 & 3000 & 2640 & 1 & 2 & 55 & 65 & 881.23 & 9 \\
\hline 53 & 1000 & 3500 & 2640 & 1 & 2 & 55 & 65 & 218.92 & 24.79 \\
\hline 54 & 1500 & 3500 & 2640 & 1 & 2 & 55 & 65 & 683.58 & 10.52 \\
\hline 55 & 2000 & 3500 & 660 & 2 & 2 & 55 & 65 & 239.12 & 22.04 \\
\hline 56 & 2000 & 3500 & 2640 & 1 & 2 & 55 & 65 & 866.63 & 9.17 \\
\hline 57 & 2400 & 3500 & 660 & 2 & 2 & 55 & 65 & 273.53 & 20.36 \\
\hline 58 & 2400 & 3500 & 2640 & 1 & 2 & 55 & 65 & 877.62 & 9.53 \\
\hline 59 & 1000 & 4000 & 2640 & 1 & 2 & 55 & 65 & 253.81 & 22.75 \\
\hline 60 & 1500 & 4000 & 2640 & 1 & 2 & 55 & 65 & 672.24 & 10.87 \\
\hline 61 & 2000 & 4000 & 660 & 2 & 2 & 55 & 65 & 239.43 & 22.4 \\
\hline 62 & 2000 & 4000 & 2640 & 1 & 2 & 55 & 65 & 822.71 & 9.84 \\
\hline 63 & 2400 & 4000 & 660 & 2 & 2 & 55 & 65 & 278.22 & 20.53 \\
\hline 64 & 2400 & 4000 & 2640 & 1 & 2 & 55 & 65 & 942.98 & 9.27 \\
\hline 65 & 1000 & 1000 & 2640 & 1 & 4 & 55 & 65 & 301.88 & 17.58 \\
\hline 66 & 1500 & 1000 & 2640 & 1 & 4 & 55 & 65 & 754.88 & 8.4 \\
\hline 67 & 2000 & 1000 & 660 & 2 & 4 & 55 & 65 & 247.54 & 18.86 \\
\hline 68 & 2000 & 1000 & 2640 & 1 & 4 & 55 & 65 & 859.18 & 7.97 \\
\hline 69 & 2400 & 1000 & 660 & 2 & 4 & 55 & 65 & 292.45 & 16.96 \\
\hline 70 & 2400 & 1000 & 2640 & 1 & 4 & 55 & 65 & 965.99 & 7.64 \\
\hline 71 & 1000 & 1500 & 2640 & 1 & 4 & 55 & 65 & 309.44 & 17.58 \\
\hline 72 & 1500 & 1500 & 2640 & 1 & 4 & 55 & 65 & 775.17 & 8.53 \\
\hline 73 & 2000 & 1500 & 660 & 2 & 4 & 55 & 65 & 250.59 & 19.22 \\
\hline 74 & 2000 & 1500 & 2640 & 1 & 4 & 55 & 65 & 891.43 & 8.04 \\
\hline 75 & 2400 & 1500 & 660 & 2 & 4 & 55 & 65 & 287.37 & 17.69 \\
\hline 76 & 2400 & 1500 & 2640 & 1 & 4 & 55 & 65 & 944.39 & 7.88 \\
\hline 77 & 1000 & 2000 & 2640 & 1 & 4 & 55 & 65 & 337.19 & 16.92 \\
\hline
\end{tabular}




\begin{tabular}{|c|c|c|c|c|c|c|c|c|c|}
\hline 78 & 1500 & 2000 & 2640 & 1 & 4 & 55 & 65 & 755.62 & 9.03 \\
\hline 79 & 2000 & 2000 & 660 & 2 & 4 & 55 & 65 & 267.80 & 19.03 \\
\hline 80 & 2000 & 2000 & 2640 & 1 & 4 & 55 & 65 & 859.61 & 8.51 \\
\hline 81 & 2400 & 2000 & 660 & 2 & 4 & 55 & 65 & 297.78 & 17.86 \\
\hline 82 & 2400 & 3000 & 660 & 2 & 4 & 55 & 65 & 292.28 & 18.99 \\
\hline 83 & 2400 & 3000 & 2640 & 1 & 4 & 55 & 65 & 933.21 & 8.95 \\
\hline 84 & 1000 & 3500 & 2640 & 1 & 4 & 55 & 65 & 357.52 & 17.18 \\
\hline 85 & 1500 & 3500 & 2640 & 1 & 4 & 55 & 65 & 742.89 & 9.74 \\
\hline 86 & 2000 & 3500 & 660 & 2 & 4 & 55 & 65 & 250.95 & 21.33 \\
\hline 87 & 2000 & 3500 & 2640 & 1 & 4 & 55 & 65 & 867.39 & 9.14 \\
\hline 88 & 2400 & 3500 & 660 & 2 & 4 & 55 & 65 & 295.41 & 19.43 \\
\hline 89 & 2400 & 3500 & 2640 & 1 & 4 & 55 & 65 & 936.15 & 9.11 \\
\hline 90 & 1000 & 4000 & 2640 & 1 & 4 & 55 & 65 & 310.54 & 19.48 \\
\hline 91 & 1500 & 4000 & 2640 & 1 & 4 & 55 & 65 & 721.78 & 10.31 \\
\hline 92 & 2000 & 4000 & 660 & 2 & 4 & 55 & 65 & 255.87 & 21.62 \\
\hline 93 & 2000 & 4000 & 2640 & 1 & 4 & 55 & 65 & 890.11 & 9.16 \\
\hline 94 & 2400 & 4000 & 660 & 2 & 4 & 55 & 65 & 290.31 & 20.7 \\
\hline 95 & 2400 & 4000 & 2640 & 1 & 4 & 55 & 65 & 939.59 & 9.25 \\
\hline 96 & 1000 & 1000 & 2640 & 1 & 5 & 55 & 65 & 355.58 & 15.1 \\
\hline 97 & 1500 & 1000 & 2640 & 1 & 5 & 55 & 65 & 739.05 & 8.42 \\
\hline 98 & 2000 & 1000 & 660 & 2 & 5 & 55 & 65 & 257.86 & 18.22 \\
\hline 99 & 2000 & 1000 & 2640 & 1 & 5 & 55 & 65 & 899.99 & 7.75 \\
\hline 100 & 2400 & 1000 & 660 & 2 & 5 & 55 & 65 & 302.41 & 16.73 \\
\hline 101 & 2400 & 1000 & 2640 & 1 & 5 & 55 & 65 & 949.82 & 7.75 \\
\hline 102 & 1000 & 1500 & 2640 & 1 & 5 & 55 & 65 & 293.71 & 18.23 \\
\hline 103 & 1500 & 1500 & 2640 & 1 & 5 & 55 & 65 & 769.46 & 8.48 \\
\hline 104 & 2000 & 1500 & 660 & 2 & 5 & 55 & 65 & 272.71 & 18.23 \\
\hline 105 & 2000 & 1500 & 2640 & 1 & 5 & 55 & 65 & 892.35 & 8.04 \\
\hline 106 & 2400 & 1500 & 660 & 2 & 5 & 55 & 65 & 307.91 & 16.9 \\
\hline 107 & 2400 & 1500 & 2640 & 1 & 5 & 55 & 65 & 982.69 & 7.77 \\
\hline 108 & 1000 & 2000 & 2640 & 1 & 5 & 55 & 65 & 355.90 & 16.11 \\
\hline 109 & 1500 & 2000 & 2640 & 1 & 5 & 55 & 65 & 783.00 & 8.78 \\
\hline 110 & 2000 & 2000 & 660 & 2 & 5 & 55 & 65 & 274.19 & 18.62 \\
\hline 111 & 1500 & 3000 & 2640 & 1 & 5 & 55 & 65 & 777.73 & 9.36 \\
\hline 112 & 2000 & 3000 & 660 & 2 & 5 & 55 & 65 & 264.57 & 20.16 \\
\hline 113 & 2000 & 3000 & 2640 & 1 & 5 & 55 & 65 & 912.05 & 8.76 \\
\hline 114 & 2400 & 3000 & 660 & 2 & 5 & 55 & 65 & 299.44 & 18.83 \\
\hline 115 & 2400 & 3000 & 2640 & 1 & 5 & 55 & 65 & 955.79 & 8.69 \\
\hline 116 & 1000 & 3500 & 2640 & 1 & 5 & 55 & 65 & 366.06 & 16.76 \\
\hline 117 & 1500 & 3500 & 2640 & 1 & 5 & 55 & 65 & 763.89 & 9.62 \\
\hline 118 & 2000 & 3500 & 660 & 2 & 5 & 55 & 65 & 264.53 & 20.6 \\
\hline
\end{tabular}




\begin{tabular}{|c|c|c|c|c|c|c|c|c|c|}
\hline 119 & 2000 & 3500 & 2640 & 1 & 5 & 55 & 65 & 894.47 & 9.04 \\
\hline 120 & 2400 & 3500 & 660 & 2 & 5 & 55 & 65 & 299.70 & 19.27 \\
\hline 121 & 2400 & 3500 & 2640 & 1 & 5 & 55 & 65 & 949.63 & 8.91 \\
\hline 122 & 1000 & 4000 & 2640 & 1 & 5 & 55 & 65 & 376.64 & 16.59 \\
\hline 123 & 1500 & 4000 & 2640 & 1 & 5 & 55 & 65 & 767.35 & 9.73 \\
\hline 124 & 2000 & 4000 & 660 & 2 & 5 & 55 & 65 & 280.20 & 20.46 \\
\hline 125 & 2000 & 4000 & 2640 & 1 & 5 & 55 & 65 & 895.97 & 9.24 \\
\hline 126 & 2400 & 4000 & 660 & 2 & 5 & 55 & 65 & 296.95 & 19.84 \\
\hline 127 & 2400 & 4000 & 2640 & 1 & 5 & 55 & 65 & 925.54 & 8.99 \\
\hline 128 & 1000 & 1000 & 2640 & 1 & 6 & 55 & 65 & 373.01 & 14.64 \\
\hline 129 & 1500 & 1000 & 2640 & 1 & 6 & 55 & 65 & 767.61 & 8.24 \\
\hline 130 & 2000 & 1000 & 660 & 2 & 6 & 55 & 65 & 262.64 & 18.07 \\
\hline 131 & 2000 & 1000 & 2640 & 1 & 6 & 55 & 65 & 909.09 & 7.54 \\
\hline 132 & 2400 & 1000 & 660 & 2 & 6 & 55 & 65 & 307.80 & 16.45 \\
\hline 133 & 2400 & 1000 & 2640 & 1 & 6 & 55 & 65 & 1002.54 & 7.32 \\
\hline 134 & 1000 & 1500 & 2640 & 1 & 6 & 55 & 65 & 425.60 & 13.35 \\
\hline 135 & 1500 & 1500 & 2640 & 1 & 6 & 55 & 65 & 805.92 & 8.28 \\
\hline 136 & 2000 & 1500 & 660 & 2 & 6 & 55 & 65 & 262.57 & 18.71 \\
\hline 137 & 2000 & 1500 & 2640 & 1 & 6 & 55 & 65 & 869.93 & 8.06 \\
\hline 138 & 2400 & 1500 & 660 & 2 & 6 & 55 & 65 & 309.50 & 16.86 \\
\hline 139 & 2400 & 1500 & 2640 & 1 & 6 & 55 & 65 & 972.17 & 7.86 \\
\hline 140 & 1000 & 2000 & 2640 & 1 & 6 & 55 & 65 & 415.36 & 13.9 \\
\hline 141 & 1500 & 2000 & 2640 & 1 & 6 & 55 & 65 & 762.21 & 8.81 \\
\hline 142 & 2000 & 2000 & 660 & 2 & 6 & 55 & 65 & 274.50 & 18.62 \\
\hline 143 & 2000 & 2000 & 2640 & 1 & 6 & 55 & 65 & 887.23 & 8.2 \\
\hline 144 & 2000 & 3000 & 660 & 2 & 6 & 55 & 65 & 275.00 & 19.7 \\
\hline 145 & 2000 & 3000 & 2640 & 1 & 6 & 55 & 65 & 911.86 & 8.66 \\
\hline 146 & 2400 & 3000 & 660 & 2 & 6 & 55 & 65 & 296.70 & 18.87 \\
\hline 147 & 2400 & 3000 & 2640 & 1 & 6 & 55 & 65 & 978.27 & 8.37 \\
\hline 148 & 1000 & 3500 & 2640 & 1 & 6 & 55 & 65 & 414.35 & 14.99 \\
\hline 149 & 1500 & 3500 & 2640 & 1 & 6 & 55 & 65 & 826.78 & 9.11 \\
\hline 150 & 2000 & 3500 & 660 & 2 & 6 & 55 & 65 & 270.37 & 20.45 \\
\hline 151 & 2000 & 3500 & 2640 & 1 & 6 & 55 & 65 & 863.12 & 9.11 \\
\hline 152 & 2400 & 3500 & 660 & 2 & 6 & 55 & 65 & 307.54 & 18.95 \\
\hline 153 & 2400 & 3500 & 2640 & 1 & 6 & 55 & 65 & 974.30 & 8.88 \\
\hline 154 & 1000 & 4000 & 2640 & 1 & 6 & 55 & 65 & 462.81 & 14.07 \\
\hline 155 & 1500 & 4000 & 2640 & 1 & 6 & 55 & 65 & 770.53 & 9.84 \\
\hline 156 & 2000 & 4000 & 660 & 2 & 6 & 55 & 65 & 274.31 & 20.74 \\
\hline 157 & 2000 & 4000 & 2640 & 1 & 6 & 55 & 65 & 880.33 & 9.34 \\
\hline 158 & 2400 & 4000 & 660 & 2 & 6 & 55 & 65 & 322.22 & 19.05 \\
\hline 159 & 2400 & 4000 & 2640 & 1 & 6 & 55 & 65 & 966.24 & 9.11 \\
\hline
\end{tabular}




\begin{tabular}{|c|c|c|c|c|c|c|c|c|c|}
\hline 160 & 1000 & 1000 & 2640 & 1 & 8 & 55 & 65 & 434.99 & 12.73 \\
\hline 161 & 1500 & 1000 & 2640 & 1 & 8 & 55 & 65 & 823.19 & 7.8 \\
\hline 162 & 2000 & 1000 & 660 & 2 & 8 & 55 & 65 & 288.56 & 16.95 \\
\hline 163 & 2000 & 1000 & 2640 & 1 & 8 & 55 & 65 & 938.30 & 7.5 \\
\hline 164 & 2400 & 1000 & 660 & 2 & 8 & 55 & 65 & 318.88 & 16.03 \\
\hline 165 & 2400 & 1000 & 2640 & 1 & 8 & 55 & 65 & 976.93 & 7.63 \\
\hline 166 & 1000 & 1500 & 2640 & 1 & 8 & 55 & 65 & 456.22 & 12.59 \\
\hline 167 & 1500 & 1500 & 2640 & 1 & 8 & 55 & 65 & 817.74 & 8.09 \\
\hline 168 & 2000 & 1500 & 660 & 2 & 8 & 55 & 65 & 281.45 & 17.75 \\
\hline 169 & 2000 & 1500 & 2640 & 1 & 8 & 55 & 65 & 923.09 & 7.64 \\
\hline 170 & 2400 & 1500 & 660 & 2 & 8 & 55 & 65 & 303.57 & 16.98 \\
\hline 171 & 2400 & 1500 & 2640 & 1 & 8 & 55 & 65 & 1007.66 & 7.49 \\
\hline 172 & 1000 & 2000 & 2640 & 1 & 8 & 55 & 65 & 444.71 & 13.22 \\
\hline 173 & 1500 & 2000 & 2640 & 1 & 8 & 55 & 65 & 835.33 & 8.29 \\
\hline 174 & 2000 & 2000 & 660 & 2 & 8 & 55 & 65 & 273.19 & 18.65 \\
\hline 175 & 2000 & 2000 & 2640 & 1 & 8 & 55 & 65 & 939.80 & 7.94 \\
\hline 176 & 2400 & 2000 & 660 & 2 & 8 & 55 & 65 & 320.97 & 17.17 \\
\hline 177 & 2000 & 3000 & 2640 & 1 & 8 & 55 & 65 & 930.36 & 8.34 \\
\hline 178 & 2400 & 3000 & 660 & 2 & 8 & 55 & 65 & 311.60 & 18.41 \\
\hline 179 & 2400 & 3000 & 2640 & 1 & 8 & 55 & 65 & 997.07 & 8.48 \\
\hline 180 & 1000 & 3500 & 2640 & 1 & 8 & 55 & 65 & 457.63 & 14.03 \\
\hline 181 & 1500 & 3500 & 2640 & 1 & 8 & 55 & 65 & 786.80 & 9.42 \\
\hline 182 & 2000 & 3500 & 660 & 2 & 8 & 55 & 65 & 284.82 & 19.7 \\
\hline 183 & 2000 & 3500 & 2640 & 1 & 8 & 55 & 65 & 946.88 & 8.7 \\
\hline 184 & 2400 & 3500 & 660 & 2 & 8 & 55 & 65 & 301.08 & 19.14 \\
\hline 185 & 2400 & 3500 & 2640 & 1 & 8 & 55 & 65 & 988.72 & 8.68 \\
\hline 186 & 1000 & 4000 & 2640 & 1 & 8 & 55 & 65 & 444.65 & 14.49 \\
\hline 187 & 1500 & 4000 & 2640 & 1 & 8 & 55 & 65 & 830.82 & 9.34 \\
\hline 188 & 2000 & 4000 & 660 & 2 & 8 & 55 & 65 & 284.03 & 20.14 \\
\hline 189 & 2000 & 4000 & 2640 & 1 & 8 & 55 & 65 & 932.20 & 8.94 \\
\hline 190 & 2400 & 4000 & 660 & 2 & 8 & 55 & 65 & 304.68 & 19.41 \\
\hline 191 & 2400 & 4000 & 2640 & 1 & 8 & 55 & 65 & 971.14 & 8.93 \\
\hline 192 & 1000 & 1000 & 2640 & 1 & 10 & 55 & 65 & 483.30 & 11.72 \\
\hline 193 & 1500 & 1000 & 2640 & 1 & 10 & 55 & 65 & 838.30 & 7.69 \\
\hline 194 & 2000 & 1000 & 660 & 2 & 10 & 55 & 65 & 291.11 & 16.78 \\
\hline 195 & 2000 & 1000 & 2640 & 1 & 10 & 55 & 65 & 1002.99 & 7.14 \\
\hline 196 & 2400 & 1000 & 660 & 2 & 10 & 55 & 65 & 331.05 & 15.71 \\
\hline 197 & 2400 & 1000 & 2640 & 1 & 10 & 55 & 65 & 1031.78 & 7.18 \\
\hline 198 & 1000 & 1500 & 2640 & 1 & 10 & 55 & 65 & 526.41 & 11.33 \\
\hline 199 & 1500 & 1500 & 2640 & 1 & 10 & 55 & 65 & 869.72 & 7.75 \\
\hline 200 & 2000 & 1500 & 660 & 2 & 10 & 55 & 65 & 305.03 & 16.86 \\
\hline
\end{tabular}




\begin{tabular}{|c|c|c|c|c|c|c|c|c|c|}
\hline 201 & 2000 & 1500 & 2640 & 1 & 10 & 55 & 65 & 935.70 & 7.51 \\
\hline 202 & 2400 & 1500 & 660 & 2 & 10 & 55 & 65 & 319.02 & 16.44 \\
\hline 203 & 2400 & 1500 & 2640 & 1 & 10 & 55 & 65 & 999.53 & 7.55 \\
\hline 204 & 1000 & 2000 & 2640 & 1 & 10 & 55 & 65 & 564.48 & 10.85 \\
\hline 205 & 1500 & 2000 & 2640 & 1 & 10 & 55 & 65 & 823.71 & 8.3 \\
\hline 206 & 2000 & 3000 & 2640 & 1 & 10 & 55 & 65 & 973.62 & 8.32 \\
\hline 207 & 2400 & 3000 & 660 & 2 & 10 & 55 & 65 & 320.41 & 17.91 \\
\hline 208 & 2400 & 3000 & 2640 & 1 & 10 & 55 & 65 & 1050.50 & 8.08 \\
\hline 209 & 1000 & 3500 & 2640 & 1 & 10 & 55 & 65 & 569.63 & 11.84 \\
\hline 210 & 1500 & 3500 & 2640 & 1 & 10 & 55 & 65 & 871.28 & 8.7 \\
\hline 211 & 2000 & 3500 & 660 & 2 & 10 & 55 & 65 & 284.60 & 19.68 \\
\hline 212 & 2000 & 3500 & 2640 & 1 & 10 & 55 & 65 & 1008.75 & 8.34 \\
\hline 213 & 2400 & 3500 & 660 & 2 & 10 & 55 & 65 & 317.66 & 18.59 \\
\hline 214 & 2400 & 3500 & 2640 & 1 & 10 & 55 & 65 & 1042.29 & 8.24 \\
\hline 215 & 1000 & 4000 & 2640 & 1 & 10 & 55 & 65 & 554.09 & 12.36 \\
\hline 216 & 1500 & 4000 & 2640 & 1 & 10 & 55 & 65 & 800.03 & 9.6 \\
\hline 217 & 2000 & 4000 & 660 & 2 & 10 & 55 & 65 & 292.28 & 19.78 \\
\hline 218 & 2000 & 4000 & 2640 & 1 & 10 & 55 & 65 & 925.12 & 8.93 \\
\hline 219 & 2400 & 4000 & 660 & 2 & 10 & 55 & 65 & 319.58 & 18.91 \\
\hline 220 & 2400 & 4000 & 2640 & 1 & 10 & 55 & 65 & 1061.37 & 8.52 \\
\hline 221 & 2000 & 2000 & 660 & 2 & 0 & 55 & 65 & 205.89 & 22.52 \\
\hline 222 & 2000 & 2000 & 2640 & 1 & 0 & 55 & 65 & 780.19 & 9.06 \\
\hline 223 & 2400 & 2000 & 660 & 2 & 0 & 55 & 65 & 264.92 & 19.18 \\
\hline 224 & 2400 & 2000 & 2640 & 1 & 0 & 55 & 65 & 842.14 & 8.94 \\
\hline 225 & 1000 & 2500 & 2640 & 1 & 0 & 55 & 65 & 175.42 & 27.42 \\
\hline 226 & 1500 & 2500 & 2640 & 1 & 0 & 55 & 65 & 622.08 & 10.68 \\
\hline 227 & 2000 & 2500 & 660 & 2 & 0 & 55 & 65 & 206.96 & 22.99 \\
\hline 228 & 2000 & 2500 & 2640 & 1 & 0 & 55 & 65 & 768.51 & 9.49 \\
\hline 229 & 2400 & 2500 & 660 & 2 & 0 & 55 & 65 & 265.62 & 19.75 \\
\hline 230 & 2400 & 2500 & 2640 & 1 & 0 & 55 & 65 & 845.27 & 9.04 \\
\hline 231 & 1000 & 2500 & 2640 & 1 & 2 & 55 & 65 & 270.16 & 20.66 \\
\hline 232 & 1500 & 2500 & 2640 & 1 & 2 & 55 & 65 & 685.50 & 9.91 \\
\hline 233 & 2000 & 2500 & 660 & 2 & 2 & 55 & 65 & 237.20 & 21.12 \\
\hline 234 & 2000 & 2500 & 2640 & 1 & 2 & 55 & 65 & 844.69 & 8.84 \\
\hline 235 & 2400 & 2500 & 660 & 2 & 2 & 55 & 65 & 269.83 & 19.49 \\
\hline 236 & 2400 & 2500 & 2640 & 1 & 2 & 55 & 65 & 894.89 & 8.65 \\
\hline 237 & 1000 & 3000 & 2640 & 1 & 2 & 55 & 65 & 264.37 & 21.46 \\
\hline 238 & 1500 & 3000 & 2640 & 1 & 2 & 55 & 65 & 631.84 & 10.64 \\
\hline 239 & 2000 & 3000 & 660 & 2 & 2 & 55 & 65 & 236.98 & 21.64 \\
\hline 240 & 2000 & 3000 & 2640 & 1 & 2 & 55 & 65 & 835.36 & 9.22 \\
\hline 241 & 2400 & 2000 & 2640 & 1 & 4 & 55 & 65 & 966.81 & 7.99 \\
\hline
\end{tabular}




\begin{tabular}{|c|c|c|c|c|c|c|c|c|c|}
\hline 242 & 1000 & 2500 & 2640 & 1 & 4 & 55 & 65 & 292.42 & 19.23 \\
\hline 243 & 2000 & 2500 & 660 & 2 & 4 & 55 & 65 & 248.47 & 20.41 \\
\hline 244 & 2000 & 2500 & 2640 & 1 & 4 & 55 & 65 & 865.78 & 8.62 \\
\hline 245 & 2400 & 2500 & 660 & 2 & 4 & 55 & 65 & 295.91 & 18.36 \\
\hline 246 & 2400 & 2500 & 2640 & 1 & 4 & 55 & 65 & 960.16 & 8.38 \\
\hline 247 & 1000 & 3000 & 2640 & 1 & 4 & 55 & 65 & 352.39 & 17.02 \\
\hline 248 & 1500 & 3000 & 2640 & 1 & 4 & 55 & 65 & 723.46 & 9.79 \\
\hline 249 & 2000 & 3000 & 660 & 2 & 4 & 55 & 65 & 253.10 & 20.82 \\
\hline 250 & 2000 & 3000 & 2640 & 1 & 4 & 55 & 65 & 880.93 & 8.91 \\
\hline 251 & 2000 & 2000 & 2640 & 1 & 5 & 55 & 65 & 882.81 & 8.3 \\
\hline 252 & 2400 & 2000 & 660 & 2 & 5 & 55 & 65 & 295.34 & 17.94 \\
\hline 253 & 2400 & 2000 & 2640 & 1 & 5 & 55 & 65 & 938.30 & 8.25 \\
\hline 254 & 1000 & 2500 & 2640 & 1 & 5 & 55 & 65 & 349.58 & 16.55 \\
\hline 255 & 1500 & 2500 & 2640 & 1 & 5 & 55 & 65 & 777.83 & 9.09 \\
\hline 256 & 2000 & 2500 & 660 & 2 & 5 & 55 & 65 & 277.67 & 19.09 \\
\hline 257 & 2000 & 2500 & 2640 & 1 & 5 & 55 & 65 & 879.71 & 8.5 \\
\hline 258 & 2400 & 2500 & 660 & 2 & 5 & 55 & 65 & 290.75 & 18.65 \\
\hline 259 & 2400 & 2500 & 2640 & 1 & 5 & 55 & 65 & 888.58 & 8.42 \\
\hline 260 & 1000 & 3000 & 2640 & 1 & 5 & 55 & 65 & 346.94 & 16.99 \\
\hline 261 & 2400 & 2000 & 660 & 2 & 6 & 55 & 65 & 310.17 & 17.33 \\
\hline 262 & 2400 & 2000 & 2640 & 1 & 6 & 55 & 65 & 944.68 & 7.92 \\
\hline 263 & 1000 & 2500 & 2640 & 1 & 6 & 55 & 65 & 406.31 & 14.58 \\
\hline 264 & 1500 & 2500 & 2640 & 1 & 6 & 55 & 65 & 760.19 & 9.1 \\
\hline 265 & 2000 & 2500 & 660 & 2 & 6 & 55 & 65 & 273.94 & 19.24 \\
\hline 266 & 2000 & 2500 & 2640 & 1 & 6 & 55 & 65 & 901.34 & 8.48 \\
\hline 267 & 2400 & 2500 & 660 & 2 & 6 & 55 & 65 & 316.04 & 17.78 \\
\hline 268 & 2400 & 2500 & 2640 & 1 & 6 & 55 & 65 & 939.13 & 8.4 \\
\hline 269 & 1000 & 3000 & 2640 & 1 & 6 & 55 & 65 & 394.18 & 15.3 \\
\hline 270 & 1500 & 3000 & 2640 & 1 & 6 & 55 & 65 & 760.44 & 9.36 \\
\hline 271 & 2400 & 2000 & 2640 & 1 & 8 & 55 & 65 & 1009.21 & 7.86 \\
\hline 272 & 1000 & 2500 & 2640 & 1 & 8 & 55 & 65 & 456.61 & 13.39 \\
\hline 273 & 1500 & 2500 & 2640 & 1 & 8 & 55 & 65 & 795.63 & 8.73 \\
\hline 274 & 2000 & 2500 & 660 & 2 & 8 & 55 & 65 & 298.03 & 18.09 \\
\hline 275 & 2000 & 2500 & 2640 & 1 & 8 & 55 & 65 & 952.37 & 8.15 \\
\hline 276 & 2400 & 2500 & 660 & 2 & 8 & 55 & 65 & 313.96 & 17.81 \\
\hline 277 & 2400 & 2500 & 2640 & 1 & 8 & 55 & 65 & 997.66 & 8.25 \\
\hline 278 & 1000 & 3000 & 2640 & 1 & 8 & 55 & 65 & 502.79 & 12.71 \\
\hline 279 & 1500 & 3000 & 2640 & 1 & 8 & 55 & 65 & 778.93 & 8.91 \\
\hline 280 & 2000 & 3000 & 660 & 2 & 8 & 55 & 65 & 276.78 & 19.57 \\
\hline 281 & 2000 & 2000 & 660 & 2 & 10 & 55 & 65 & 287.93 & 17.95 \\
\hline 282 & 2000 & 2000 & 2640 & 1 & 10 & 55 & 65 & 928.68 & 7.79 \\
\hline
\end{tabular}




\begin{tabular}{|c|c|c|c|c|c|c|c|c|c|}
\hline 283 & 2400 & 2000 & 660 & 2 & 10 & 55 & 65 & 322.10 & 17.2 \\
\hline 284 & 2400 & 2000 & 2640 & 1 & 10 & 55 & 65 & 970.00 & 7.67 \\
\hline 285 & 1000 & 2500 & 2640 & 1 & 10 & 55 & 65 & 544.78 & 11.54 \\
\hline 286 & 1500 & 2500 & 2640 & 1 & 10 & 55 & 65 & 813.72 & 8.62 \\
\hline 287 & 2000 & 2500 & 660 & 2 & 10 & 55 & 65 & 284.93 & 18.56 \\
\hline 288 & 2000 & 2500 & 2640 & 1 & 10 & 55 & 65 & 971.28 & 8.04 \\
\hline 289 & 2400 & 2500 & 660 & 2 & 10 & 55 & 65 & 313.43 & 17.63 \\
\hline 290 & 2400 & 2500 & 2640 & 1 & 10 & 55 & 65 & 1043.42 & 7.88 \\
\hline 291 & 1000 & 3000 & 2640 & 1 & 10 & 55 & 65 & 559.26 & 11.67 \\
\hline 292 & 1500 & 3000 & 2640 & 1 & 10 & 55 & 65 & 836.27 & 8.7 \\
\hline 293 & 2000 & 3000 & 660 & 2 & 10 & 55 & 65 & 302.97 & 18.46 \\
\hline
\end{tabular}


APPENDIX C 
The following subsections describe the models and their properties for a $55 \mathrm{mph}$ speed limit followed by the notations mentioned below.

Flow Rate $=\mathrm{F}$

Activity Area Length $=\mathrm{L}$

Number of Open Lanes $=\mathrm{N}$

Heavy Vehicle Percentage $=\mathrm{H}$

Delay Model - Under Saturated - 55 mph

Delay $=-685.56+\left(1.3776^{*} \mathrm{~F}\right)+\left(0.000718^{*} \mathrm{~L}\right)+(353.07 * \mathrm{~N})-\left(2.616^{*} \mathrm{H}\right)+\left(0.00002^{*} \mathrm{~F}^{\wedge} 2\right)+$ $\left(0.1645 * \mathrm{H}^{\wedge} 2\right)-\left(0.70877 * \mathrm{~F}^{*} \mathrm{~N}\right)+\left(0.003335^{*} \mathrm{~F}^{*} \mathrm{H}\right)-(0.599 * \mathrm{~N} * \mathrm{H})$

Goodness of Fit: $\quad$ R-Squared $=99.28 \% \quad$ p-Values $<0.001$

Hence, all of the variables satisfactorily explained the delay variation and this model is recommended for delay for under saturated flow conditions with a $55 \mathrm{mph}$ speed limit.

\section{Average Speed Model - Under Saturated - 55 mph}

Average Speed $=95.25-(0.07404 * \mathrm{~F})-(0.000464 * \mathrm{~L})-(20.412 * \mathrm{~N})+(0.804 * \mathrm{H})-\left(0.000007 * \mathrm{~F}^{\wedge} 2\right)$

$$
-\left(0.04664 * \mathrm{H}^{\wedge} 2\right)+(0.04315 * \mathrm{~F} * \mathrm{~N})-(0.001079 * \mathrm{~F} * \mathrm{H})+(0.1972 * \mathrm{~N} * \mathrm{H})
$$

Goodness of Fit: $\quad$ R-Squared $=91.75 \% \quad$ p-Values $<0.001$

Hence, all of the variables satisfactorily explained the average speed variation and this model is recommended for average speed for under saturated flow conditions with a $55 \mathrm{mph}$ speed limit. 


\section{Delay Model - Saturated - 55 mph}

$$
\begin{aligned}
\text { Delay }= & -429.9+(1.6069 * \mathrm{~F})-(664.1 * \mathrm{~N})+(59.38 * \mathrm{H})-\left(0.000344 * \mathrm{~F}^{\wedge} 2\right)-\left(0.511 * \mathrm{H}^{\wedge} 2\right)+ \\
& \left(0.0309 * \mathrm{~F}^{*} \mathrm{~N}\right)-\left(0.01252 * \mathrm{~F}^{*} \mathrm{H}\right)-(9.83 * \mathrm{~N} * \mathrm{H})
\end{aligned}
$$

Goodness of Fit: $\quad$ R-Squared $=91.75 \% \quad$ p-Values $<0.001$

Hence, all of the variables satisfactorily explained the delay variation and this model is recommended for delay for saturated flow conditions with a $55 \mathrm{mph}$ speed limit.

\section{Average Speed Model - Saturated - 55 mph}

Average Speed $=10.701-0.005961 * \mathrm{~F}+0.000675^{*} \mathrm{~L}+11.069 * \mathrm{~N}-0.4405^{*} \mathrm{H}$

Goodness of Fit: $\quad$ R-Squared $=80.94 \% \quad$ p-Values $<0.001$

Hence, all of the variables satisfactorily explained the average speed variation and this model is recommended for average speed for saturated flow conditions with a $55 \mathrm{mph}$ speed limit.

\section{Model Validation}

All of the proposed models were validated with $25 \%$ of the simulation scenarios of each category, as described in subsection 3.7. The validation data set of each category was substituted in the proposed models and generated the calibrated values for the delay and speed. Those calibrated values are named Y-Calibrated. The original delay and speed values in the validation data sets are named Y - Actual.

The Y - Actuals are then plotted against the Y - Calibrated and checked against the distribution of points around the 45-degree line of fit. All of the graphs showed a satisfactory distribution of points. Hence, the proposed models were predicted quite successfully. Figures C.1, C.2, C.3 and C. 4 represent the models related to the $55 \mathrm{mph}$ speed limit category. 


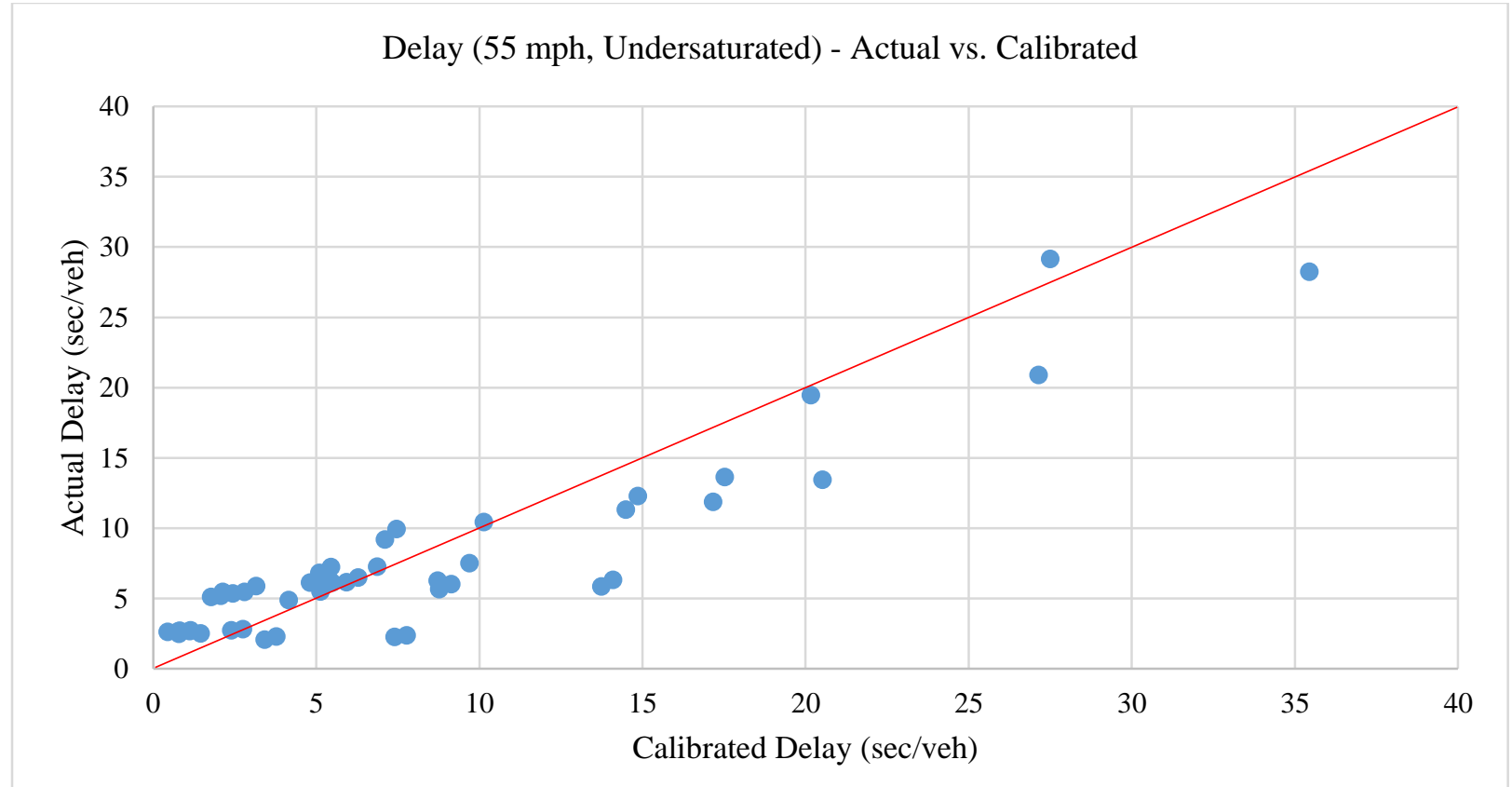

Figure C.1: Actual vs. Calibrated Values for Delay Model (55 mph, Undersaturated)

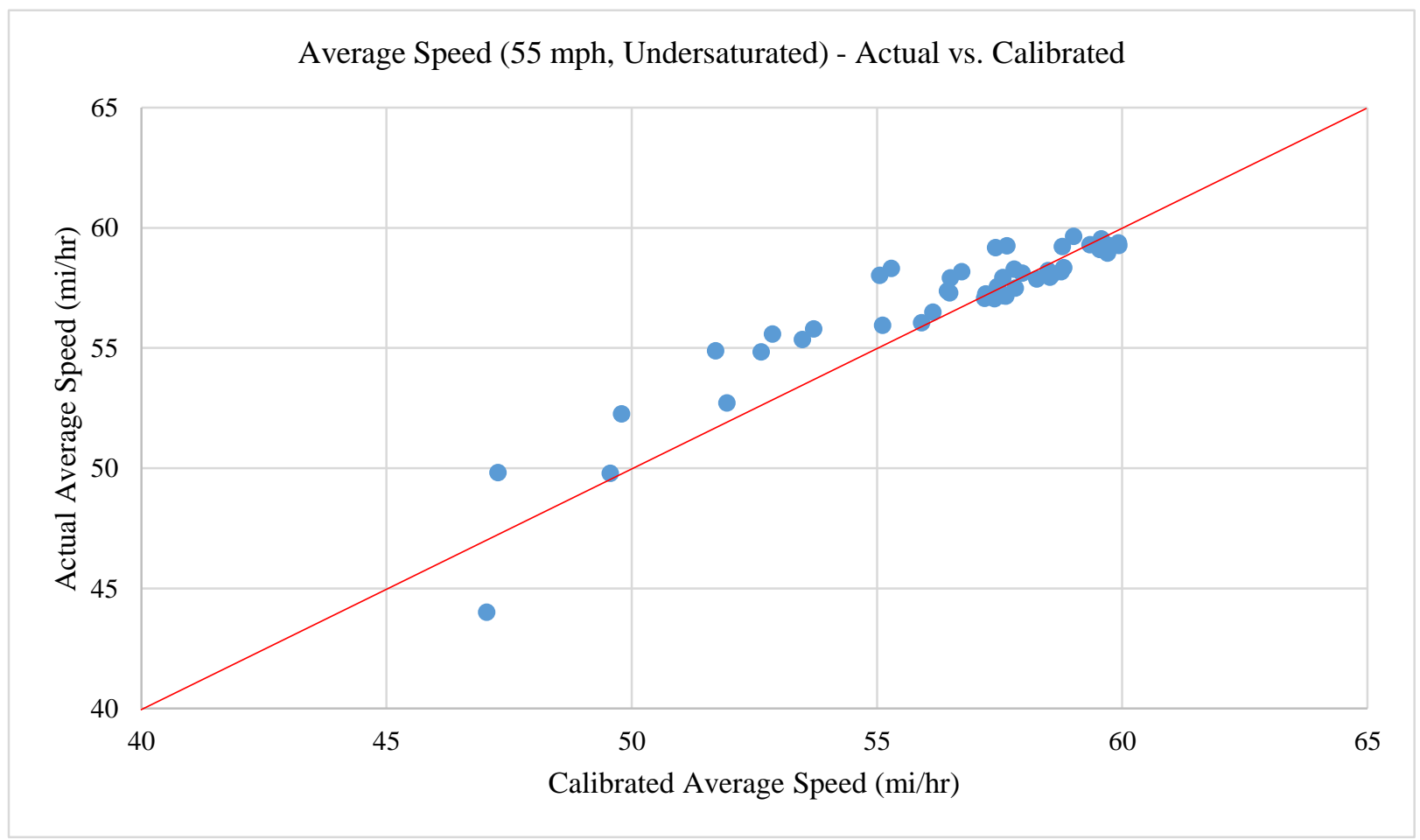

Figure C.2: Actual vs. Calibrated Values for Average Speed Model (55 mph, Undersaturated) 


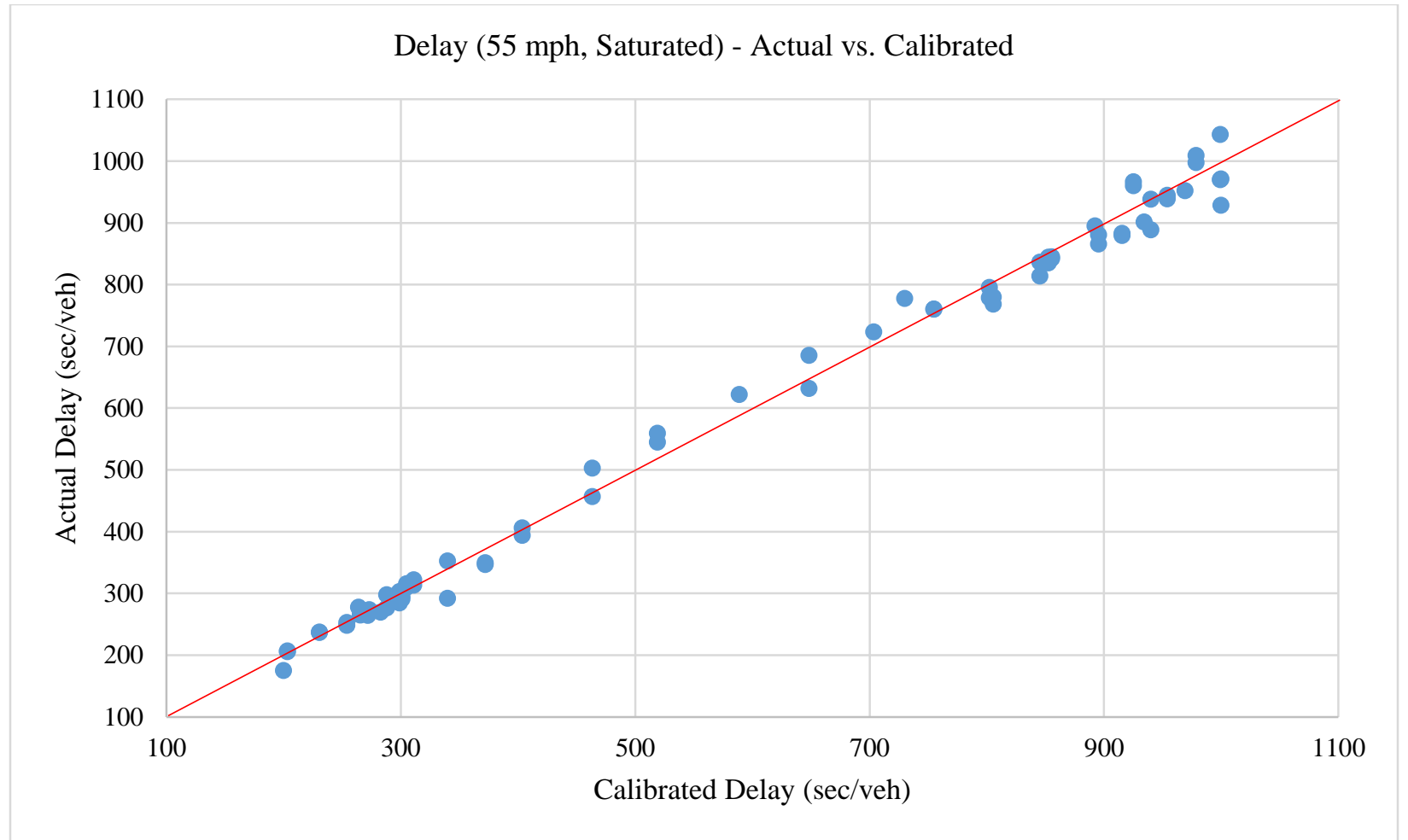

Figure C.3: Actual vs. Calibrated Values for Delay Model (55 mph, Saturated)

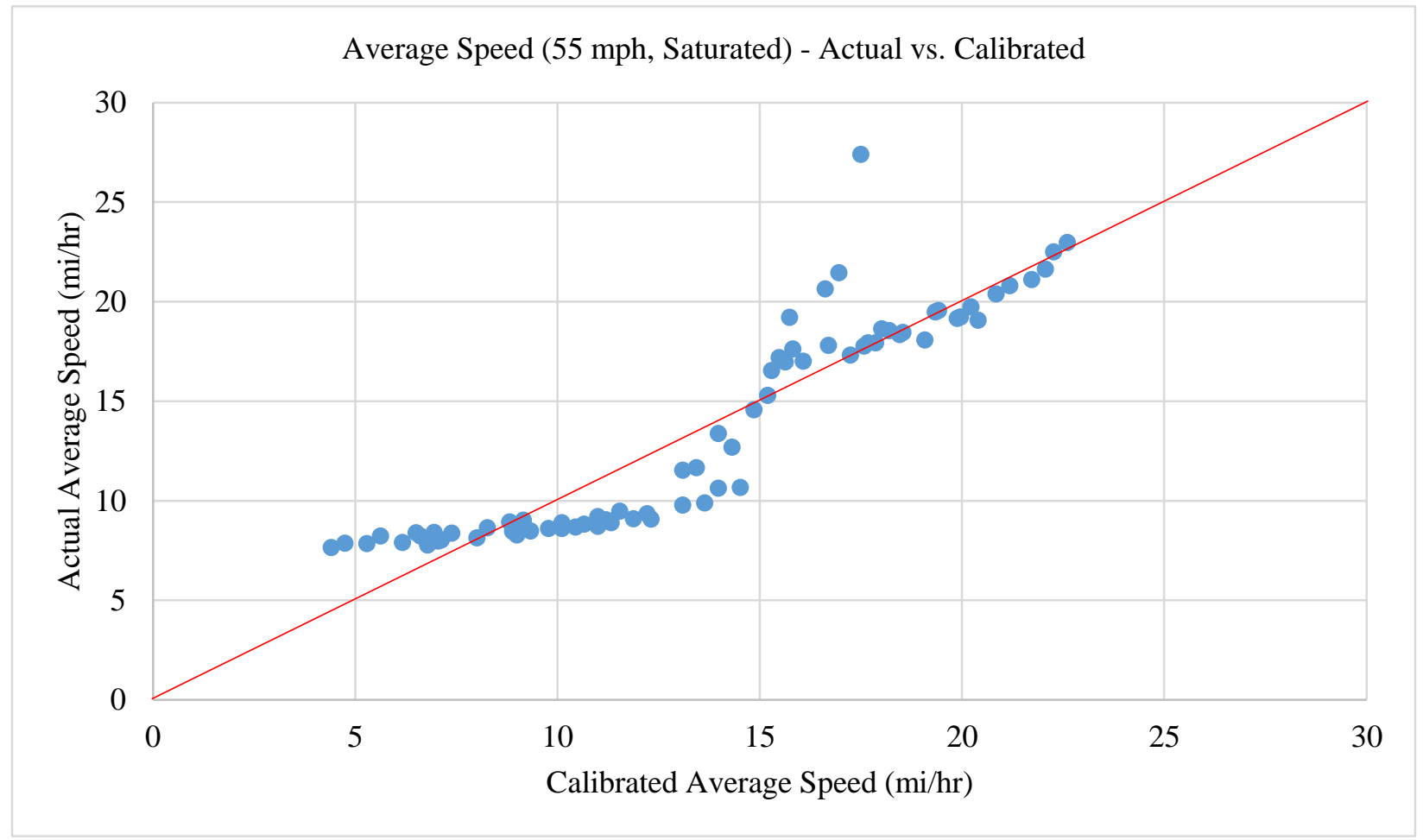

Figure C.4: Actual vs. Calibrated Values for Average Speed Model (55 mph, Saturated) 


\section{REFERENCES}

Abdelmohsen, A. Z. 2016. Optimizing the construction planning of highway work zones. ProQuest Dissertations Publishing.

Adeli, A. 2014. Work zone speed analysis using driving simulator data. ProQuest Dissertations Publishing.

Ahmed, K., Al-Zoubi, K., Siddiqui, M. A. and Anas, M. 2016;2015. Evaluation of the effectiveness of portable variable message signs in work zones in united arab emirates. IET Intelligent Transport Systems 10 (2): 114-21.

Bai, Y. and Li, Y. 2011. Determining the drivers' acceptance of EFTCD in highway work zones. Accident Analysis and Prevention 43 (3): 762-8.

Bai, Y., Finger, K. and Li, Y. 2010. Analyzing motorists' responses to temporary signage in highway work zones. Safety Science 48 (2): 215-21.

Bie, Y., Xu W., Lei, N. and Tony, Z. Q. 2017. Effect of speed limits at speed transition zones. Canadian Journal of Civil Engineering 44 (1): 10-7.

Chambless, J., Ghadiali A. M., Lindly J. K. and McFadden, J. 2002. Multistate work-zone crash characteristics. Institute of Transportation Engineers. ITE Journal 72 (5): 46.

Chen, E. and Tarko, A. P. 2014. Modeling safety of highway work zones with random parameters and random effects models. Analytic Methods in Accident Research 1: 86-95.

Chen, Y., Xiao Q., Noyce D. A., and Chanyoung, L. 2010. Interactive process of microsimulation and logistic regression for short-term work zone traffic diversion. Journal of Transportation Engineering 136 (3): 243-54.

Chen, Y. 2008. A highway work zone design and traffic management decision system. ProQuest Dissertations Publishing.

Chien, S. and Kyriacos C. M. 2015. Optimizing work zones for highway maintenance with floating car data (FCD). Final Report. 
Chin, C. 2004. A slot model for highway flow optimization through entry, exit, and flow control. ProQuest Dissertations Publishing.

Chou, C. 2010. Understanding the impact of incidents and incident management programs on freeway mobility and safety. ProQuest Dissertations Publishing.

Chundury, S. and Wolshon, B. 2000. Evaluation of CORSIM car-following model by using global positioning system field data. Transportation Research Record: Journal of the Transportation Research Board 1710: 114-21.

Chung, Y. 2011. Assessment of non-recurrent traffic congestion caused by freeway work zones and its statistical analysis with unobserved heterogeneity. Transport Policy 18 (4): 587-94.

Ding, M., Zhang, C., Yan, J. and Tsai, J. 2013. Key factors analysis of work zone safety and mobility based on micro-simulation. Procedia - Social and Behavioral Sciences 96: 582-90.

Du, B. and Chien, S. I. 2014. Feasibility of shoulder use for highway work zone optimization. Journal of Traffic and Transportation Engineering (English Edition) 1 (4): 235-46.

Elghamrawy, T. M. 2011. Optimizing work zone practices for highway construction projects. ProQuest Dissertations Publishing.

FHWA. 2011. HERS-ST Technical Report.

FHWA, M., 2009. Manual on uniform traffic control devices.

Gambatese, J. A. and Zhang, F. 2017. Highway construction work-zone safety: Effectiveness of traffic-control devices. Practice Periodical on Structural Design and Construction 22 (4).

Gambatese, J. and Zhang, F. 2016. Impact of advisory signs on vehicle speeds in highway nighttime paving project work zones. Transportation Research Record: Journal of the Transportation Research Board 2555: 65-71.

Hajbabaie, A., Medina, J., Wang, M., Benekohal, R. and Chitturi, M. 2011. Sustained and halo effects of various speed reduction treatments in highway work zones. Transportation Research Record: Journal of the Transportation Research Board 2265: 118-28. 
Hajdin, R. and Lindenmann, H. 2007. Algorithm for the planning of optimum highway work zones. Journal of Infrastructure Systems 13 (3): 202-14.

Hamdar, S. H., Hiam, K. and Zehtabi, S. 2016. A simulator-based approach for modeling longitudinal driving behavior in construction work zones: Exploration and assessment. Simulation 92 (6): 579-94.

Heaslip, K., Collura, J. and Knodler, M. 2011. Evaluation of work zone design features to aid older drivers. Institute of Transportation Engineers. ITE Journal 81 (3): 36.

Huang, Y. and Yong, B. 2014. Effectiveness of graphic-aided portable changeable message signs in reducing vehicle speeds in highway work zones. Transportation Research Part C: Emerging Technologies 48: 311-21.

Isaiah, S. E. 2014. Testing and evaluation of methods for automated speed identification on highway work zones. ProQuest Dissertations Publishing.

Kaewmoracharoen, M. 2009. Feasibility of visualization and simulation applications to improve work zone safety and mobility. ProQuest Dissertations Publishing.

Kang, K., Chang, G. and Zou, N. 2004. Optimal dynamic speed-limit control for highway work zone operations. Transportation Research Record: Journal of the Transportation Research Board 1877: 77-84.

Kang, K. and Chang, G. 2006. A robust model for optimal time-of-day speed control at highway work zones. IEEE Transactions on Intelligent Transportation Systems 7 (1): 115-23.

Kang, K., Chang, G. and Paracha, J. 2006. Dynamic late merge control at highway work zones: Evaluations, observations, and suggestions. Transportation Research Record: Journal of the Transportation Research Board 1948: 86-95.

Kang, K. 2006. Development of optimal control strategies for freeway work zone operations. ProQuest Dissertations Publishing. 
Kang, K. and Chang, G. 2009. Lane-based dynamic merge control strategy based on optimal thresholds for highway work zone operations. Journal of Transportation Engineering 135 (6): $359-70$.

Kim, C. 2008. A mechanistic model of work zone capacity. ProQuest Dissertations Publishing.

Kurker, M. G. 2013. Evaluation of freeway work zone merge concepts. ProQuest Dissertations Publishing.

Li, X. 2008. Evaluate the effectiveness of the speed monitoring display for work zones in las vegas. ProQuest Dissertations Publishing.

Li, Y. and Bai, Y. 2009. Highway work zone risk factors and their impact on crash severity. Journal of Transportation Engineering 135 (10): 694-701.

Li, Y. and Yong, B. 2008. Comparison of characteristics between fatal and injury accidents in the highway construction zones. Safety Science 46 (4): 646-60.

Li, Y. and Yong, B. 2009. Effectiveness of temporary traffic control measures in highway work zones. Safety Science 47 (3): 453-8.

Li, Y. 2007. Analyzing highway work zone crashes and traffic control effectiveness. ProQuest Dissertations Publishing.

Manual, H.C., 2010. HCM2010. Transportation Research Board, National Research Council, Washington, DC.

Mathes, J. A. 2012. Integrated risk management for improving internal traffic control, work zone safety, and mobility during major construction. ProQuest Dissertations Publishing.

Miatudila, A. S. Sr. 2016. Modeling the crash injury severity in work zone areas on freeways. ProQuest Dissertations Publishing.

Moradpour, S., Wu, S., Long, S., Ming, C. L., Dincer, K. and Qin, R. 2015. Use of traffic simulators to determine driver response to work zone configurations. Proceedings of the International Annual Conference of the American Society for Engineering Management: 1. 
Nadathur, V. R. and Narayanan, H. 2016. Data analysis for driving pattern identification and driver's behavior modeling in a freeway work zone. ProQuest Dissertations Publishing.

Nannapaneni, P. L. V. 2011. Evaluating the use of steady burn warning lights on drums for work zone safety. ProQuest Dissertations Publishing.

Ng, M. 2012. Traffic flow Theory-Based stochastic optimization model for work zones on twolane highways. Journal of Transportation Engineering 138 (10): 1269-73.

Patil, S. S. 2015. Evaluation of portable traffic signals in conjunction with pilot car operations at two-lane, two-way temporary rural work zones in kansas. ProQuest Dissertations Publishing.

Phanomchoeng, G., Rajamani, R. and Hourdos, J. 2010. Directional sound for long-distance auditory warnings from a highway construction work zone. IEEE Transactions on Vehicular Technology 59 (5): 2266-76.

Pilanavithana, U. S., Qu, X. and Easa, S. 2018. Freeway work zones: current trends and future needs. Canadian society for civil engineering. Fredericton, NB, Canada.

Liu, P., Zhang, J., Qu, J., Lu, J., Cheng, Y. and Tan, H. 2017. Evaluation of mobility impact on urban work zones using statistical models. Journal of Central South University 24 (6): 151321.

Qi, Y. and Zhao, Q. 2017. Safety impacts of signalized lane merge control at highway work zones. Transportation Planning and Technology 40 (5): 577.

Qiao, F., Rahman, R., Li, Q. and Yu, L. 2017; 2016; Safe and environment-friendly forward collision warning messages in the advance warning area of a construction zone. International Journal of Intelligent Transportation Systems Research 15 (3): 166-79.

Qu, T. 2014. Travel time reliability based work zone scheduling. ProQuest Dissertations Publishing.

Radwan, E., Zaidi, Z. and Harb, R. 2011. Operational evaluation of dynamic lane merging in work zones with variable speed limits. Procedia - Social and Behavioral Sciences16: 460-9.

Rao, S.S. 2009. Engineering optimization: theory and practice. John Wiley \& Sons. 
Schonfeld, P., Steven C. and Yimin T. 2002. Optimizing work zones for two-lane highway maintenance projects. Journal of Transportation Engineering 128 (2): 145-55.

Schrock, S. and Ullman, G. 2003. Spacing of law enforcement pullout areas in highway work zones. Transportation Research Record: Journal of the Transportation Research Board 1824: 37-43.

Shakouri, M., Laura, H. I., Fereydoun, A. and Sherif, I. 2016. Drivers' merging behavior data in highway work zones. Data in Brief 6: 829-32.

Son, Y. T. 1999. Queueing delay models for two-lane highway work zones. Transportation Research Part B 33 (7): 459-71.

Sukumaran, P., Bayraktar, M. E., Hong, T. and Hastak, M. 2006. Model for analysis of factors affecting construction schedule in highway work zones. Journal of Transportation Engineering 132 (6): 508-17.

Sukumaran, P., Hong, T., Bayraktar, M. E. and Hastak, M. 2006. Validation of a model for predicting schedule changes in highway work Zones-Case studies. Journal of Transportation Engineering 132 (8): 638-48.

Tang, Y. and Chien, S. 2008. Scheduling work zones for highway maintenance projects: Considering a discrete time-cost relation. Transportation Research Record: Journal of the Transportation Research Board 2055: 21-30.

Turley, B. M. 2002. Daniel B. fambro student paper award: Dancing diamonds in highway work zones: A evaluation of arrow panel caution displays. Institute of Transportation Engineers. ITE Journal 72 (11): 34.

Turley, B., Saito, M. and Sherman, S. 2003. Dancing diamonds in highway work zones: Evaluation of arrow-panel caution displays. Transportation Research Record: Journal of the Transportation Research Board 1844: 1-10.

Wang, C., Dixon, K. and Jared, D. 2003. Evaluating speed-reduction strategies for highway work zones. Transportation Research Record: Journal of the Transportation Research Board 1824: 44-53.

Whitmire, J. II. 2007. The effect of in -vehicle warning systems on driver response in work zones. ProQuest Dissertations Publishing. 
Wiegand, J. D. 2007. State transportation agencies' utilization of work zone congestion mitigation strategies. ProQuest Dissertations Publishing.

Wong, J. M. 2009. Analysis of ArmorGuard ${ }^{\mathrm{TM}}$ work zone protection barrier system. ProQuest Dissertations Publishing.

Wong, J. M., Arico, M. C. and Ravani, B. 2011. Factors influencing injury severity to highway workers in work zone intrusion accidents. Traffic Injury Prevention12 (1): 31-8.

Yang, N. 2010. Optimization of highway work zone decisions considering short-term and longterm impacts. ProQuest Dissertations Publishing.

Yeom, C. H. 2015. Statistical and simulation models of freeway work zones. ProQuest Dissertations Publishing.

Zech, W. C., Mohan, S. and Dmochowski, J. 2005. Evaluation of rumble strips and police presence as speed control measures in highway work zones. Practice Periodical on Structural Design and Construction 10 (4): 267-75.

Zech, W. C., Mohan, S. B. and Dmochowski, J. 2008. Evaluation of messages on changeable message signs as a speed control measure in highway work zones. Practice Periodical on Structural Design and Construction 13 (1): 11-8.

Zehtabi, S. 2014. Work zone characteristics in microscopic acceleration modeling: Calibration and numerical analysis. ProQuest Dissertations Publishing.

Zhang, K. 2016. Traffic impact analysis of several dynamic lane management strategies for congestion mitigation based on DTA model. ProQuest Dissertations Publishing.

Zheng, N., Andreas, H., Serge H., Henk, V. Z. and Peters, D. 2011. A comparison of freeway work zone capacity prediction models. Procedia - Social and Behavioral Sciences 16: 419-29.

Zhu, W. 2015. Two-lane highway work zone capacity model and control analysis. ProQuest Dissertations Publishing. 